ERNEST BERKELEY NATIUNAL LAB⿴RATGRY

\title{
Yucca Mountain Drift Scale Test Progress Report
}

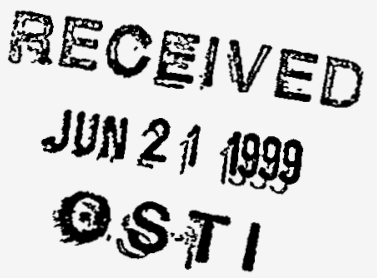

Y.W. Tsang, J. Apps, J.T. Birkholzer, J.E. Peterson, E. Sonnenthal, N. Spycher, and K.H. Williams

Earth Sciences Division

January 1999

the 


\section{DISCLAIMER}

This document was prepared as an account of work sponsored by the United States Government. While this document is believed to contain correct information, neither the United States Government nor any agency thereof, nor The Regents of the University of California, nor any of their employees, makes any warranty, express or implied, or assumes any legal responsibility for the accuracy, completeness, or usefulness of any information, apparatus, product, or process disclosed, or represents that its use would not infringe privately owned rights. Reference herein to any specific commercial product, process, or service by its trade name, trademark. manufacturer, or otherwise, does not necessarily constitute or imply its endorsement, recommendation, or favoring by the United States Government or any agency thereof, or The Regents of the University of California. The views and opinions of authors expressed herein do not necessarily state or reflect those of the United States Government or any agency thereof, or The Regents of the University of California.

This report has been reproduced directly from the best available copy.

Available to DOE and DOE Contractors

from the Office of Scientific and Technical Information

P.O. Box 62, Oak Ridge, TN 37831

Prices available from (615) 576-8401

Available to the public from the National Technical Information Service

U.S. Department of Commerce

5285 Port Royal Road, Springfield, VA 22161

Ernest Oriando Lawrence Berkeley National Laboratory

is an equal opportunity employer. 


\section{DISCLAIMER}

Portions of this document may be illegible in electronic image products. Images are produced from the best available original document. 


\section{Yucca Mountain Drift Scale Test Progress Report}

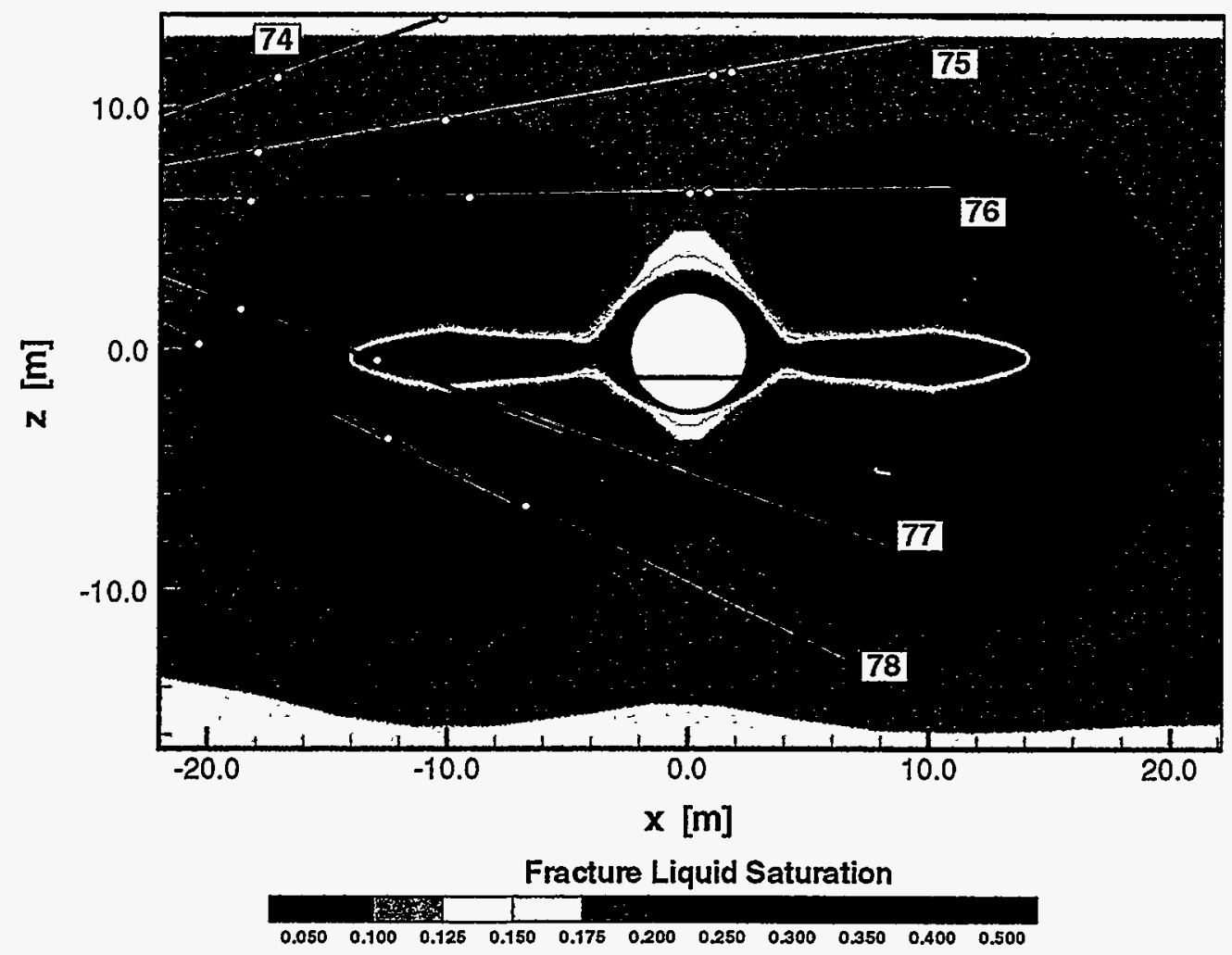

Y.W. Tsang, J. Apps, J.T. Birkholzer, J.E. Peterson, E. Sonnenthal, N. Spycher, and K.H. Williams

\section{Earth Sciences Division}

Ernest Orlando Lawrence Berkeley National Laboratory

University of California, Berkeley, California 94720 US 


\section{Table of Contents}

Chapter 1 Overview - Status of the Drift Scale Test at Six Months of Heating ........................................................ 1-1

Y.W. Tsang

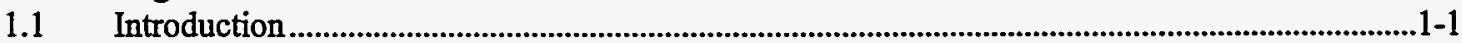

1.2 Quality Assurance Status of Data and Software Used in This Report..............................................1-2

1.3 Thermo-Hydrological Processes in the DST .........................................................................................1-3

1.4 Thermo-Hydrological-Chemical Processes for the DST..................................................................1-6

1.5 Status of the DST from Radar Tomography and Acoustic Emissions Monitoring .........................1-8

1.5.1 Cross-Hole Radar Tomography............................................................................... 1-8

1.5.2 Acoustic Emission Monitoring.............................................................................. 1-8

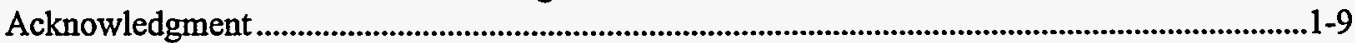

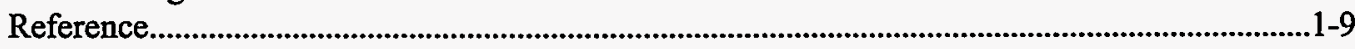

Figures .......................................................................................................................................................1-11

Chapter 2 Interpretive Analysis of the Thermo-hydrological Processes of the Drift Scale Test.................................. 2-1

J.T. Birkholzer and Y.W. Tsang

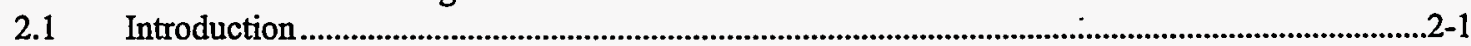

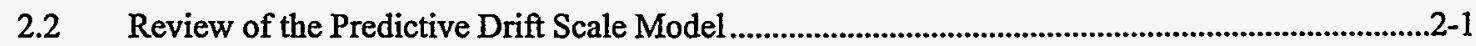

2.2.1 Simulator and Processes .................................................................................................... 2-2

2.2.2 Model Domain ................................................................................................................ 2-2

2.2.3 Conceptual Model for Flow in Fractures and Matrix ................................................... 2-3

2.2.4 Percolation Flux ................................................................................................................ 2-3

2.2.5 Model Properties..................................................................................................... 2-3

2.2.6 Heater Schedule and Power................................................................................................. 2-4

2.2.7 Radiative Heat Exchange in the Heated Drift....................................................................... 2-5

2.2.8 Model Representation of Heaters ........................................................................................... 2-5

2.2.9 Model Representation of Thermal Bulkhead........................................................................... 2-6

2.2.10 Assumed Test Geometry and Grid Design ....................................................................... 2-6

2.2.11 Initial and Boundary Conditions ......................................................................................... 2-7

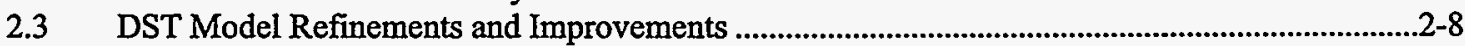

2.3.1 Simulator and Processes ........................................................................................... 2-8

2.3.2 Model Domain ............................................................................................................... 2-9

2.3.3 Conceptual Model for Flow in Fractures and Matrix...................................................... 2-9

2.3.4 Percolation Flux ............................................................................................................ 2-9

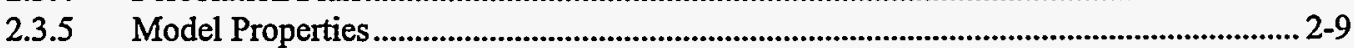

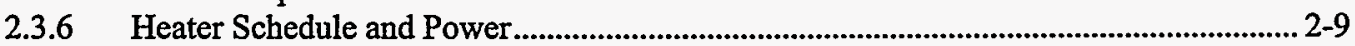

2.3.7 Radiative Heat Exchange in the Heated Drift..................................................................... 2-10

2.3.8 Model Representation of Heaters ....................................................................................... 2-11

2.3.9 Model Representation of Thermal Bulkhead.................................................................... 2-11

2.3.10 Assumed Test Geometry and Grid Design ........................................................................ 2-12

2.3.11 Initial and Boundary Conditions .......................................................................... 2-13

2.4 Comparison of Modeled Results and Measured Temperature Data ................................................2-13

2.4.1 Contour Plots of Simulation Results ............................................................................. 2-14

2.4.2 Comparison of Measured and Simulated Temperature.................................................... 2-15

2.4.3 Temperature Evolution at the Heated Drift Wall ................................................................ 2-17

2.5 Sensitivity Study to Model Conceptualization and Properties..........................................................2-17

2.5.1 Model Representation of Thermal Bulkhead..................................................................... 2-18

2.5.2 Initial Drying due to Ventilation ............................................................................. 2-19

2.5.3 Formation Properties and Percolation Flux ......................................................... 2-19

2.5.4 ECM Versus DKM ........................................................................................................ 2-20 
2.6 Interpretation of the Active Hydrological Testing Data..................................................................2-21

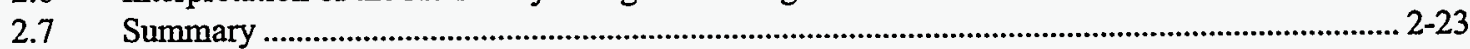

Acknowledgment ....................................................................................................................2-24

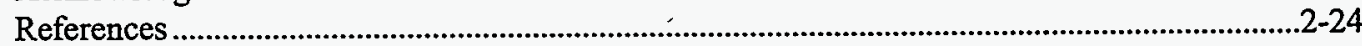

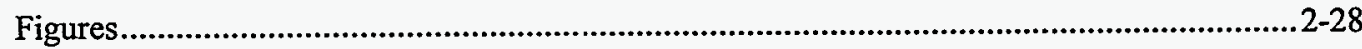

Chapter 3 Interpretive Analysis of the Thermo-Hydrological-Chemical Processes of the Drift-Scale Test............... 3-1

E. Sonnenthal, N. Spycher, and J. Apps

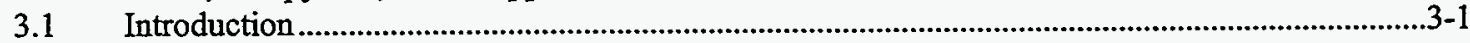

3.1.1 New Chemical Data Acquired...................................................................................... 3-2

3.1.2 Numerical Model Development, Simulations, and Sensitivity Studies........................... 3-2

3.1.3 Geochemical Model Refinement........................................................................................ 3-3

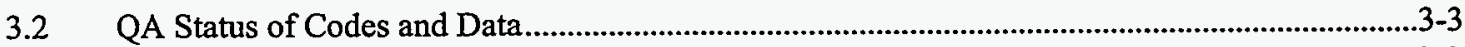

3.2.1 QA Status of Data Used in Chapter ........................................................................... 3-3

3.2.2 QA Status of Codes......................................................................................................... 3-4

3.3 Numerical Model and Simulations................................................................................................ 3-5

3.3.1 Numerical Model, Grid, and THC Boundary Conditions ............................................... 3-5

3.3.2 Geochemical Parameters .................................................................................................... 3-5

3.3.3 Simulation of Thermo-Hydrological-Chemical Processes in the Drift-Scale Test ......... 3-7

3.3.4 Simulations to Investigate Sensitivity of THC Processes to Initial Fracture Porosity

3.4 Geochemical Model Refinement...............................................................................................

3.4.1 Examples Illustrating the Ostwald Rule of Stages in Relation to Groundwater and Mineralogy at YM.......................................................................................................... 3-15

3.4.2 Theoretical Interpretation of the Ostwald Rule of Stages ............................................... 3-20

3.4.3 A Kinetic Basis for the Ostwald Rule ............................................................................... 3-21

3.4.4 Recommendations for Further Work to Refine Geochemical Model ............................. 3-23

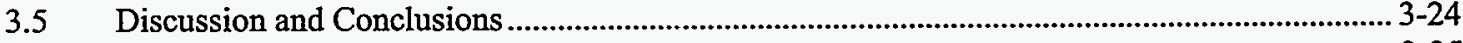

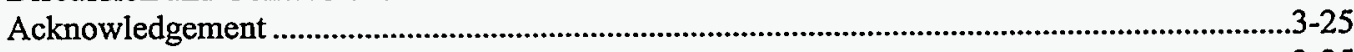

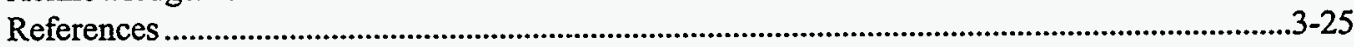

Figures ................................................................................................................................ $3-31$

Chapter 4 Interpretive Analysis of the Geophysical Measurements: Ground Penetrating Radar and Acoustic

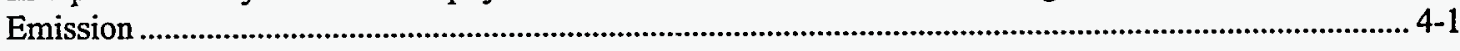

J.E. Peterson and K.H. Williams

$4.1 \quad$ Ground Penetrating Radar (GPR) Introduction ................................................................................4-1

4.2 GPR Equipment Description ..................................................................................................... 4-2

4.2.1 Antenna Specifications ................................................................................................ 4-2

4.2.2 Transmitter Electronics Specifications ........................................................................... 4-2

4.2.3 Receiver Electronics Specifications ............................................................................ 4-2

4.2.4 Control Console ............................................................................................................. 4-2

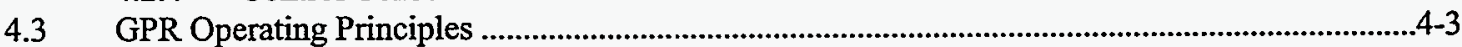

4.4 GPR Survey Methodology...........................................................................................................4-3

4.5 GPR Velocity field construction ................................................................................................. $4-5$

4.5.1 Velocity inversions in the 47-51. plane.............................................................................. 4-6

4.5.2 Velocity inversions in the 64-68 plane ............................................................................ 4-7

4.5.3 Velocity differences between first quarter and pre-heat acquisition................................ 4-8

4.6 Saturation estimates from GPR data ................................................................................................4-9

4.7 GPR Summary ....................................................................................................................

$4.8 \quad$ Acoustic Emission ................................................................................................................. 4-10

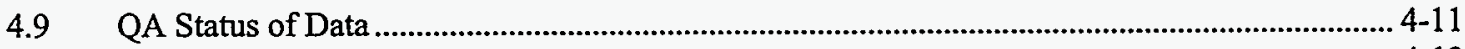

Acknowledgement .........................................................................................................................4-12

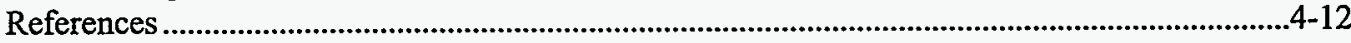

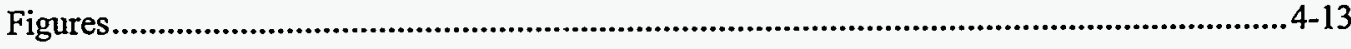


-

, 


\title{
Chapter 1 Overview - Status of the Drift Scale Test at Six Months of Heating
}

\author{
Y.W. Tsang \\ Earth Sciences Division, LBNL
}

\subsection{Introduction}

The Drift Scale Test (DST) is part of the Exploratory Studies Facility (ESF) Thermal Test being conducted underground at the potential high-level nuclear waste repository at Yucca Mountain, Nevada. The purpose of the ESF Thermal Test is to acquire a more in-depth understanding of the coupled thermal, mechanical, hydrological, and chemical processes likely to be encountered in the rock mass surrounding the potential geological repository at Yucca Mountain. These processes are monitored by a multitude of sensors to measure the temperature, humidity, gas pressure, and mechanical displacement, of the rock formation in response to the heat generated by the heaters. In addition to collecting passive monitoring data, active hydrological and geophysical testing is also being carried out periodically in the DST. These active tests are intended to monitor changes in the moisture redistribution in the rock mass, to collect water and gas samples for chemical and isotopic analysis, and to detect microfracturing due to heating.

On December 3, 1998, the heaters in the DST were activated. The planned heating phase of the DST is 4 years, and the cooling phase following the power shutoff will be of similar duration. The present report summarizes interpretation and analysis of thermal, hydrological, chemical, and geophysical data for the first 6 months; it is the first of many progress reports to be prepared during the DST.

Figure 1.1 shows a 3D perspective of the DST, with the heaters and different boreholes color- coded according to their functions: thermal, mechanical, hydrological, and chemical. The DST consists of a 47.5-m-long, 5-m-diameter Heated Drift. The Heated Drift is complemented with both Connecting and Observation Drifts of similar diameter. Heat is generated from 50 wing heaters and 9 floor (canister) heaters (Figure 1.2). To monitor the temperature evolution, there are radial arrays of boreholes originating from the Heated Drift, as well as longitudinal holes parallel to the Heated Drift. Most boreholes for monitoring the moisture redistribution are in planes orthogonal to the Heated Drift and these boreholes were drilled from the Observation Drift. These are labeled "hydrological" in Figure 1.1 and are for active testing such as air-permeability and gas tracer tests, for neutron logging, electrical resistivity tomography, and for cross-hole radar tomography. The boreholes labeled chemistry are for sampling of gas and water. 
The main responsibility of conducting and analyzing of the DST is shared among four National Laboratories: Lawrence Berkeley National Laboratory (LBNL), Lawrence Livermore National Laboratory (LLNL), Los Alamos National Laboratory (LANL), and Sandia National Laboratories (SNL). All of the data all shared so that a complete set of passive monitoring data from all sensors and heaters installed in the DST is made available to the thermal testing team members in all the laboratories. The passive monitoring data are recorded on the Data Collection System of the Drift Scale Test and placed on a secure FTP site, at bi-weekly intervals, by the DST data manager. The data are also transmitted to the thermal testing team on a monthly basis, on compact disks (Homuth, 1998). At the time of writing this report, we have access to all passive monitoring data through the early part of June 1998. Exchange of data acquired through active testing by respective laboratories are carried out by means of weekly telephone conferences, quarterly workshops and data reports.

In this first progress report of the DST, we shall discuss the status of the DST at six months of heating. An interpretive analysis of the thermo-hydrological aspects of the DST is presented in Chapter 2. The analysis is based on the first six months of collected passive monitoring data, as well as the results of active hydrological testing by air injection. Measured data are compared to simulated results using the 3D thermo-hydrological model developed at the Lawrence Berkeley National Laboratory. The interpretive analysis of the thermo-hydrological-chemical aspects of the DST is discussed in Chapter 3. There, $\mathrm{CO}_{2}$ and $\mathrm{pH}$ analyses of gas and water samples collected at the DST are used to check on the hypotheses and parameters of the thermo-hydrological-chemical model, developed at the Lawrence Berkeley National Laboratory. Results of geophysical testing by cross-hole radar tomography and acoustic emission monitoring are discussed in Chapter 4. Salient points from each of the following chapters are summarized here in Chapter 1.

\subsection{Quality Assurance Status of Data and Software Used in This Report}

For this interpretive report, data are used but not generated. The data used for this progress report are based mainly on the passive monitoring data and active testing data of the DST. Q-Status of chemical and geophysical data used are presented in 3.2 and 4.9 , respectively.

The passive monitoring data transmitted to the thermal testing team on a monthly basis on compact discs (Homuth, 1998) are qualified. These cover all the data collected at the DST through May 31, 1998. For the analysis in Chapter 2, we also use monitored temperature data at six months of heating (i.e., on June 3, 1998). The data for the first two weeks of June, placed on the secure FTP site by the DST data manager, do not have a $Q$-pedigree. However, the non-Q temperature values will not be very different, if at all, from the Q-data that will be transmitted on the compact disk for the entire month of June. 
The active testing data for the DST (both laboratory and field measurements) were collected by qualified personnel, with calibrated equipment, under the LBNL QA program. Therefore, the air- permeability data, radar and acoustic emission data, and isotopic analysis data of gas samples are qualified data.

Due to a deficiency related to the software qualification process, numerical codes such as TOUGH2 used in Chapter 2 and TOUGH-REACT used in Chapter 3 and are considered unqualified at this time. Revised software procedures, YMP-LBNL-QIP-SI.0 and YMP-LBNL-QIP-SI.1, which meet the QARD, were issued on June 30,1998. We are in the process of qualifying all the above software to the new procedures. The software CART used in Chapter 4 was qualified under the USGS QA program. Its QA status will be evaluated according to the revised LBNL software procedures.

Standard spreadsheets, as well as visualization and plotting routines, were used to generate graphics. Such programs are not subject to QA requirements under QARD Rev. 8.

\subsection{Thermo-Hydrological Processes in the DST}

In Chapter 2, we carry out a thorough study of the measured data collected in the first 6 months of heating and compare them with simulated results. The thermo-hydrological simulations are based on the threedimensional predictive model prepared prior to the initiation of the DST (Birkholzer and Tsang, 1997). The predictive model was intended to provide insight into the DST performance, and to serve as a baseline that can be refined and calibrated against measured data. In the predictive modeling work, the relative importance of different input parameters, such as heating schedules, percolation fluxes, and rock properties were examined. Also, the impact of alternative conceptualization of several processes on DST performance was studied. By the iterative comparison of simulations with DST data, we address the issue of parameter uncertainty and conceptual model uncertainty.

In order to interpret the first 6 months of heating data, modifications were made to the baseline predictive model (Birkholzer and Tsang, 1997), to conform more closely to the actual test conditions. The modifications are as follows.

For the time period between December 3, 1997 to April 21, 1998, the operating average total power for the canister heaters was $52 \mathrm{~kW}$ (77\% of the maximum power). The average total power of the wing heaters for the same period was $135 \mathrm{~kW}$ (94\% of the maximum power). These power values are used in the numerical model for comparison with data.

The concrete invert with a maximum thickness of $1.2 \mathrm{~m}$ at the bottom of the Heated Drift was not included in the baseline predictive model. It is incorporated in the present model, as the temperature data 
from the first quarter of heating indicate that the concrete liner plays a significant role in retarding temperature build-up below the Heated Drift (Birkholzer and Tsang, 1998).

The Heated Drift was not explicitly modeled in the predictive baseline model; therefore, by default the Heated Drift wall was treated as a closed boundary. There was clear evidence from the first few months of heating that the thermal bulkhead installed at the entrance of the Heated Drift is not a perfect seal for heat, gas, and liquid. Moist air can escape from the Heated Drift, and vapor was observed to condense on the cold side of the bulkhead. Consequently, the refined DST model incorporated a gas-permeable boundary for the Heated Drift wall and the thermal bulkhead, so that vapor can leave the Heated Drift, and heat can be transported by convection, but not by conduction, across the bulkhead.

Prior to the test, it was not known how effective the radiative heat exchange would be from the canister heaters to the Heated Drift wall. Two limiting cases were simulated in the predictive modeling work: one corresponds to $100 \%$ effective black body heat radiation, the other pertains to ineffective heat radiation. In the latter case, temperature at the springline of the Heated Drift wall can be $25^{\circ} \mathrm{C}$ higher than that at the crown. Furthermore, temperature along the Heated Drift wall can differ by as much as $40^{\circ} \mathrm{C}$ between the center and the end sections. However, the first few months of DST data show that temperature is rather uniform, both around and along the Heated Drift wall, indicating that very effective radiative heat exchange is in operation. Thus, the limiting case of $100 \%$ effective radiative heat exchange is implemented for the thermo-hydrological simulations in this report.

During installation of the DST, the average temperature in the drifts was considerably higher than the $25^{\circ} \mathrm{C}$ assumed in the predictive model. Also the ventilation in the drifts has a drying effect on the rock mass. Both the effects of elevated drift temperature and drying from drift ventilation have been incorporated in the revised initial conditions for the simulations of the DST.

Other than the above modifications to conform to the actual test conditions, we have made no adjustment to other model parameters. Chapter 2 gives a detailed description of the DST model results in comparison with the measured data from the first six months of heating. In a comparative analysis of model results and measured data, snapshots of temperature measurements, from one representative radial array of thermal boreholes collared on the Heated Drift, are used. Comparison of measured data with simulation results is made at $1,2,3,4,5$, and 6 months of heating. For selected sensors from the hydrology holes, temperature histories from the start of the DST heating through May 31, 1998, are compared with simulated results. Only those sensors in close proximity to wing heaters are selected, because at this early phase of heating many sensors in the hydrology holes are too far away from the heaters to measure significant temperature increases. In studying the match between observed data and simulation results, we pay special attention to those regions where temperature has risen above boiling, where heat-induced vapor and liquid fluxes can be present, and where temperature signatures can provide a good indication of the accuracy of the thermo-hydrological model. 
Generally, the measured and simulated temperature compare favorably. Overall, the measured temperatures are slightly higher than the simulated values, in particular for elevated temperature above nominal boiling. This indicates that the model overestimates heat pipe effects, which can often arise from erroneous rock properties, or possibly from the effective-continuum conceptualization of the matrixfracture interaction. A sensitivity study indicates that an alternative property set described in our predictive model, similar to that used for the Single Heater Test, can further improve the match between the observed and calculated data. However, it is premature at this early phase of the DST to perform a model calibration in order to develop the most appropriate DST model property set. The early-phase data also do not yet discriminate between the different conceptualization of the fracture-matrix interaction; that is, the data agree equally well with simulations using the effective-continuum or the dual-permeability conceptual model. As the DST progresses and more data become available, the DST model properties will be carefully evaluated, and more work will be performed on the model representation of the fracturematrix interaction. Results of our investigation will be forwarded to the flow and transport modeling group responsible for the development of hydrological property sets.

Air-permeability measurements are also correlated to model results. Air-permeability measurements are aimed to monitor the change in moisture content in the fractures. An increase in fracture liquid saturation from condensation will be evidenced by a decrease in local permeability values. The zones in the hydrology holes where air-permeability values were found to decrease at 4 and 6 months of heating indeed coincide with the simulated condensation zones. Furthermore, on June 4, 1998, 5.7 liters of water was recovered by pumping from Borehole 60, Zone 2 (60-2), and $250 \mathrm{ml}$ from 60-3. For water to seep into the borehole - that acts as a capillary barrier - liquid saturation of portions of rock mass surrounding the borehole wall must become unity. Fully saturated local conditions to allow seepage into boreholes are promoted by permeability heterogeneity, fast paths in fractures for vapor transport, acting in concert with an average high liquid saturation background. The zones in the hydrology holes from which water had been recovered are in the regions where simulations predict increased matrix saturation approaching 1 at 6 months of heating.

One objective of the predictive modeling (Birkholzer and Tsang, 1997) was to recommend a heating schedule for the DST such that a large volume of rock-fluid system could be quickly brought to two phase conditions with both liquid and vapor, while the Heated Drift wall temperature remains below $200{ }^{\circ} \mathrm{C}$. This would require a high level of heat power initially and a reduction of the heater power at some point during the DST heating phase. Since the actual test conditions are not identical to that assumed in the predictive model, calculations to guide an appropriate heating schedule are carried out using our updated numerical model. This model uses current average heater output ( $77 \%$ capacity for the canister heaters, and $94 \%$ capacity for the wing heaters), implements $100 \%$ effective radiative heat exchange, and uses one of the two baseline property sets. Our current model predicts that the temperature at the Heated Drift wall will barely reach $200^{\circ} \mathrm{C}$ at 2 years after heat initiation. In other words, reduction of the heater power from its present operating level should not be necessary for another 18 months of heating. If the alternative baseline property set were applied in the simulation, temperature would be higher, and the threshold 
temperature of $200^{\circ} \mathrm{C}$ at the Heated Drift wall would be reached 2 to 3 months earlier. The match between the simulations and the first 6 months of data at the Heated Drift wall is good. Measured and predicted temperature at the Heated Drift will be monitored closely in the coming months; and additional simulations will be performed, if warranted, to guide the schedule for heater power adjustment.

\subsection{Thermo-Hydrological-Chemical Processes for the DST}

Chapter 3 presents thermo-hydrological-chemical simulations of the DST. The thermo-hydrologic basis for these simulations is the predictive model for thermo-hydrological processes (Birkholzer and Tsang, 1997). Vertical 2D simulations are carried out using a dual conceptualization of the fracture and matrix media. Because of the large differences in aqueous concentrations and mineral assemblages between fractures and the rock matrix, the latter is critical for accurate simulation of water-gas-rock-chemical interactions affecting the DST.

A conceptual model for coupling the rate-limited reactions of minerals, gas, and water to the thermohydrologic calculations is presented in Sonnenthal et al. (1998). In that report, an initial model prediction of the eight-year DST is presented for a chemical system containing $\mathrm{Na}, \mathrm{Cl}, \mathrm{Si}$, and silica minerals. A four-year simulation for the full heating phase (including gaseous $\mathrm{CO}_{2}$ transport and calcite in fractures) reveals that the transport dynamics (advection and diffusion) of $\mathrm{CO}_{2}$ in the gas phase are crucial in controlling the system $\mathrm{pH}$ and other geochemical behavior. Also, several studies of shorter duration with many more components such as alumino silicates, $\mathrm{CO}_{2}$, and sulfates have been completed. These studies show that the mineral assemblage, and the thermodynamic and kinetic parameters considered in the model control the pore-water chemistry and overall rates of reactions. These data are quite uncertain; therefore our approach is to have a baseline predictive model, including a wide range of simulations involving alternative mineral assemblages and a range of input parameter values; with the intent of refining and calibrating the model with data from the ongoing DST.

Only a few simulations were included in the initial predictive modeling report of the DST (Sonnenthal et al., 1998). Therefore, two additional simulations are presented in Chapter 3 of this progress report. One is an eight-year simulation of the DST for the chemical system that consists of $\mathrm{Na}, \mathrm{Cl}, \mathrm{Si}, \mathrm{Ca}, \mathrm{CO}_{2}$, calcite and silica minerals. The other is a simulation of the silica system (with $\mathrm{Na}$ and $\mathrm{Cl}$ ) for a range of fracture porosity values. These simulations are considered to be part of the predictive baseline model. The thermohydrological setup of the model is that of the predictive model (Birkholzer and Tsang, 1997), and none of the modifications as described in Section 1.3 have been incorporated in the chemical simulations. All these elements of the current thermo-hydrological model will need to be incorporated for the next phase of thermo-hydrological-chemical modeling. We also would reiterate the fact that because of the disequilibrium between matrix and fractures with respect to chemical processes, it is imperative that the fracture and matrix be treated as two distinct continua. Therefore, in all thermo-hydrological-chemical 
simulations a dual permeability conceptual model is implemented. Furthermore, simulations are carried out in 2D cross-sections orthogonal to the Heated Drift, as the boreholes for conducting hydrological testing and or collecting chemistry date lie in such cross sections (Figure 1.1).

Limited chemical data are available at this early phase of the DST. Gas samples from different zones of the DST were collected in February and June of 1998 (Conrad, 1998a; 1998b). They were analyzed for $\mathrm{CO}_{2}$. From the $\mathrm{CO}_{2}$ fraction, the isotopic ratio of $\delta^{13} \mathrm{C}$ and $\delta^{18} \mathrm{O}$ were also determined. The measured $\mathrm{CO}_{2}$ concentrations for samples collected in June 1998 are compared to the modeled results. Thermohydrological-chemical simulation results show that $\mathrm{CO}_{2}$ transport will occur well outside the region of strongly elevated temperature. The measured $\mathrm{CO}_{2}$ concentration in gas samples appears to confirm the predicted formation of a halo with higher $\mathrm{CO}_{2}$ partial pressure than atmospheric around the Heated Drift and the wing heaters. The higher partial pressure originates from volatization of $\mathrm{CO}_{2}$ from water in zones of elevated temperatures, and being transported away from the heaters by convection and diffusion. However, the measured $\mathrm{CO}_{2}$ concentrations are not consistent with a predicted $\mathrm{CO}_{2}$ depletion in hot areas (i.e. between the heaters and the $\mathrm{CO}_{2}$ halo). The discrepancy between modeled and measured data in this area possibly arises from not accounting in the simulations for communication with the ambient $\mathrm{CO}_{2}$ in the Heated Drift. The injection of air from permeability tests may also preclude $\mathrm{CO}_{2}$ depletion below atmospheric concentrations. Both these hypotheses will be tested by further modeling.

Carbon and oxygen isotopic studies on the collected gas samples are consistent with the conceptual model of $\mathrm{CO}_{2}$ loss through boiling, followed by gas transport, with progressive condensation and dissolution in cooler regions. Future modeling will incorporate carbon, oxygen and hydrogen isotopic species, with the hope that they will help to constrain not only the geochemical processes, but also thermohydrologic and transport processes of the DST.

Fracture (combined lithophysal and fracture) porosity estimates from gas tracer testing in the hydrology holes (Freifeld and Tsang, 1998; Freifeld, 1998) is on the order of 0.01 . This value is considerably larger than the mean fracture porosity for the middle non lithophysal unit of the Topopah Spring welded tuff estimated for the Site Scale Unsaturated Zone Flow Model (Sonnenthal et. al., 1997). Because of the strong relation of the fracture porosity to transport velocities, a sensitivity study was performed on the effect of fracture porosity on the thermo-hydrological regime and its coupling to reaction-transport phenomena for the DST. Three cases were compared: fracture porosity of $0.00263,5$ times higher, and 10 times higher. Simulations show that both chloride and aqueous silica concentrations are higher in the higher porosity case in the boiling zone adjacent to the final dryout zone. In the condensation zone of elevated liquid saturation, water can drain through gravity. Both chloride and aqueous silica concentrations are higher in the drainage region for the large porosity case, due to the lower fracture saturation in the higher porosity simulations. Over the course of the DST there would likely be porosity modifications from precipitation and dissolution processes of about $1 \%$ of the total fracture porosity. The coupling of porosity and permeability changes to flow field is presently under development in the numerical model. 


\subsection{Status of the DST from Radar Tomography and Acoustic Emissions Monitoring}

Interpretive analysis of the geophysical measurements conducted in the DST is presented in Chapter 4.

\subsubsection{Cross-Hole Radar Tomography}

The objective of the borehole radar data acquisition is to perform repeated surveys in the course of the DST to monitor the moisture redistribution in the rock matrix. The radar surveys are being carried out in 10 boreholes (labeled "hydrology" in Figure 1.1) orthogonal to the Heated Drift. They form two fans of five holes each, all drilled from the Observation Drift, extending 40 meters toward the Heated Drift. Each fan brackets the Heated Drift with three upward incline holes and two downward decline holes (labeled "hydrology" in Figure 1.1).

The pre-heat radar velocity tomograms and the first quarter radar velocity tomograms show that the most significant differences in velocity occur near the wing heaters. This seems to agree well with the temperature field interpolated from the simulated temperatures from the thermo-hydrological model (Birkholzer and Tsang, 1998; Chapter 2, this report). During the first quarter of heating, the most dominant effect seen in the radar data is that of temperature change in the proximity of the wing heater. Since the dielectric constant is a function of both temperature and liquid saturation, saturation estimates can be obtained from relationships between radar frequency, temperature, liquid saturation, and rock formation dielectric constant under laboratory conditions. Model development is in progress to separate out from the radar data the effects of temperature from the change in liquid saturation.

By the second quarter of heating, evidence of increased liquid saturation in regions further removed from the immediate vicinity of the wing heaters is anticipated. Unfortunately, all attempts to acquire data during this quarter were hindered by the design of the radar antennas being adversely affected by the elevated temperature present in the survey boreholes (Williams and Peterson, 1998). After several rounds of testing, several design modifications and enhancements were made. The modified antenna design was successfully tested on June 26,1998 , to perform well under the field conditions. Radar data acquisition will resume as soon as the fabrication of the redesigned instrumentation is complete.

\subsubsection{Acoustic Emission Monitoring}

The rock mass in the DST was continuously monitored for acoustic emissions. These microseismic data were intended to monitor microfracturing activities arising from thermal-mechanical coupling. The data acquisition and processing have been ongoing from pre-heat until April 1, 1998. Due to intermittent problems with the trigger box controller (Peterson et. al., 1998, Williams and Peterson, 1998), the trigger box controller was brought back to Lawrence Berkeley National Laboratory for modifications. Full-scale monitoring and recording will resume in July 1998. The data acquired to date were typically insignificant and dominated by false triggers on electrical noise. In the time period from November 1997 until April 1, 
1998, only 12 microseismic events were identified, 7 of which could be located. The coordinates of these events are given in Chapter 4. Four of the seven located events are near the drift wall at approximately $y=30$ meters. These events are probably due to a release in stress at the drift wall at around $y=30$ meters. The other three events occur within several meters of each other and may be due to some shifting.

\section{Acknowledgment}

We are grateful to Jens Birkholzer and Nicolas Spycher for their review of this chapter and comments for improvement. We would also like to thank Colleen Haraden and Maryann Villavert for production, and Dan Hawkes for editing all the chapters of this report. This work was supported by the Director, Office of Civilian Radioactive Waste Management, U.S. Department of Energy, through Memorandum Purchase Order EA9013MC5X between TRW Environmental Safety Systems. Inc. and the Ernest Orlando Lawrence Berkeley National Laboratory, under Contract No. DE-AC03-76SF00098.

\section{Reference}

Birkholzer, J.T. and Tsang, Y.W. 1997. Pretest Analysis of the Thermal-hydrological Conditions of the ESF Drift Scale Test. Yucca Mountain Project Level 4 Milestone SP9322M4. Berkeley, California: Lawrence Berkeley National Laboratory. ACCN: MOY-970627-12. MOL 199712010805.0810

Birkholzer, J.T. and Tsang, Y.W. 1998. "Comparison of Temperature Data with Thermal-Hydrological Model Predictions." Chapter 6 in First Quarter TDIF Submission for the Drift Scale Test (Hydrological, Radar, Microseismic). Yucca Mountain Project Level 4 Milestone SP2770M4. Berkeley, California. Lawrence Berkeley National Laboratory.

Conrad, M. 1998a. "Carbon Isotope Analyses of $\mathrm{CO}_{2}$ Evolved During the Initial Stages of the Drift Scale Test." Chapter 3 in First Quarter TDIF Submission (Hydrological, Radar and Microseismic. Yucca Mountain Project Level 4 Milestone Report SP2770M4. Berkeley, California: Lawrence Berkeley National Laboratory.

Conrad, M. 1998b. "Isotope Analyses of Samples from the Drift Scale Test Hydrology Holes." Chapter 3 in Second Quarter TDIF Submission (Hydrological, Radar and Microseismic. Yucca Mountain Project Level 4 Milestone Report SP2790M4. Berkeley, California: Lawrence Berkeley National Laboratory. DTN: LB980715123142.003 (Q).

Freifeld, B. and Tsang, Y.W. 1998. Active Hydrogeological Testing Chapter 2 in "First Quarter TDIF Submission for the Drift Scale Test (Hydrological, Radar, Microseismic)." Yucca Mountain Project Level 4 Milestone SP2770M4. Berkeley, California. Lawrence Berkeley National Laboratory. DTN.LB980420123142.002 (Q). 
Freifeld, B. 1998. "Active Hydrogeological Testing." Chapter 2 in Second Quarter TDIF Submission for the Drift Scale Test (Hydrological, Radar, Microseismic). Yucca Mountain Project Level 4 Milestone SP2790M4. Berkeley, California: Lawrence Berkeley National Laboratory. DTN.LB980715123142.002 (Q).

Homuth, F. 1998. QA: L Memo on transmittal of data to Drift Scale Test Principal Investigators. Memorandum (LA-EES-7-03-98-004; LA-EES-7-04-98-012; LA-EES-7-05-98-008; LA-EES-7-06-98005) on Data from ESF data collections systems used for the Drift Scale Test-time Interval. November 1, 1997 through May 31, 1998.

Peterson, J.E.; Williams, K.; and Majer, E. 1998. "Acoustic Emission Monitoring/Seismic Wave Monitoring: First Quarter Data." Chapter 5 in First Quarter TDIF Submission for the Drift Scale Test (Hydrological, Radar, Microseismic). Yucca Mountain Project Level 4 Milestone SP2770M4. Berkeley, California. Lawrence Berkeley National Laboratory. DTN.LB980420123142.004 (Q).

Sonnenthal, E.; Spycher, N.; Apps, J.; and Simmons, A. 1998. Thermo-Hydro-Chemical Predictive Analysis for the Drift-Scale Heater Test. Yucca Mountain Project Level 4 Milestone SPY289M4. Berkeley, California: Lawrence Berkeley National Laboratory.

Tsang, Y.W. and Freifeld, B. 1998. "Hydrological Baseline Measurements." Chapter 2 in ESF Drift Scale Test As-Built Data and Baseline Measurements (Hydrological, Radar, and Microseismic). Yucca Mountain Project Level 4 Milestone SPY193M4. Berkeley, California, Lawrence Berkeley National Laboratory. DTN.LB980120123142.004 (Q).

Williams, K. and Peterson, J.E. 1998. "Radar Imaging and Acoustic Emission Monitoring at the DST." Chapter 4 in Second Quarter TDIF Submission for the Drift Scale Test (Hydrological, Radar, Microseismic). Yucca Mountain Project Level 4 Milestone SP2790M4. Berkeley, California. Lawrence Berkeley National Laboratory. 
Yucca Mountain Drift Scale Test Progress Report

\section{Figures}




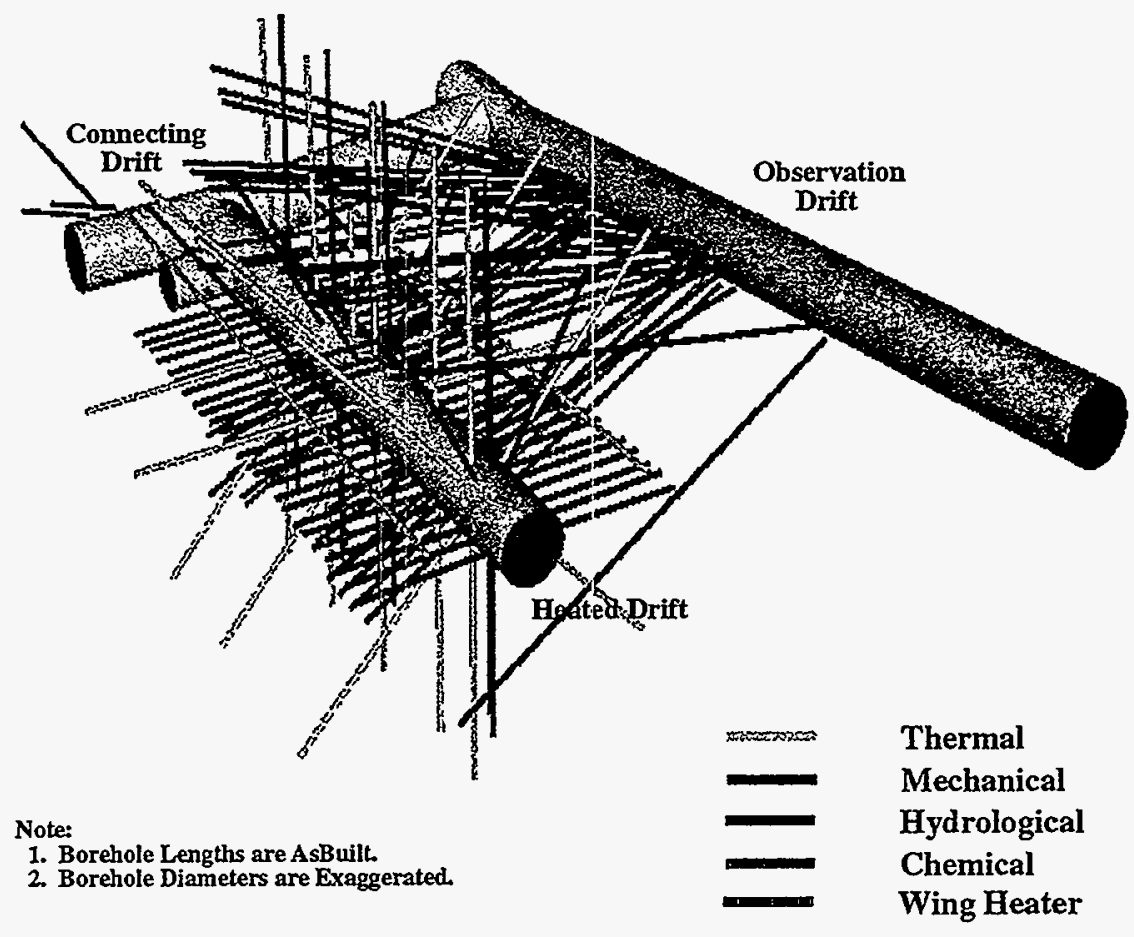

Figure 1.1. As-Built 3D perspective of Boreholes in the DST. 


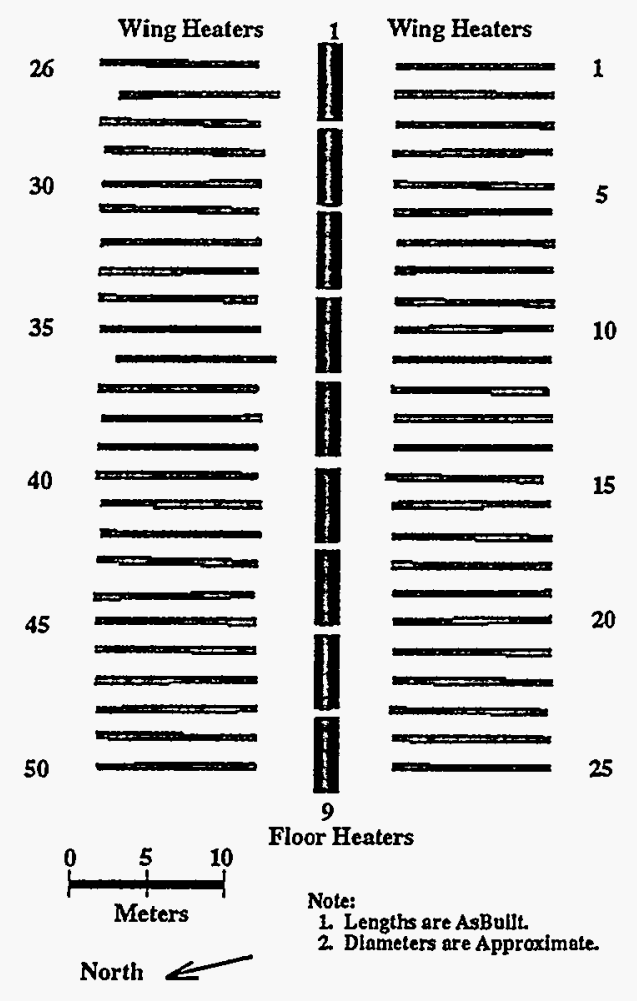

Figure 1.2. As-Built canister and wing heaters of the DST. 
THIS PAGE IS INTENTIONALLY LEFT BLANK. 


\title{
Chapter 2 Interpretive Analysis of the Thermo-hydrological Processes of the Drift Scale Test
}

\author{
J. T. Birkholzer and Y.W. Tsang \\ Earth Sciences Division, LBNL
}

\subsection{Introduction}

In this chapter we conduct interpretive analysis of the thermo-hydrological processes of the Drift Scale Test (DST) at Yucca Mountain. We carry out a thorough study of the measured data collected in the first 6 months of heating and compare them with simulated results. Special attention is paid to understand the plausible cause of agreement and discrepancies between data and simulation, with the intent to constrain conceptual model assumptions and input parameter uncertainties for the coupled thermo-hydrological processes.

The numerical model is based on the three-dimensional predictive model developed by Lawrence Berkeley National Laboratory in 1997 (Birkholzer and Tsang, 1997). Several improvements and refinements have been made to the predictive model to better represent the actual test conditions. A brief review of the predictive model is given in Section 2.2 of this report, while the improvements and refinements made to the predictive model are presented in Section 2.3.

The temperature results obtained from the new DST model are compared with the measured temperature data for the first 6 months of heating in Section 2.4. Even though the new model represents the actual test conditions much better than the predictive model, uncertainties over model assumptions and formation properties still remain and need to be addressed. Therefore, in Section 2.5 , we present a sensitivity analysis of certain model assumptions and properties. In Section 2.6, the simulated moisture redistribution results are analyzed in terms of their correlation with active hydrological testing data.

\subsection{Review of the Predictive Drift Scale Model}

In June 1997, Lawrence Berkeley National Laboratory developed a three-dimensional numerical model to perform predictive simulations of the thermo-hydrological processes in the Drift Scale Heater test domain. Details of the conceptual model, basic assumptions, properties, initial and boundary conditions, grid 
design, and simulation results are given in Birkholzer and Tsang (1997). The predictive modeling work was intended to provide insight into the DST performance and to serve as a baseline that can be refined and calibrated against measured data. The relative importance of different input parameters, such as heating schedules, percolation fluxes, and rock properties, was examined. Also, alternative conceptualizations of various physical processes were examined to address the issue of uncertainty in the conceptual model. In particular, we examined (1) alternative conceptualizations of the fracture-matrix interaction, such as the effective continuum model (ECM) and the dual-permeability formulation (DKM), and (2) the effect of radiative heat exchange in the Heated Drift. In this subsection, we will review important features and basic assumptions of the predictive Drift Scale Test Model. Changes, refinements, and improvements to the predictive model are introduced in Section 2.3.

\subsubsection{Simulator and Processes}

The thermo-hydrological simulations of the DST were performed with the Integrated Finite Difference code TOUGH2 (Pruess, 1991, 1996; Wu et al., 1996). TOUGH2 is a numerical simulation program for nonisothermal flows of multicomponent, multiphase fluids in porous and fractured media. The TOUGH2-EOS4 module was used, which accounts for the nonisothermal two-phase flow of components water and air, including vapor-pressure lowering effects. Binary vapor-air diffusion rather than enhanced vapor diffusion was implemented.

\subsubsection{Model Domain}

The Drift Scale Test block is located in the Topopah Spring Middle Nonlithophysal unit at Yucca Mountain (tsw34), the average thickness of which is on the order of $40 \mathrm{~m}$ in the DST area (Birkholzer and Tsang, 1997). Preliminary calculations had shown that, with the design heat load, the spatial extent of the thermo-hydrological perturbation from the applied heat would extend beyond the boundaries of the tsw34 stratigraphic unit at the end of four years of heating. Therefore, stratigraphic units above and below tsw34 are included in the model domain of the DST, and significant rock volumes are added in all directions of the immediate thermal testing block to guarantee a proper definition of boundary conditions. The vertical extent of the model area is comprised of the Topopah Spring Middle Nonlithophysal unit (tsw34), where the Heated Drift resides, the overlying layer, the Topopah Spring Upper Lithophysal unit (tsw33), and the underlying layer, the Topopah Spring Lower Lithophysal unit (tsw36). The thickness of the geological layers was interpolated from the UZ site-scale model. Due to the dipping of the geological units, the thickness and elevation of the tsw34 is not uniform along the Heated Drift; e.g., the elevation at the interface between the tsw34 and the tsw33 units gradually increases from the bulkhead side to the western terminus by about $10 \%$. However, a constant thickness and elevation for the geological layers in the model area was assumed, interpolated for one representative location in the middle of the heated section of the Heated Drift. The interfaces of the tsw34 to the upper and lower layers were estimated from the UZ site-scale flow model to be at $z=+14.0 \mathrm{~m}$ and at $\mathrm{z}=-26.58 \mathrm{~m}$, respectively. The top and 
Yucca Mountain Drift Scale Test Progress Report

bottom boundaries of the model domain are $99.39 \mathrm{~m}$ and $156.76 \mathrm{~m}$ from the centerline of the Heated Drift.

\subsubsection{Conceptual Model for Flow in Fractures and Matrix}

In the predictive DST model, the fractures and matrix were each approximated to be a continuum for flow of liquid, gas and heat (Birkholzer and Tsang, 1997). The assumption that fractures form a continuous network for flow is consistent with fracture mapping data, borehole videos, and interference air permeability data obtained from the DST test block. These latter data did not uncover discrete continuous high-permeability features; thus as a first approximation, the DST domain was represented as a homogeneous continuum with an average permeability of $10-13 \mathrm{~m}^{2}$, which is the geometric mean of all air injection test data. At some point in the future, the conceptual model may need to be refined by incorporating heterogeneity.

In addition to assuming an appropriate conceptualization for flow within the fracture network and within the rock matrix, it is important to account for the interaction between them. Conceptual models typically used in fractured porous rock are the dual-permeability model (DKM) and the effective continuum model (ECM). Previous experience with the Single Heater Test (Birkholzer and Tsang, 1996, 1997, 1998b) shows that the dual-permeability conceptualization appears to represent the thermo-hydrological behavior in fractured tuff more accurately than the effective continuum model. The DKM method typically gives rise to higher liquid saturation in the fractures, results in stronger gravity-driven downward flow, and features smaller heat-pipe effects. In the predictive DST model, however, due to computational limitations, the effective continuum approach was applied in all three-dimensional simulations. The dual permeability formulation was used for certain two-dimensional runs to study the sensitivity of model results to the fracture-matrix interaction concept.

\subsubsection{Percolation Flux}

The percolation flux at the DST horizon affects the thermo-hydrological response of the rock formation to the applied heat, in that a higher flux can give rise to lower temperature and a more extensive condensation zone. Percolation flux is related to the surface infiltration flux, which is one of the most uncertain parameters at Yucca Mountain. Therefore, the numerical simulation was exercised for two different infiltration rates - the best estimate of $3.6 \mathrm{~mm} / \mathrm{yr}$ for the location of the heater test (Bodvarsson et al., 1997), and one-tenth of the expected estimate, $0.36 \mathrm{~mm} / \mathrm{yr}$-in order to include a full range of plausible responses. Infiltration was assumed to be constant in time; no episodic events were considered.

\subsubsection{Model Properties}

The model domain encompasses three stratigraphic layers of Yucca Mountain, i.e., the Topopah Spring layers tsw33, tsw34, and tsw35, with the Heated Drift situated in the tsw34 layer. The fractured tuff was 
assumed to be homogeneous within each layer; however, the different layers were assigned different properties, which were based on site-specific measurements whenever possible. If site-specific measurements were not available properties were derived from mountain-scale calibration runs for ambient conditions, using the ECM concept with a 1-D vertical column representation (Birkholzer and Tsang, 1997). The calibration runs were performed for two different infiltration rates, $3.6 \mathrm{~mm} / \mathrm{yr}$ and $0.36 \mathrm{~mm} / \mathrm{yr}$, generating two alternative property sets, the $3.6 \mathrm{~mm} / \mathrm{yr}$ case and the $0.36 \mathrm{~mm} / \mathrm{yr}$ case. Table 2.1 gives the material properties of the DST model layers derived for infiltration rates of $3.6 \mathrm{~mm} / \mathrm{yr}$ and $0.36 \mathrm{~mm} / \mathrm{yr}$, respectively. Several hydrological and thermal properties were directly based on laboratory and field measurements (Table 2.2). In these cases, no distinction is made between the high and low infiltration scenario. Some further assumptions related to rock properties are:

- All thermo-hydrological properties are isotropic.

- Hydrogeologic properties (such as porosity, permeability, etc.) are not affected by mechanical or chemical reactions to heat; i.e., they are assumed to be constant in time.

- Rock properties are assumed for all the boreholes since we make the implicit assumption that wiring, grouting, and instrumentation in the test block does not affect the thermo-hydrological behavior of the rock.

In future modeling efforts, the model properties for the DST will have to be carefully evaluated. One reason is that new mountain-scale calibration results from FY98 have only recently become available, based on a dual-continuum concept with reduced fracture-matrix interaction area (Wu et al., 1998). This conceptual model is believed to give more realistic fracture van Genuchten properties, differing from those used now for the $3.6 \mathrm{~mm} / \mathrm{yr}$ case. Ultimately, the choice of the most appropriate DST model properties will be determined by how well the simulated thermo-hydrological conditions compare with the measured data from the DST.

\subsubsection{Heater Schedule and Power}

Nine heater canisters are placed into the Heated Drift. The power of each of the heat canisters can be regulated in intervals of $250 \mathrm{~W}$ with a maximum power of $7.5 \mathrm{~kW}$. In addition to the canister heaters, a total number of 50 wing heaters are placed into 50 horizontal boreholes uniformly distributed along both sides of the Heated Drift. Each of the wing heaters has an inner and outer section, which operate on different power levels. The maximum power of each wing heater is $1.145 \mathrm{~kW}$ for the inner part and $1.716 \mathrm{~kW}$ for the outer part. The power can be regulated in 5\% intervals; however, the $2 / 3$ power ratio between inner and outer heater must be maintained. Altogether, the in-drift heaters have a total maximum power output of $67.5 \mathrm{~kW}$, while the 50 wing heaters have a total maximum power output of $143.05 \mathrm{~kW}$.

The heating schedule considered in the predictive DST simulations was as follows (Birkholzer and Tsang, 1997): After turning on heat, both the canister heaters and the wing heaters run with full capacity for 1 year, i.e., they run with $67.5 \mathrm{~kW}+143.1 \mathrm{~kW}=210.6 \mathrm{~kW}$ power. After 1 year, the power output of 
canister and wing heaters drops to 50\% capacity for another 3 years. After a total heating period of 4 years, all heaters will be turned off, and the rock mass will be allowed to cool down. The particular heating schedule was developed to meet the constraint that temperature at the Heated Drift wall must remain below $200^{\circ} \mathrm{C}$ throughout the duration of the heating phase.

\subsubsection{Radiative Heat Exchange in the Heated Drift}

In the predictive DST model, the Heated Drift was not incorporated in the model domain, as the drift walls were assumed to form a closed inner boundary for heat, gas, and liquid flow (Birkholzer and Tsang, 1997). Thus, the exact locations and geometries of the nine canister heaters were not represented, and heat radiation within the Heated Drift was not explicitly modeled. Instead, the heat load generated inside the drift was applied directly to the rock elements adjacent to the drift wall. This is a valid assumption considering the relatively fast process of thermal radiation. Since it was not clear if heat radiation would be effective enough to completely equilibrate the temperature along the drift wall, two extreme cases of drift wall boundary conditions were studied to bound the effect of thermal radiation: in the first case, a uniform areal heat load was introduced at the rock surfaces along the drift wall, which would eventually give rise to cooler temperatures at the two ends of the Heated Drift. In the second case, a uniform temperature was assumed at the rock surfaces along the entire length of the Heated Drift. The first case represents a less effective radiative heat exchange within the drift, and the second case represents totally effective black body radiation within the drift.

\subsubsection{Model Representation of Heaters}

The DST has nine canister heaters inside the $47.5-\mathrm{m}$-long drift, and 50 wing heaters placed into 50 horizontal boreholes, which are uniformly distributed along the length of the drift (Birkholzer and Tsang, 1997; Sandia National Laboratories, 1998). The as-built lateral distance between the wing heaters is about $1.83 \mathrm{~m}$, and the elevation of the wing heaters is $25 \mathrm{~cm}$ below the centerline of the drift. A typical wing heater consists of two 4.44-m-long heating elements. The first element in each wing heater borehole starts at about $1.67 \mathrm{~m}$ from the drift wall, and the second element ends at about $11.21 \mathrm{~m}$ from the drift wall. There is a gap between the two heating elements of $0.66 \mathrm{~m}$ (Sandia National Laboratories, 1998).

In the predictive DST model, individual canister or wing heaters were not explicitly represented. As already mentioned, heat radiation inside the Heated Drift was not modeled, since the thermal energy generated by the canisters was applied directly to the rock elements adjacent to the drift wall. Modeling individual wing heaters with their exact location and geometry was not feasible because of the geometrical complexity of the numerical grid involved with such a task. Therefore, wing heaters were modeled as horizontal smeared-out heat sources on either side of the drift, a good approximation except for the very early phase of heating. Based on the design test setup, which is slightly different from the asbuilt situation, the predictive DST model assumed that the inner and outer wing heater sections are each $4.75 \mathrm{~m}$ long, that the inner heating element starts at $2.0 \mathrm{~m}$ from the drift wall, and that there is no gap 
between the two heater elements. With the wing heater power output uniformly distributed along the 47.5-m-long heated portion of the drift, the areal horizontal thermal energy amounts to a maximum of $126.9 \mathrm{KW} / \mathrm{m}^{2}$ for the inner wing heater and $190.1 \mathrm{KW} / \mathrm{m}^{2}$ for the outer wing heater. In vertical direction, the wing heater power input is distributed over a $0.5-\mathrm{m}$ thick portion of rock.

\subsubsection{Model Representation of Thermal Bulkhead}

The thermal bulkhead, which separates the heated and the nonheated parts of the Heated Drift, was assumed to be a perfect seal for heat flow, gas flow, and liquid flow in the predictive DST model; in that, the Heated Drift was essentially modeled as a closed boundary for the surrounding rock mass-it would not allow for heat, vapor, or liquid to escape. The first months of heating in the DST show, however, that the bulkhead in fact provides an open conduit, through openings for the instrumental cables, for significant gas flux between the heated and nonheated parts of the Heated Drift. Therefore, some amount of the thermal energy introduced into the drift can leave the test domain by heat convection; additionally, gas pressure within the Heated Drift does not build up, and a gas pressure gradient can form between the heated rock and the drift.

\subsubsection{Assumed Test Geometry and Grid Design}

In the predictive DST model, test geometry and dimensions were taken from the design plan, because the DST was still under construction during model development. Minor deviations between the design and the final as-built configuration are to be expected, and need to be accounted for in the interpretation of test data. The test design assumes that the Heated Drift extends $47.5 \mathrm{~m}$ along its centerline from the bulkhead to the west. On the cold side of the bulkhead, the unheated section of the Heated Drift extends about $11 \mathrm{~m}$ to the connecting drift. The horizontal distance between the south wall of the Heated Drift and the north wall of the parallel Observation Drift is $27.0 \mathrm{~m}$. The Heated Drift is designed perfectly horizontal, with a circular shape of $5.0 \mathrm{~m}$ in diameter. The Observation Drift gradually declines from the ESF main drift towards the test area, with a slope of about $11.5 \%$. It is designed to be $5.0 \mathrm{~m}$ wide by 5.0 $\mathrm{m}$ high, measured from the invert to the crown. The Connecting Drift is $4.5 \mathrm{~m}$ wide; its height varies, as its invert is gradually declining from the Observation Drift to the Heated Drift.

The three-dimensional numerical grid designed for the DST was developed to honor the designed test configuration as closely as possible, allowing for accurate, yet efficient simulation of the DST thermohydrological conditions. The origin of the coordinate system is located on the hot side of the bulkhead, in the center of the drift. The positive $x$-axis points horizontally approximately north (transverse to the Heated Drift away from the Observation Drift); the positive y-axis points horizontally along the Heated Drift approximately west; and the positive $\mathrm{z}$-direction points vertically upward from the origin. The grid development started with a two-dimensional vertical mesh for the local xz-plane, i.e., a plane orthogonal to the Heated Drift centerline. In a second step, the complete three-dimensional DST grid was created by appropriately extending several vertical 2-D planes into the third dimension and merging them together. 
This merging procedure maintains the refined 2-D mesh structure in all the planes incorporating the heated section of the drift; however, when moving outward from the heated section, the local mesh refinement is gradually reduced. The entire three-dimensional grid of the predictive DST comprises 24 two-dimensional vertical planes; it is composed of 48,249 gridblocks and 157,474 connections between them.

Figure 2.1 shows the 2-D vertical grid in a typical $x z$-cross section intersecting the Heated Drift at $y \sim 10$ $\mathrm{m}$ from the bulkhead (i.e., in the plane of hydrology holes 57 through 61). As already mentioned, the model area includes three geological layers of the Topopah Spring unit, the Upper and Lower Lithophysal, and the Middle Nonlithophysal unit, which hosts the heater test area. The grid was designed such that the assumed interfaces between layers are represented by gridblock interfaces (i.e., interfaces are maintained at $\mathrm{z}=+14.0 \mathrm{~m}$ and $\mathrm{z}=-26.68 \mathrm{~m}$ ). Figure $2.2 \mathrm{a}$ shows the same cross section in a close-up view of the rock areas adjacent to the Heated Drift and the wing heaters. As mentioned before, the heated section of the drift is treated as a closed boundary in the predictive DST model, since the radiative heat exchange within the Heated Drift is not explicitly modeled. The wing heaters are represented by horizontal smeared-out heat sources on either side of the drift. In the vertical direction, the wing heater source is distributed over a thickness of $0.5 \mathrm{~m}$, extending from $\mathrm{z}=-0.5 \mathrm{~m}$ to $\mathrm{z}=0.0 \mathrm{~m}$, thus fixing the center of the distributed heater source at the centerline of the wing heater boreholes at $-0.25 \mathrm{~m}$. Note that the concrete invert at the bottom of the Heated Drift is not represented in the predictive DST model; also, the concrete liner in the end section of the Heated Drift is not accounted for. The figure also depicts the as-built location of five hydrology holes 57 through 61 , which are collared in the Observation Drift. The square symbols indicate the as-built location of thermocouple temperature sensors. Figure $2.2 \mathrm{~b}$ gives another $\mathrm{xz}$-cross section located at $\mathrm{y} \sim 30 \mathrm{~m}$ from the bulkhead, showing the as-built configuration of hydrology holes 74 through 78. Figure 2.3 presents the configuration of Boreholes 158 through 165, which form a cluster oriented radially outward from the Heated Drift. This vertical plane intersects the long axis of the drift at $y \sim 23 \mathrm{~m}$. About 67 RTD temperature sensors are grouted in each of these boreholes at approximately $0.3 \mathrm{~m}$ spacing.

\subsubsection{Initial and Boundary Conditions}

As already mentioned, property sets for the predictive DST model were developed using a onedimensional vertical column calibration for the ambient flow situation at Yucca Mountain. Results obtained with this vertical column model were used to interpolate vertical profiles of initial saturation, pressure, and temperature for the DST model grid, depending on the z-coordinate of respective gridblocks. At the bottom of the DST domain, the interpolated values were used as Dirichlet-boundary conditions; i.e., the boundary elements have constant pressure, saturation and temperature throughout the simulation period. At the top boundary, a constant temperature and the respective percolation fluxes of $3.6 \mathrm{~mm} / \mathrm{yr}$ and $0.36 \mathrm{~mm} / \mathrm{yr}$ for the two scenarios were prescribed, thus allowing for minor pressure and saturation deviations from the interpolated values. These deviations can occur as a result of the mapping from the 1-D column to the DST grid, which may introduce minor numerical inaccuracies. To avoid 
unwanted perturbations, initialization runs with the $3-\mathrm{D}$ ) grid were performed for a time period of 10,000 years prior to turning on heat to ensure that a consistent initial state is achieved. No attempt was made in the predictive simulations to model a possible dry-out of the rock adjacent to tunnel walls due to ventilation.

All drifts, except from the heated section of the Heated Drift, were modeled by a constant pressure, temperature, and saturation boundary condition, assuming that they are ventilated and the heating of the rock does not affect their thermo-hydrological situation. Insulation with a very low thermal conductivity material was assumed for some of the drift walls: complete wall insulation was modeled for the nonheated section of the Heated Drift, while the Connection Drift and Observation Drift were assumed to be insulated on the near-heater walls only. The insulation was explicitly represented in the model, with a 15.2-cm thickness, a $0.0447 \mathrm{Watt} /(\mathrm{m} 2 \mathrm{~K})$ thermal conductivity, a density of $32 \mathrm{~kg} / \mathrm{m} 3$, and a heat capacity of $835 \mathrm{~J} /(\mathrm{kg} \mathrm{K}$ ) (values chosen are similar to the SHT-design calculations, Birkholzer and Tsang, 1996). The insulation allows for moisture to escape from the test block in the form of both liquid water and vapor.

\subsection{DST Model Refinements and Improvements}

Based on 6 months of heating data measured in the Drift Scale Test, we have made a thorough evaluation of the predictive DST simulations performed in June 1997 (Birkholzer and Tsang, 1997), in terms of the model conceptualization and the model parameters. As a result of our study, the predictive DST model is refined and improved to better match test conditions and data. Modifications made and motivation for these changes are listed in the following sub-sections. In general, model modifications can be categorized as follows:

- Modifications to conform to actual test conditions

- Adjustments to model conceptualization

- Alternative choice of hydrogeological and thermal rock properties

So far, we have focused on the first two items, i.e., a better representation of the actual test conditions, and a review of the conceptual model. We have not yet attempted to perform a model calibration in order to develop an improved rock property set.

\subsubsection{Simulator and Processes}

No modifications have been made. 


\subsubsection{Model Domain}

So far, no modifications have been made to the extent of the model domain. In the vertical, it comprises the three stratigraphic units tsw33, tsw34, and tsw35. The interfaces of the tws34 to the upper and lower layers are estimated from the UZ site-scale flow model to be $14 \mathrm{~m}$ above and $26.6 \mathrm{~m}$ below the Heated Drift centerline. This fairly simple stratigraphic model for the DST may need to be adjusted and refined in the future to conform to detailed site-specific information about the near-drift geologic structure (e.g., from borehole videos).

\subsubsection{Conceptual Model for Flow in Fractures and Matrix}

Data collected so far do not indicate the presence of discrete continuous high-permeability features; thus the continuum conceptualization chosen for the DST seems appropriate. With respect to ECM or DKM, there is not enough evidence yet in the measured data to favor one conceptualization over the other. In this study, we apply the effective-continuum approach in all three-dimensional simulation cases (Section 2.4). The dual-permeability formulation is used for certain two-dimensional runs to investigate the sensitivity of model results to the fracture-matrix interaction concept (Section 2.5.4).

\subsubsection{Percolation Flux}

So far, there is not enough evidence in the data to favor one percolation flux scenario over the other. The current best-estimate value of $3.6 \mathrm{~mm} / \mathrm{yr}$ (Bodvarsson et al., 1997) is applied in all three-dimensional simulation cases (Section 2.4); sensitivity to percolation flux is studied in Section 2.5.3.

\subsubsection{Model Properties}

A valuable indication of the accuracy of thermo-hydrological model properties would be the goodness of fit between measured and simulated temperature data above nominal boiling. At 6 months of testing, only a small portion of the rock has heated up above boiling; more data is needed for a thorough model calibration. Thus, no attempt has yet been made to calibrate the model in order to develop a "best-fit" property set. In this study, we still use the two alternative property sets developed in the predictive model. The $3.6 \mathrm{~mm} / \mathrm{yr}$ property set is used in all three-dimensional simulation cases in Section 2.4 , and a comparison of both parameter sets is given for a two-dimensional case in Section 2.5.3. Revision of rock properties will be performed in future modeling efforts.

\subsubsection{Heater Schedule and Power}

Heater schedule and power need to be modified from the predictive modeling values, because the DST heaters were not operated under $100 \%$ power during the first 6 months of the test (as was assumed in the predictive model). In fact, the average total power of the canister heaters was $52 \mathrm{~kW}$, for the time period from December 3, 1997 to April 21, 1998. This is about $77 \%$ of the maximum power. The average total 
power of the wing heaters for the same time period was $135 \mathrm{~kW}$, which amounts to about $94 \%$ of the maximum power. (The $2 / 3$ power ratio between the inner and the outer wing heaters is maintained, as was assumed in the model.) A closer look at the time evolution of heater output reveals that the power values have a declining trend over time, probably due to aging of the heater elements (Sandia National Laboratories, 1998). This trend, however, is slight so far, so the average power over time is used as input to the modified model.

Since the heaters are not operated under full capacity, it will take a longer time to build up high temperature in the Heated Drift and the adjacent rock. In our modified DST model, we assume that the current average of heater power, i.e., $77 \%$ for the canisters and $94 \%$ for the wing heaters, will be maintained over several years. One objective of our modeling effort is to determine when the heater output should be reduced in order to meet one main temperature criterion for the heater test, namely that the wall temperature at the Heated Drift wall should be close to, but not exceed $200^{\circ} \mathrm{C}$.

\subsubsection{Radiative Heat Exchange in the Heated Drift}

Temperature data of the rock surface in the Heated Drift indicate that thermal radiation is effective enough to equilibrate temperature inside the drift. Figure 2.4 shows the temperature evolution at surface thermocouples over the first 6 months of heating; three sensors present temperature at $y=21.5 \mathrm{~m}$ from the bulkhead measured at different angular distance from the crown; the other five sensors are located at $y$ $=44.6 \mathrm{~m}$ from the bulkhead in the back section of the drift, where the concrete liner covers the wall. There is almost no temperature difference between sensors located at the same distance from the bulkhead, and only a slight temperature difference between the $y=21.5 \mathrm{~m}$ location and the $\mathrm{y}=44.6 \mathrm{~m}$ location. The lower temperatures in the back section of the Heated Drift are mainly due to the concrete liner. This is indicated by a noticeable dip in temperature at $\mathrm{y}=35 \mathrm{~m}$ from the bulkhead, which corresponds exactly with the beginning of the concrete liner (Sandia National Laboratories, 1998).

In contrast to these findings, in the case where heat radiation was not very effective, our predictive model indicated that the rock wall temperature at the crown and at the springline could differ by as much as 25 ${ }^{\circ} \mathrm{C}$. Furthermore, wall temperatures along the drift could differ by as much as $40^{\circ} \mathrm{C}$ between the middle and the end section. Clearly, this ineffective heat radiation concept does not capture the thermal response to heat in the Heated Drift. In our interpretive analysis, we choose the alternative heat radiation case of our predictive model described in Section 2.2.7, which assumes a uniform temperature distribution at the wall surface along the drift, representing totally effective black body heat radiation. This conceptualization gives results fairly close to the measured data. In future studies, however, we may refine our modeling work by explicitly representing heat radiation in the Heated Drift. 


\subsubsection{Model Representation of Heaters}

No modifications have been made to the representation of heaters in the model. As described in Section 2.2.8, the thermal energy generated by the canisters is applied directly to the rock elements adjacent to the drift wall, while wing heaters are modeled as horizontal smeared-out heat sources on either side of the drift. There are some important implications arising from this simplified representation of heaters:

- The model does not account for differences in the power output of individual heaters. In fact, several anomalies in heater power occurred during the first 6 test months (Sandia National Laboratories, 1998). The model, however, uses the total amount of power for the canister heaters, the inner wing heater section, and the outer wing heater section, respectively.

- The temperature measured in boreholes close to wing heaters is sensitively dependent on their geometry and configuration in relation to individual heater elements. For example, in a vertical cross section orthogonal to the Heated Drift, the horizontal Boreholes 160 and 164 run slightly above, but parallel to the wing heater array. Laterally, however, they are separated from the adjacent wing heaters by about $0.9 \mathrm{~m}$. This separation distance, which certainly affects early-time temperature buildup, cannot be accounted for in the model.

- Gas-driven convective heat flow can potentially equilibrate temperature along open boreholes. The model cannot represent the wing heater boreholes acting as possible conduits for vapor flux, which may be particularly important for the wing heaters.

- Due to differences between design and as-built configuration, the geometry and location of wing heaters was slightly misrepresented in the predictive DST model. Adaption of the model to the as-built situation would require a major regridding effort, which we consider unnecessary since the effect of this misrepresentation is probably very small, compared to the impact of other model uncertainties.

\subsubsection{Model Representation of Thermal Bulkhead}

There is clear evidence from the first 6 months of heating that the thermal bulkhead installed at the entrance of the Heated Drift is not a perfect seal for heat, gas and liquid flow. Moist air can escape from the Heated Drift, at times forming puddles of water on the cold side of the bulkhead as the vapor condenses. Other evidence stems from pressure data: pressure readings from a gage located inside the Heated Drift are plotted as a function of time in Figure 2.5. The data indicate no trend of pressure buildup due to heating. Apparently, the thermal bulkhead is permeable enough to gas flow such that any pressure buildup can be immediately released. Furthermore, the pressure fluctuations within the Heated Drift correlate with pressure fluctuations in the Connection Drift or Observation Drift, which stem from barometric pressure changes.

Our refined DST model utilizes a modified bulkhead boundary condition that conforms better to the actual test conditions. Instead of using a closed boundary for the bulkhead, as was done in the predictive model, we introduce a connection between the Heated Drift and a constant 
pressure/temperature/saturation boundary element, which represents the cold side of the bulkhead. Vapor can leave the Heated Drift via this connection; heat can only be transported by convection, not by conduction. The impact of the property values given to this bulkhead connection was studied by varying the permeability value assigned to it. It turned out that there is almost no sensitivity to this parameter as long as the connection is permeable enough to guarantee a constant pressure in the Heated Drift.

Recall that the predictive DST model did not represent the Heated Drift and the thermal bulkhead at all; the drift was treated as a closed inner boundary condition for the rock elements. For the refined model, introduction of the bulkhead connection requires explicit modeling of the Heated Drift. Therefore, the new model features one additional drift element, which represents the entire length of the drift. At this point, as thermal radiation inside the Heated Drift is not explicitly modeled, the one-element representation is sufficient. In future studies, this fairly simple representation of only one drift element may need to be refined. We may also introduce the measured barometric pressure fluctuations to the bulkhead boundary element instead of using a constant average. The time-dependent boundary condition may enable a better estimate of the impact of the air and vapor exchange between the Heated Drift and the outside drifts.

\subsubsection{Assumed Test Geometry and Grid Design}

No major changes were made to the assumed test geometry and the three-dimensional mesh design of the predictive model. The DST model geometry still represents design coordinates, not as-built coordinates, so that there are minor discrepancies. Changes made to the computational grid used for the new DST model are inclusion of a Heated Drift element and a bulkhead boundary element, as discussed above, and representation of the concrete invert in the Heated Drift. The concrete invert seems to retard the temperature build-up vertically downward from the Heated Drift, as reflected in the measured data (Birkholzer and Tsang, 1998a). Therefore, additional model elements are placed into the lower part of the Heated Drift, representing the concrete invert with a maximum thickness of $1.2 \mathrm{~m}$. We make no attempt to capture the potentially very complex thermo-hydrological behavior in concrete under the presence of heat; instead we assign properties to the concrete similar to the surrounding rock, with the exception of porosity and heat conductivity. Porosity is set to a very small value of 0.0011 to guarantee a small initial water content in the concrete. Heat conductivity of the concrete is assumed to be $3.0 \mathrm{~W} /\left(\mathrm{m}^{\circ} \mathrm{K}\right)$ which is an average value for concrete depending on the type of aggregate used (Neville, 1996). This value will be updated once measurements of thermal conductivity become available for the concrete used in the DST. Note that the concrete liner in the back section of the drift is not yet represented in our model.

Figure 2.6 demonstrates the effect of the concrete invert represented in the refined model. Temperature is plotted as a function of time at temperature gage $60-4$, which is located below the Heated Drift at a radial distance of about $4.8 \mathrm{~m}$ from the centerline. The measured data correspond perfectly with the simulated temperature for the concrete-invert case, whereas simulation results obtained without modeling the concrete invert show a distinct overestimation of temperature. 


\subsubsection{Initial and Boundary Conditions}

Initial conditions for the predictive DST model had been derived from initialization runs representing the ambient situation at Yucca Mountain. No attempt was made in the predictive simulations to account for the impact of elevated drift temperature or ventilation of drifts prior to heating. However, pre-heat data of the DST show temperature values of about $32{ }^{\circ} \mathrm{C}$ at the rock walls close to the drifts, which is several degrees higher than the assumed ambient in the predictive model. Related studies have also shown that ventilation can create a dry-out zone around drifts with lower matrix saturation extending several meters into the rock. For our new model, we decided to account for the possible impact of a ventilated Heated Drift with slightly elevated temperatures. This is done by performing a second initialization run for a simulation time period of 6 months prior to heating, using a constant boundary condition of $32{ }^{\circ} \mathrm{C}$ and $50 \%$ relative humidity in the Heated Drift. The results of this run are used as initial condition for the heater simulation. Boundary conditions of the new model remain unchanged from the predictive simulations, with the exception of the new thermal bulkhead representation (see Section 2.3.9).

\subsection{Comparison of Modeled Results and Measured Temperature Data}

This section gives a detailed description of the DST model results in comparison with the measured data from the first 6 months of heating. The simulated data represent results from our current "best" model, featuring all the refinements and improvements outlined in Section 2.3. The simulations described below are performed using a three-dimensional representation of the DST, applying the effective-continuum model for fracture-matrix interaction, and assigning rock properties calibrated for the $3.6-\mathrm{mm} / \mathrm{yr}$ percolation scenario. The impact of alternative fracture-matrix conceptualization and property sets is discussed in Section 2.5.4.

The following Section 2.4.1 presents contour plots of simulated temperature, fracture, and matrix saturation, and pressure in the rock at different stages during the test. This is intended to provide a basic understanding of the important processes related to the heating of the formation. Then, in a comparative analysis of model results and measured data, we shall mainly present temperature measurements from RTD boreholes that are located in close proximity to the Heated Drift and the wing heaters (Section 2.4.2). Some of these gages already show significant temperature build-up above nominal boiling. Additionally, we shall give some results for selected temperature gages in the hydrology holes; however, at this early phase of heating, most of the temperature sensors in hydrology holes are too far away from heaters to show significant changes. Finally, we will discuss implications of our results on the heating schedule for the DST in Section 2.4.3. 


\subsubsection{Contour Plots of Simulation Results}

Simulated temperature distributions after 3 months and 6 months of heating are presented in Figure 2.7 for a xz-cross section, i.e., in a vertical plane perpendicular to the Heated Drift axis. The cross section chosen is located at $y=30 \mathrm{~m}$ from the bulkhead, including hydrology Boreholes 74 through 78 . Other vertical cross sections show very similar simulation results; at this early phase of heating, the thermohydrological processes are mainly two-dimensional, radially away from the Heated Drift and the wing heater array. The highest temperatures are observed in the outer section of the wing heaters and at the Heated Drift wall. The temperature contours clearly indicate the effect of the concrete invert, as the rock temperature below the Heated Drift is smaller than above and at the sides. At three months, some portions of the rock have just reached nominal boiling, while at 6 months, temperature at the wing heaters and close to the drift wall are clearly above the $97{ }^{\circ} \mathrm{C}$ isotherm. For the comparison of measured and simulated data, it is important to understand the effect of the simplified model representation of wing heater geometry. Since the wing heaters are modeled as smeared-out heat sources, some temperature gages, e.g., Sensor 77-3 in Borehole 77, are located in very close proximity to the heater in the simulations. In reality, these sensors and the wing heaters are laterally separated by about $0.9 \mathrm{~m}$.

Figure 2.8 gives the simulated gas pressures for the same $\mathrm{xz}$-cross section as above. Gas pressure is expected to increase as the rock heats up and vapor is generated. Thus, pressure build-up is observed in the heated rock areas around the wing heaters. However, no pressure build-up is seen in the regions of elevated temperature close to the drift wall. Here, the generated vapor is readily driven into the Heated Drift, because the drift with gas-permeable bulkhead acts as a constant pressure boundary for the surrounding rock.

Fracture liquid saturation is presented in Figure 2.9 at 3 months and at 6 months into the test. The saturation contours indicate significant changes from the initial saturation at ambient, which is about $17 \%$ for this particular property set. At three months, localized regions of dry-out have developed at the wing heaters and around the Heated Drift. At 6 months, an extended dry-out zone has formed, all the way connected from the wing heater tips to the Heated Drift. (Note that the dry-out around the Heated Drift is partially due to the ventilation of the drift prior to heating.) The vapor generated by heating the rock is carried away driven by the gas pressure gradient, into cooler regions of the rock or into the Heated Drift. In cooler regions of the rock, the vapor eventually condenses and liquid saturation builds up. We can see a slight nonsymmetry of moisture distribution in the vertical direction, with a stronger saturation build-up below the heaters. This indicates the presence of gravity-driven flux in the fractures. Figure 2.10 shows matrix liquid saturation at 3 months and 6 months of heating. The moisture redistribution in the matrix resembles that of the fractures, since the ECM concept assumes pressure equilibrium between fractures and matrix. 


\subsubsection{Comparison of Measured and Simulated Temperature}

In our comparative analysis, we shall focus on temperature measurements inside and close to the Heated Drift and close to the wing heaters. During the early phase of heating considered in this study, these regions already show temperature increase above boiling, indicating the possibility of significant heatinduced vapor and liquid fluxes, which in turn may have a strong impact on the temperature evolution. Thus, comparison of the measured and simulated temperature for the above-boiling zones can provide a good indication of the accuracy of the thermo-hydrological model.

Figures 2.11 through 2.16 present a sequence of measured and simulated temperature profiles along Boreholes 158 through 165 for 1, 2, 3, 4, 5, and 6 months of heating (i.e., at January 3, February 3, March 3, April 3, May 3, and June 3). Temperature is plotted as a function of the distance to the borehole collar. The boreholes chosen are arranged in a cluster oriented radially outward from the Heated Drift at a distance of $y=23 \mathrm{~m}$ to the bulkhead (Figure 2.3). Boreholes 160 and 164 are horizontal and run slightly above the wing heater horizon. Boreholes 158,165 and 159 are oriented upward with angles of $0^{\circ}$ and $\pm 45^{\circ}$ to the vertical axis, while Boreholes 162,163 , and 161 are oriented downward with angles of $0^{\circ}$ and $\pm 45^{\circ}$ to the vertical axis. The latter three holes are collared in the concrete invert at the bottom of the Heated Drift.

Each of the RTD boreholes are equipped with up to 67 RTD sensors at approximately $0.3 \mathrm{~m}$ spacing, providing very detailed information about the temperature distribution in the rock formation. Symbols indicate the location of the individual sensors. The spikes in the measured data, shown in the top graphs, denote obvious erroneous sensor readings and should be ignored. The temperature data obtained for the 6-month snapshot are considered not qualified at the time of this report, but were added for completeness. No major differences are expected to the final qualified data (see Section 1.2). The simulated data, shown in the bottom graphs, are interpolated from the three-dimensional grid using borehole coordinates. The interpolation algorithm searches for intersections between the borehole axis and the gridblock connections; for each intersection found, a temperature value is linearly interpolated from the two gridblock temperatures associated with the respective connection. Symbols indicate the location of intersections where temperature is interpolated. Again, some discrepancies between measured and simulated data can stem from the representation of the wing heaters as a smeared-out heat source in the model.

Generally, the measured and simulated temperature data compare favorably. The highest temperatures are obtained along the two horizontal boreholes, 160 and 164, because of their proximity to the wing heaters. After a fast temperature build-up in the first two months, the temperature profile flattens out around $97^{\circ} \mathrm{C}$ at 3 months of heating, indicating gas-liquid two-phase conditions in this area. After 4 months, the temperature profiles in 160 and 164 have just started to rise again. Finally, at 5 and 6 months, the temperature along these boreholes is well above $97^{\circ} \mathrm{C}$, and a small heat-pipe region can be seen close to the tip of the wing heaters. It is obvious that the two horizontal boreholes are much warmer than the other boreholes; also, the angled boreholes are slightly warmer than the vertical boreholes, both 
of which is clearly dependent on the borehole orientation relative to the wing heater axes. It is interesting to note that only minor heat pipe signals form in the rock close to the Heated Drift. We will later show that this observation is mainly due to the Heated Drift acting as an open boundary for gas, allowing vapor to escape from the formation (Section 2.5.1).

Overall, the measured temperatures appear to be slightly higher than the simulated values, in particular for elevated temperature above nominal boiling. This would indicate that the model overestimates heat pipe effects, which can often arise from erroneous rock properties, or possibly from the ECM conceptualization. We will later show that an alternative property set, developed from the $0.36 \mathrm{~mm} / \mathrm{yr}$ percolation flux calibration, appears to give better results (Section 2.5.3). Another interesting observation is related to the power output ratio of $2 / 3$ between the inner and the outer wing heater. One should expect that the temperature close to the outer heater should be higher than in the inner region, and the model results indeed show such behavior. However, the measured temperatures along Boreholes 160 and 164 are almost identical for the inner and outer section. One possible explanation is that the wing heater boreholes serve as effective conduits for gas flow, so that the temperature difference between the inner and outer heater section diminishes.

In the next set of graphs, we show temperature as a function of time at certain locations in Borehole 160 . The top graph in Figure 2.17 gives measured temperature for a time period of 6 months at the following sensors: RTD-1, located at the Heated Drift wall; RTD-17, located close to the inner wing heater section; RTD-27, located close to the outer wing heater section; RTD-44 and RTD-60, both located several meters beyond the tip of the wing heaters. In the bottom graphs, we show the simulated temperature evolution at the numerical grid elements closest to the sensor location. The temperature curves at RTD-17 and RTD27 show distinct heat-pipe plateaus maintained over a long time period, which indicates well-defined gasliquid two-phase conditions in the rock. RTD-1 data represent the temperature evolution in the rock close to the drift wall; heat pipe signals are absent here, mainly due to the fact that the vapor generated is immediately carried away into the open drift. Temperature at RTD-44 and RTD-60 maintains well below boiling. Overall, the simulated results correspond well with the measured data in both general trend and magnitude of values. The model appears to overestimate the temporal extent of the heat-pipe plateau, which can be corrected by assigning different rock properties (Section 2.5.3). Also, the model predicts a faster temperature build-up at RTD-27, but a slower build-up at RTD-17. This relates to the anomaly described earlier that the measured temperatures along the inner and outer wing heater sections are almost identical, despite a power ratio of $2 / 3$ between the inner and the outer heater.

Another set of figures presents the temperature evolution at sensors located in the hydrology holes 59, 60 , 76 and 77 (Figures 2.18-2.21). These are the hydrology holes closest to the Heated Drift, 59 and 76 above, 60 and 77 below, as shown in Figure 2 of this report. Sensor 1 is nearest the collar of the borehole (i.e., closest to the Observation Drift), and Sensor 4 is nearest to the bottom of the borehole. Only three sensors are installed in Borehole 77. Again, there is reasonably good agreement between measurement and simulation. The faster increase of simulated temperature at Sensors 60-3 and 77-3 is mainly related 
to the simplified wing heater geometry adopted in the model, placing the sensors in close proximity to heater elements. Other discrepancies might stem from the fact that simulated temperature is not interpolated to the exact location of the sensor, but simply taken from the grid element closest to the sensor. In some cases, particularly where the gridding is less refined, the distance between sensor and gridblock can be significant. In the future, we shall use more sophisticated interpolation techniques. Note that the temperature in Sensor 60-4 would be much higher without the retarding effect of the concrete invert.

\subsubsection{Temperature Evolution at the Heated Drift Wall and Implications on Heating Schedule}

The top graph in Figure 2.22 shows the temperature data measured at the Heated Drift wall, as was already presented in Figure 2.4, together with the simulated drift temperature for the first 6 months of heating. The agreement between the model and data is very good. The slight heat pipe signal observed in the model results (at around 80 days) will vanish when using the $0.36 \mathrm{~mm} / \mathrm{yr}$ property set or when utilizing the DKM concept (Sections 2.5.3 and 2.5.4). The bottom graph gives the simulated drift temperature over a longer time period of 1000 days. At the end of this time period, drift temperature is still slightly below $200{ }^{\circ} \mathrm{C}$, which is the maximum temperature to be reached in the DST. Thus, according to our simulation, the current heater power (about $77 \%$ for the canisters, $94 \%$ for the wing heaters) can be maintained for another 18 months. However, we shall demonstrate in Section 2.5.3 that this time period may be two or three months shorter when assigning alternative rock properties to the formation.

\subsection{Sensitivity Study to Model Conceptualization and Properties}

In this section we analyze how different model conceptualizations and model properties affect the temperature simulation for the DST. We shall first illustrate the impact of some of the more important model improvements and refinements outlined in Section 2.3, such as introducing the new bulkhead boundary condition or simulating the rock dry-out prior to heating due to ventilation. We shall also analyze sensitivity to model properties and to the fracture-matrix interaction concept ECM or DKM.

The DST model presented in Section 2.4 is used as the reference case for comparison with alternative model concepts or properties. To recapitulate, the reference case involves the effective-continuum conceptual model, uses the $3.6 \mathrm{~mm} / \mathrm{yr}$ calibrated property set, accounts for initial drying of rock due to ventilation prior to heating, assumes a gas-permeable bulkhead, and simulates very effective heat radiation in the Heated Drift. The sensitivity study is performed for a vertical plane orthogonal to the Heated Drift centerline, on a two-dimensional grid identical to the xz-cross section shown in Figure 1. Results from a two-dimensional model cannot exactly represent the actual three-dimensional behavior of the rock mass; the 2-D temperature response overestimates the three-dimensional system behavior. However, two-dimensional simulations have considerable merit in a sensitivity study. They are 
instructive to uncover the relative importance of parameters and processes, while allowing for more efficient computation and data handling compared to a fully three-dimensional study.

\subsubsection{Model Representation of Thermal Bulkhead}

Figure 2.23 shows simulated gas pressure after 6 months of heating for two cases, a gas-permeable bulkhead (which is the reference case from Section 2.4) and a perfectly sealed bulkhead. The effect of opening the bulkhead is obvious; gas pressure in the Heated Drift does not build up, and a pressure gradient develops from the rock to the drift, allowing for significant amounts of moist air to leave the formation. For the closed bulkhead case (and closed Heated Drift wall), the region of increased gas pressure extends all the way from the wing heater tips to the Heated Drift.

These differences have significant impact on the local temperature close to the Heated Drift, as Figure 2.24 shows for the temperature field after 6 months of heating. The temperature profiles in the top graph give the open-bulkhead results; the bottom graph presents the closed bulkhead simulation. In the latter case, a distinct heat pipe zone develops within $2 \mathrm{~m}$ of the Heated Drift, indicating strong vapor-liquid counterflow. In contrast, since vapor can escape from the formation for the open bulkhead case, the heat pipe signal is very subtle, and temperature close to the Heater Drift wall is several degrees centigrade higher. The measured temperature data (Figure 2.16) display a behavior very similar to the simulated open-bulkhead case, where heat pipe signals are seen in proximity to the wing heaters, but not close to the Heated Drift. We may conclude that the new bulkhead boundary condition is a major improvement of the DST model.

Figure 2.25 shows temperature at the Heated Drift wall as a function of time for a time period of 185 days (top graph) and 1000 days (bottom graph) for the alternative bulkhead boundary conditions. Up to the nominal boiling temperature, both bulkhead boundary conditions give identical temperature. Above nominal boiling, as the pore water in the rock formation close to the Heated Drift wall starts to boil and vapor is generated, the temperature at the Heated Drift wall is higher for the open bulkhead boundary. For example, after 6 months of heating, the temperature difference between the two cases is about 6 degrees centigrade. The closed bulkhead condition forces vapor to remain in the rock and induces heat pipe effects, i.e., vapor flux away from the boiling zone and condensate reflux towards the boiling zone. This effectively carries away heat from the boiling zone, thus depressing the temperature at the Heated Drift wall. In contrast, in the open bulkhead case, vapor can escape from the formation and less moisture is available for heat pipe effects to occur in the rock. However, the bottom graph in Figure 2.25 indicates that after about 2 years, the temperature trends reverse and the open bulkhead boundary condition leads to lower temperatures at the Heated Drift wall. This is related to the effect of the cumulative loss of thermal energy from the test domain by thermal convection through the bulkhead. 


\subsubsection{Initial Drying due to Ventilation}

The effect of the initial saturation condition close to the drift wall is less important in the long run, but significant at early times. Figure 2.26 shows the temperature profile along the RTD holes 158 through 165 after 6 months of heating, simulated with initial drying prior to heating (top graph), which is the reference case from Section 2.4, and without initial drying (bottom graph). The differences between the two cases are subtle and very localized; temperature right at the Heated Drift wall is about 2 degrees centigrade higher for the initial drying case. The temperature evolution in Figure 2.27 indicates that the simulation without initial drying gives a distinct heat-pipe signal at about 70 to 80 days of heating, while the initial drying case shows almost no heat pipe signal. The latter is more commensurate with the measured temperature data, which give no indication of heat pipes. Note that at later times, the differences between the two simulation cases disappear, and the temperature evolution becomes almost identical.

\subsubsection{Formation Properties and Percolation Flux}

In this section, we compare simulation results of the two alternative model property sets developed for the DST in June 1997 (Birkholzer and Tsang, 1997). As discussed in Section 2.2.4, the property sets were derived from 1-D mountain-scale calibration runs for two alternative percolation flux scenarios, the 3.6$\mathrm{mm} / \mathrm{yr}$ case and the $0.36 \mathrm{~mm} / \mathrm{yr}$ case. Thus, the different thermo-hydrological condition simulated for these cases may result from the differences in the calibrated properties as well as from differences in the flux percolating down the mountain. However, experience from the Single Heater Test indicates that the formation properties have a far greater impact on the temperature field than the percolation flux, at least for a small-scale thermal perturbation as in the SHT.

We first compare the simulated temperature profile for the two alternative property sets along the RTD holes 158 through 165 at 6 months heating (Figure 2.28; also compare to the measured data in Figure 2.16). The $0.36-\mathrm{mm} / \mathrm{yr}$ case results in higher temperatures above nominal boiling, indicating that fewer heat pipe effects occur compared to the $3.6-\mathrm{mm} / \mathrm{yr}$ case. The maximum difference is about $8{ }^{\circ} \mathrm{C}$ at the drift wall and about $10^{\circ} \mathrm{C}$ close to the wing heaters in Boreholes 160 and 164 . Figure 2.29 shows temperature evolution at selected sensors in Borehole 160, for the first 6 months of heating. For both property sets, heat pipe plateaus develop at gages 17 and 27; however, the heat pipe signal is significantly shorter for the $0.36-\mathrm{mm} / \mathrm{yr}$ property set.

These results suggest that the alternative $0.36-\mathrm{mm} / \mathrm{yr}$ property set may give a better representation of the measured temperature data than the $3.6-\mathrm{mm} / \mathrm{yr}$ property set, which appeared to overestimate heat pipe signals (see Section 2.4.2). The most prominent parameter difference between the two property sets is the magnitude of capillarity in the fractures, which is rather high for the $3.6 \mathrm{~mm} / \mathrm{yr}$ scenario. Calibration studies performed for the Single Heater Test have shown that such high values of fracture capillarity give rise to strong vapor-liquid counterflow in the simulation results, which do not match the measured data. 
The 2-D sensitivity results obtained for the DST seem to support this finding. A thorough reexamination of formation properties using three-dimensional simulations will be performed in future studies.

Figure 2.30 shows the potential impact of formation properties and percolation flux on the temperature evolution at the Heated Drift wall. As expected, the $0.36-\mathrm{mm} / \mathrm{yr}$ simulated temperatures are higher throughout the entire time period. The subtle heat pipe signal seen in the 3.6-mm/yr data completely vanishes for the $0.36-\mathrm{mm} / \mathrm{yr}$ run. Again, the latter wrould better conform to the measured data. The impact to the heating schedule for the DST is that the $200^{\circ} \mathrm{C}$ temperature criterion for the Heated Drift wall will be reached about 2 to 3 months earlier for the $0.36-\mathrm{mm} / \mathrm{yr}$ property set.

\subsubsection{ECM versus DKM}

In this section, a dual-permeability formulation is applied for modeling the thermo-hydrological behavior of the rock mass, and the DKM results are compared to the ECM results obtained from the reference case. A dual-permeability model can capture the transient response in the matrix to perturbations of temperature, pressure, or saturation in the fractures. In other words, fracture and matrix continua do not need to be in thermodynamic equilibrium at all times, as with ECM. The matrix is represented by one continuum, i.e., a dual permeability formulation rather than a "MINC" formulation (Multiple Interacting Continua, after Pruess and Narasimhan, 1985). This means that the fracture-matrix interaction is proportional to the primary variable difference between the two continua. Several studies have shown that this approach, often referred to as "quasi-steady," may underestimate the exchange rates between fractures and matrix, mainly because it cannot accurately account for the early time behavior in matrix blocks with steep gradients at the block surfaces. The real system behavior may be bounded somewhere between the two extreme cases of ECM and DKM.

The material properties used for the DKM runs are identical to the properties previously used in Section 2.4 , i.e., those for the 3.6- $\mathrm{mm} / \mathrm{yr}$ case. DKM requires some additional information regarding the geometry of the fractured rock (i.e., the interface area between fractures and matrix, and the size and shape of matrix blocks). Both parameters are derived from fracture frequencies estimated by Sonnenthal et al. (1997) for the different model layers, namely 0.69 fractures per meter for the tsw33, 1.88 fractures per meter for the tsw34, and 1.81 fractures per meter for the tsw35. The geometrical model for estimating the fracture-matrix interface area and the matrix block shape is quite simple; one set of fractures is assumed with parallel equidistant fractures. The entire geometrical fracture-matrix interface area is supposed to be available for heat and mass exchange between fractures and matrix.

The simulated temperature field is fairly insensitive to the model conceptualization, as is apparent from Figure 2.31. The temperature evolution in Hole 160 is almost identical for the two models; very minor differences show around nominal boiling temperature, where the DKM curves seem somewhat smoother. The temperature presented for the DKM is the matrix temperature; it is typically less affected by heat pipe signals than the fracture temperature. Obvious differences between ECM and DKM become apparent in 
the saturation contour plots, presented for fracture saturation in Figure 2.32 and for matrix saturation in Figure 2.33. In the DKM, the saturation build-up in the fractures migrates much further than in the matrix. This is particularly evident in the vertical downward direction, indicating that there is a large region of enhanced gravity-driven flux. The reason for this behavior is in the different dynamics of thermo-hydrological response in fractures and matrix, which cannot be captured with the equilibrium assumption associated with ECM. As vapor is driven away from the heaters, it will eventually condense at the fracture walls, and liquid saturation in the fractures will increase. This gives rise to enhanced liquid flux in the fractures, away from the condensation zone. At the same time, part of the liquid imbibes into the matrix, as a capillary pressure gradient between the fractures and the matrix develops. However, because matrix imbibition is relatively slow, some fraction of the condensate can migrate a long distance in the fractures before being imbibed. The ECM concept cannot capture this retarded response in the matrix; it assumes a pressure equilibrium between fractures and matrix at all times, implying that the imbibition rate is strong enough to guarantee a zero response time. Therefore, the ECM results underestimate the potential for gravity-driven liquid flux far away from the near-heat environment; at the same time, they overestimate the matrix saturation in the condensation zone (Figure 2.33).

We may conclude from the above simulation results that temperature data will not diagnostically discriminate the ECM and DKM concepts. However, we believe that a thorough analysis of the airpermeability tests performed in different borehole intervals at different heating phases could provide such information, as the ECM and the DKM modeling concept clearly results in different fracture saturation fields. Our experience from the Single Heater Test seems to indicate that a MINC model would probably give the most accurate representation of the thermo-hydrological response in the rock (Birkholzer and Tsang, 1998b). Further analysis of the different modeling concepts will be performed in future studies.

\subsection{Interpretation of the Active Hydrological Testing Data}

Active testing by air injection and gas tracer tests is being carried out periodically throughout the DST to probe the redistribution of moisture in the DST rock mass due to heating. Test results for pre-heat baseline measurements and first quarter of heating have been reported (Tsang and Freifeld, 1998; Freifeld and Tsang, 1998). The second quarter results are being summarized in another Level 4 deliverable (Freifeld, 1998). In this section, we correlate the observation in hydrological testing to date to the modeled results.

For this analysis, we use the simulation results from the 3-D model as presented in Section 2.4, i.e., applying the ECM concept and the $3.6 \mathrm{~mm} / \mathrm{yr}$ percolation scenario. The simulated fracture liquid saturation is shown in Figure 2.34 at 3 months and 6 months of heating, in the vertical cross section of the hydrology Boreholes 57, 58, 59, 60, and 61. Figure 2.35 presents the matrix liquid saturation at 3 months and 6 months of heating, in the same cross section. The zones of simulated increased and decreased liquid saturation for fracture and matrix in these two figures are similar because of the effective- 
continuum conceptualization. Corresponding contours of liquid saturation for the other vertical cross section defined by hydrology Boreholes $74,75,76,77,78$ have been presented earlier in Figures 2.9 and 2.10 .

The active testing by air injection and gas tracer is aimed at detecting the change in moisture content in the fractures. The pre-heat liquid saturation is very small in fractures, and the measured permeability to air will approximately reflect the permeability of dry fractures. An increase in the fracture liquid saturation from condensation will be evidenced by a decrease in the local air permeability value, as the relative permeability to air decreases with the presence of water. Each of the 12 hydrology boreholes are typically subdivided by high temperature packers into four zones, and a complete set of air permeability tests are being carried out in every zone, at least once per quarter. Each packed-off interval is equipped with sensors for temperature, pressure, and relative hurnidity.

Air-injection testing during February, March and April of 1998 indicate that significant changes in estimated local air permeability values occurred in Zones 2, 3, and 4 of Borehole 60 in April. These zones correspond to the length of borehole between the temperature Sensors 2 (at $\mathrm{x} \sim-18 \mathrm{~m}$ ) and 3 (at $\mathrm{x} \sim-$ $7 \mathrm{~m}$ ); Sensors 3 and 4 (at $\mathrm{x} \sim-1 \mathrm{~m}$ ); and Sensor 4 and the bottom hole. The ratios of pre-heat air permeability to air permeability measured on April 4, 1998 (4 months after heating) are respectively 3.8, 4.8, and 2.9. For Zone 4 in Borehole 60, an air-injection test carried out on March 3, 1998, three months after heating, shows a smaller decrease in estimated air permeability from the pre-heat value. The simulated fracture saturation contours given in Figure 2.34 indicate increase of saturation in Zone 2 of Borehole 60 at 3 months, and increase of saturation in Zones 2, 3, and 4 of Borehole 60 at 6 months. Thus, zones of reduced air permeability correlate with areas of increased fracture saturation; i.e., the active test results appear to be consistent with the simulated saturation data.

A complete set of air-injection tests was carried out again in June 1998, for all the 46 zones in the 12 hydrology holes. The estimated air permeability values are similar to those measured in April 1998, in most zones. For Borehole 59, Zone 2 and Borehole 78, Zone 3 there is a trend of decreasing permeability from its pre-heat values, through the April measurements, to the June testing. However, the reduction is slight in that the ratio of June values to pre-heat values is only on the order of 1.6. These zones of reduced air permeability are also consistent with the simulated zones of saturation built up. These are in Figure 2.34 at 6 months (between the temperatures sensor located at $\mathrm{x} \sim-15 \mathrm{~m}$ and $-7 \mathrm{~m}$ ) for Borehole 59 ; and in Figure 2.9 at 6 months (between the temperature sensors located at $\mathrm{x} \sim-13 \mathrm{~m}$ and $-7 \mathrm{~m}$ ) for Borehole 78.

While the air injection tests probe the moisture redistribution in the fractures, the bulk of the condensate resides in the matrix because of the larger matrix porosity. The simulated matrix liquid saturation in Figures 2.35 and 2.10 show that by 6 months after heating, moisture builds up to near full saturation close to sections along Boreholes $60,61,77$, and 78 , raising the plausibility of water seepage into these boreholes. The high-temperature packer strings in the hydrology holes are designed in such a way that 
the air-injection line for each zone is positioned at the lowest elevation within the zone, with the intent that the air-injection line would also double as a water recovery line. In the event that condensate raises the local liquid saturation to 1 in some areas around the borehole, thus overcoming the capillary barrier of the borehole wall (allowing water to seep into the borehole interval) then this water may be drained by gravity from the upward inclining boreholes, or pumped from the downward declining borehole. Since the numerical model does not account for site-specific small scale heterogeneity in either the matrix or the fracture continuum, it cannot predict the specific location where seepage might occur, although the general zone of potential seepage is expected to coincide with regions of high water saturation. The pressure reading for each zone in the hydrology holes may help to signal the presence of accumulated water. Since May 1998, the pressure reading in Borehole 60, Zone 2 indicates an upward trend, and on June 4, 1995, 5.7 liters of water was pumped from Borehole 60, Zone 2, and another $250 \mathrm{ml}$ of water was recovered from the neighboring Zone 3 of Borehole 60 .

Results of air-injection tests and gas-tracer tests, as well as location of zones with accumulated water, will be monitored closely as the DST progresses. Studying the agreement between measurements and simulated results can shed light on the issues of heterogeneity and alternative conceptualization of matrixfracture interaction.

\subsection{Summary}

Results from our thermo-hydrological model for the Drift Scale Test were compared with the measured data obtained during the first two quarters of the heating phase of the DST. The predictive DST model used in our June 1997 report (Birkholzer and Tsang, 1997) and also applied for the first-quarter model analysis (Birkholzer and Tsang, 1998) was refined and improved to better conform to actual test conditions. Our observation so far is that the simulation results compare favorably with temperature data as well as with results from active hydrological testing. Model refinements such as the concrete invert, a gas-permeable bulkhead, effective heat radiation within the Heated Drift, and initial drying of rock due to ventilation prior to heat all contribute to better match between simulation results and field data.

We have not yet performed a model calibration in order to develop the most appropriate DST model property set. However, our sensitivity study indicates that the already good temperature match between measured and simulated temperatures (Section 2.4) may be improved further by using a property set with less fracture capillarity. In future studies, the DST model properties will be carefully evaluated. The early-phase heating data do not yet discriminate between the different conceptualization of the fracturematrix interaction. As the DST progresses, more work will be performed on the model representation of fracture-matrix interaction, i.e., on the validity of ECM and DKM conceptualization, respectively. 


\section{Acknowledgment}

We thank Sumit Mukhopadhyay, Nicolas Spycher, Don Mangold, and Dan Hawkes for their critical and careful review of the manuscript and comments for improvement.

\section{References}

Birkholzer, J.T. and Tsang, Y.W. 1998a. "Comparison of Temperature Data with Thermal-Hydrological Model." Chapter 6 of First Quarter TDIF Submission for the Drift Scale Test (Hydrological, Radar, Microseismic). Yucca Mountain Project Level 4 Milestone SP2770M4. Berkeley, California: Lawrence Berkeley National Laboratory. DTN: LB980420123142.002.

Birkholzer, J. T. and Tsang, Y.W. 1998b. Numerical Analysis of Thermal-Hydrological Conditions in the Single Heater Test at Yucca Mountain. Proceedings of TOUGH Workshop '98. Berkeley, California: Lawrence Berkeley National Laboratory.

Birkholzer, J.T. and Tsang, Y.W. 1997. Pretest Analysis of the Thermal-Hydrological Conditions of the ESF Drift Scale Test. Yucca Mountain Project Level 4 Milestone SP9322M4. Berkeley, California: Lawrence Berkeley National Laboratory. MOY-970627-12, MOL. 199712010805.0810.

Birkholzer, J.T. and Tsang, Y.W. 1996. Forecast of Thermal-Hydrological Conditions and Air Injection Test Results of the Single Heater Test at Yucca Mountain. Yucca Mountain Project Level 4 Milestone SP918M4, Report LBNL-39789, UC-814. Berkeley, California: Lawrence Berkeley National Laboratory. MOY-970521-04.

Bodvarsson, G.S.; Bandurraga, T.M.; and Wu, Y.S., eds. 1997. The Site Scale Unsaturated Zone Model of Yucca Mountain, for the Viability Assessment. Yucca Mountain Project Level 4 Milestone SP24UFM4, Report LBNL-40376. Berkeley, California: Lawrence Berkeley National Laboratory. DTN: LB970601233129.001(Q).

Freifeld, B. 1998. “Active Hydrologic Testing” Chapter 2 of Second Quarter TDIF Submission for the Drift Scale Test (Hydrological, Radar, Microseismic). Yucca Mountain Project Level 4 Milestone SP2790M4. Berkeley, California: Lawrence Berkeley National Laboratory. DTN: LB980715123142.002 (Q).

Freifeld, B. and Tsang, Y.W. 1998. “Active Hydrogeological Testing” Chapter 2 of First Quarter TDIF Submission for the Drift Scale Test (Hydrological, Radar, Microseismic). Yucca Mountain Project Level 4 Milestone SP2770M4. Berkeley, California: Lawrence Berkeley National Laboratory. DTN: LB980420123142.002(Q).

Neville, A.M. 1996. Properties for Concrete/ A.M. Neville. $4^{\text {th }}$ and final ed. New York: Wiley. 
Pruess, K; Simmons, A.; Wu, Y.S.; and Moridis, G.J. 1996. TOUGH2 Software Qualification Report. Report LBL-38383. Berkeley, California: Lawrence Berkeley National Laboratory. MOL19960610.0010-0020.

Pruess K. 1991. TOUGH2-A General Purpose Numerical Simulator for Multiphase Fluid and Heat Flow. Report LBL-29400, UC-814. Berkeley, California: Lawrence Berkeley National Laboratory. NNA.1940202.0088.

Pruess, K. and Narasimhan, T.N. 1985. "A Practical Method for Modeling Fluid and Heat Flow in Fractured Porous Media." Soc. Pet. Eng. J., 25(1), 14-26. NNA.19890522.0235

Sandia National Laboratories. 1997. Evaluation and Comparative Analysis of the Drift Scale Test Thermal and Thermomechanical Data: First Quarter Results. Yucca Mountain Project Milestone SP2520M4. Albuquerque, NM: Sandia National Laboratories.

Sonnenthal, E.L.; Ahlers, C.F.; and Bodvarsson, G.S. 1997. Fracture and Fault Properties for the UZ SiteScale Flow Model. In: G.S. Bodvarsson, T.M. Bandurraga, and Y.S. Wu, eds. The Site-Scale Unsaturated Zone Model of Yucca Mountain, Nevada, for the Viability Assessment, Chapter 7. Yucca Mountain Project Level 4 Milestone SP24UFM4. Report LBNL-40376, UC-814. Berkeley, California: Lawrence Berkeley National Laboratory. LB970601233129.001 (Q).

Tsang, Y.W. and Birkholzer, J. T. 1997. Interpreting the Thermal-Hydrological Response of the ESF Single Heater Test. Yucca Mountain Site Characterization Project Milestone SP9267M4. Berkeley, California: Lawrence Berkeley National Laboratory. MOY-970627-12, MOL. 199712010805.0810.

Tsang, Y.W. and Freifeld, B. 1998. "Hydrological Baseline Measurements" Chapter 2 of ESF Drift Scale Test As-Built Data and Baseline Measurements (Hydrological, Radar, and Microseismic). Yucca Mountain Project Level 4 Milestone SPY193M4. Berkeley, California: Lawrence Berkeley National Laboratory. DTN: LB980120123142.004 (Q).

Wu, Y.S.; Ritcey, A.C.; Ahlers, C.F.; Hinds, J.J.; Mishra, A.K.; Haukwa, C.; Bandurraga, T.M.; Liu, H.H.; Sonnenthal, E.L.; and Bodvarsson, G.S. 1998. 3-D Site-Scale Model for Abstraction in TSPA$V A$. Yucca Mountain Project Level 4 Milestone SLX01LB3. Berkeley, California: Lawrence Berkeley National Laboratory.

Wu, Y.S.; Ahlers, C.F.; Fraser, P.; Simmons, A.; and Pruess, K. 1996. Software Qualification of Selected TOUGH2 Modules. Report LBL-39490 UC-800. Berkeley, California: Lawrence Berkeley National Laboratory. MOL.19970219.0100-0105. 
Table 2.1 Calibrated parameters for the DST model layers (Birkholzer and Tsang, 1997)

\begin{tabular}{|c|c|c|}
\hline Fracture Permeability $\left(\mathrm{m}^{2}\right)$ & Infiltration $3.6 \mathrm{~mm} / \mathrm{yr}$ & Infiltation $0,36 \mathrm{~mm} / \mathrm{yr}$ \\
\hline tptpul & $0.20210^{-11}$ & $0.63510^{-12}$ \\
\hline tptpmn & $0.10010^{-12} *$ & $0.10010^{-12} *$ \\
\hline tptpll & $0.155410^{-11}$ & $0.18710^{-11}$ \\
\hline Matrix Permeability (n) & & $\therefore$ \\
\hline tptpul & $0.20010^{-16}$ & $0.52510^{-17}$ \\
\hline tptpmn & $0.91410^{-17}$ & $0.12410^{-16}$ \\
\hline tptpll & $0.23310^{-16}$ & $0.24710^{-15}$ \\
\hline Fracture van Genuchten $\alpha(\mathbf{1} / \mathbf{P a})$ & & $\therefore \because$ \\
\hline tptpul & $0.31410^{-4}$ & $0.15710^{-3}$ \\
\hline tptpmn & $0.21710^{-4}$ & $0.97310^{-4}$ \\
\hline tptpll & $0.23410^{-4}$ & $0.16610^{-4}$ \\
\hline Matrix van Genuchten $\alpha$ (1/Pa) & $\therefore$ & \\
\hline tptpul & $0.61110^{-5}$ & $0.10610^{-4}$ \\
\hline tptpmn & $0.17110^{-5}$ & $0.22510^{-5}$ \\
\hline tptpll & $0.33510^{-5}$ & $0.28210^{-5}$ \\
\hline Fracture van Genuchten m & $\therefore \therefore \quad \therefore$ & . \\
\hline tptpul & 0.492 & 0.492 \\
\hline tptpmn & 0.483 & 0.492 \\
\hline tptpll & 0.492 & 0.492 \\
\hline Matrix van Genuchten m & $\therefore$ & $\therefore \therefore$. \\
\hline tptpul & 0.252 & 0.243 \\
\hline tptpmn & 0.320 & 0.247 \\
\hline tptpll & 0.229 & 0.207 \\
\hline
\end{tabular}

* parameter "fixed" in calibration 
Table 2.2 Hydrogeological and Thermal Input Values (Birkholzer and Tsang, 1997)

\begin{tabular}{|c|c|c|c|}
\hline 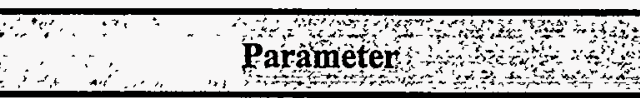 & 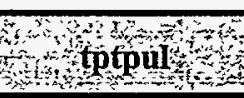 & tptpma & 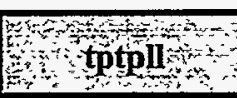 \\
\hline Matrix Porosity & 0.154 & 0.11 & 0.13 \\
\hline Matrix Residual Liquid Saturation & 0.06 & 0.18 & 0.08 \\
\hline Rock Particle Density in $\mathrm{kg} / \mathrm{m}^{3}$ & 2510.0 & 2530.0 & 2540.0 \\
\hline Fracture Porosity & 0.000171 & 0.000263 & 0.000329 \\
\hline Fracture Residual Liquid Saturation & 0.01 & 0.01 & 0.01 \\
\hline $\begin{array}{l}\text { Rock Thermal Conductivity in } \mathrm{W} /\left(\mathrm{m}^{\circ} \mathrm{K}\right) \\
\text { ("wet") }\end{array}$ & 1.7 & 2.0 & 2.29 \\
\hline $\begin{array}{l}\text { Rock Thermal Conductivity in } W /\left(\mathrm{m}^{\circ} \mathrm{K}\right) \\
\text { ("dry") }\end{array}$ & 1.15 & 1.67 & 1.59 \\
\hline Rock Mass Heat Capacity in $\mathrm{J} /\left(\mathrm{kg}^{\circ} \mathrm{K}\right)$ & 916.7 & 952.9 & 952.9 \\
\hline Vapor Diffusion Coefficient in $\mathrm{m}^{2} / \mathrm{s}$ & $2.14 \times 10^{-5}$ & $2.14 \times 10^{-5}$ & $2.14 \times 10^{-5}$ \\
\hline Factor for Temperature Dependence & 2.334 & 2.334 & 2.334 \\
\hline Tortuosity & 0.2 & 0.2 & 0.2 \\
\hline
\end{tabular}


Chapter 2 Interpretive Analysis of the Thermo-Hydrological Processes of the Drift Scale Test

Figures 


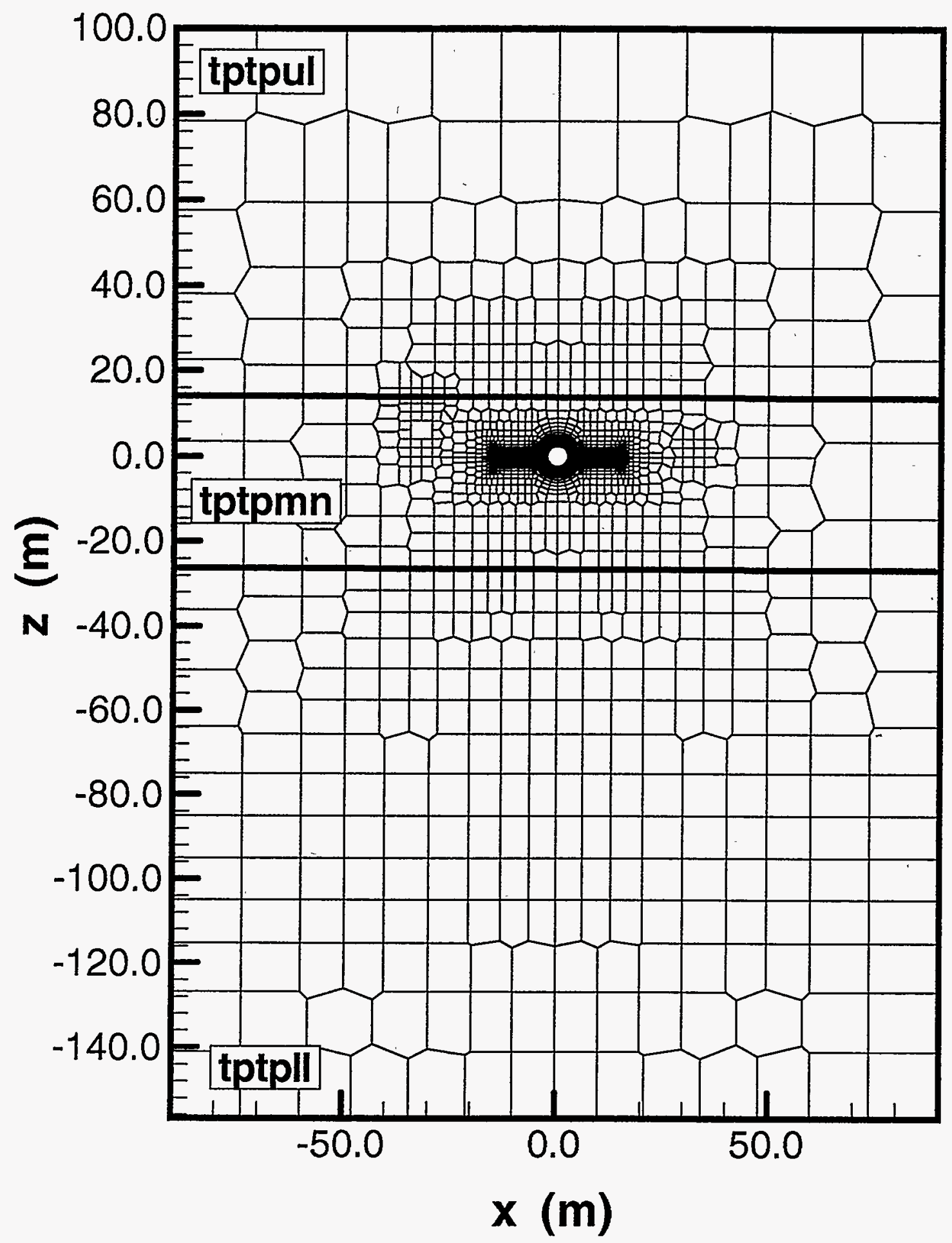

Figure 2.1. Discretization of the DST model in a typical xz-cross section. 
a)

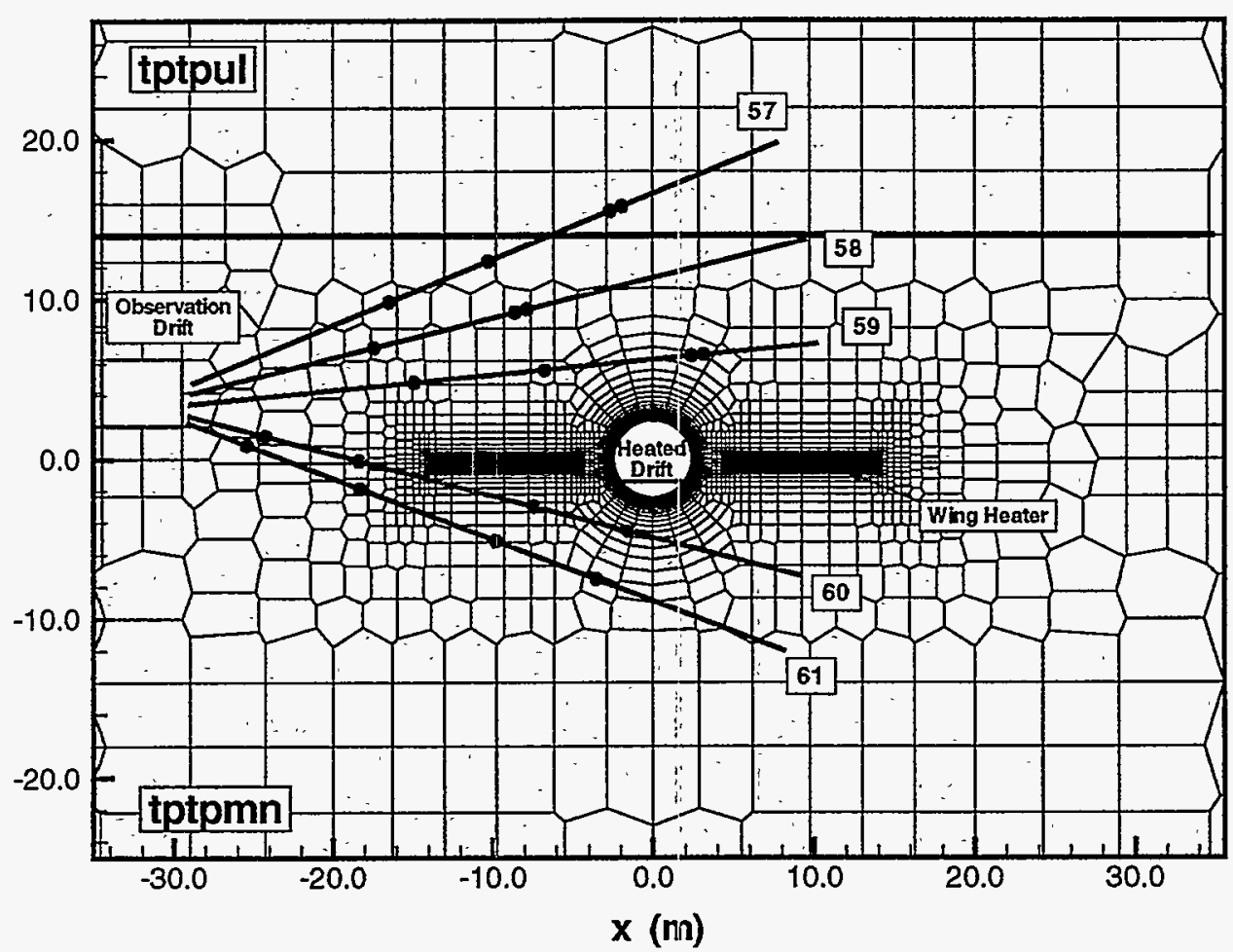

b)

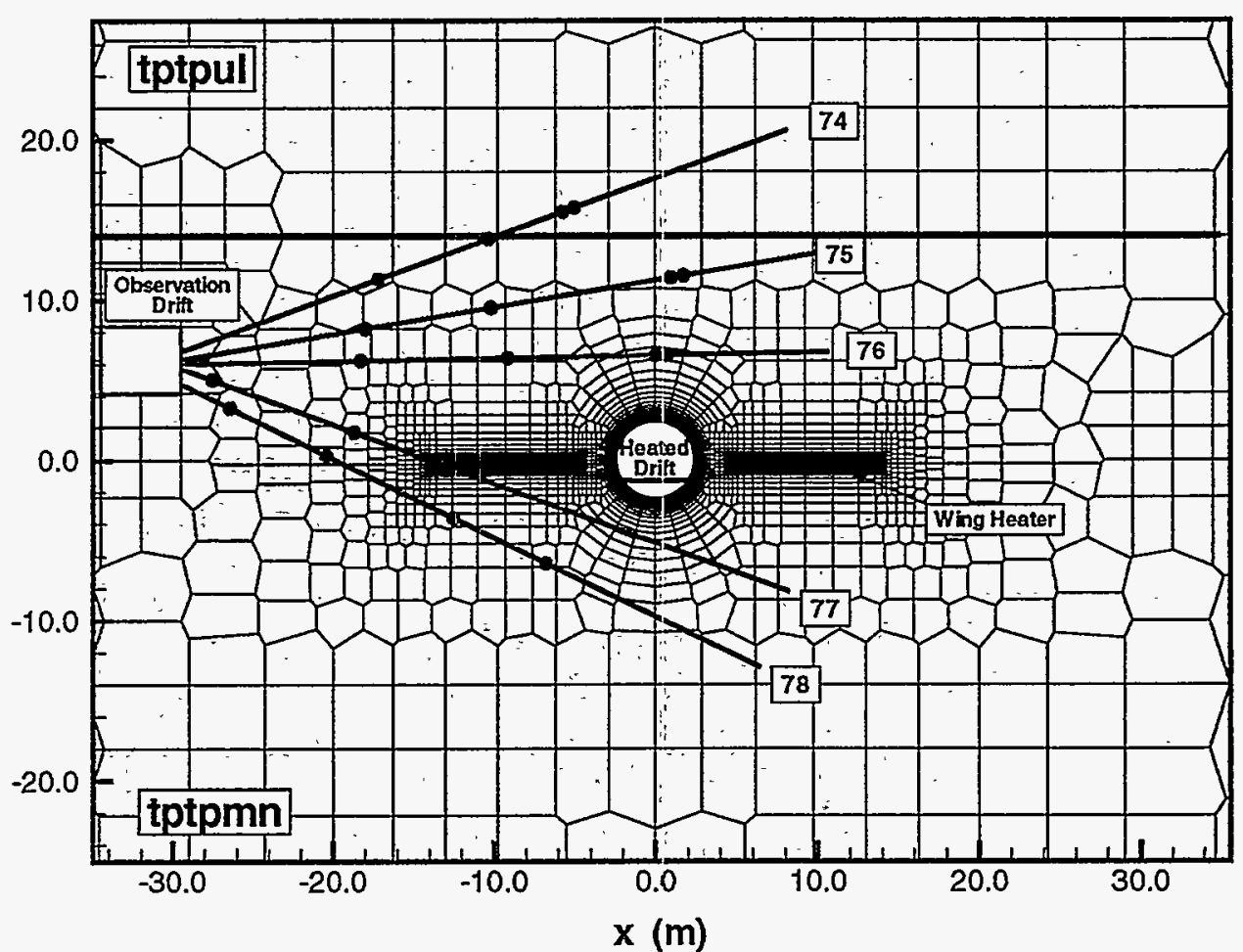

Figure 2.2. Close-up view of model grid at (a) $\mathrm{y}=10 \mathrm{~m}$ with hydrology holes 57 through 61 and (b) $\mathrm{y}$ $=30 \mathrm{~m}$ with hydrology holes 74 through 78 . Red symbols indicate temperature gages. 


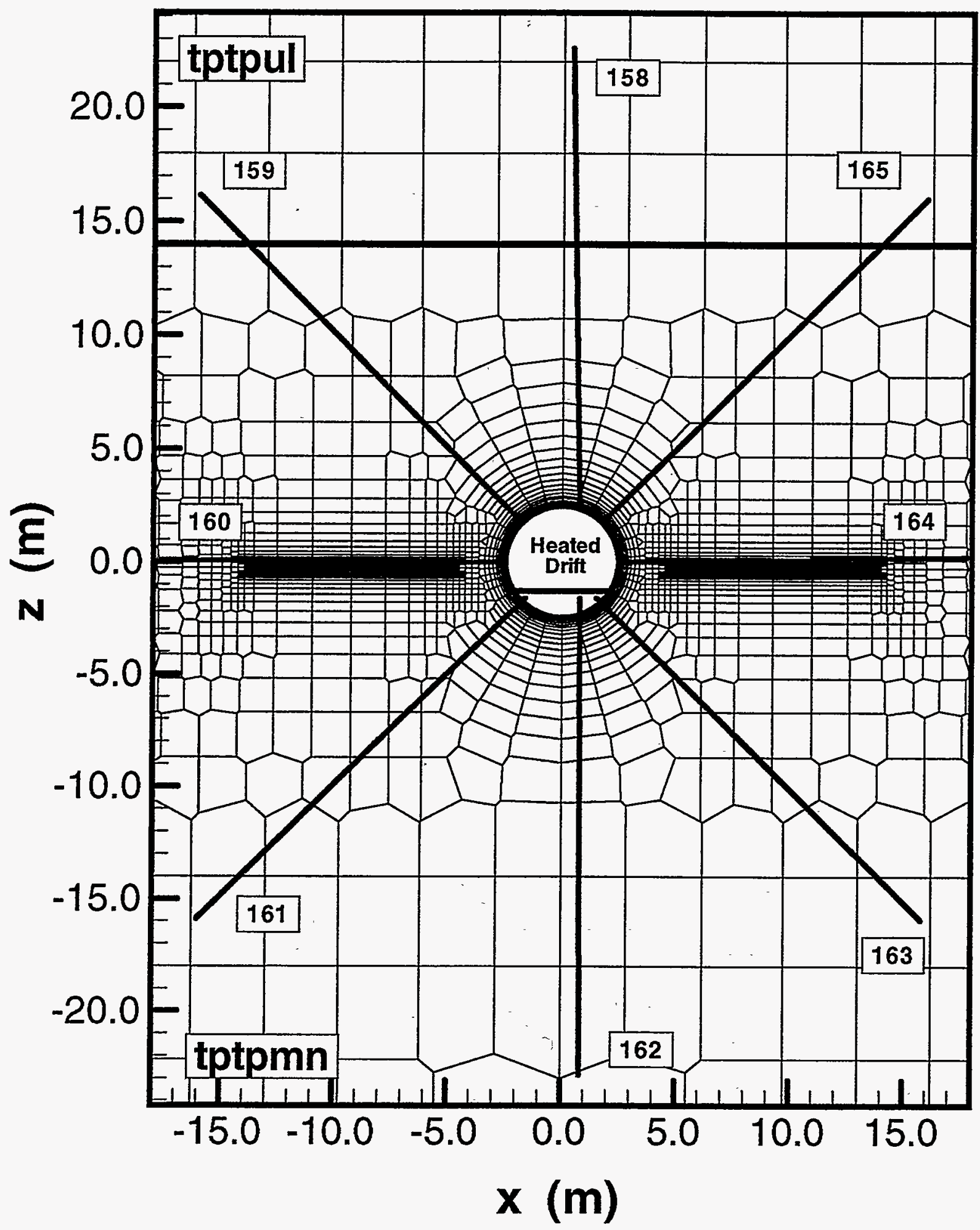

Figure 2.3. Close-up view of model grid at $y=23 \mathrm{~m}$ with RTD holes 158 through 164 . 


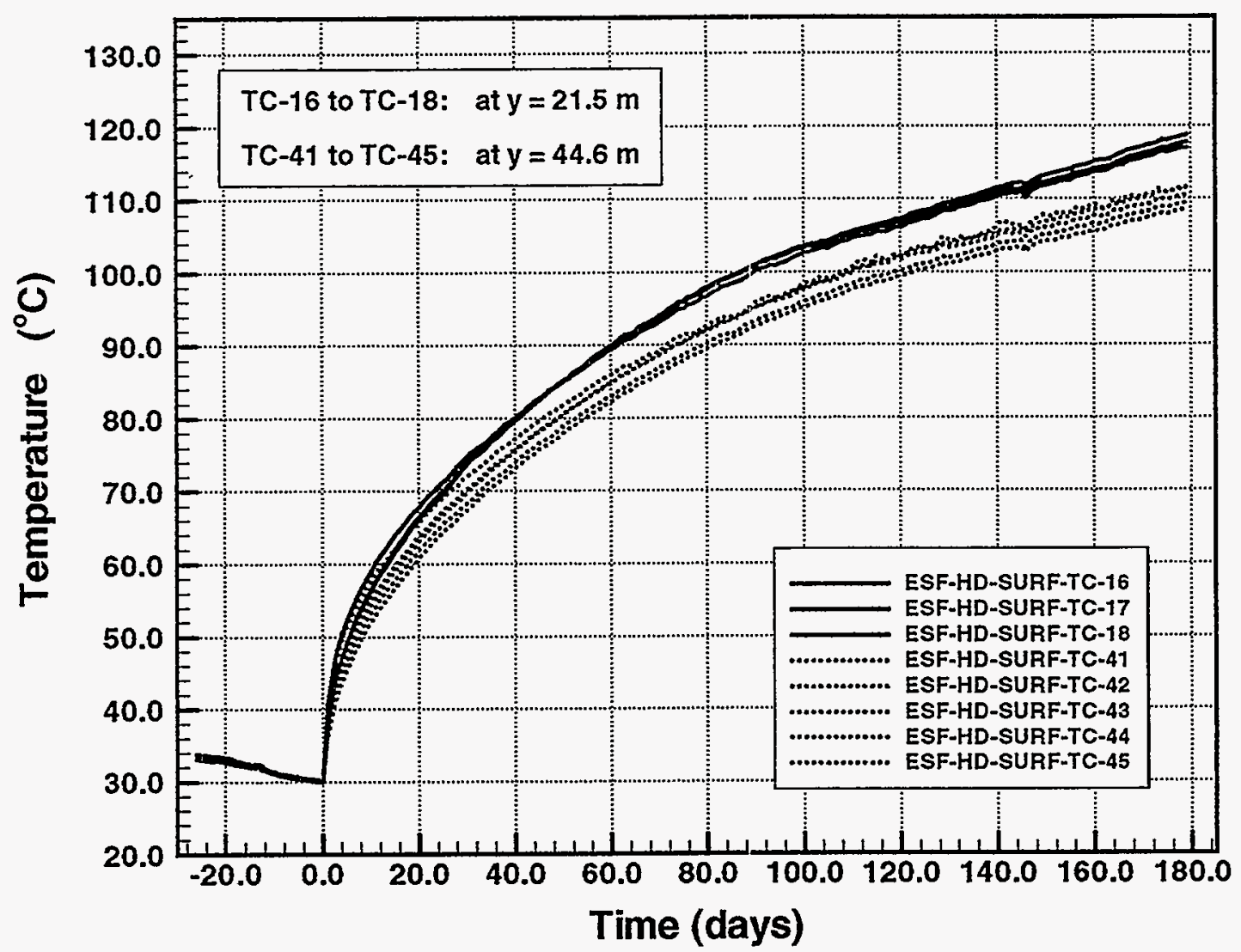

Figure 2.4. Measured temperature evolution at surface thermocouples inside the Heated Drift. Temperature is shown at two different cross sections along the Heated Drift. Note that temperature at $\mathrm{y}=44.6 \mathrm{~m}$ is influenced by the concrete liner. 


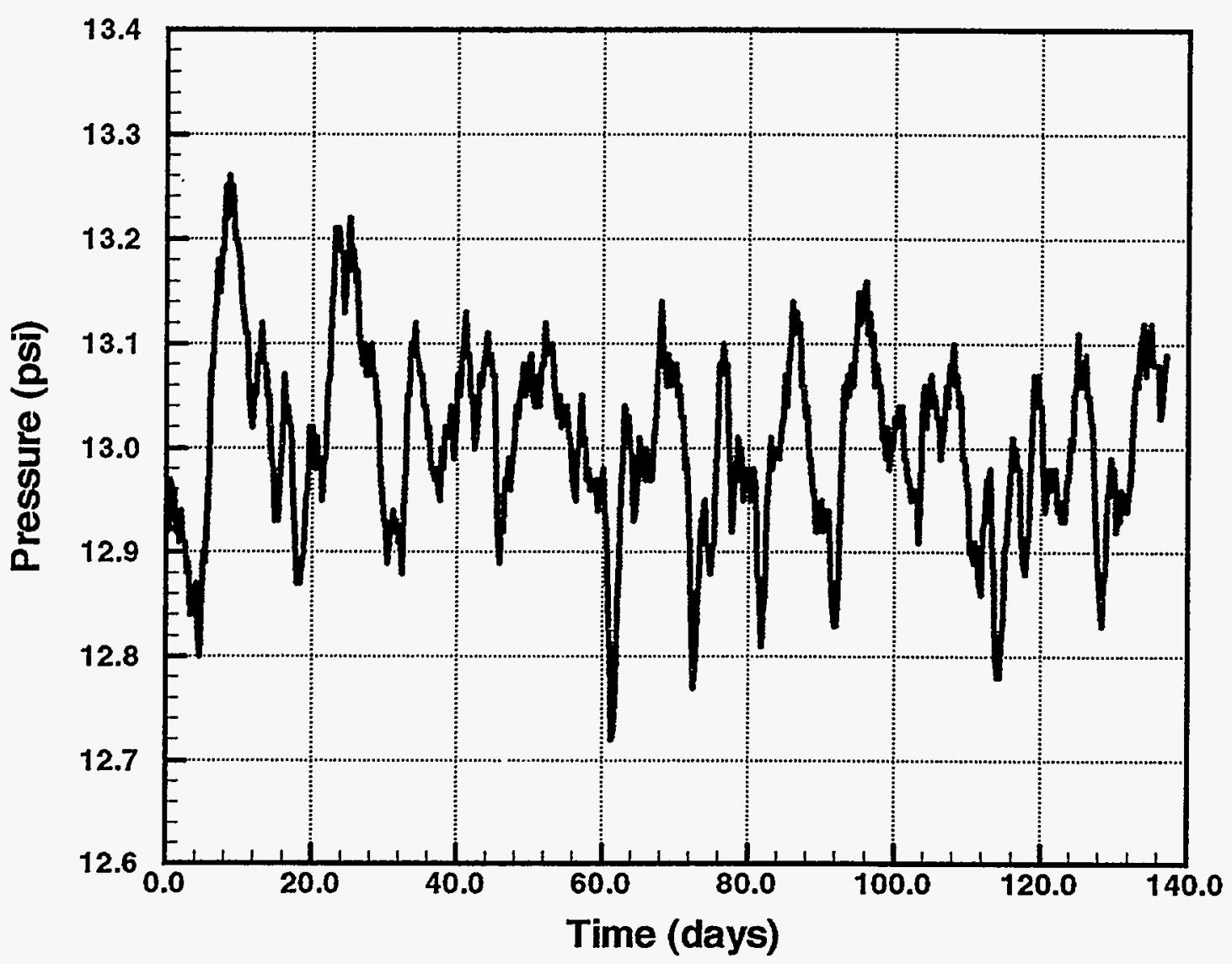

Figure 2.5. Measured pressure evolution at pressure gage ESD-HD-AIR-PRES-1 inside the Heated Drift. 


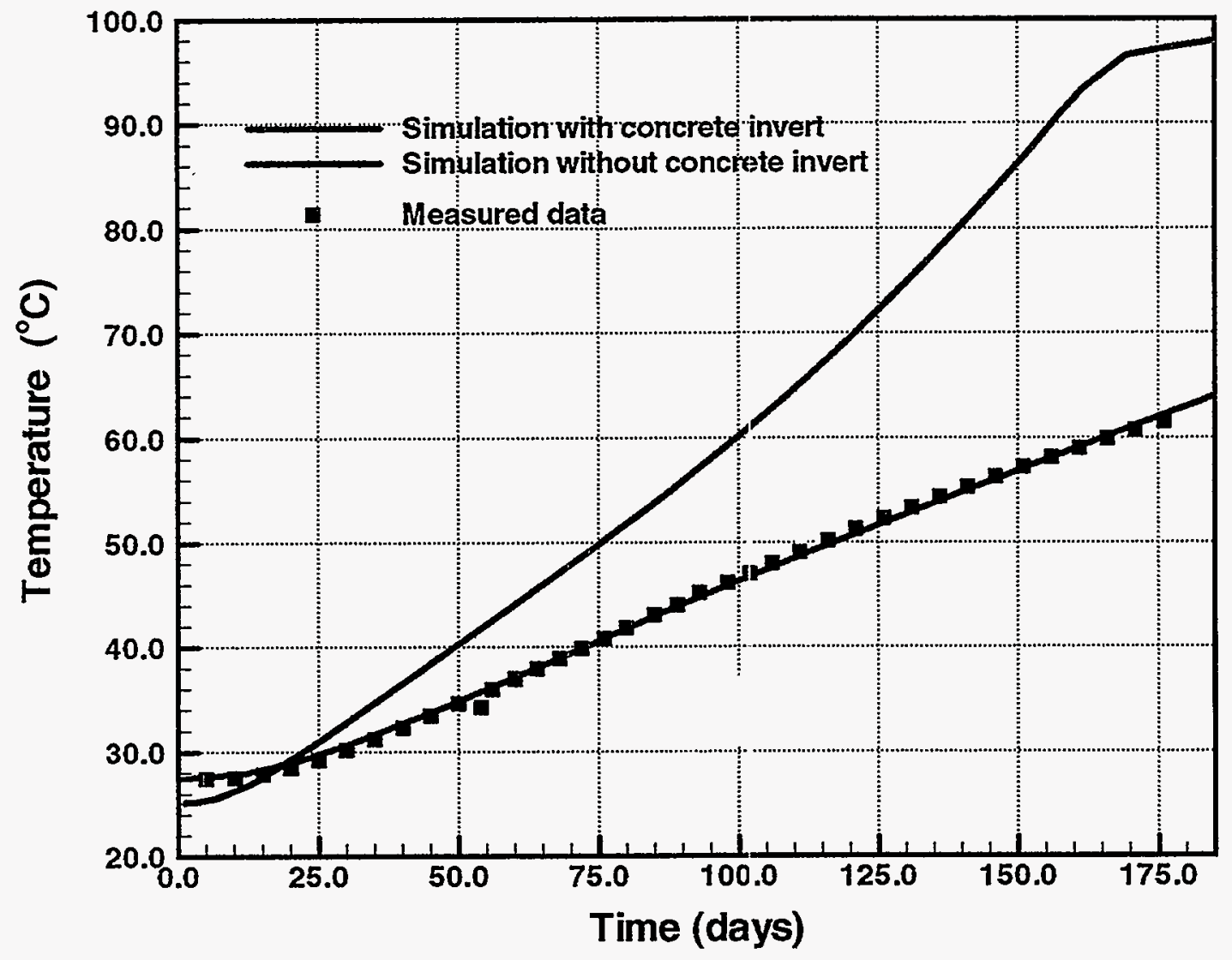

Figure 2.6. Measured and simulated temperature evolution at sensor 60-4 in hydrology hole 60, located below the drift at a radial distance of about $4.8 \mathrm{~m}$ from the drift centerline. 

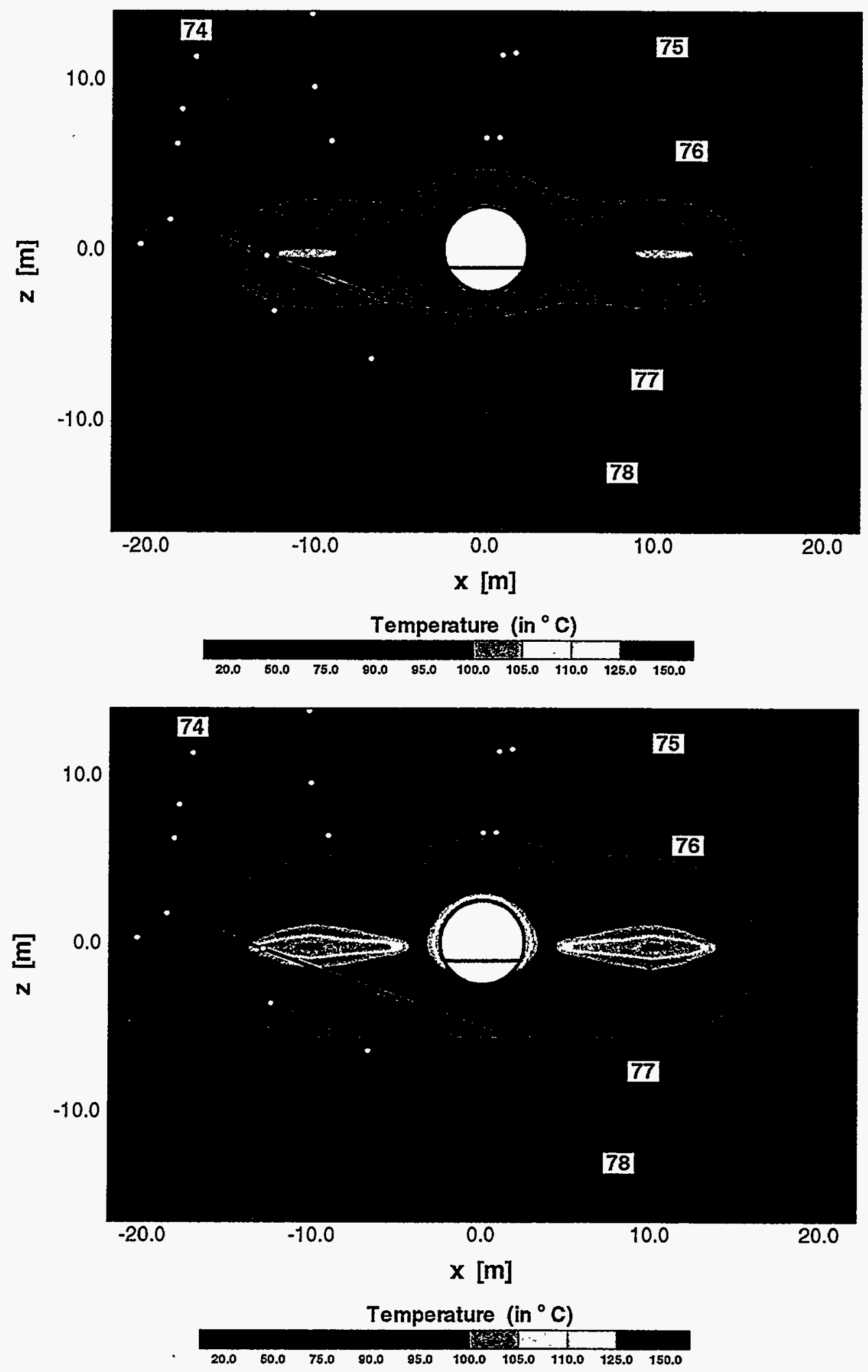

Figure 2.7. Simulated temperature response at 3 months (top) and 6 months (bottom) of heating in $\mathrm{xz}$-cross section at $\mathrm{y}=30 \mathrm{~m}$. 

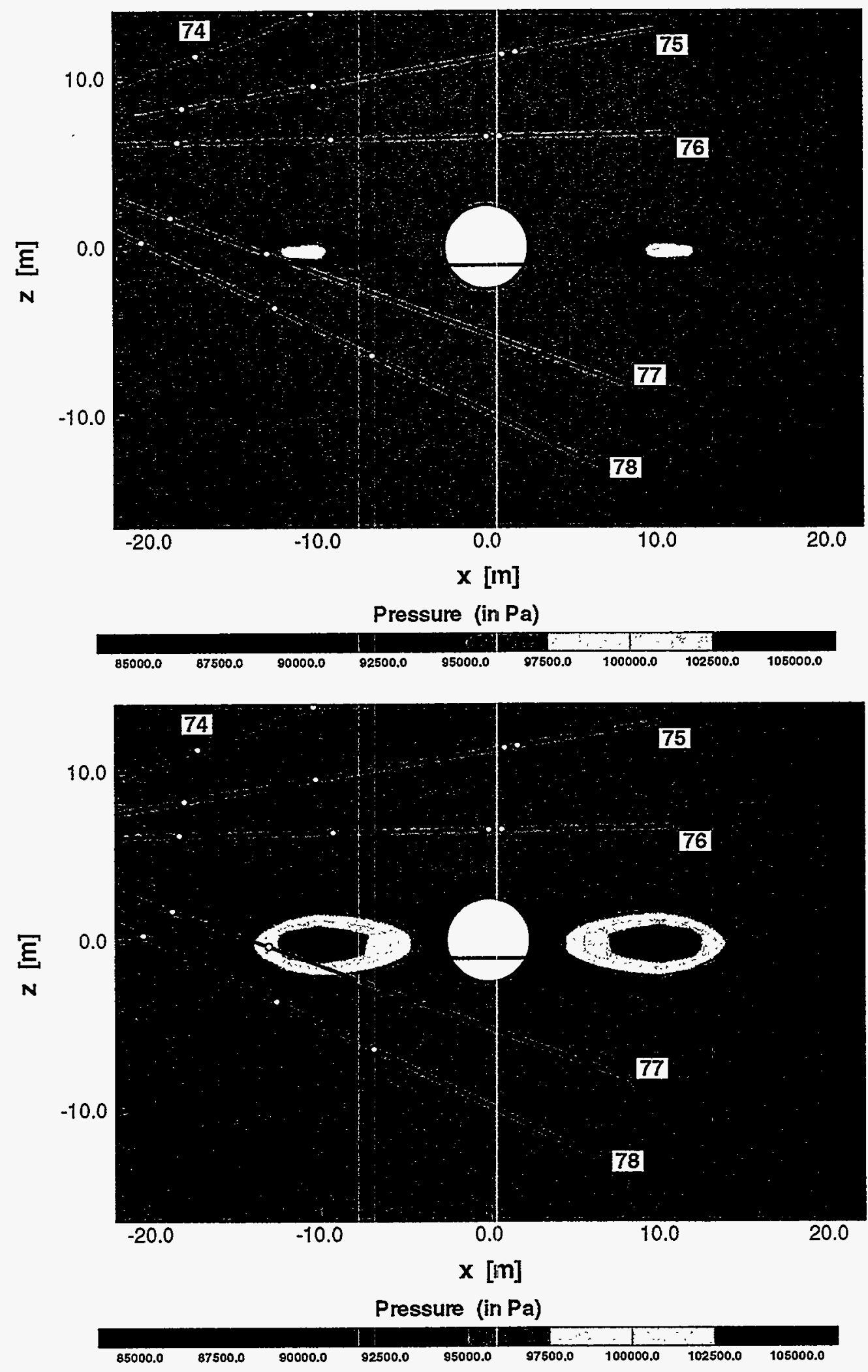

Figure 2.8. Simulated pressure response at 3 months (top) and 6 months (bottom) of heating in xzcross section at $y=30 \mathrm{~m}$. 


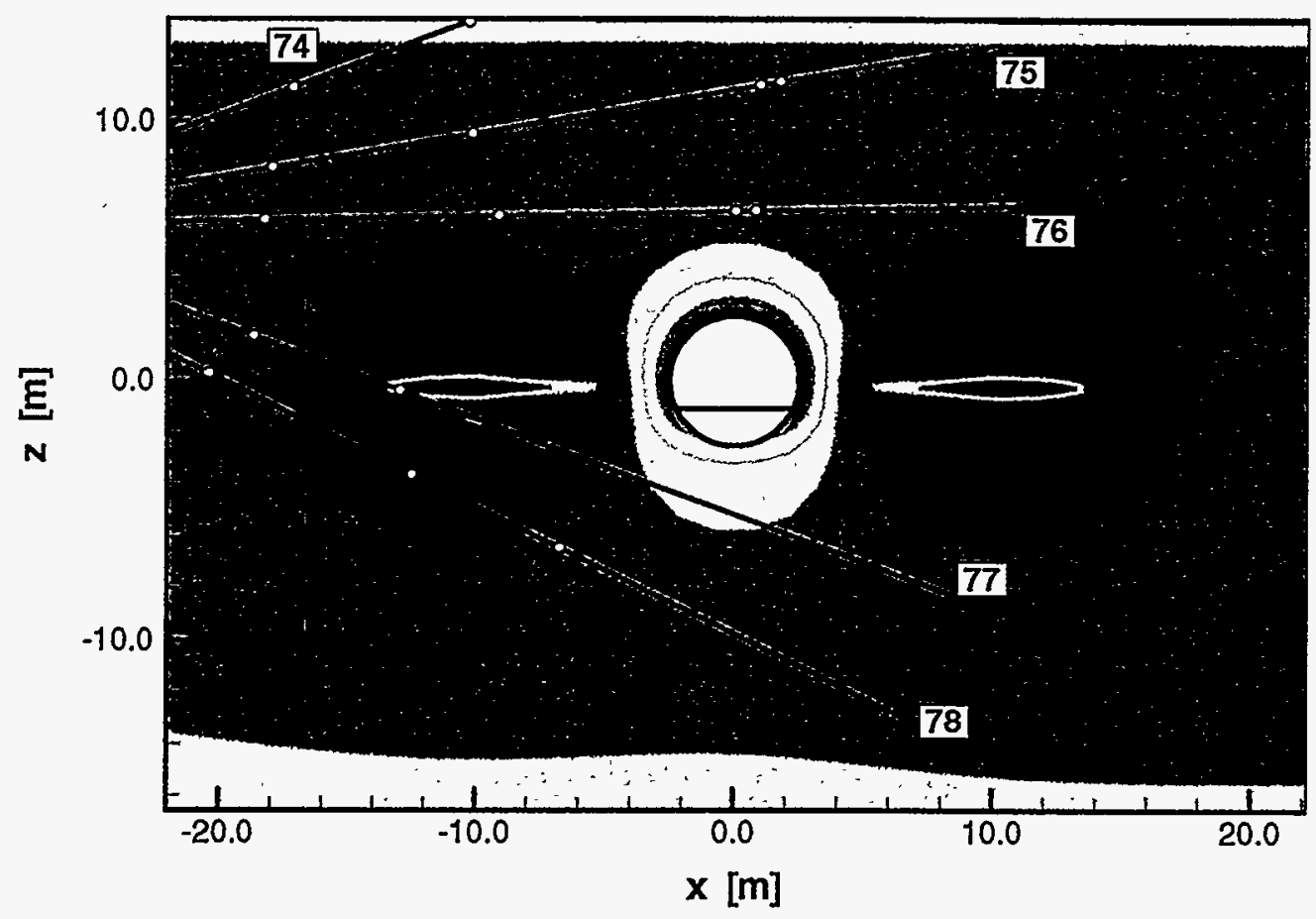

Fracture Liquid Saturation

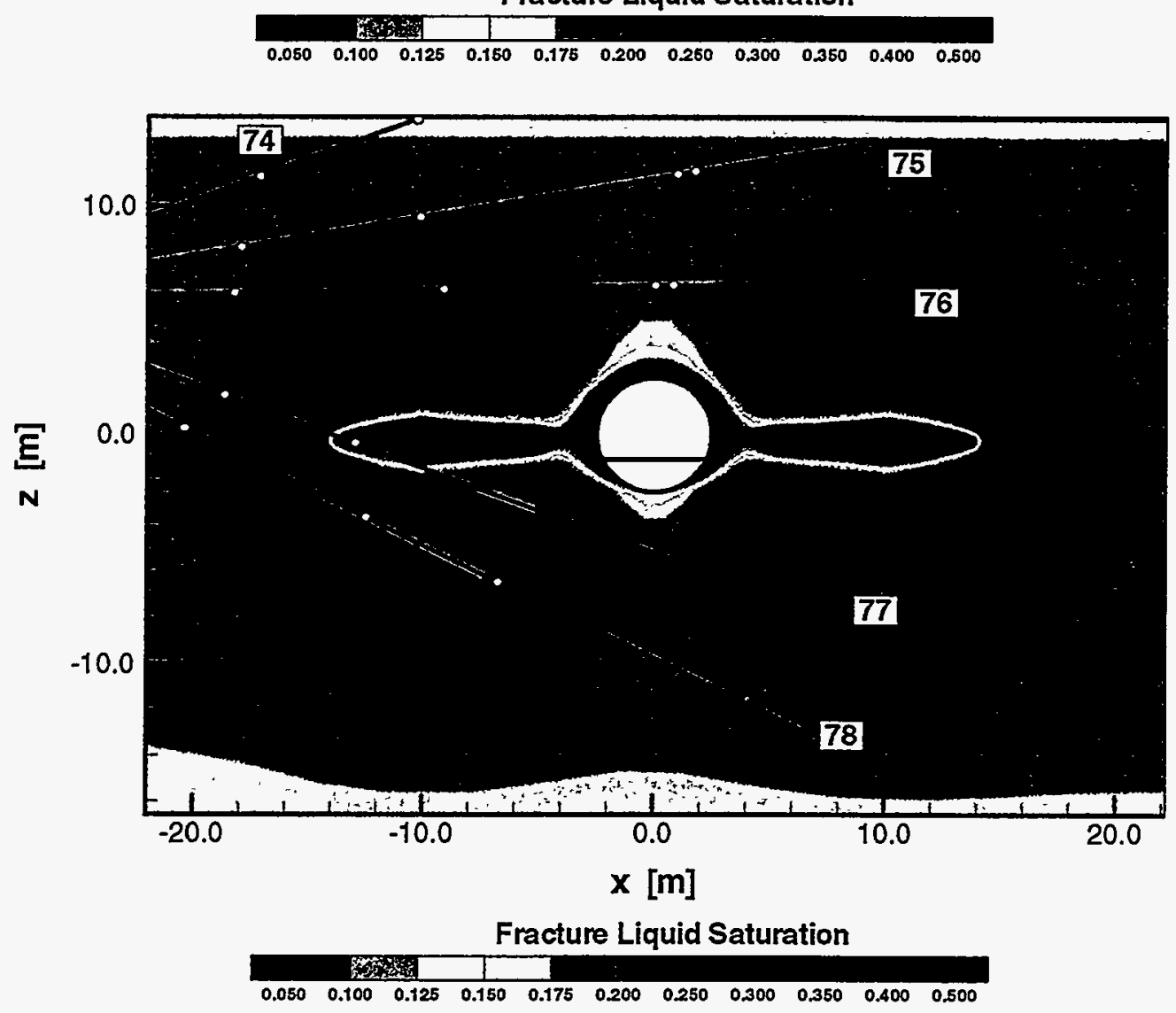

Figure 2.9 Simulated fracture saturation at 3 months (top) and 6 months (bottom) of heating in xzcross section at $\mathrm{y}=30 \mathrm{~m}$. 

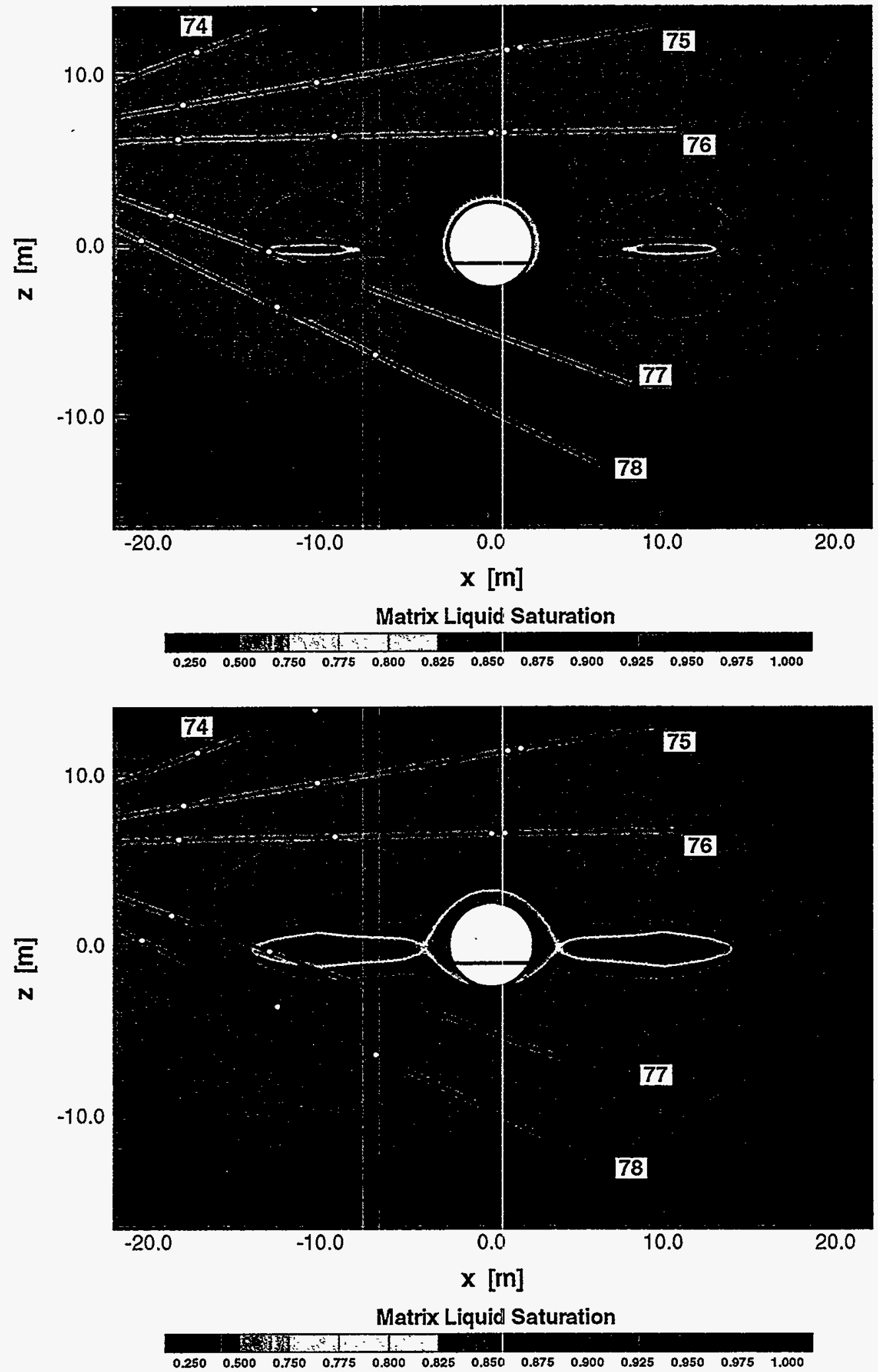

Figure 2.10. Simulated matrix saturation at 3 months (top) and 6 months (bottom) of heating in xzcross section at $\mathrm{y}=30 \mathrm{~m}$. 

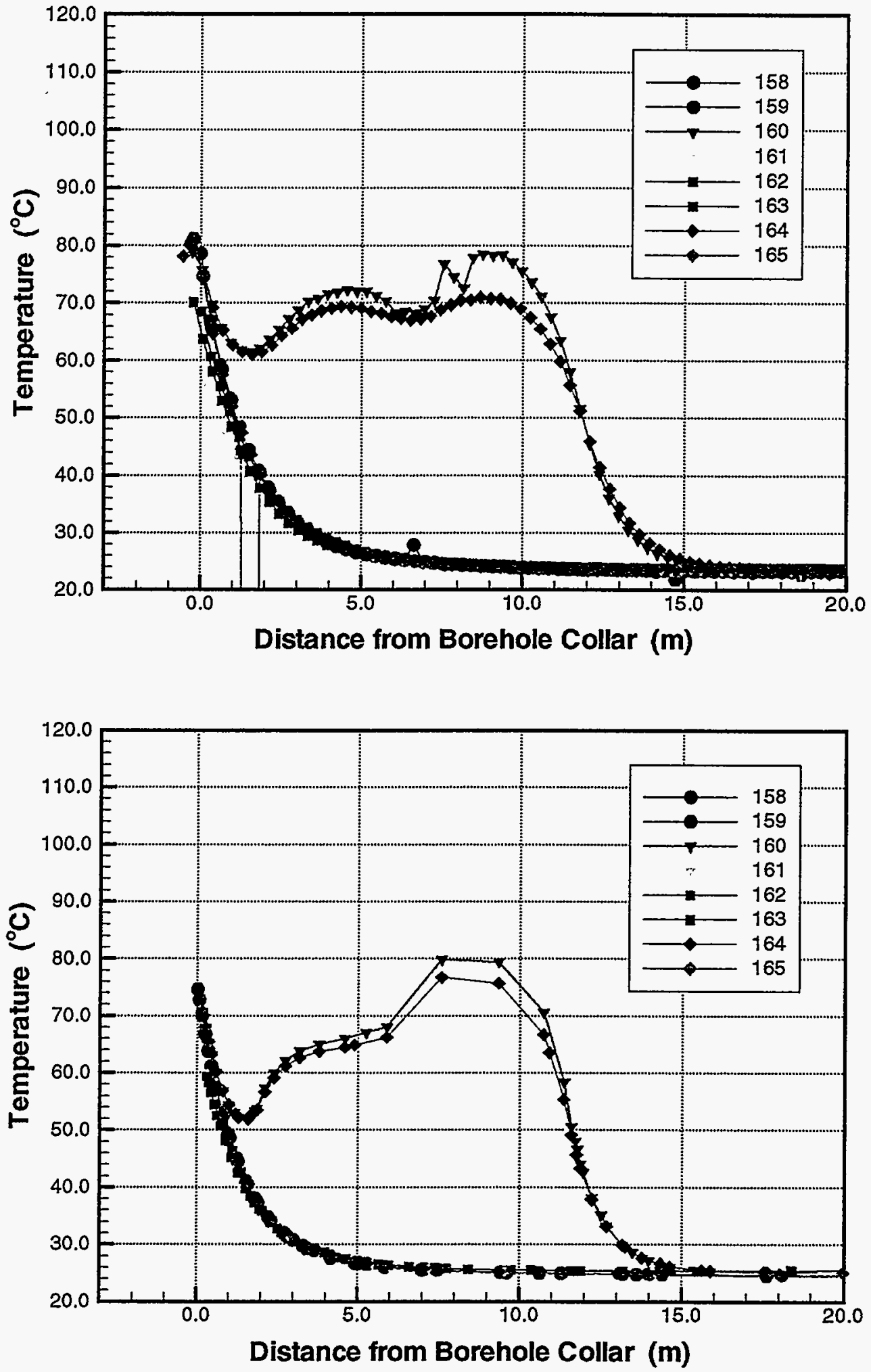

Figure 2.11. Measured (top) and simulated (bottom) temperature profiles along boreholes 158 to 165 at 1 month of heating 

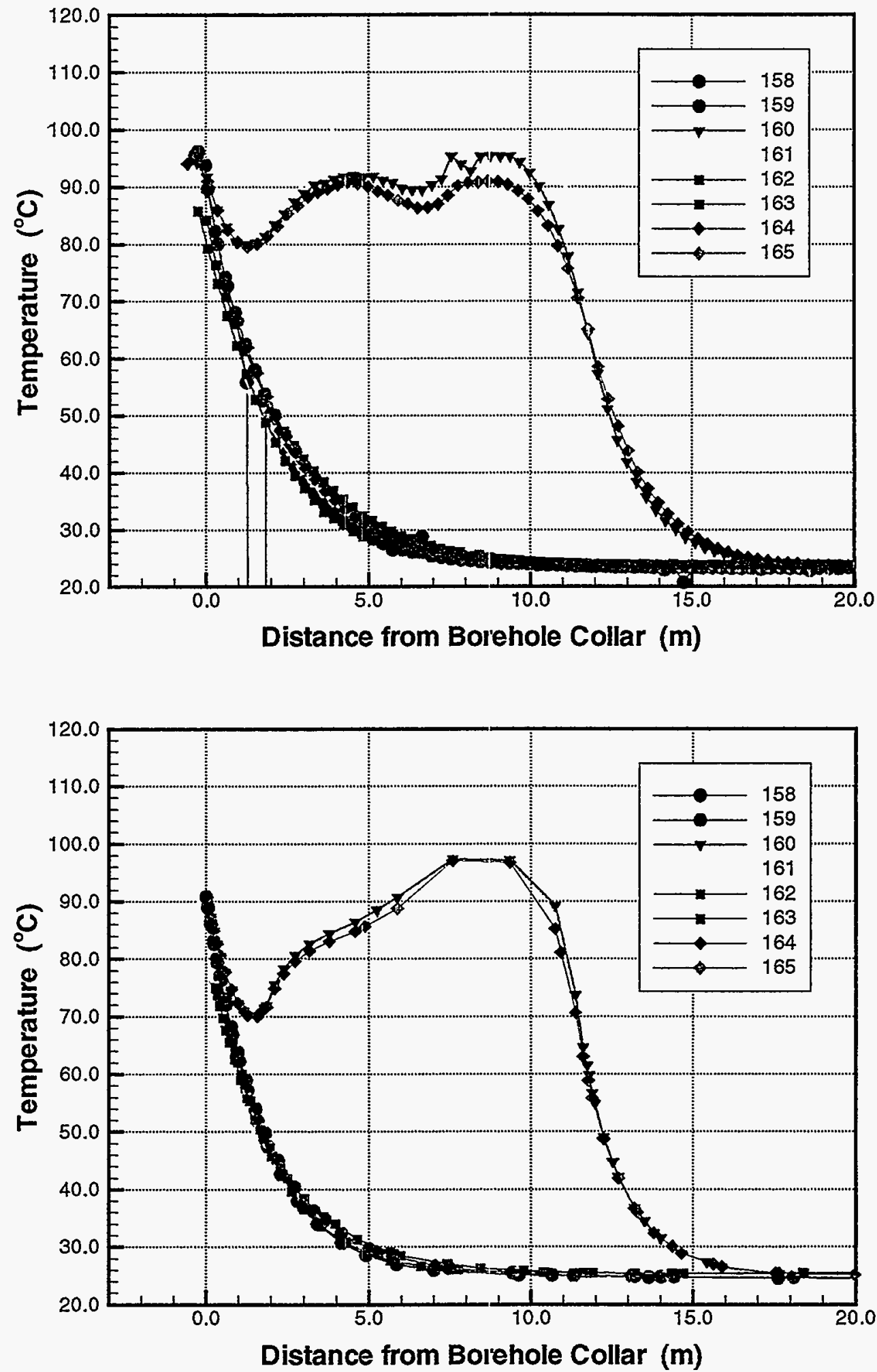

Figure 2.12. Measured (top) and simulated (bottom) temperature profiles along boreholes 158 to 165 at 2 months of heating. 

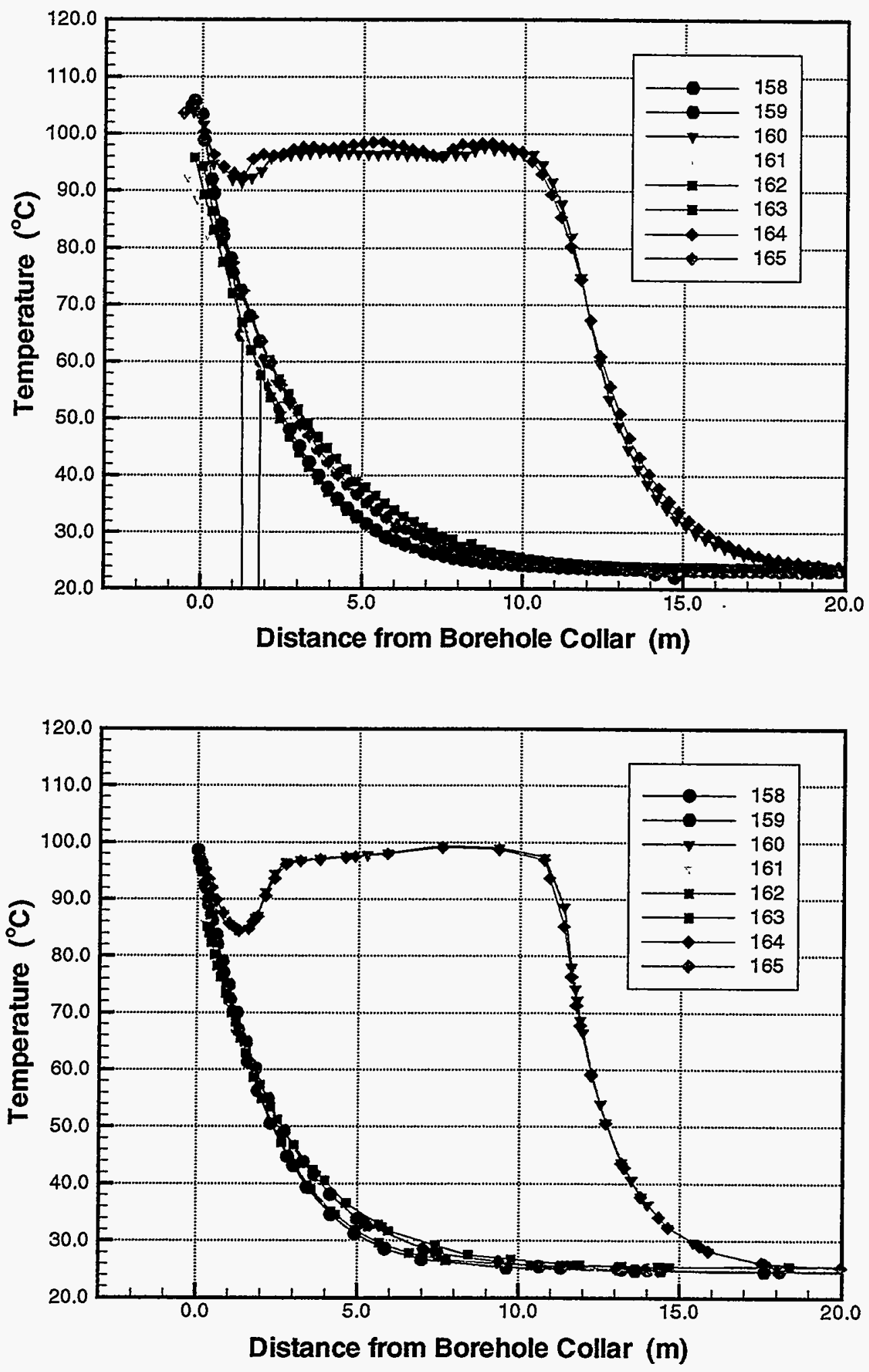

Figure 2.13. Measured (top) and simulated (bottom) temperature profiles along boreholes 158 to 165 at 3 months of heating 

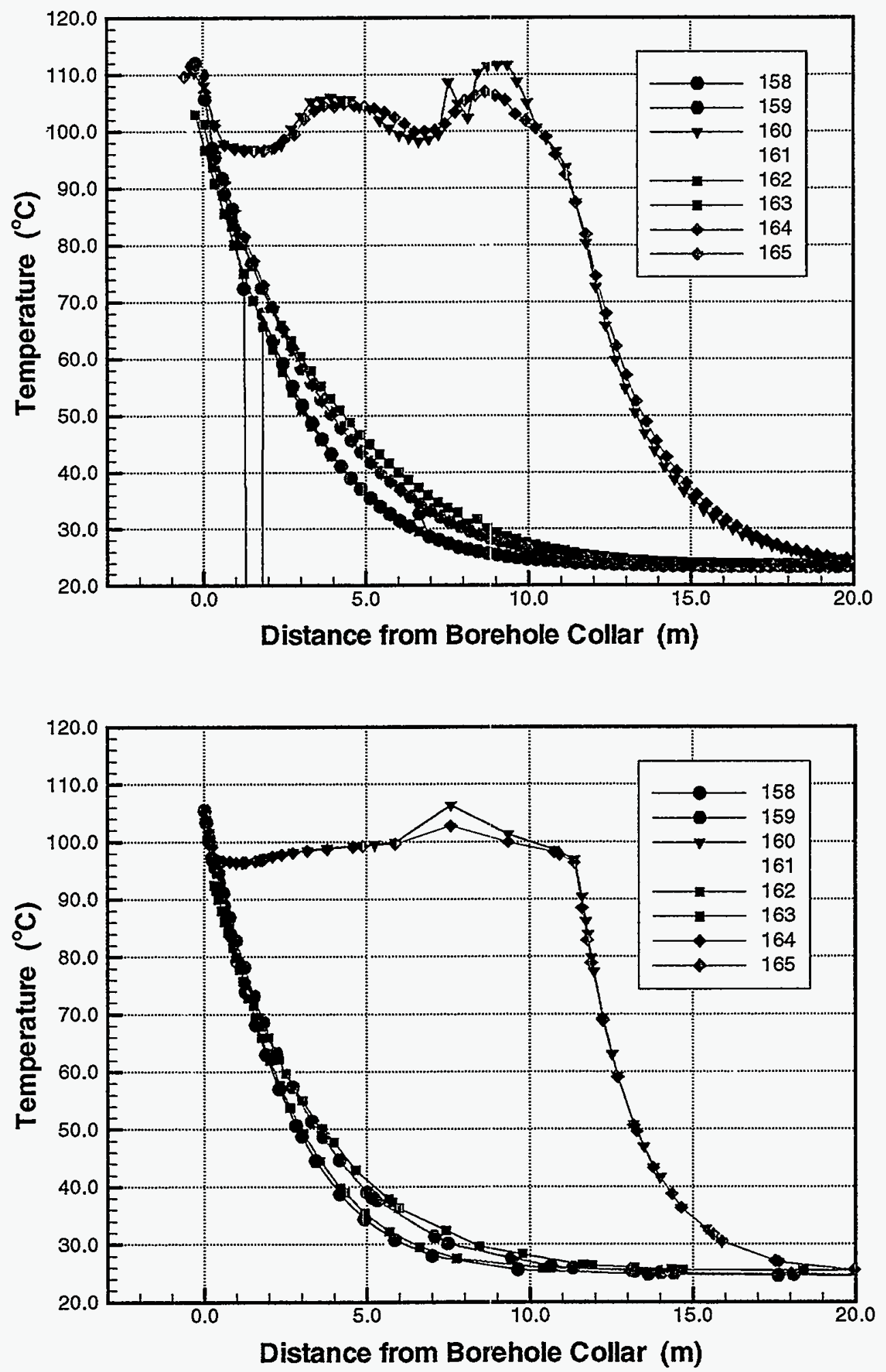

Figure 2.14. Measured (top) and simulated (bottom) temperature profiles along boreholes 158 to 165 at 4 months of heating. 

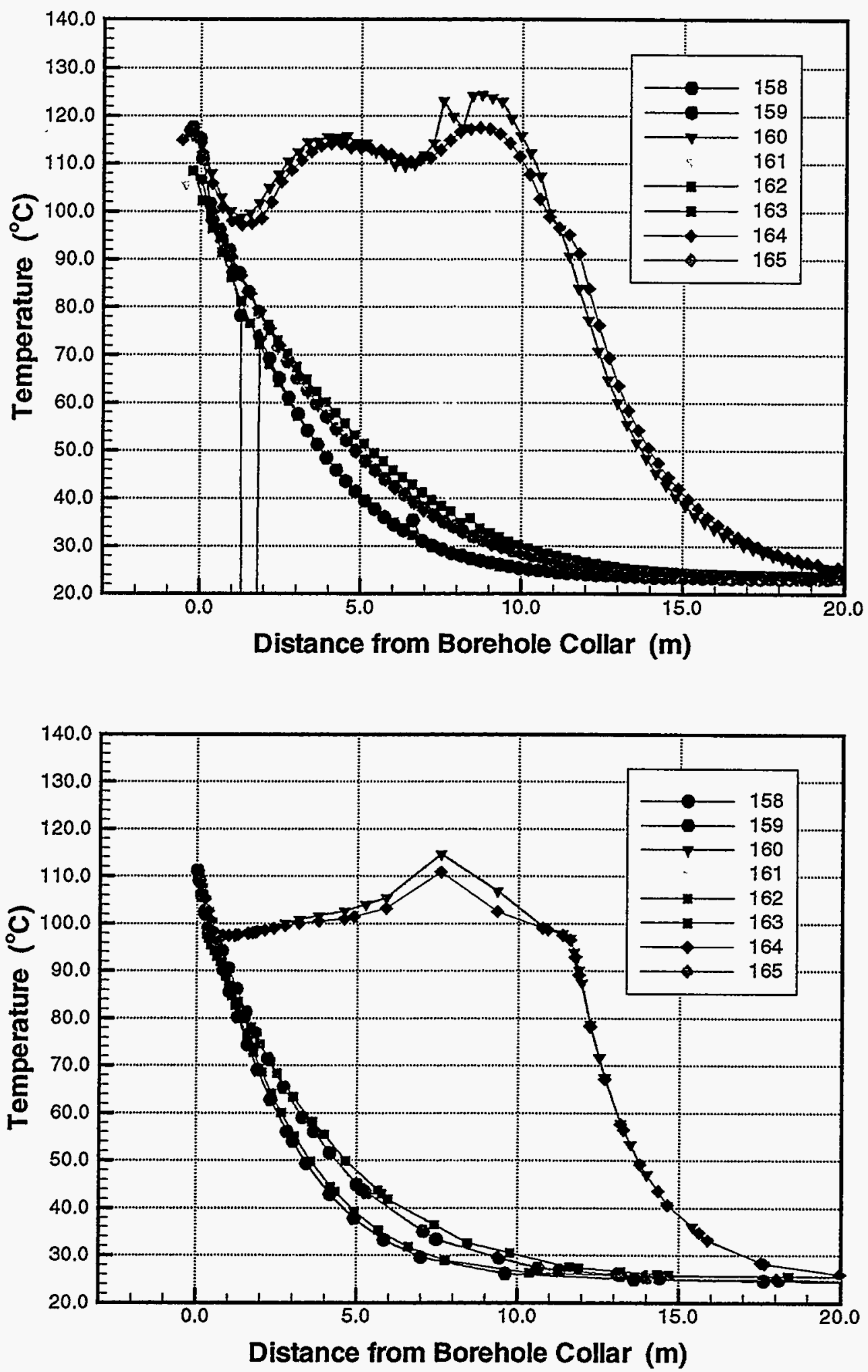

Figure 2.15. Measured (top) and simulated (bottom) temperature profiles along boreholes 158 to 165 at 5 months of heating. 

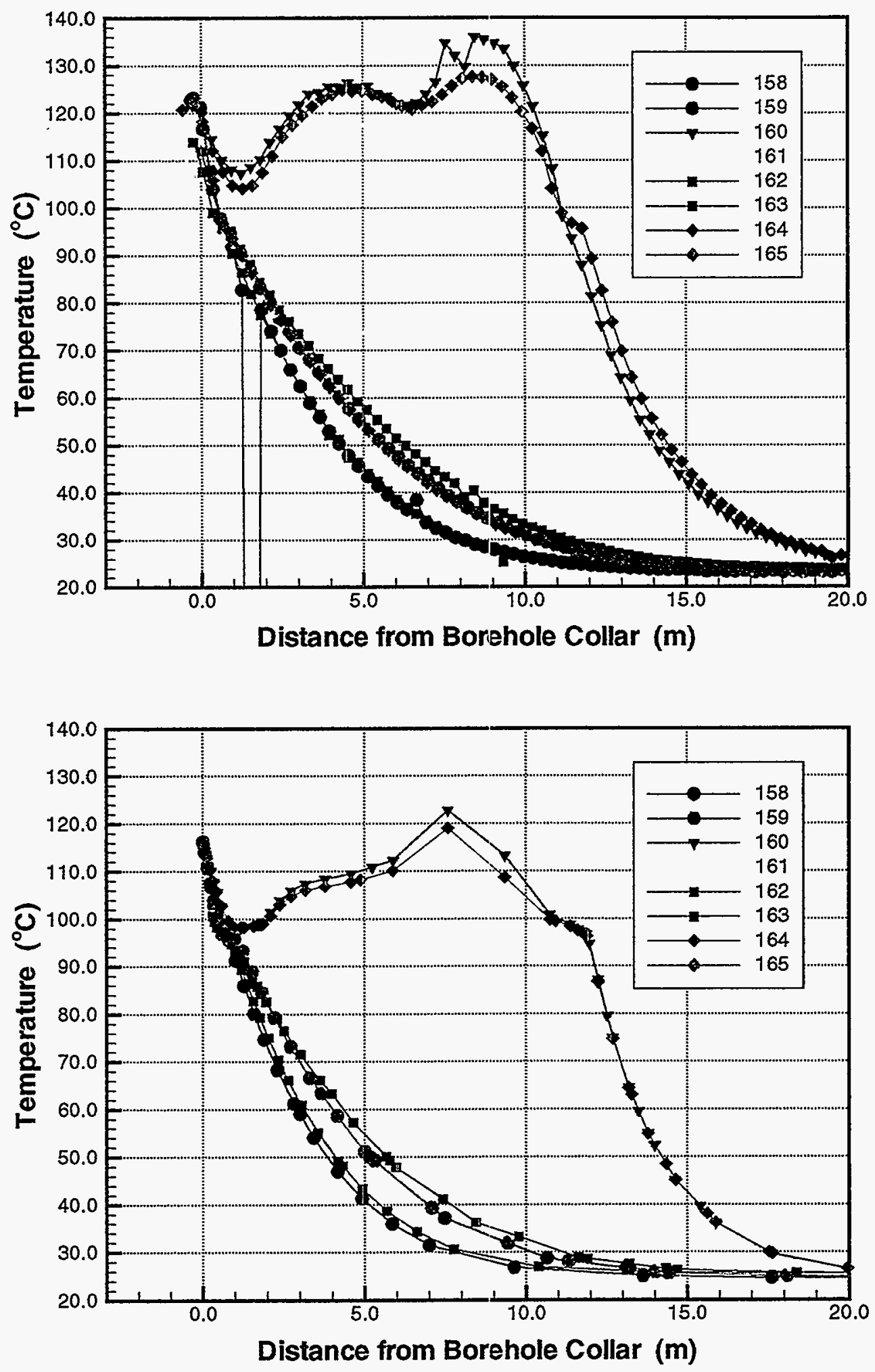

Figure 2.16. Measured (top) and simulated (bottom) temperature profiles along boreholes 158 to 165 at 6 months of heating. 

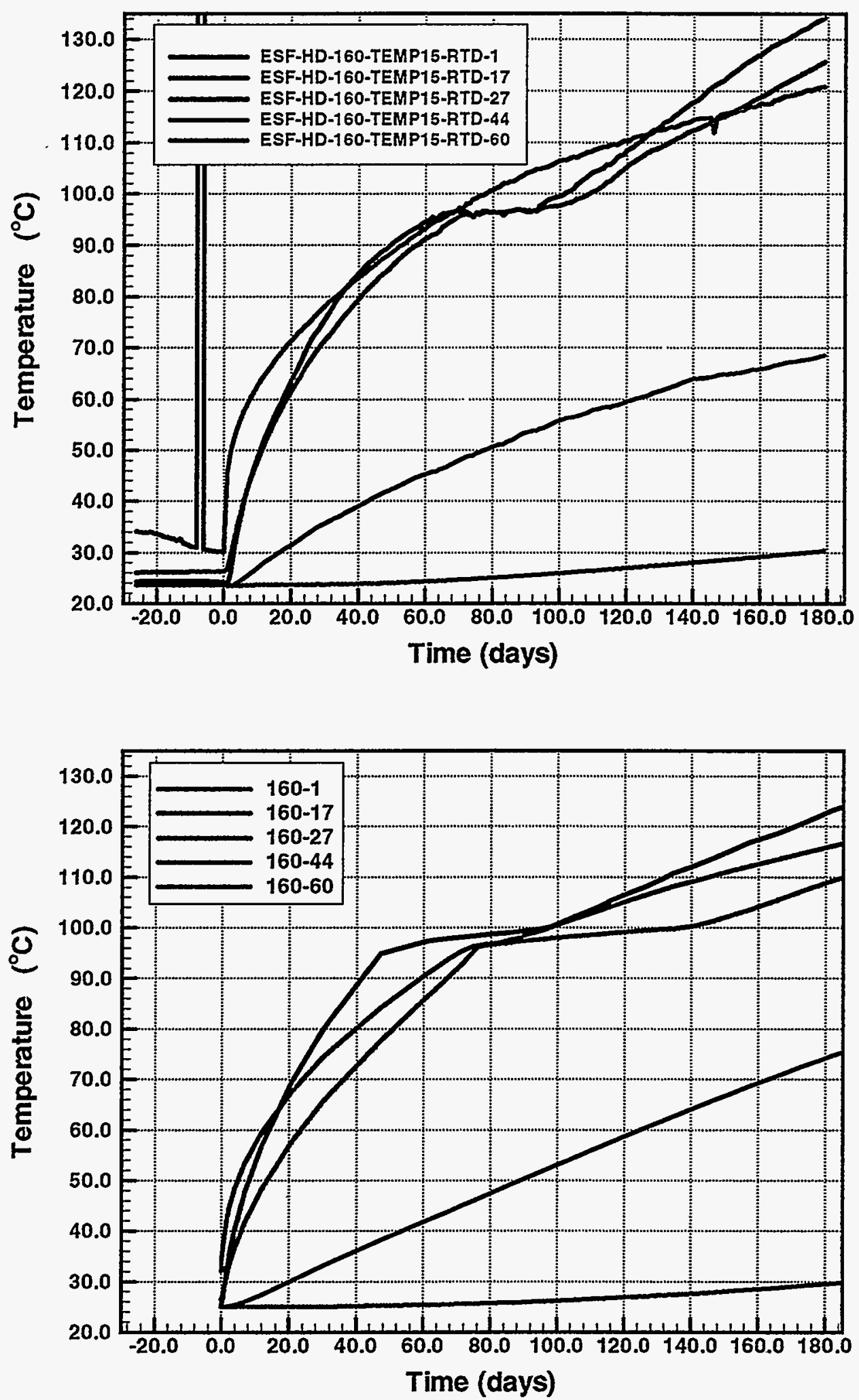

Figure 2.17. Measured (top) temperature and simulated (bottom) temperature evolution in borehole 160 for the first 6 months of heating. 

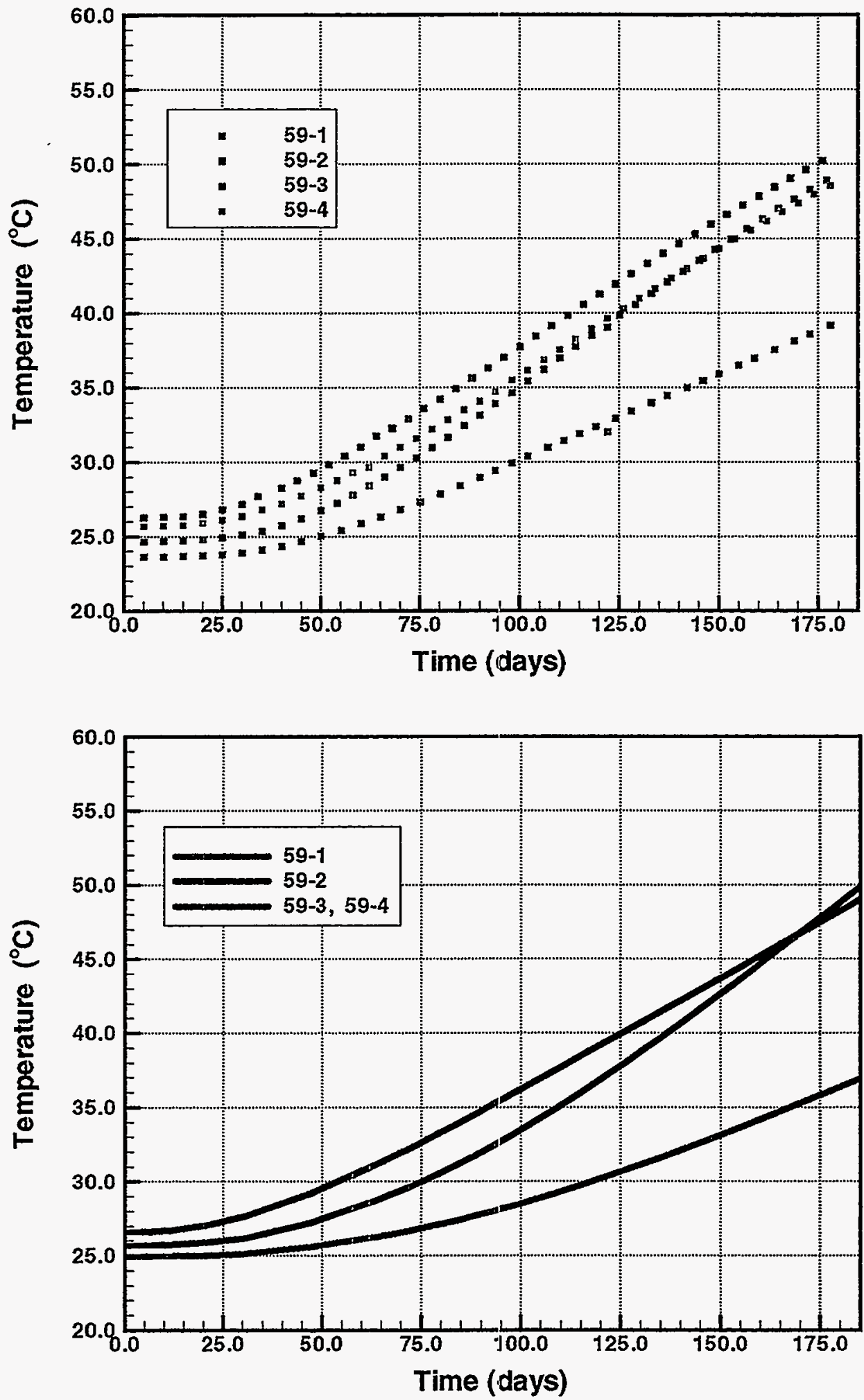

Figure 2.18. Measured (top) and simulated (bottom) temperature evolution in hydrology borehole 59 for the first 6 months of heating. 

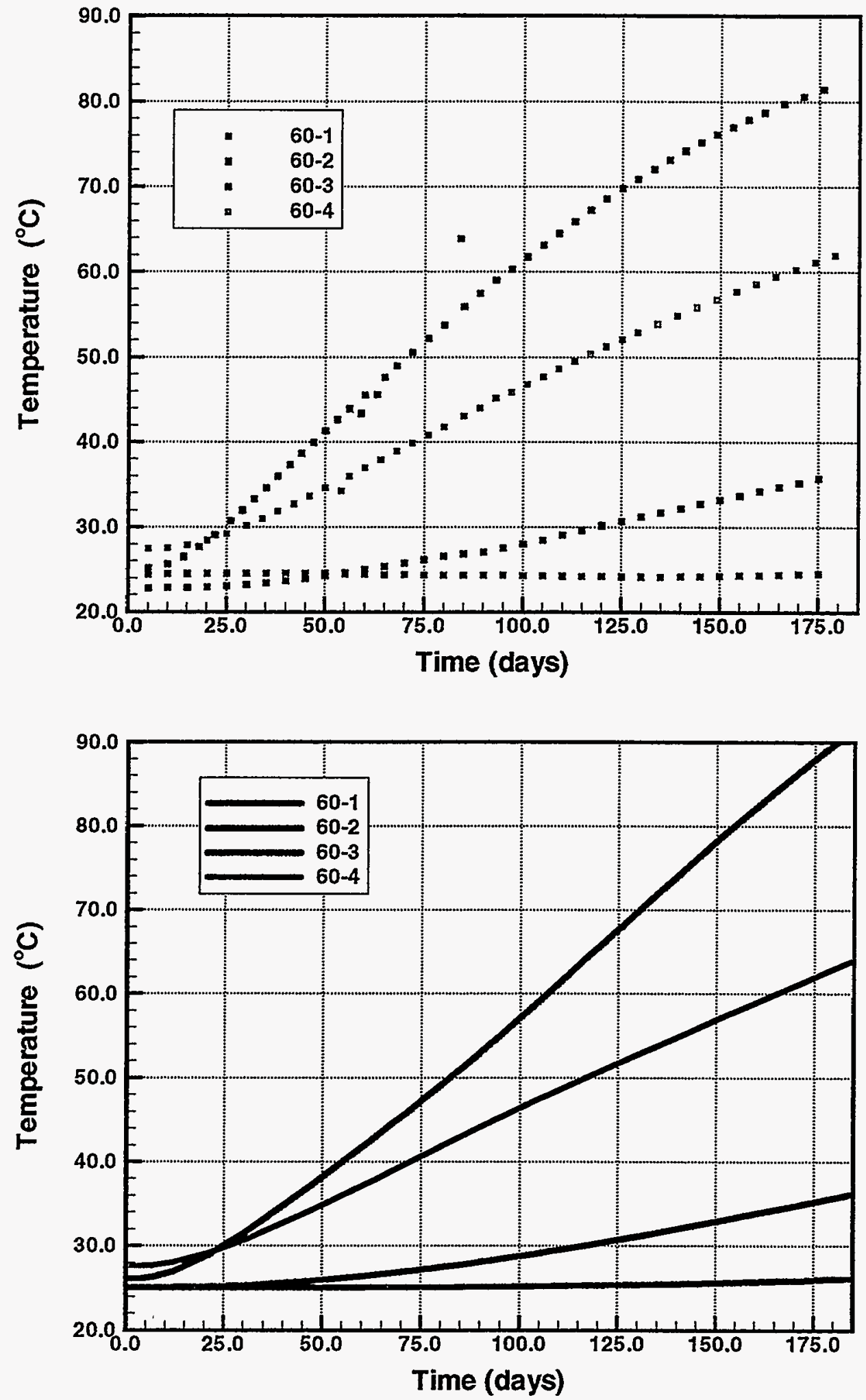

Figure 2.19. Measured (top) and simulated (bottom) temperature evolution in hydrology borehole 60 for the first 6 months of heating. 

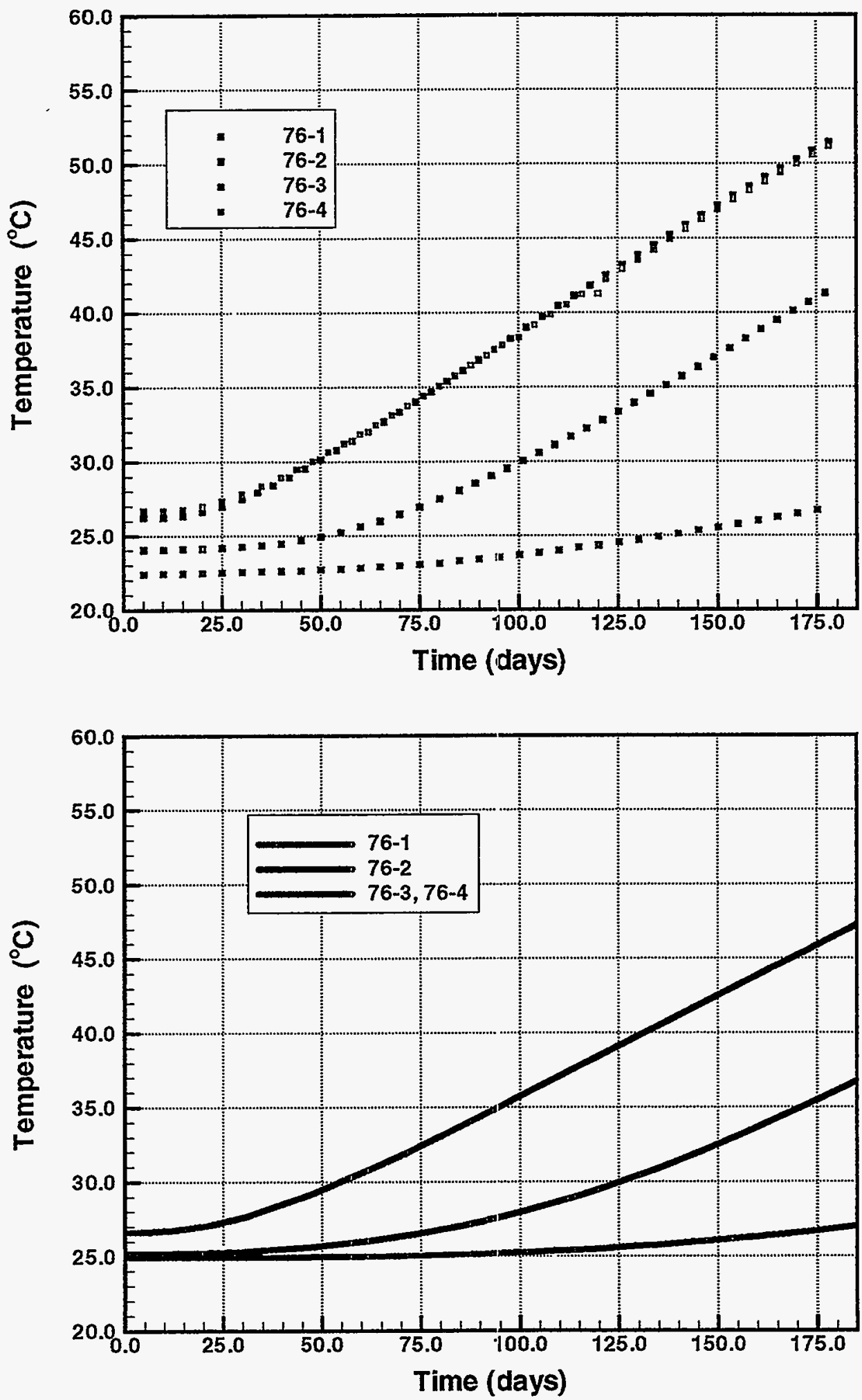

Figure 2.20. Measured (top) and simulated (bottom) temperature evolution in hydrology borehole 76 for the first 6 months of heating. 

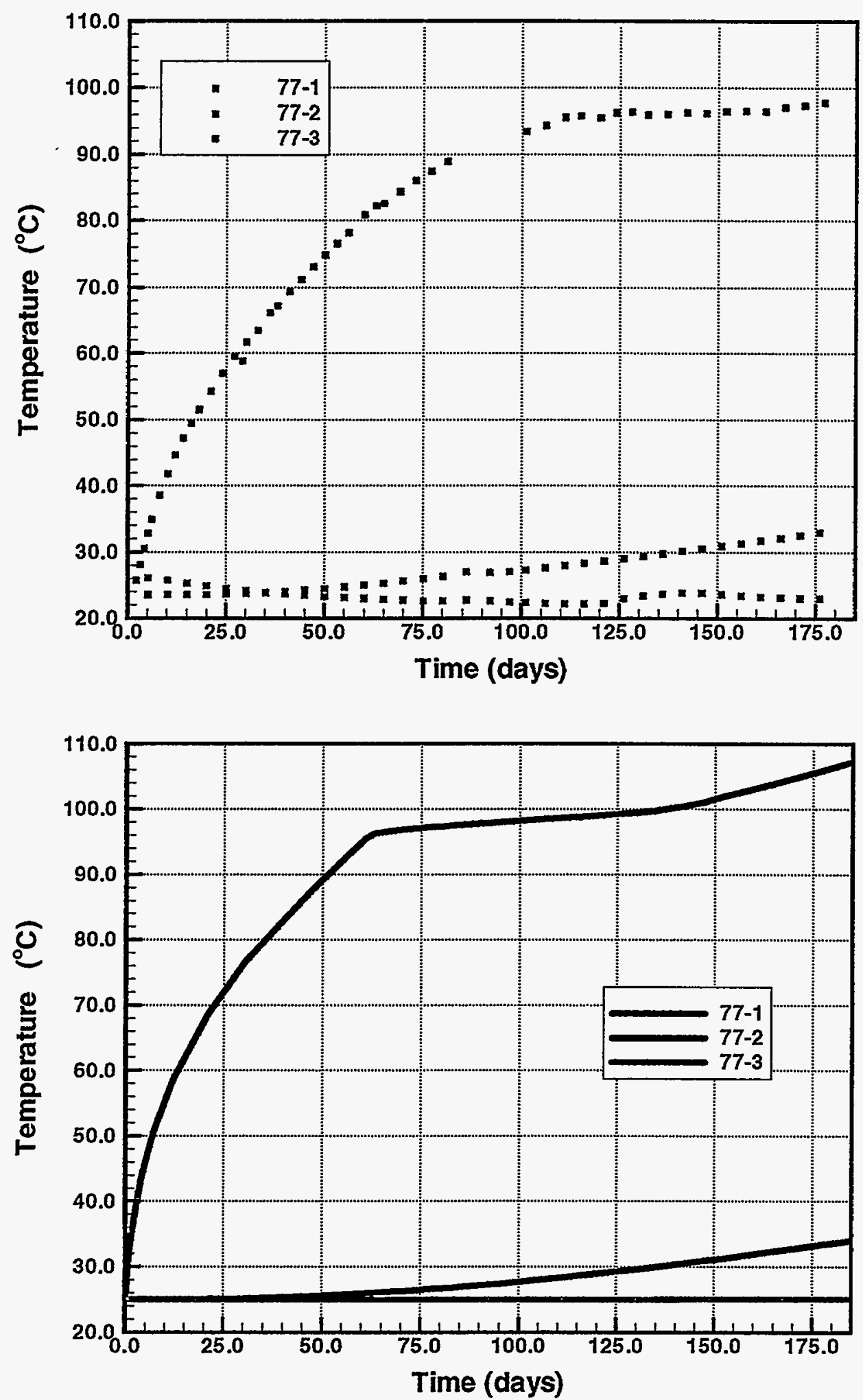

Figure 2.21. Measured (top) and simulated (bottom) temperature evolution in hydrology borehole 77 for the first 6 months of heating. 

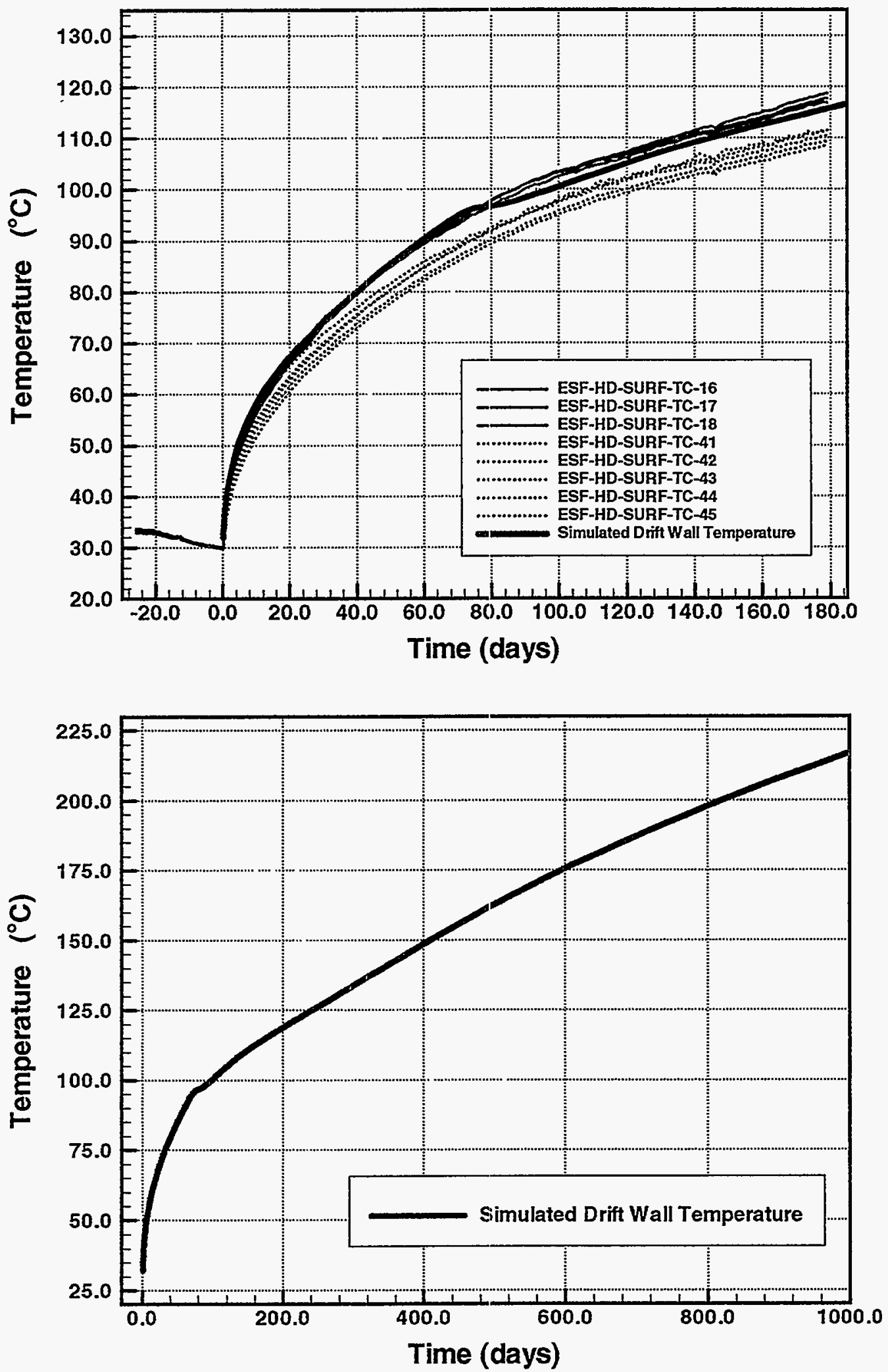

Figure 2.22. Measured and simulated temperature evolution at the Heated Drift wall. Measured temperature is shown at two different cross sections along the Heated Drift. 

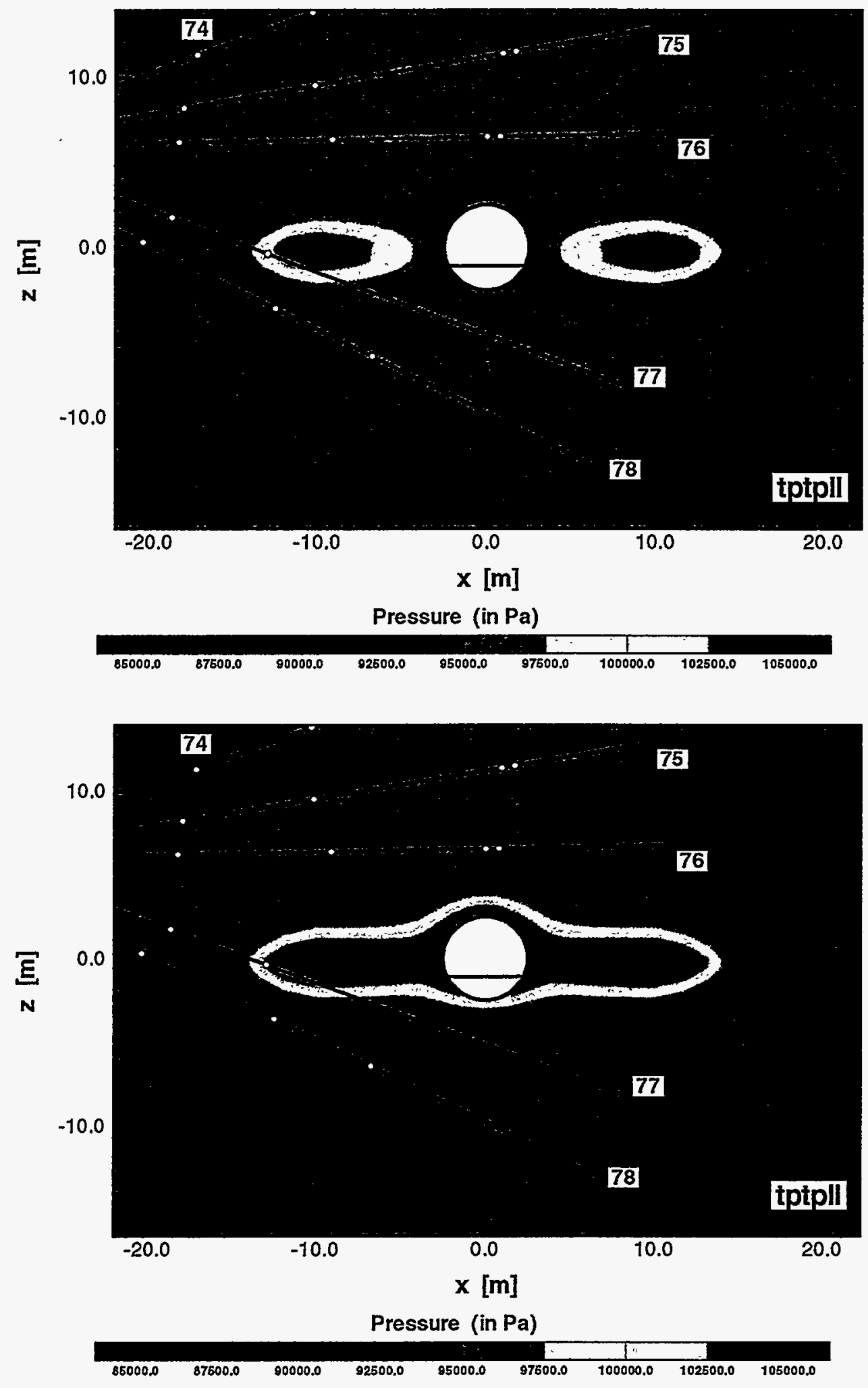

Figure 2.23. Gas pressure at 6 months of heating, using a gas-permeable bulkhead (top) and a perfectly sealed bulkhead (bottom). 

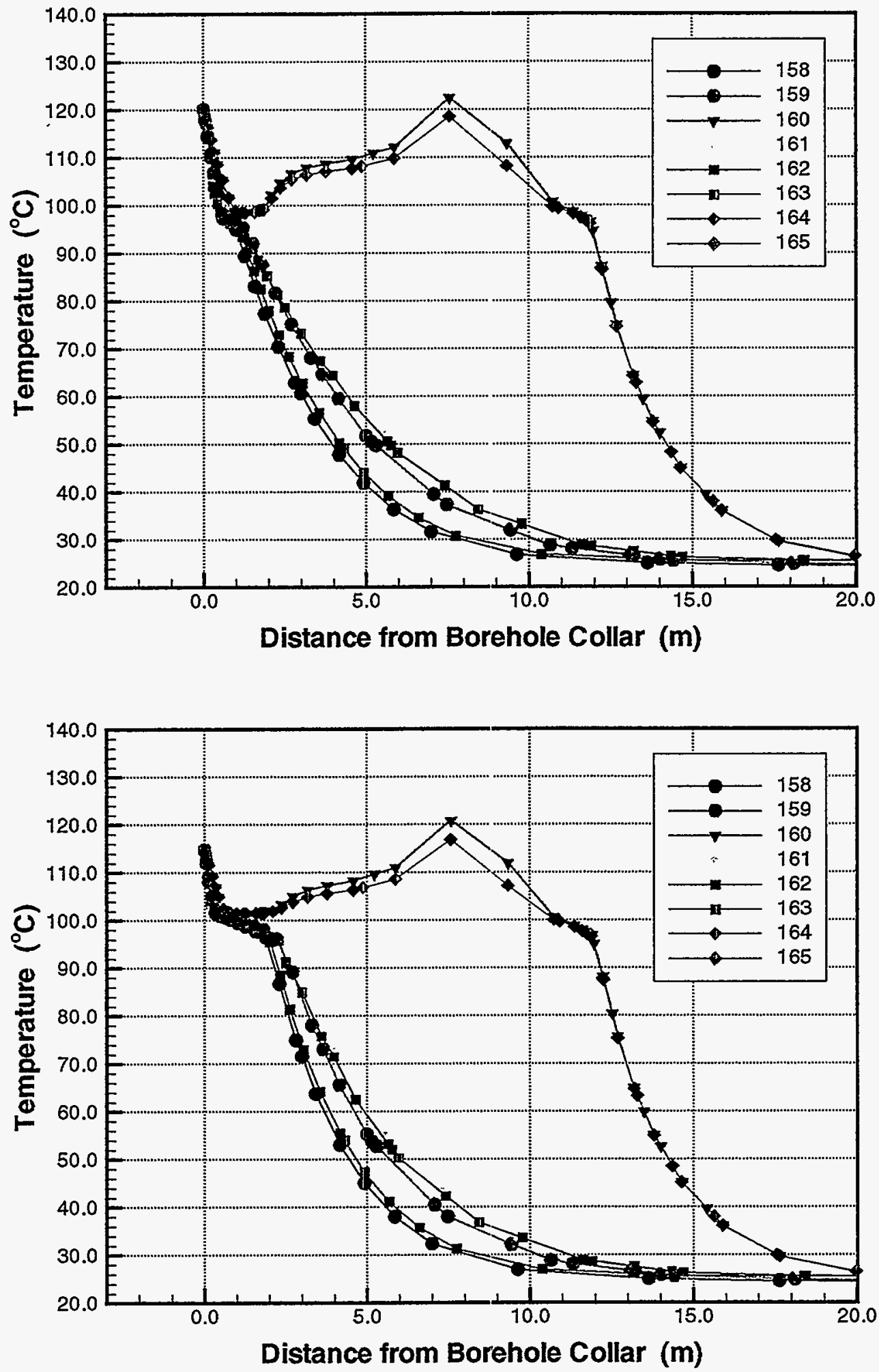

Figure 2.24. Simulated temperature profiles along boreholes 158 to 165 at 6 months of heating, using a gas-permeable bulkhead (top) and a perfectly sealed bulkhead (bottom). 

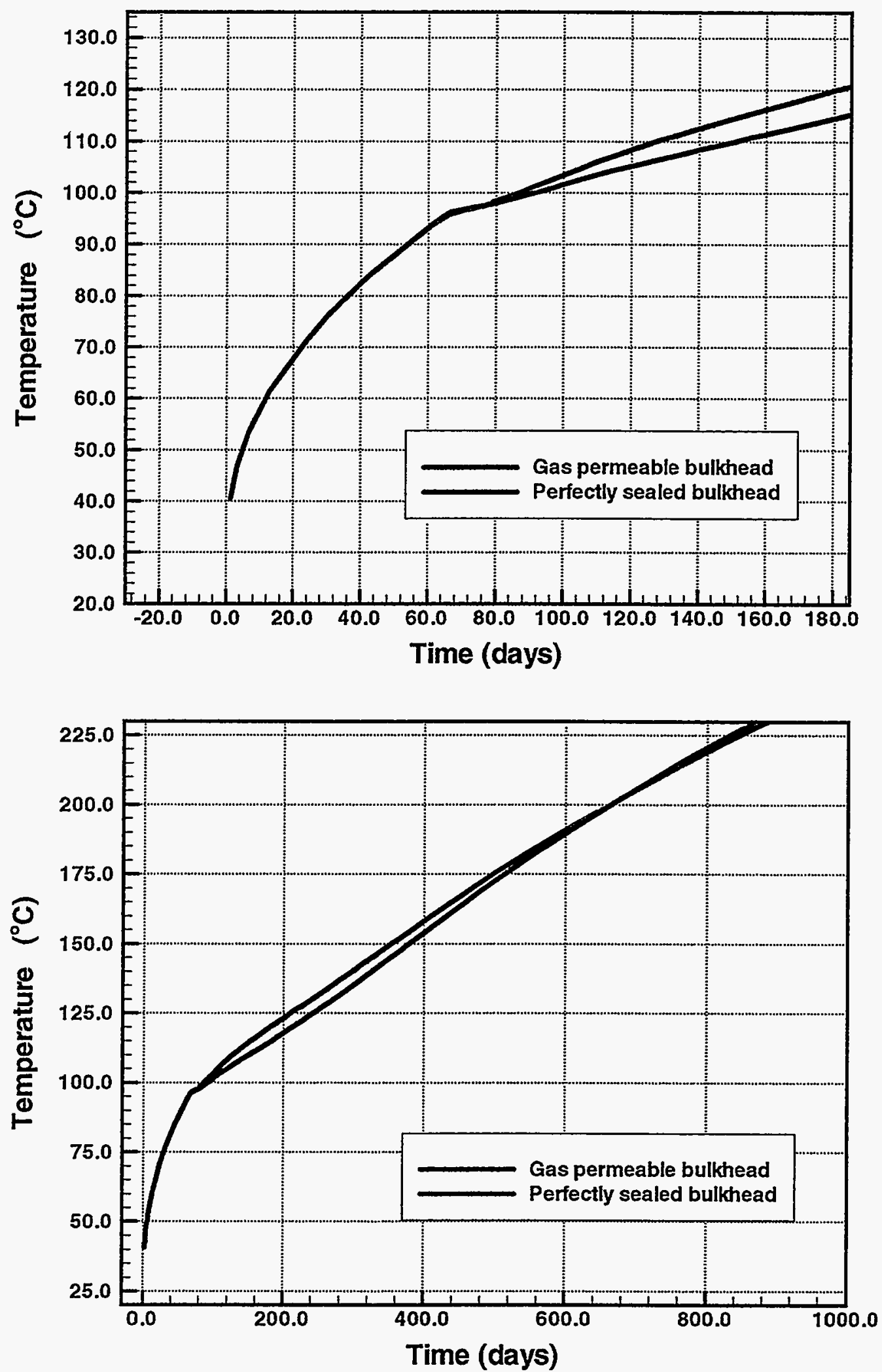

Figure 2.25. Simulated temperature evolution at the Heated Drift wall for alternative bulkhead boundary conditions up to 185 days (top) and up to 1000 days (bottom). 

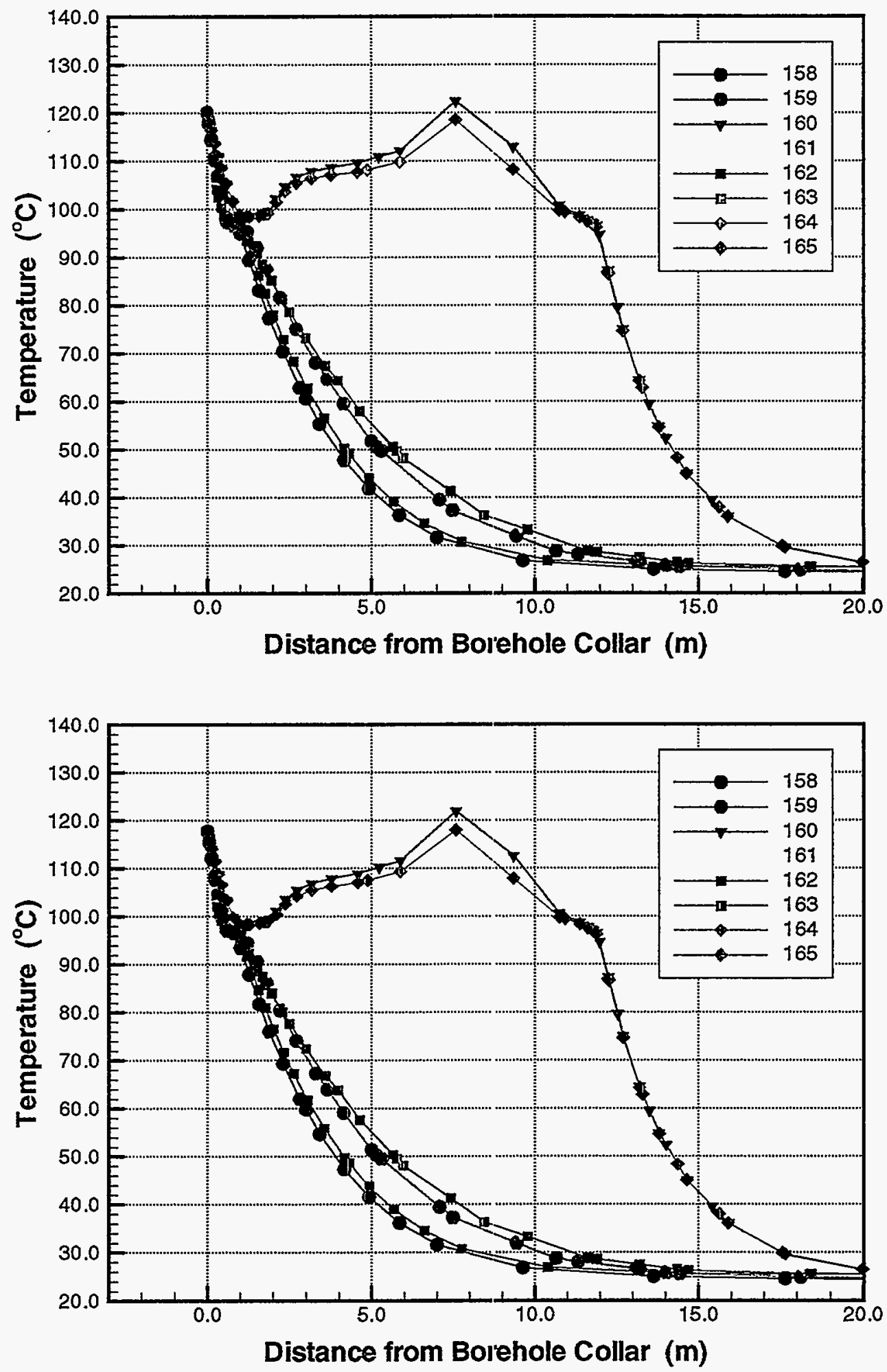

Figure 2.26. Simulated temperature profiles along boreholes 158 to 165 at 6 months of heating, with initial drying due to ventilation (top) and without initial drying (bottom). 

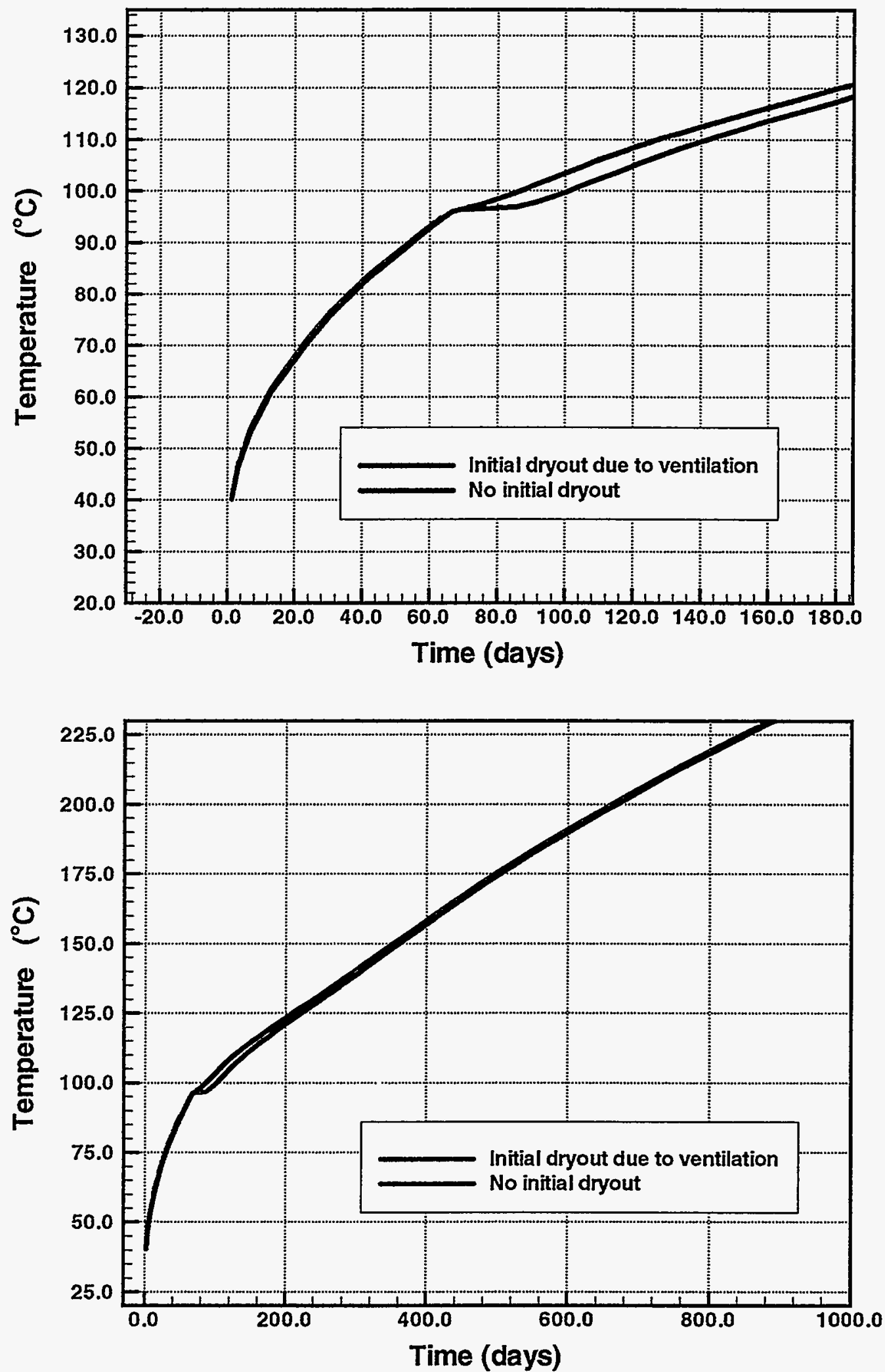

Figure 2.27. Simulated temperature evolution at the Heated Drift wall, with initial drying due to ventilation and without drying, up to 185 days (top) and up to 1000 days (bottom). 

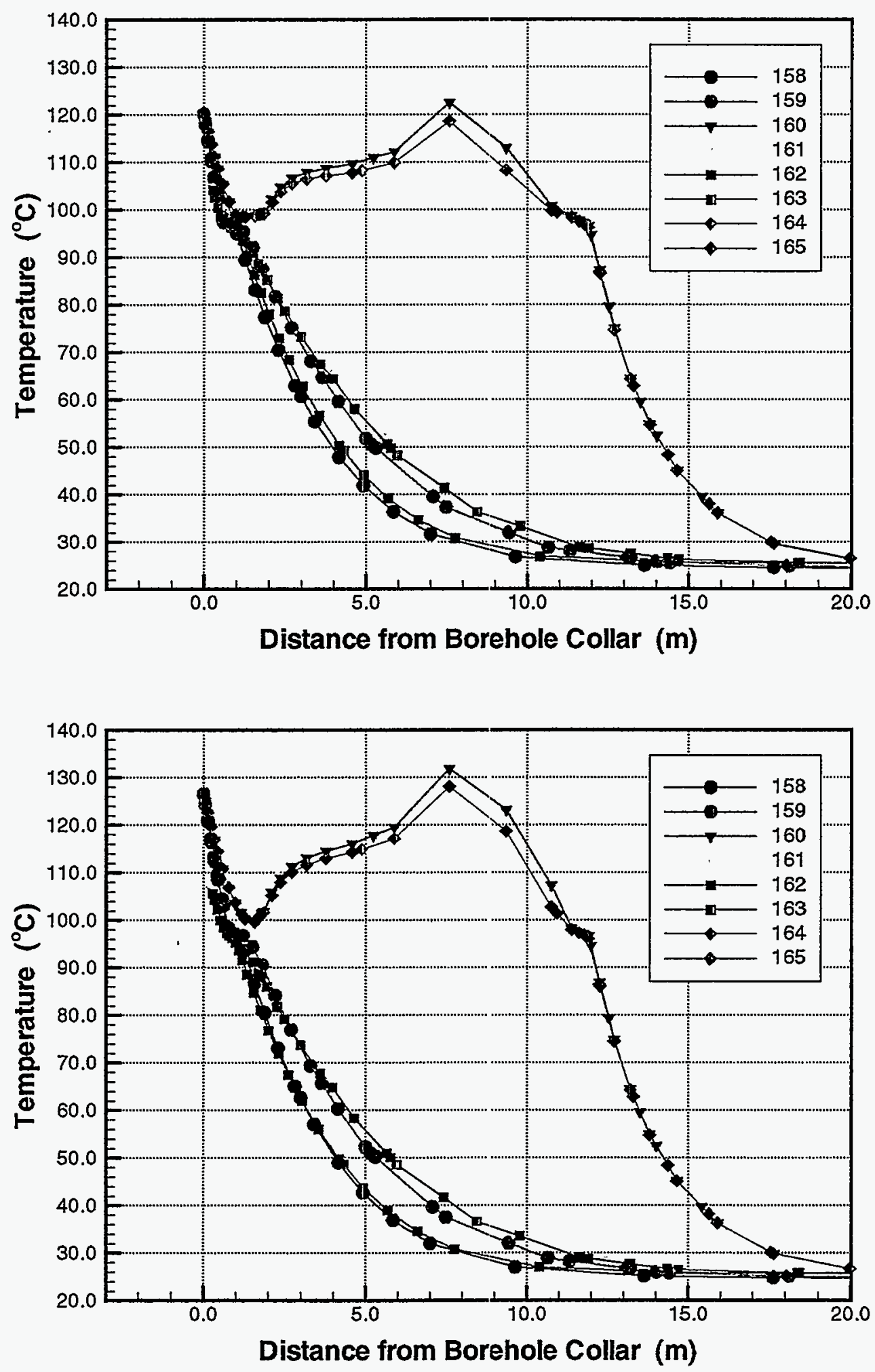

Figure 2.28. Simulated temperature profiles along boreholes 158 to 165 at 6 months of heating, using a $3.6 \mathrm{~mm} / \mathrm{yr}$ percolation flux (top) and a $0.36 \mathrm{~mm} / \mathrm{yr}$ percolation flux (bottom). 

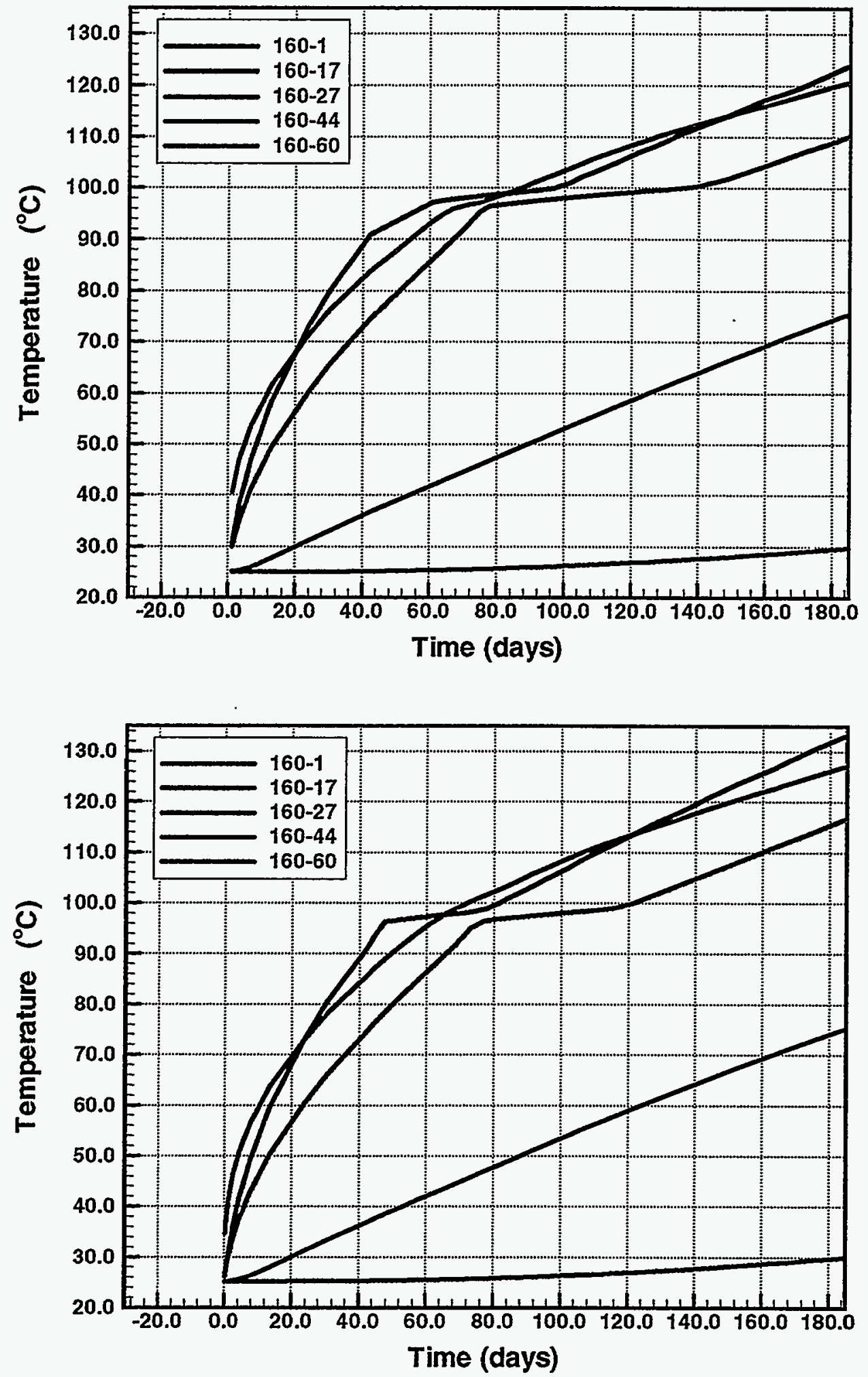

Figure 2.29. Simulated temperature evolution in borehole 160 for the first 6 months of heating, using a $3.6 \mathrm{~mm} / \mathrm{yr}$ percolation flux (top) and a $0.36 \mathrm{~mm} / \mathrm{yr}$ percolation flux (bottom). 

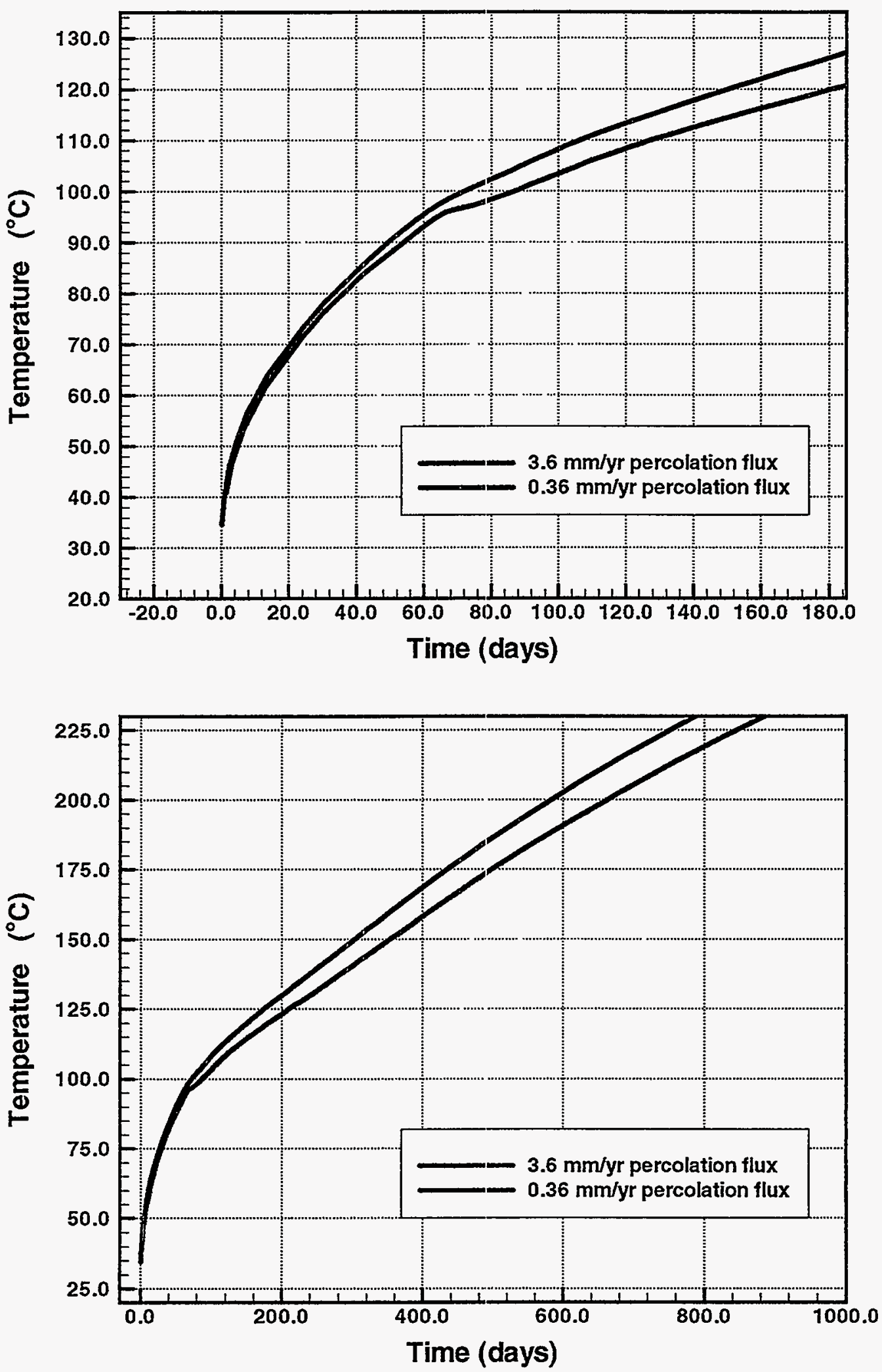

Figure 2.30. Simulated temperature evolution at the Heated Drift wall, using a $3.6 \mathrm{~mm} / \mathrm{yr}$ percolation flux and a $0.36 \mathrm{~mm} / \mathrm{yr}$ percolation, up to 185 days (top) and up to 1000 days (bottom). 

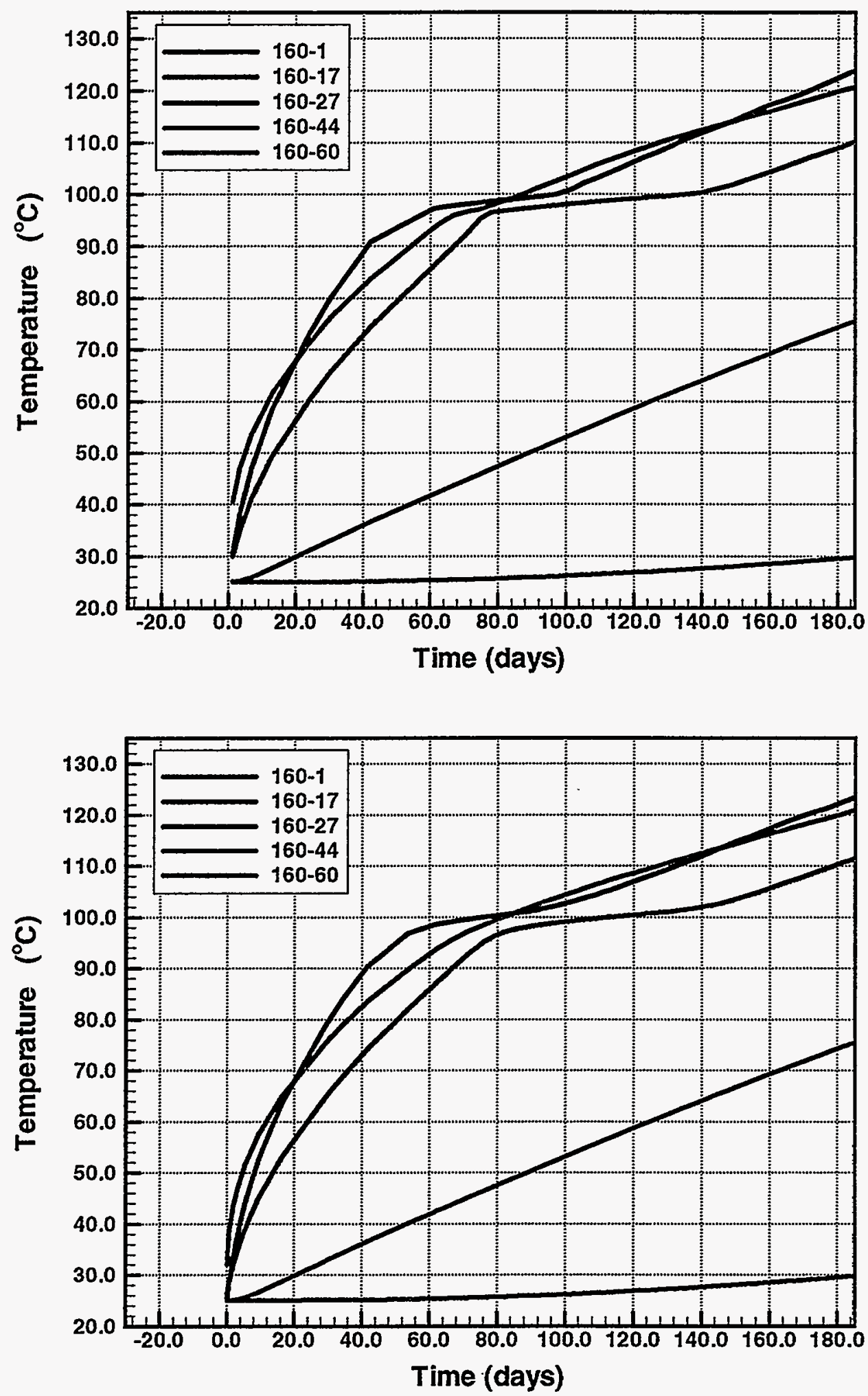

Figure 2.31. Simulated temperature evolution in borehole 160 for the first 6 months of heating, using an ECM representation (top) and a DKM representation (bottom). The temperature presented for the DKM is matrix temperature. 

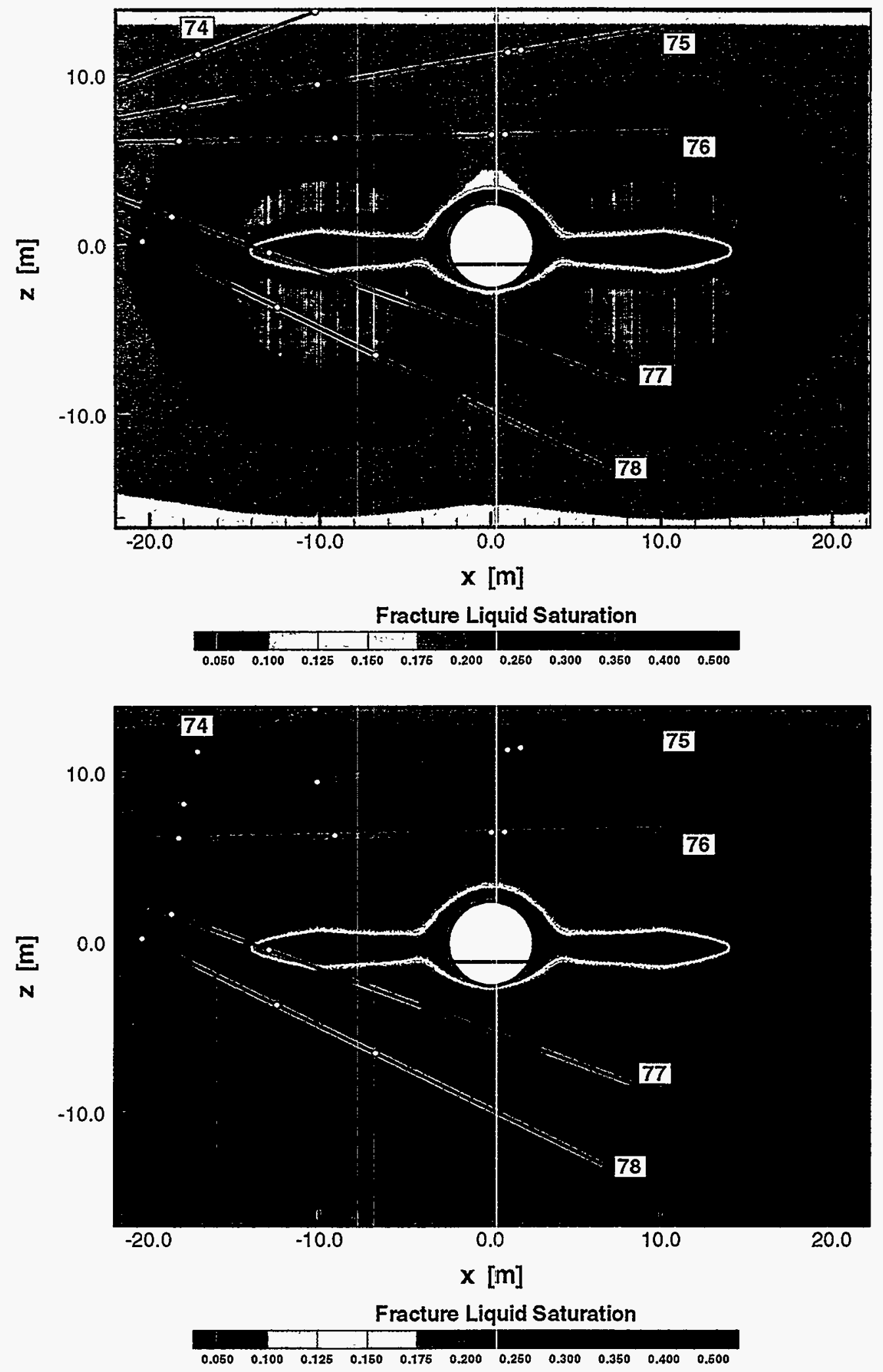

Figure 2.32. Fracture liquid saturation at 3 months of heating, using an ECM representation (top) and a DKM representation (bottom). 

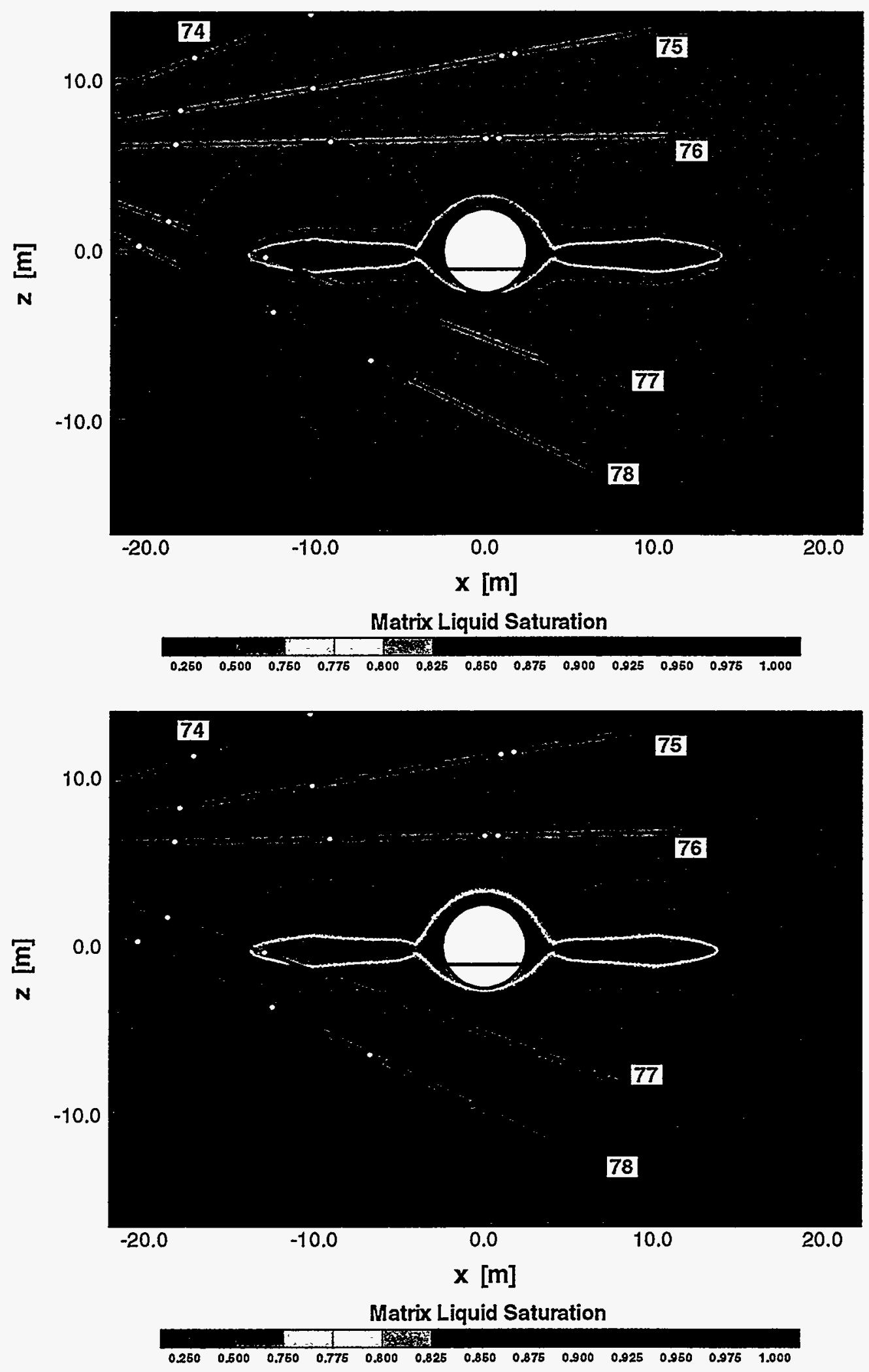

Figure 2.33. Matrix liquid saturation at 3 months of heating, using an ECM representation (top) and a DKM representation (bottom). 


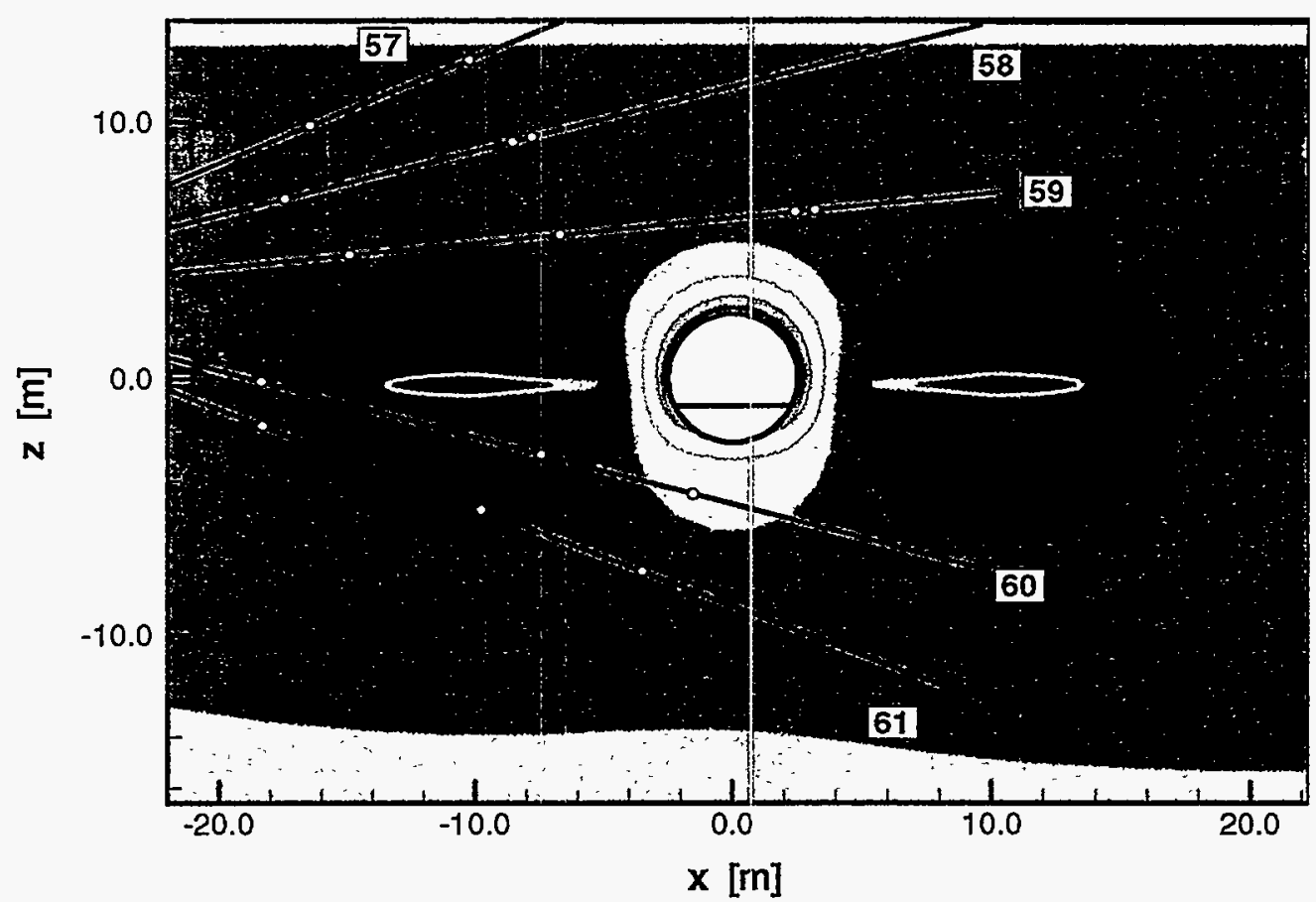

Fracture Liquid Saturation

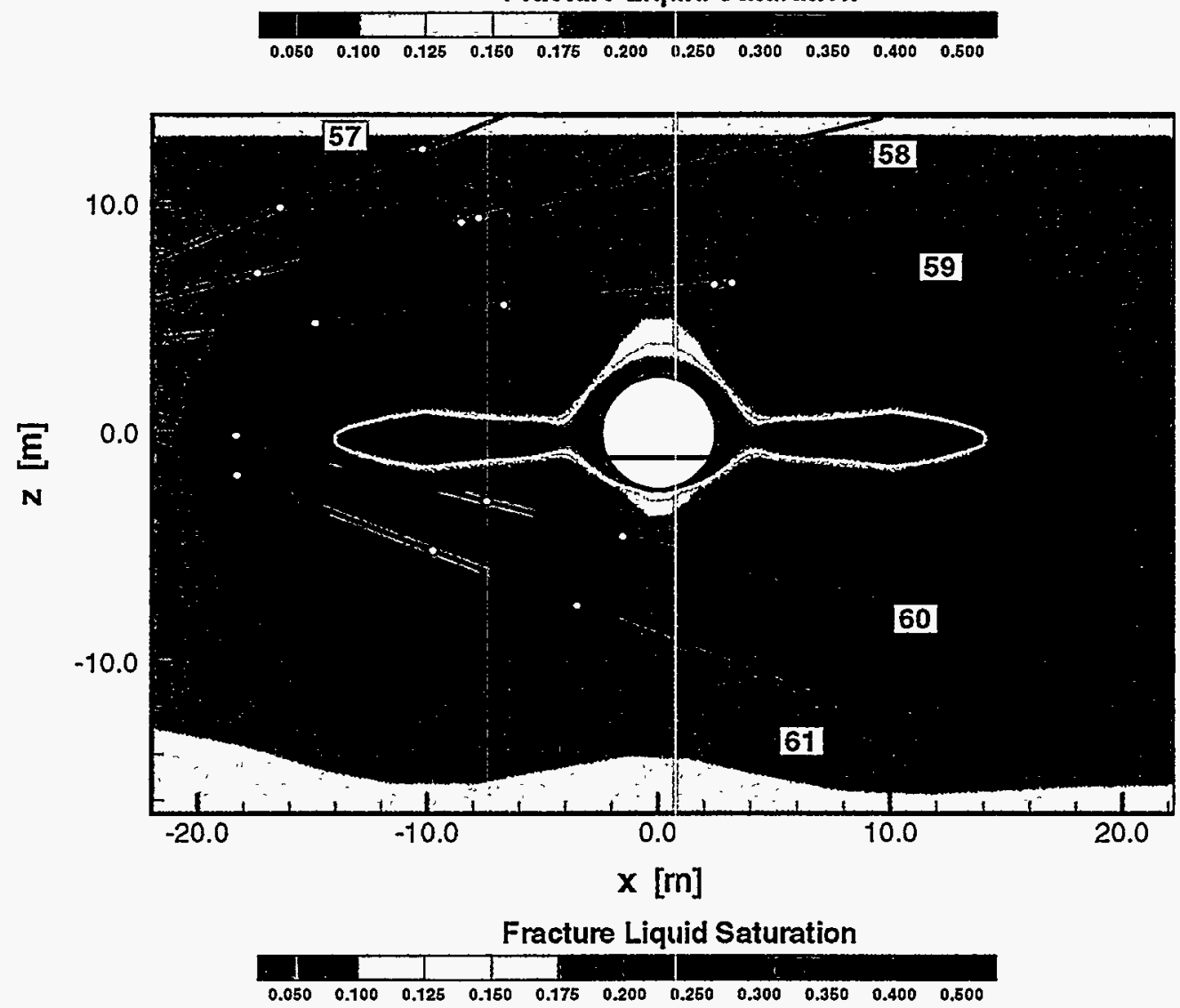

Figure 2.34. Simulated fracture saturation at 3 months (top) and 6 months (bottom) of heating in xzcross section at $\mathrm{y}=10 \mathrm{~m}$. 

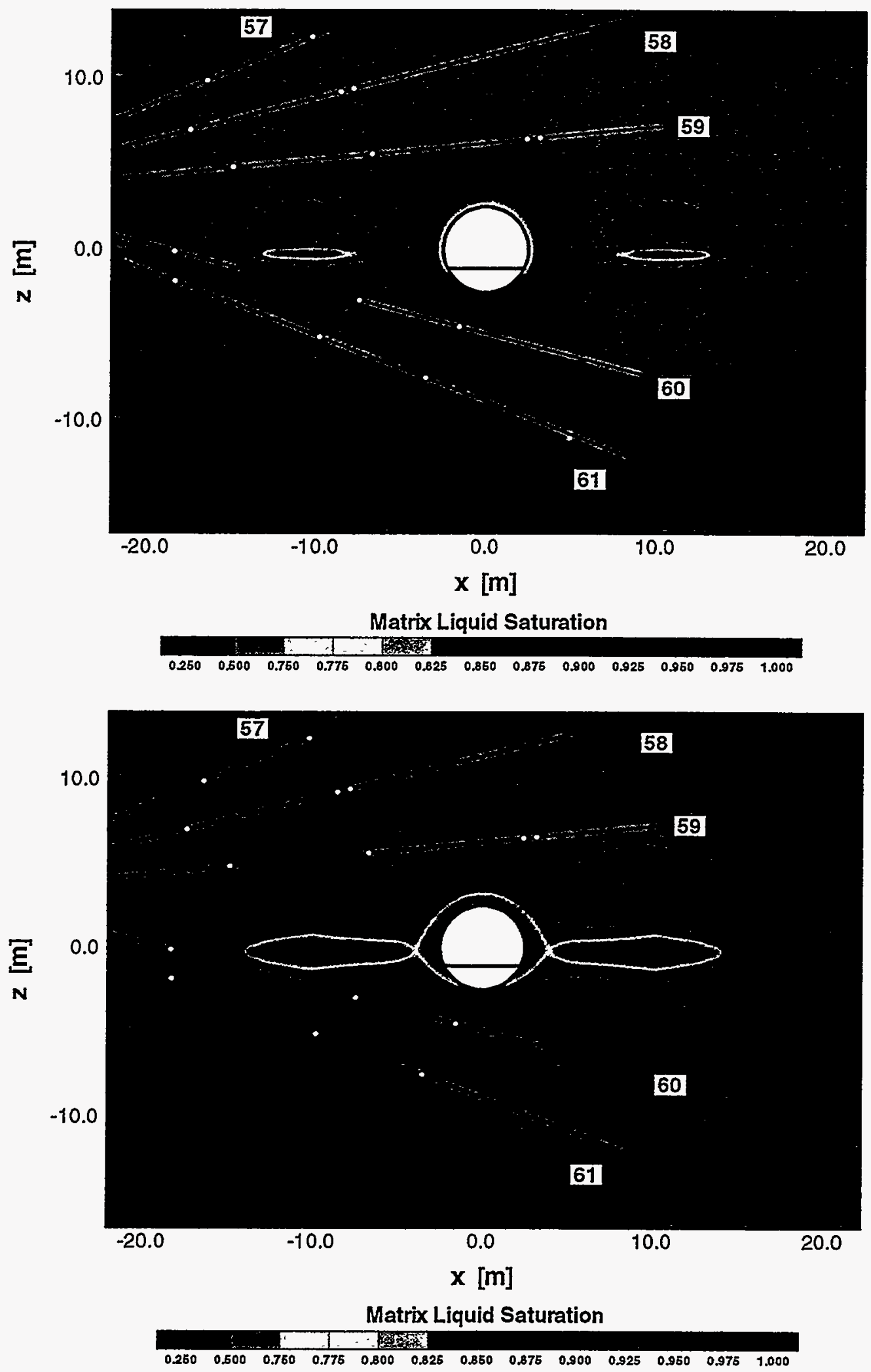

Figure 2.35. Simulated matrix saturation at 3 months (top) and 6 months (bottom) of heating in xzcross section at $\mathrm{y}=10 \mathrm{~m}$. 
Chapter 2 Interpretive Analysis of the Thermo-Hydrological Processes of the Drift Scale Test

THIS PAGE IS INTENTIONALLY LEFT BLANK. 


\title{
Chapter 3 Interpretive Analysis of the Thermo-Hydrological-Chemical Processes of the Drift-Scale Test
}

\author{
E. Sonnenthal, N. Spycher, and J. Apps \\ Earth Sciences Division, LBNL
}

\subsection{Introduction}

The objective of this chapter is to provide an update on modeling and the geochemical model refinement of coupled thermo-hydro-chemical (THC) processes accompanying the Drift-Scale Test (DST). This chapter follows the development of the conceptual and numerical models for thermo-hydrologicalchemical (THC) processes in the DST presented earlier in 1998 (Sonnenthal et al., 1998). In addition, limited gas and water sampling has provided some data for which comparisons to the modeling can be made.

The basis of the thermohydrologic model used in the thermo-hydrological-chemical simulations is the two-dimensional dual-permeability mesh and thermohydrological parameters described in Birkholzer and Tsang (1997). A conceptual model for treating the rate-limited reactions of minerals, gas, and water coupled to the thermohydrologic calculations is presented in Sonnenthal et al. (1998). The code used for these coupled reaction-transport simulations is TOUGHREACT (Xu et al., 1997; 1998) which has been modified and enhanced as part of this effort to study THC processes in the DST. Briefly, the full equations for heat, water, and gas flow are solved simultaneously, followed by the transport (advectiondiffusion) of primary aqueous and gaseous chemical species in a sequential fashion, and then solution of the chemical system at each grid volume element. Thus, the full multiphase thermohydrologic system is solved identically to the modeling presented by Birkholzer and Tsang (1997) and in Chapter 2 of this report, along with solving the rate-limited precipitation and dissolution of aqueous and gaseous species and solid phases.

The following subsections give an overview of some of the new chemical data that have been made available, the new DST simulations presented in this chapter, and the progress on refining the conceptual and numerical model of geochemical processes. 


\subsubsection{New Chemical Data Acquired}

Gas samples were recently collected from the hydrology holes in the DST (June 4, 1998) by Mark Conrad of LBNL and analyzed for $\mathrm{CO}_{2}$ (Conrad, 1998b). From the $\mathrm{CO}_{2}$ fraction, the isotopic ratios $\delta^{13} \mathrm{C}$ and $\delta^{18} \mathrm{O}$ were also determined (Conrad, 1998b). Analysis of the carbon and oxygen isotopic data are presented in the latter report. Future modeling will consider these isotopic systems, in addition to the Sr isotopic system already examined in Sonnenthal et al. (1998). Comparisons of the measured $\mathrm{CO}_{2}$ concentrations to the model results are shown in Section 3.3.

Two water samples were collected from Borehole 60 (Intervals 2 and 3). Full chemical analyses have not been made available; however, initial $\mathrm{pH}$ measurements were 7.5 and 7.7 collected at temperatures of 36.2 and $82.1^{\circ} \mathrm{C}$. Very low $\mathrm{Br}$ concentrations $(<1 \mathrm{ppm})$ indicated that the water was not derived from construction water $(\mathrm{Br}$ is approximately $20 \mathrm{ppm})$.

\subsubsection{Numerical Model Development, Simulations and Sensitivity Studies}

This chapter presents additional simulations and sensitivity studies since the first predictive report on THC processes in the DST (Sonnenthal et al., 1998). First we examine the evolution of the aqueous system that includes $\mathrm{Ca}^{2+}, \mathrm{Na}^{+}, \mathrm{Cl}^{-}, \mathrm{SiO}_{2}(\mathrm{aq}), \mathrm{HCO}_{3}{ }^{-}$, and $\mathrm{H}^{+}$, considering the minerals quartz, cristobalite, amorphous silica, and calcite, and $\mathrm{CO}_{2}$ transport in the gas phase. Results are presented for the approximate time of the most recent gas and water sampling (approximately 6 months after the start of the DST) and for various times and locations through the heating and cooling periods. Comparisons of model results to measured $\mathrm{CO}_{2}$ concentrations from gas sampling (Conrad, 1998a, b) are made.

It should be noted that direct comparisons of model geochemical data at a specific location to collected water and gas samples cannot always be made because collected samples are often derived from a large packer interval and most likely from an extended region around the borehole. In addition, because of strong temperature gradients, temperature sensors may not reflect the actual in-situ temperature of the sample. Also, differences in the actual power output from the modeled values, and the observations of heat loss from the heater drift, resulted in a different temperature distribution and rate of temperature increase. Therefore, comparisons at a single location can only be approximate and preliminary until a new heating schedule and boundary conditions are used in the THC modeling. Instead, it is important that modeling reflect the general geochemical trends and the processes occurring within temperature regions and not at specific locations. In addition, it was shown in Sonnenthal et al. (1998) that the mineral assemblage and chemical system considered in the modeling will influence some of the results, depending on the rate of the particular chemical reaction. Thus, the refinement of thermodynamic, kinetic, and mineral surface and chemical data as the test and modeling proceeds is extremely important to a better understanding of the full system. 
Yucca Mountain Drift Scale Test Progress Report

We also present simulations of the silica phases (cristobalite, quartz, amorphous silica) plus $\mathrm{Na}^{+}$and $\mathrm{Cl}^{-}$, assuming a five times and ten times higher fracture porosity than our base case value. The latter work is meant to address some of the findings of higher fracture porosity (fractures plus lithophysal cavities) suggested by the in-situ gas tracer test results (Tsang and Freifeld, 1998).

\subsubsection{Geochemical Model Refinement}

Despite considerable progress in the development of an integrated THC model, as embodied in the current version of the TOUGHREACT code, the current geochemical model does not incorporate certain interrelated chemical processes. These processes are known to occur and are very important to the system under study. Furthermore, they must be accounted for if model validation for many secondary phases is to be achieved. The processes, first described by W. Ostwald over 100 years ago, and named after him, i.e., Ostwald Ripening and the Ostwald Rule of Stages (or step rule), relate to systems that are proceeding towards thermodynamic equilibrium from an unstable or metastable state. In this chapter, we review the literature on these processes and identify the steps needed to achieve closer agreement with field conditions.

\subsection{QA Status of Codes and Data}

\subsubsection{QA Status of Data Used in Chapter}

The data used as input to modeling in this chapter come from a variety of qualified and unqualified sources, making data developed from these sources and conclusions derived from these data non- $Q$. The QA status of specific input data sources is provided in Table 3.2.1. The data fall into several classes and the mixed nature of their qualification status can easily be seen:

1. Mineralogy - Qualified x-ray diffraction mineralogy of the DST (Roberts and Viani, 1997; see Table 3.2.1).

2. Thermodynamic data are taken from the EQ3/6 database (Wolery, 1992), which consists mostly of data from SUPCRT92 (Johnson et al., 1992) and from Pokrovskii and Helgeson (1995), Holland and Powell (1985); and from SOLTHERM.HP and SOLTHERM.JOH databases (same data sources, courtesy of M.H. Reed, University of Oregon). All of these are unqualified data sources.

3. Water chemistry data come from both qualified and unqualified sources and are shown in Table 3.2.1. 
4. Carbon dioxide data from Conrad (1998a, b), unqualified. Isotope data from Conrad (1998b) are qualified.

5. Hydrologic parameters and other specifications of the DST are taken from Birkholzer and Tsang (1997), which used qualified DST design parameters and hydrologic properties taken from the UZ Site-Scale Model (Bandurraga and Bodvarsson, 1997; Sonnenthal et al. 1997).

6. Kinetic data are unqualified (Hardin, 1998; Rimstidt and Barnes, 1980).

The thermodynamic database was developed as part of a previous study (Sonnenthal et al., 1998) and are considered preliminary. The pore water chemistry data are also preliminary and require additional quality assurance checks. All of the model output data are considered scoping.

Table 3.2.1. Study Data Summary and Q Status

\begin{tabular}{l|l|l}
\hline $\begin{array}{l}\text { Borehole/Data Type } \\
\text { Organization- Principal Investigator }\end{array}$ & Q Status & DTN/AN (if available) \\
\hline $\begin{array}{l}\text { XRD Mineralogy, LLNL, Roberts and } \\
\text { Viani (1997) }\end{array}$ & Y & DTN LL980106404244.050 \\
\hline $\begin{array}{l}\text { UZ Pore Water, USGS, Yang et al., } \\
\text { 1996a,b }\end{array}$ & Y & $\begin{array}{l}\text { DTN GS970108312271.001 (a) } \\
\text { NA (b) }\end{array}$ \\
\hline J-13 water, Harrar et al.(1990) & N & NA \\
\hline & $\begin{array}{l}\text { NA= Not Available; Y= qualified, } \\
\text { N= unqualified data; TBQ = To be } \\
\text { qualified }\end{array}$ \\
\hline
\end{tabular}

\subsubsection{QA Status of Codes}

TOUGHREACT (authors: Tianfu Xu and Karsten Pruess) is the code used for all numerical simulations presented in this chapter. The qualification of TOUGHREACT is currently underway and the code cannot be considered QA at this time. Nevertheless, several benchmark tests have been performed to verify the overall behavior of the geochemical reaction and transport modules of TOUGHREACT (Sonnenthal et al., 1998; Xu et al., 1998). It is our intent to incorporate the results of these tests into software qualification of TOUGHREACT for the Yucca Mountain Project.

Although EQ3/6 v.7.2b is qualified for use in the Yucca Mountain Project, neither SUPCRT92 (Johnson et al., 1992), nor the thermodynamic data in SUPCRT92 have been qualified. 


\subsection{Numerical Model and Simulations}

Coupled flow-transport-reaction simulations of the DST were performed using the numerical model TOUGHREACT (Xu et al., 1997) as described and modified by Sonnenthal et al. (1998). The objectives of this modeling effort include the following:

- Compare pore-gas $\mathrm{CO}_{2}$ partial pressures and pore-water $\mathrm{pH}$ measured in hydrology boreholes six months into the DST with calculated values-to assess the model for THC processes and to provide a means for further model adjustment and calibration.

- Provide further understanding of THC processes affecting the DST over the projected eight-year length of this test.

- Perform sensitivity studies on the effect of uncertain hydrological properties, i.e. fracture porosity.

\subsubsection{Numerical Model, Grid, and THC Boundary Conditions}

The numerical results presented in this chapter are based on the two-dimensional dual-permeability grid, thermohydrologic parameters, and boundary conditions for the base case DST simulation developed by Birkholzer and Tsang (1997). This was the same model adopted for the base case predictive report on thermo-hydrological-chemical processes for the DST (Sonnenthal et al., 1998). Further refinements of the model, parameters and heating schedule will be incorporated as these become available, are tested and refined (see Chapter 2 of this report). The grid layout is shown in Chapter 2 (Figures 2.2 and 2.3). Details on the heating schedule, thermohydrologic parameters and grid generation can be found in Section 2 of this chapter and in Birkholzer and Tsang (1997). Briefly, the base case model considers full heat output for 1 year, followed by an abrupt drop to $50 \%$ power for 3 years, then followed by a planned 4 year cooling period (no heat output).

Although the rock properties and lithologic units vary over the area of influence of the DST, they are assumed uniform for this simulation, and equivalent to the Tptpmn unit properties (Birkholzer and Tsang, 1997). For the simulations presented in this chapter, it is assumed that there is no percolation flux at the top of the model boundary for the entire period of the DST. Because the bottom boundary and all drifts are considered to have a constant pressure and temperature, they are also assumed to have a constant chemical composition.

\subsubsection{Geochemical Parameters}

The geochemical parameters used in the simulations are those employed in the base-case THC simulation DST-1a presented in Sonnenthal et al. (1998) and given below in Table 3.3.1. A starting pore-water 
composition (Table 3.3.2) was averaged from analyses derived from Yang et al. (1996a,b). Detailed discussions of these pore water compositions can be found in the latter references, and in Apps (1997); the averaging techniques can be found in Sonnenthal et al. (1998). The system is assumed to be initially homogeneous with respect to mineral proportions, pore water chemistry, and all other geochemical parameters. The initial distinction between fractures and matrix is in the small amount of calcite assumed to be in fractures, versus none in the matrix.

Table 3.3.1. Starting mineral assemblage, volume fractions in matrix $\left(f_{m}\right)$ and fractures $\left(f_{f}\right)$, and possible secondary phases considered (where volume fraction is zero). Reaction rate law parameters $k_{0}$ (rate constant) and $E_{a}$ (activation energy) and surface area $S$ are assumed the same for precipitation and dissolution, except amorphous silica for which a precipitation rate law is given below. Calcite is considered an equilibrium mineral. Primary aqueous species listed in the far right column are those considered in reactions and for transport.

\begin{tabular}{|c|c|c|c|c|c|c|}
\hline Minerals & $\underset{\text { (matrix) }}{f_{m}}$ & $\begin{array}{c}f_{f} \\
\text { (fractures) }\end{array}$ & $\begin{array}{c}k_{0} \\
\left(\mathrm{~mol} / \mathrm{m}^{2} \mathrm{~s}\right)\end{array}$ & $\begin{array}{c}E_{a} \\
(\mathrm{~kJ} / \mathrm{mol})\end{array}$ & $S\left(\mathrm{~m}^{2} / \mathrm{kgH}_{2} \mathrm{O}\right)$ & $\begin{array}{l}\text { Aqueous } \\
\text { Species }\end{array}$ \\
\hline Quartz & 0.1018 & 0.0995 & $1.2589 \mathrm{e}-14$ & 87.5 & 71.07 & $\mathrm{H}_{2} \mathrm{O}$ \\
\hline Cristobalite & 0.2292 & 0.2241 & $3.1623 \mathrm{e}-13$ & 69.08 & 71.07 & $\mathrm{H}^{+}$ \\
\hline Am. $\mathrm{SiO}_{2} *$ & 0.0 & 0.0 & $7.944 \mathrm{e}-13$ & 62.8 & 142.14 & $\mathrm{Ca}^{2+}$ \\
\hline Calcite & 0.0 & 0.02 & - & - & - & $\begin{array}{l}\mathrm{Na}^{+} \\
\mathrm{Cl}^{-} \\
\mathrm{SiO}_{2}(\mathrm{aq}) \\
\mathrm{HCO}_{3}^{-}\end{array}$ \\
\hline
\end{tabular}

- Precipitation rate law from Rimstidt and Barnes (1980): $\log k=-7.07-2598 / \mathrm{T}(\mathrm{K})$. Reactive surface area for amorphous silica set twice that of the other silica phases. Quartz and cristobalite precipitation was suppressed 
Table 3.3.2. Full pore water composition for TOUGHREACT simulations (Sonnenthal et al., 1998). A subset of these concentrations was used for the simulations, as described in the text.

\begin{tabular}{ll} 
& Average $(\mathrm{mg} / \mathrm{L})$ \\
\hline $\mathrm{Ca}$ & 27 \\
$\mathrm{Mg}$ & 5 \\
$\mathrm{Na}$ & 91 \\
$\mathrm{HCO}_{3}^{-}$ & $191\left(219^{*}\right)$ \\
$\mathrm{Cl}^{-}$ & 41 \\
$\mathrm{NO}_{3}{ }^{-}$ & 13 \\
$\mathrm{SO}_{4}{ }^{2-}$ & 40 \\
$\mathrm{SiO}_{2}$ & 60 \\
$\mathrm{Al}^{-}$ & $1 \times 10^{-6 * *}$ \\
$\mathrm{~K}^{*}$ & $4 * *$ \\
$\mathrm{pH}^{*}$ & 8.2 \\
${ }^{* *}$ Adjusted for charge balance
\end{tabular}

\subsubsection{Simulation of Thermo-Hydrological-Chemical Processes in the Drift-Scale Test}

An eight-year 2-D simulation of the DST was run using the same thermal and hydrogeologic setup as simulations presented by Sonnenthal et al. (1998). The considered chemical system consists of $\mathrm{Na}, \mathrm{Cl}, \mathrm{Si}$, $\mathrm{Ca}, \mathrm{CO}_{2}$, calcite, and silica minerals (Table 3.3.1). For simplicity, computing efficiency, and because of the current uncertainty regarding the effective reaction rates of aluminosilicate minerals (Sonnenthal et al., 1998), these phases were not considered in the present simulation.

Simulation results are presented as 2-D cross sections at time periods of six months, four years and eight years (Figures 3.3-1 through 3.3-13). Profiles of physico-chemical parameters across a wing heater for the fractured media after six months heating are plotted in Figures 3.3-14 and 3.3-15, and eight-year time histories of these parameters in the fracture and matrix media at a selected location are shown in Figures 3.3-16 through 3.3-19. Results are discussed below in the context of newly acquired gas and water analytical data as well as our current understanding of processes affecting the DST (Sonnenthal et al., 1998).

Chloride is essentially a conservative, unreactive species in the considered chemical system. Therefore, cross-section plots showing chloride concentrations (Figures 3.3-1 to 3.3-3) are useful to show the evolution of the condensation zones (concentrations decreasing below a background of approximately 
$41 \mathrm{mg} / 1$ due to steam condensation and dilution) and boiling or dryout zones (concentrations above background due to steam loss). Dryout conditions typically prevail in fractures at temperatures above $100^{\circ} \mathrm{C}$. The extent of the dryout zone, is predicted to grow from about $1 \mathrm{~m}$ from the heaters at six months to approximately $4 \mathrm{~m}$ after four years (end of heating period). Asymmetries in the temperature contours are due to the Observation Drift, which is considered as a constant temperature grid volume in the model. In the dryout zone the chloride concentrations in the pore waters (just before dryout, at a liquid saturation of $1 \times 10^{-4}$ ) only reach several thousands of $\mathrm{mg} / \mathrm{L}$, which is still less than an order of magnitude than the approximate concentration required for halite precipitation from a saline brine (Holser, 1979). Below a liquid saturation of $1 \times 10^{-4}$, TOUGHREACT no longer computes aqueous species and mineral/water reactions (for computing efficiency and current limitations on calculations of activity coefficients). At this liquid saturation the residual water composition is saved, so as to be available for reactions if rewetting takes place. During rewetting, the dilution of this residual water composition acts as if soluble salts were redissolved completely into the aqueous phase.

The condensation zone extends to about $10 \mathrm{~m}$ from the heaters at 6 months to about $20 \mathrm{~m}$ at 4 years; however, the greatest amount of condensation buildup takes place in a zone between about $70^{\circ} \mathrm{C}$ and $95^{\circ} \mathrm{C}$, where chloride concentrations decrease to a few $\mathrm{mg} / \mathrm{L}$. Below the heaters, a large region of dilution is evident where condensate drains through fractures up to about $25 \mathrm{~m}$ at 6 months (Figure 3.3-1) and about $40 \mathrm{~m}$ at 4 years (Figure 3.3-2). In this area, fracture waters are more dilute than the ambient pore waters and approximately thermally equilibrated, but they have higher chloride concentrations than the high temperature fluids in the $70^{\circ} \mathrm{C}$ to $95^{\circ} \mathrm{C}$ region. After 8 years (4 years of cooling after the 4 years of heating) some rewetting of the dryout zone fractures has occurred, thus reducing the region of high chloride concentrations somewhat (Figure 3.3-3). At that time, chloride concentrations in the condensate and drainage areas are still below background levels but have increased significantly, owing to diffusive equilibration with matrix pore waters and through transport during refluxing.

$\mathrm{CO}_{2}$ volatilization with increasing temperature generally causes the $\mathrm{pH}$ to rise, as discussed by Sonnenthal et al. (1998). The transport of $\mathrm{CO}_{2}$ away from the heaters results in a predicted $\mathrm{CO}_{2}$ halo approximately $15 \mathrm{~m}$ away from the heaters after 6 months (Figure 3.3-4), growing to about $35 \mathrm{~m}$ after four years (Figure 3.3-5) and over $40 \mathrm{~m}$ after 8 years (Figure 3.3-6). $\mathrm{CO}_{2}$ partial pressures $\left(\mathrm{P}_{\mathrm{CO} 2}\right)$ in this halo are calculated to be in the range of $\log \mathrm{P}_{\mathrm{CO} 2}=-2$ (approximately 1.5 orders of magnitude higher than background levels). Although temperatures decline in the period from 4 to 8 years, $\mathrm{CO}_{2}$ distributions are continuously modified due to gas transport out of the system and changes in liquid saturation, and therefore contours of $\mathrm{P}_{\mathrm{CO} 2}$ deviate from temperature contours at 8 years much more than during the heating cycle. Between the heaters and the $\mathrm{CO}_{2}$ halo, $\mathrm{P}_{\mathrm{CO} 2}$ is predicted to decrease below background values due to depletion by transport as well as to the precipitation of calcite. As discussed in more detail below, the modeled trend of decreasing $\mathrm{P}_{\mathrm{CO} 2}$ in the high temperature condensate region may not take place in the actual DST, depending on whether air in the Heated Drift is exchanged with air in the fractured wallrocks. In the basecase model of Birkholzer and Tsang (1997) and in Sonnenthal et al. (1998) it was assumed that the drift 
wall and bulkhead were closed to air and water. A modification of this boundary condition is presented by Birkholzer and Tsang (Chapter 2, this report) and will be incorporated in future THC simulations.

Decreasing $\mathrm{pH}$ in fracture pore waters is closely tied to the increase in $\mathrm{P}_{\mathrm{CO} 2}$ in cooler regions around the drift (Figure 3.3-7) and therefore are only plotted at six months after heating was initiated. The initial $\mathrm{pH}$ of about 8.2 decreases to around 7.8 (background value in Figure 3.3-7) after initial equilibration with calcite at the start of the simulation. After 6 months, this $\mathrm{pH}$ decreases to a minimum of 6.97 in the cooler condensate region (approximately $25^{\circ} \mathrm{C}$ to $40^{\circ} \mathrm{C}$ ) where $\mathrm{P}_{\mathrm{CO} 2}$ has increased due to gas transport. At a temperature of about $36^{\circ} \mathrm{C}$ (similar to the temperature of one of the collected water samples, Section 3.1.1) and in the region below the wing heater (approximate vicinity of Borehole 60, Interval 2) the model gives a range of $\mathrm{pH}$ values from about 7.0 to 7.5 , compared to 7.5 in the sample. Another water sample was collected at a temperature of about $82^{\circ} \mathrm{C}$ with a pH of 7.7 (Borehole 60, Interval 3). The model gives a range of $\mathrm{pH}$ values from about 8.2 to 8.4 at the location where that sample was taken (Figure 3.3-7). This calculated higher $\mathrm{pH}$ range is related to degassing of $\mathrm{CO}_{2}$ in the model. In reality, $\mathrm{P}_{\mathrm{CO} 2}$ may be buffered by drift air, which would explain the lower measured $\mathrm{pH}$.

Calcite generally dissolves in fractures in the outer edges of the condensation zone, where $\mathrm{pH}$ values are lowest and waters are most dilute (Figures. 3.3-8 to 3.3-10). Closer to the heaters in boiling areas and dryout areas, calcite precipitates. However, as the dryout front advances, precipitation takes place in areas where calcite previously dissolved, such that the total volume change may still show apparent dissolution or no net change in calcite abundance. The pattern of initial dissolution followed by precipitation should be apparent in samples through morphology and surface textures of preexisting calcite and the spatial distribution of newly precipitated calcite.

As examined in more detail by Sonnenthal et al. (1998), cristobalite and, to a lesser extent, quartz, are predicted to dissolve in fractures in the boiling area adjacent to the dryout zone (Figures 3.3-11 to 3.3-12). Cristobalite dissolution is strongest outside the ends of the wing heaters where consistent high temperatures and high condensation rates result in a locally higher dissolution rate (Figure 3.3-12).

Dryout forces amorphous silica to precipitate (the only silica phase allowed to precipitate in the model), although in our model the rate of dryout relative to amorphous silica rates of precipitation is so high that substantial silica remains in solution in the residual fluid. In reality, some increase in the rate of precipitation might occur or a metastable silica gel could form. The distribution of precipitated amorphous silica in fractures after eight years is shown in Figure 3.3-13. It occurs as a band around the Heated Drift, but is volumetrically insignificant. The calculated precipitated mineral amounts are very small and cannot account for any significant porosity decrease over the 8 year period of the DST. However, over longer periods of time the porosity decrease may become significant.

Profiles of the model results across a wing heater were drawn to gain further insight in the simulations and their consistency with observed data (Figures 3.3-14 to 3.3-19). These profiles were plotted at a 
simulation time six months after initiation of heating to allow comparison with DST data collected in June 1998 (approximately six months after the start of the test). The profiles were selected between seven and eight meters away from the Heated Drift. This location was chosen to cut through the projected locations of the third packed intervals in Boreholes 57 to 61,74 to 78,185 and 186. $\mathrm{CO}_{2}$ and $\mathrm{pH}$ data available from these locations (Section 3.1.1) were then plotted on the profiles for comparison with the model results. These data were plotted at a vertical distance (from the wing heater) approximately equal to the intersection of the profile with the boreholes' projections onto the simulated 2-D cross-section. Only data from the fracture medium are shown, as most gas and water samples collected should represent mostly gas and water in the fractures.

Measured $\mathrm{P}_{\mathrm{CO} 2}$ in borehole intervals 78-3, 59-3, 76-3 agree relatively well with the calculated data (Figure 3.3-14b). $\mathrm{P}_{\mathrm{CO} 2}$ values observed at other locations are less consistent with simulated results, although measured and calculated temperatures at the sampling locations are generally consistent (Figure 3.3.-14a). $\mathrm{P}_{\mathrm{CO} 2}$ during the DST is most likely affected by air in the Heated Drift and possibly also by air injected for permeability tests. These effects have not been included in the current simulations and may explain, at least in part, the difference in calculated versus observed $\mathrm{P}_{\mathrm{CO} 2}$. Air contamination $\left(\log \mathrm{P}_{\mathrm{CO} 2}\right.$ near -3.5$)$ would be expected to prevent $\mathrm{CO}_{2}$ depletion around the Heated Drift and possibly also to dilute higher $\mathrm{P}_{\mathrm{CO} 2}$ caused by $\mathrm{CO}_{2}$ transport away from the drift.

The $\mathrm{pH}$ measured in a water sample from borehole Interval 60-3 (7.7 at 82.1 C) is significantly lower than the calculated $\mathrm{pH}$ near 8.5 at this projected location (Figure $3.3-14 \mathrm{~b}$ ), as discussed earlier. The observed temperature at this point is nearly $15^{\circ} \mathrm{C}$ lower than the calculated value (Figure 3.3.-14a), which could in part explain the $\mathrm{pH}$ difference. Temperature differences between calculated and measured may be due to the proximity to the wing heaters, that are, in reality, discrete heat sources, and not a smeared heat source as they are modeled. The $\mathrm{pH}$ was also measured in a sample from borehole Interval $60-2\left(7.5\right.$ at $\left.36.2^{\circ} \mathrm{C}\right)$. This interval does not intersect the selected profile, and therefore, this $\mathrm{pH}$ measurement is not shown on Figure 3.3-14. It shows better agreement with calculated values as mentioned previously in the discussion of Figure 3.3-7.

Profiles of fracture liquid saturation, aqueous concentrations, and changes in mineral volume fractions (Figures 3.3-14c, 3.3-15a, and 3.3-15b) show trends similar to other simulations described by Sonnenthal et al. (1998). The computed water saturation in fractures below the wing heater is higher than above it because more drainage occurs below the heaters (see also Section 2). Concentrations of aqueous species decrease towards the heater as the result of dilution by steam condensation; closer to the heaters, $\mathrm{Na}, \mathrm{Cl}$, and Si concentrations stop decreasing and start increasing as evaporative loss through boiling exceeds the amount of dilution due to steam condensation. Also, Si concentrations increase in the condensation zone closer to the heaters (due to the increased dissolution rate of cristobalite at higher temperatures), resulting in a competition between the dissolution rate and the rate of dilution owing to condensation. The rate of amorphous silica precipitation is slower than the dryout rate, causing the silica concentration in remaining water at the margin of the dryout zone to steeply increase. In contrast, calcite precipitates at the margin of 
the dryout zone, depleting calcium in solution. Eventually, dryout will force precipitation of all aqueous species. This is not seen in these simulations because, as mentioned earlier, the system is not allowed to dry below a saturation of $1 \times 10^{-4}$ for computing efficiency and activity coefficient considerations.

Time-series plots (Figures 3.3-16 through 3.3-19) were generated for a point located within the profiles discussed above. This point was selected at a location where complete dryout never occurs during the eight-year test, but close enough to the heat source such that condensation and boiling can be observed. This point is located approximately $5 \mathrm{~m}$ above the wing heater and 7 meters away from the heater. Simulated results for fractures and matrix are discussed below.

The temperatures in the fracture and matrix are essentially identical (Figure 3.3-16a). After approximately one year, the temperature remains nearly constant near $100^{\circ} \mathrm{C}$ until cool-down at four years, as the system experiences continued boiling and condensation effects. During this period, the water saturation decreases steadily in fractures and to a lesser extent in the matrix (Figure 3.3-16b,c).

Calculated $\mathrm{pH}$ and $\mathrm{P}_{\mathrm{CO} 2}$ (Figure 3.3-17a) show different trends in the fracture than in the matrix. In fractures, $\mathrm{pH}$ and $\mathrm{P}_{\mathrm{CO} 2}$ values show a sharp reversal in trends after the first few months of heating. This effect is interpreted to represent expansion of the $\mathrm{CO}_{2}$ halo discussed earlier. Both $\mathrm{pH}$ and $\mathrm{P}_{\mathrm{CO} 2}$ then remain relatively constant in the condensation zone, as $\mathrm{CO}_{2}$ influx (from volatilization in the matrix and other areas in fractures) is balanced by depletion through boiling and calcite precipitation (Figure 3.317b). After heaters are turned off (4 years), condensation stops, but the system is still hot and $\mathrm{CO}_{2}$ continues to volatilize (this time not balanced by an influx from other boiling areas), which results in a further $\mathrm{pH}$ increase (to a maximum near 9) and a corresponding $\mathrm{P}_{\mathrm{CO} 2}$ decrease. In the matrix, however, the $\mathrm{pH}$ displays a more typical trend of decreasing with temperature increase without boiling for the first year of heating, followed by a steady decrease due to boiling and continued $\mathrm{CO}_{2}$ loss in fractures (Figure 3.317b).

\subsubsection{Simulations to Investigate Sensitivity of THC Processes to Initial Fracture Porosity}

Recent studies (Tsang and Freifeld, 1998) have indicated that fracture porosity at the DST site (porosity of combined lithophysae and fracture) may be much greater than the mean fracture porosity for the Tptpmn unit estimated for the Site-Scale Unsaturated Zone Flow Model (Sonnenthal et al., 1997) and which were initially modified for use in the base case TH prediction by Birkholzer and Tsang (1997). However, detailed geologic studies in the ESF and in the DST boreholes have shown the presence of up to a few percent lithophysae in a subzone of the Tptpmn unit (D. Buesch, presentation at Fifth Quarterly Thermal Test Workshop, June 1998) which most likely accounts for the much higher porosities calculated from the gas tracer tests. Although lithophysae are dissimilar to both fracture geometries and to typical matrix pore geometries, they could be considered to act as part of the fracture porosity, even though their hydrological properties may be very different (Tsang and Freifeld, 1998). Because of the strong relation of fracture porosity to transport velocities, a sensitivity study was performed on the effect of a modified 
fracture porosity on the thermo-hydrologic regime and its coupling to reaction-transport phenomena for the DST. Three cases are compared: 1) the base case fracture porosity of $0.00263,2$ ) approximately 5 times higher fracture porosity, and 3) approximately 10 times higher fracture porosity.

The simulations for this sensitivity analysis are less complex chemically than that described in the previous section, as they include only the silica phases (quartz, cristobalite, and amorphous silica), $\mathrm{Na}, \mathrm{Cl}$, and $\mathrm{H}$. All thermohydrological properties are kept the same as that in the previous simulation, except for the fracture porosity modifications.

Figures 3.3-20 to 3.3-23 show vertical profiles of temperature, liquid saturation, chloride and silica concentrations in fractures through a wing heater approximately $10 \mathrm{~m}$ to the right of the drift center at a period of 6 months after the initiation of heating. Temperatures are affected only slightly (Figure 3.3-20), with the temperatures in the dryout region highest for the higher fracture porosity simulation, because of more rapid dryout, and slightly lower in the region below $100^{\circ} \mathrm{C}$. Liquid saturations in fractures (Figure 3.3-21) in the drainage region below the heaters are much lower in the high porosity simulations. Saturations are also lower in the other areas of condensation and in the boiling region as it nears the dryout zone.

These effects on liquid saturation distributions are clearly reflected in the chloride (Figure 3.3-22) and aqueous silica concentrations (Figure 3.3-23). Chloride concentrations are higher in the higher porosity simulations in the boiling zone adjacent to the final dryout zone because of the more rapid approach to dryout. They are also higher in the drainage region because of the lower fracture saturations in the higher porosity simulations. Silica concentrations are affected more strongly than chloride because of the strong relation of reaction rates to temperature and silica concentration which are in turn related to the extent of dilution and evaporation. Overall, the chemical trends for the 3 cases are similar, and thus do not change the general conclusions found in the simulations discussed in Section 3.3. or in Sonnenthal et al. (1998).

\subsection{Geochemical Model Refinement}

The current TOUGHREACT code used to simulate both the DST and SHT represents a major advance over previous reactive chemical transport codes. It includes the dual porosity continuum model incorporated in TOUGH2, which is capable of simulating non isothermal processes in saturated and unsaturated media in three dimensions. It also incorporates both heterogeneous equilibrium chemistry and the kinetics of precipitation and dissolution of solid reactant and product minerals. Furthermore, the thermodynamic data of many of the reactant and product minerals have been refined (Sonnenthal et al., 1998), using the most recent information available in the published literature. Thus, the initial simulations of the THC environment surrounding the DST (Sonnenthal et al., 1998) will be more representative of evolving near-field conditions than any prior study. 
Despite the progress made to date, several aspects concerning the geochemical modeling component of the TOUGHREACT code will require attention before comprehensive field data from the DST or natural system analogues can be used to fully validate the model. Somé of these aspects involve:

- Introduction of more accurate and internally consistent thermodynamic data for participating minerals

- Incorporation of the thermochemical properties of additional potentially important minerals as a result of initial simulations or new field observations, e.g., heulandite, mordenite, or stellerite

- Incorporation of solid solutions, and review of the thermodynamic properties of several aqueous species that have been found to be very important to current simulations, but whose data is suspect or poorly characterized.

However, we will not address these subjects here, although work is presently ongoing to address them. Instead, we will focus on those aspects concerning the kinetics of heterogeneous reactions involving the dissolution and precipitation of unstable and metastable phases under conditions departing from thermodynamic equilibrium. In particular, we wish to address the phenomenon commonly observed in altering volcanic rocks, where less stable minerals precipitate in preference to those phases that are most stable, commonly referred to as the Ostwald Rule of Stages, or the Ostwald Step Rule.

W. Ostwald studied reaction progress under conditions far from equilibrium over 100 years ago (Ostwald, 1897). He described the phenomenon characterizing his rule (as cited in Schmeltzer et al., 1998), thus:

[I]n the course of transformation of an unstable (or metastable) state into a stable one the system does not go directly to the most stable conformation (corresponding to the modification with the lowest free energy) but prefers to reach intermediate stages (corresponding to other metastable modifications) having the closest free energy to the initial state.

Although Ostwald was referring to heterogeneous systems far from chemical equilibrium, and under conditions observable in the laboratory, the same phenomenon has been observed extensively in natural geochemical systems, particularly under hydrothermal or low temperature, conditions typical of the earth's surface. Indeed, so widespread is the phenomenon, that few, if any, geochemical parageneses involving the subcritical aqueous phase can be described without invoking the Ostwald Rule of Stages.

Morse and Casey (1988) cite carbonates, silica, clay minerals, iron and manganese oxides, iron sulfides, and zeolites as sedimentary minerals where the Ostwald Rule of Stages must be invoked to account for the occurrence of metastable phase assemblages. With the possible exception of iron sulfides, all of these mineral classes are present in the volcaniclastic sequence at Yucca Mountain (YM). Therefore, 
simulations involving natural or anthopogenically enhanced diagenetic processes at YM must also be consistent with field observations describable by the Ostwald Rule.

Geochemists have long been familiar with the Ostwald Rule, but, with one exception (Steefel and Van Cappellen, 1990), have not attempted to incorporate the underlying chemical principles justifying the Ostwald Rule in chemical simulations involving reaction progress. Instead, they have adopted empirical fixes, involving the arbitrary suppression of the thermodynamically most stable phases, e.g., by suppressing the precipitation of quartz in favor of $\alpha$-cristobalite, or by making precipitation "irreversible" by prohibiting the re-dissolution of minerals already precipitated (Helgeson, 1968; Helgeson et al., 1969). Although these fixes commonly depart far from reality, they were rarely, if ever challenged, because geochemical simulations have been rarely tested rigorously against field observations.

Yet another closely related issue is the contribution of interfacial free energy to the total free energy of a geochemical system. The interfacial free energy contribution becomes vanishingly small for crystal sizes in excess of 1 micrometer, and is therefore irrelevant when discrete crystals of a rock, soil, or sediment are readily seen under the microscope. But the alteration of devitrified tuff or volcanic glass entails both the dissolution of finely crystalline products of diagenesis and heterogeneous nucleation, and precipitation of new phases. The latter phases are commonly microcrystalline or amorphous, with substantial contributions of surface free energy to the total Gibbs free energy of the phase. Such contributions must be taken into account when modeling the chemical evolution of a system such as that of the near field of the planned YM radioactive waste repository, because they can affect calculated aqueous species concentrations by a factor of at least 10. Furthermore, by a process known as Ostwald Ripening, larger crystallites, possessing a lesser surface free-energy contribution, and being therefore more stable, will grow at the expense of smaller crystals, leading to a decreased seed crystal size distribution, and the growth of progressively fewer crystals. This process leads to a diminution of the reactive specific surface area, which decreases the rate of crystal growth.

Crystal growth can take place through several mechanisms, including epitaxial overgrowth, growth on a screw dislocation, and edge or step growth. The number of growth sites can increase or decrease with time, thereby affecting the growth rate as a function of the geometric surface area of the mineral in question. Empirical crystal growth laws are commonly determined through laboratory experiment, where the number of growth sites is far greater than occurs in the natural environment, because of defects introduced during sample preparation. Hence, any attempt to simulate diagenetic processes requires arbitrary adjustments to the geometric surface area to achieve a temporal match (Bruton, 1985: White and Peterson, 1989). These adjustments can be by a factor as large as 1000 . Finally, foreign ionic or molecular species can adsorb at the growth sites of a crystal, and inhibit further growth. This is commonly observed in soils where the growth of calcite is inhibited by traces (approximately $1 \mathrm{mg} / \mathrm{L}$ ) of dissolved organic carbon. A reduction in crystal growth by a factor of at least 100 is observed at $25^{\circ} \mathrm{C}$ (Lebron and Suarez, 1998), leading to saturation states, $\Omega$, of 3-5 times. 
In summary, the issues requiring quantification and development of a realistic treatment in THC models are:

- A process incorporating the Ostwald Rule of Stages, thereby allowing the model to select automatically that phase (or those phases) that should precipitate from solution under specific conditions, rather than forcing the model to precipitate an arbitrarily selected phase. This feature is particularly important when two or more phases with differing thermodynamic stabilities may be precipitating simultaneously.

- A model that incorporates nucleation, growth, and Ostwald Ripening. The model should allow for varying rates of precipitation, and the progressive reduction of growth sites with time.

- Provision for kinetic hindrance of precipitation or dissolution of phases due to the adsorption of "foreign" species from solution.

In the following sections, we illustrate with examples pertinent to YM conditions, mineralogical sequences that obey the Ostwald rule of stages. Then we summarize attempts reported in the literature to interpret the Ostwald Rule of Stages and Ostwald Ripening from a phenomenological viewpoint. Finally, we discuss the implications of this work in terms of future modeling incorporating the described phenomena.

\subsubsection{Examples Illustrating the Ostwald Rule of Stages in Relation to Groundwater and Mineralogy at YM}

We start with a distribution of species calculation of $\mathrm{J}-13$ well water. The water recovered from the J-13 well are probably the most thoroughly studied of any water at the Nevada Test Site. (Harrar et al., 1990). Numerous chemical analyses have been made on samples collected from this well over a period of years. Although uncertainties remain concerning certain components, (e.g., $\mathrm{pH}$ and $\mathrm{Al}$ ) of its chemical composition, and the quality and rigor of collection and analytical procedures (e.g. see Apps, 1997), it is generally agreed that further characterization of this well water is no longer an issue of high priority. As a representative example, the chemical analysis conducted by Canepa (1987; cited in Harrar et al., 1990) was selected, and augmented with analyses for Al, B and Li from Daniels (1981) and other analysts also cited in Harrar et al. (1990). A comparison of these analyses in Table 3.4.1a shows that most reported species are essentially identical. Table 3.4 .1b summarizes selected calculated saturation indices (SI = $\log \mathrm{Q} / \mathrm{K}$ at $31^{\circ} \mathrm{C}$, where $\mathrm{Q}$ is the ion activity product, and $\mathrm{K}$ is the solubility product) using the EQ3 v7.2b code together with its associated thermodynamic database, which is a later version than that described by Wolery (1992). 
Table 3.4.1a. Composition of $\mathrm{J}-13$ well water used in calculation of aqueous species distribution.

\begin{tabular}{llll}
\hline \multicolumn{2}{l}{ Concentration, $\mathrm{mg} / \mathrm{L}$} & & \\
\hline & Daniels & Canepa & EQ3.v7.2b \\
& LANL, 9/1981 & LANL, 1987 & Input \\
\hline $\mathrm{Li}$ & 0.010 & 0.040 & 0.040 \\
$\mathrm{Na}$ & 45 & 45 & 45 \\
$\mathrm{~K}$ & 5.5 & 4.5 & 4.5 \\
$\mathrm{Mg}$ & 1.73 & 2.0 & 2.0 \\
$\mathrm{Ca}$ & 11.5 & 13.0 & 13.0 \\
$\mathrm{Sr}$ & 0.040 & 0.040 & 0.040 \\
$\mathrm{Mn}$ & 0.011 & - & 0.011 \\
$\mathrm{Fe}$ & 0.044 & $<0.010$ & 0.010 \\
$\mathrm{~B}$ & - & - & $0.82^{*}$ \\
$\mathrm{Al}$ & 0.026 & $<0.10$ & 0.026 \\
$\mathrm{Si}$ & 30.0 & 30.0 & $64.3 \dagger$ \\
$\mathrm{F}^{-}$ & 2.1 & 2.1 & 2.1 \\
$\mathrm{Cl}^{-}$ & 6.4 & 7.1 & 7.1 \\
$\mathrm{NO}_{3}^{-}$ & 10.1 & 8.9 & 8.9 \\
$\mathrm{SO}_{4}^{-}$ & 18.0 & 18.7 & 18.7 \\
$\mathrm{PO}_{4}^{-}$ & 0.10 & - & 0.1 \\
$\mathrm{Alkalinity}^{-}$ & 143 & 143 & 143 \\
a HCO $_{3}^{-}$ & & & $8.2^{+}$ \\
$\mathrm{pH}^{-}$ & 8.3 & 8.2 & \\
\hline
\end{tabular}

* as $\mathrm{B}(\mathrm{OH})_{3}(\mathrm{aq})$, calculated from the mean value of $\mathrm{B}$ for 6 analyses

$\dagger$ as $\mathrm{SiO}_{2}(\mathrm{aq})$

+ at $25^{\circ} \mathrm{C}$ 
Yucca Mountain Drift Scale Test Progress Report

Table 3.4.1b. Saturation indices and saturation states of selected minerals in $\mathrm{J}-13$ well water at $31^{\circ} \mathrm{C}$, using EQ3 v7.2b.

\begin{tabular}{lllll}
\hline Mineral & $\mathrm{Al}=0.026 \mathrm{mg} / \mathrm{L}$ & & $\mathrm{Al}=0.008 \mathrm{mg} / \mathrm{L}$ & \\
\cline { 2 - 5 } & Saturation Index & Saturation State & Saturation Index & Saturation State \\
& Log Q/K & $\Omega$ & Log $\mathrm{Q} / \mathrm{K}$ & $\Omega$ \\
\hline albite high* & 0.22 & 1.7 & 0.05 & 1.1 \\
albite low* & 0.65 & 4.5 & 0.47 & 3.0 \\
analcime* & 0.49 & 3.1 & 0.24 & 1.7 \\
calcite & 0.08 & 1.2 & 0.08 & 1.2 \\
chalcedony & 0.64 & 4.4 & 0.64 & 4.4 \\
cristobalite (alpha) & 0.37 & 2.3 & 0.37 & 2.9 \\
Fe(OH) & 0.09 & 1.2 & 0.09 & 1.2 \\
gibbsite & 0.67 & 4.6 & 0.16 & 1.4 \\
goethite & 4.95 & 89,000 & 4.95 & 89,000 \\
illite* & 1.49 & 31 & 1.15 & 14 \\
kaolinite* & 1.95 & 89 & 1.43 & 27 \\
K-feldspar & 1.20 & 17 & 1.05 & 11 \\
montmorillonite* & 1.37 & 23 & 1.15 & 14 \\
sanidine high* & 0.83 & 6.8 & 0.66 & 4.6 \\
sepiolite* & 0.07 & 1.2 & 0.07 & 1.2 \\
\hline pH & 8.13 & & 8.13 & \\
log P & & -2.96 & \\
Change imbalance (\%) & -10.7 & -10.7 & \\
\hline \hline
\end{tabular}

* Stoichiometry normalized to unit $\mathrm{SiO}_{2}$

$\mathrm{J}-13$ penetrates a sequence of vitroclastic ash-fall unwelded and welded ash-fall tuffs ranging in age from the early Tertiary through the Miocene (Harrar et al., 1990). These materials readily react with water to form a sequence of mineral assemblages characterized by clays, zeolites and eventually feldspars and quartz (Smyth, 1982). The provenance of waters withdrawn from J-13 is not certain, as many million gallons have been pumped from the well since 1963. However, the primary production zone is believed to be the Topopah Spring member. Carlos (1989) has studied the fracture mineralogy from drill core recovered from J-13 bore hole, and identified smectite, clinoptilolite, quartz, opal-CT, glass, "alkali feldspar" and a trace of calcite. This mineralogy suggests the production zone falls within alteration zones I and II of the classification by Ijima (1980). If J-13 well water were in thermodynamic equilibrium with respect to these silicates at the formation temperature of $31^{\circ} \mathrm{C}$, its composition would differ from that observed. Not only is the water supersaturated with respect to secondary minerals observed in this member, it is even supersaturated with respect to gibbsite and kaolinite, minerals that would not be expected to form in the alkaline geochemical environment characteristic of the production zone. Furthermore, it is also supersaturated with respect to some of the primary minerals of the devitrified tuffs, such as high albite, sanidine and alpha-cristobalite. Given the apparent age of J-13 well water, it is clear that the composition of the water is determined, not by equilibrium thermodynamics, but by kinetic processes that are far from chemical equilibrium, and that might take many thousands if not 
millions of years to achieve equilibrium. This conclusion holds, even when taking into consideration uncertainties in the chemical analyses of J-13 water, complexation in the aqueous phase, and the thermodynamic properties of the participating minerals. For example, Table $3.4 .1 \mathrm{~b}$ also includes the calculated saturation indices and saturation states based on an $\mathrm{Al}$ concentration set at the lowest value analyzed, $0.008 \mathrm{mg} / \mathrm{L}$.

The lack of thermodynamic equilibrium between groundwaters and secondary minerals of the host rock is well known, and leads to the conclusion that primary rock alteration follows a complex path, which includes metastable or unstable reaction intermediates. In a classic paper, Paces (1978), without alluding to the Ostwald Rule of Stages, laid out a kinetic scheme in which it was presumed that rock alteration by groundwaters proceeded through a series of phases of intermediate stability, as represented pictorially by Figure 3.4-1, taken from his paper.

This figure illustrates Paces' concept that a metastable hydrated aluminosilicate of variable composition forms through the alteration of feldspars in granites and gneisses. This phase equilibrates reversibly with the groundwater, thus:

$$
\left[\mathrm{Al}(\mathrm{OH})_{3}\right]_{(1-\mathrm{x})}\left[\mathrm{SiO}_{2}\right]_{\mathrm{x}}+(3-3 \mathrm{x}) \mathrm{H}^{+}=(1-\mathrm{x}) \mathrm{Al}^{3+}+\mathrm{xH}_{4} \mathrm{SiO}_{4}+(3-5 \mathrm{x}) \mathrm{H}_{2} \mathrm{O}
$$

for which the ion activity product is:

$$
\mathrm{Q}_{\mathrm{as}}=\frac{\mathrm{a}^{(1-\mathrm{x})}{ }_{\mathrm{Al}+{ }^{+} \mathrm{a}^{\mathrm{x}}{ }_{\mathrm{HSiO4}}}}{\mathrm{a}^{(3-3 \mathrm{x})}{ }_{\mathrm{H}+}}
$$

Using evidence reported in the literature, Paces concluded that the composition of the phase was determined by an uncharged surface at the $\mathrm{pH}$ of the coexisting aqueous phase, i.e. the point of zero charge (PZC). The PZC of the end member hydrous alumina $(x=0)$ is at $\mathrm{pH}=9.2$, and that of the end member silica $(x=1)$ is at $\mathrm{pH}=1.8$. A linear correlation between the end members yields:

$$
\mathrm{x}=1.24-0.135 \mathrm{pH}
$$

By plotting $\log \mathrm{Q}_{\text {as }}$ versus $\mathrm{pH}$, from field and laboratory experimental data, Paces obtained a straight-line correlation plot, that agreed well with the above equation, as is shown in Figure 3.4-2, taken from Paces. The position of $\mathrm{J}-13$ well water, plotted on this figure, and marked by a box, indicates that $\mathrm{J}-13$ water conforms closely to other data, despite a somewhat different host rock environment.

Although Paces' analysis and interpretation is persuasive, and is consistent with experimental observations of an analogous hydrated calcium phosphate system (Feenstra and De Bruyn, 1981), there appears to be no published account confirming the actual existence of this metastable phase in nature. 
Further evidence for the presence of metastable phases in altering vitroclastic rocks at YM and vicinity is evident from mineralogical studies. The occurrence of opal-A, and opal-CT in fractures (Carlos, 1989; Carlos et al., 1991; Vaniman, 1994; Carlos et al., 1995) and matrix (Bish and Vaniman, 1985; Chipera and Bish, 1988; Duffy, 1993: Carey et al., 1997) as products of glass alteration and possibly of devitrified tuff is evidence of metastability in the subsystem $\mathrm{SiO}_{2}-\mathrm{H}_{2} \mathrm{O}$. Metastability in this system is of widespread occurrence (Kastner, 1979; Williams et al., 1985; Barrer, 1982; Parks, 1990; Chang and Yortsos, 1994), and is not restricted to the alteration of volcanic glasses or extrusive rocks in general. The low temperature silica polymorphs follow the sequence opal-A - opal-CT - chalcedony (a microcrystalline form of quartz) - quartz (the stable end product) at near surface ambient temperatures. The progressive alteration is manifested by changes in the x-ray diffraction pattern as illustrated in Figure 3.4-3 from Williams et al. (1985), although SEM and TEM imaging permits examination of morphological changes (Siffert, 1962; Tarshis, 1982).

The rates of silica polymorph conversion at near-earth-surface temperatures are extremely slow. Kastner (1979) has estimated from sub-marine sediments, that the opal-CT formation with time ( $t$ ) and temperature $(\mathrm{T})$ can be correlated:

where $t$ is in millions of years.

$$
t=80-2 T+0.01 T^{2}
$$

Because of the slow rate of change in the conversion of silica from one polymorph to another at near earth-surface temperatures, it is possible that the silica activity in solution may be controlled by the silica polymorphs, thereby stabilizing other kinetically favored metastable phases such as the clays or zeolites. However, both field evidence and model simulations are presently inconclusive on this point.

Elevated temperatures greatly accelerate silica polymorph transformations, but the Ostwald rule of stages still prevails. Barrer (1982) illustrates in Figure 3.4-14 from his book the progressive conversion of silica polymorphs observed by Siffert and Wey (1967) in a $3 \% \mathrm{KOH}$ solution at $300^{\circ} \mathrm{C}$. The sequence observed was amorphous silica - cristobalite - keatite - (cristobalite- $\alpha$ ) - quartz, and the time frame for conversion was only 30 hours (Figure 3.1-4). Both temperature and composition of the aqueous phase, as well as the initial degree of supersaturation, influence the silica polymorph sequence.

Zeolite parageneses commonly provide evidence of adherence to the Ostwald Rule of Stages (Dibble and Tiller, 1981; Barrer, 1982; van Santen, 1984; Morse and Casey, 1988), and is plainly evident in the altered vitroclastic tuffs in the region around YM. Smyth (1982) noted the following zeolite sequence with depth at YM:

$$
\text { (clinoptilolite }(+ \text { mordenite })+\text { opal-CT) } \Rightarrow(\text { analcime }+ \text { quartz }) \Rightarrow(\text { low albite }+ \text { quartz) }
$$


Analysis of this sequence in terms of the Ostwald rule of stages is complicated, because the complex chemistry of clinoptilolite in natural systems precludes analysis within a simple degenerate component system. However, Apps (1970) and Helgeson et al. (1978) have shown that the assemblage, analcime + quartz, is unstable with respect to low albite at all subsurface temperatures and pressures. Furthermore, the assemblage, clinoptilolite is stabilized by the presence of opal-CT, which is unstable with respect to quartz. The conversion of the assemblage (clinoptilolite (+ mordenite) + opal-CT) to (low albite + quartz) progresses very slowly, even at the increased temperatures at which low albite makes its appearance $\left(60^{\circ} \mathrm{C}\right)$ within the YM stratigraphy. The time frame is of the order of millions of years, in conformity with independent reasoning by Dibble and Tiller (1981b).

Barrer (1982) illustrates successive phase transformations in an analogous synthetic system at $175^{\circ} \mathrm{C}$, (here reproduced as Figure 3.4-5). Here again, the elevated temperature, and different composition of the starting solution, have a drastic effect on the kinetics of reaction.

\subsubsection{Theoretical Interpretation of the Ostwald Rule of Stages}

Ever since Ostwald stated his Rule of Stages in 1897, attempts have been made to derive a theoretical basis for the rule. Now, even after 100 years, an undisputed theoretical basis for the rule has not been formulated successfully, even though field and laboratory observations supporting the rule are now too numerous to mention. A general consensus is that the rule can be explained through an understanding of nucleation theory and reaction kinetics. However, there is no rigorous basis for the rule in fact, i.e., in principle, it is possible for the rule to be violated, and occasional exceptions to the rule have been cited.

van Santen (1984, 1988), and Casey (1988) have attempted to find a basis for the rule in irreversible thermodynamics, which maintains that the preferred path in achieving a minimum Gibbs free energy is that in which the rate of entropy production is minimized. This can be accomplished through an increase in the number of intermediate steps, proceeding closest to conditions of irreversibility. These conditions might be most closely approached in the natural environment, where free energy differences between stages can be small (e.g., see Apps et al., 1989) regarding the relative stabilities of aluminum hydroxide polymorphs. However, such low energy systems, while potentially behaving in conformity with the Ostwald rule, were not exactly what Ostwald had in mind.

In natural systems, such as that pertaining to $\mathrm{YM}$ and vicinity, manifestations of the Ostwald rule, may in fact contain components both of kinetics, irreversible thermodynamics, and equilibrium thermodynamics. (See, for example, Duffy, 1993). Because quantitative evaluations of alteration rates in complex natural systems have hardly ever been made, it is not possible at this time to comment further on the applicability of each approach, and whether or not they can be reconciled, particularly when the complexity of the problem is fully appreciated. 
In the authors' view, the strongest argument for preferring a kinetic treatment for the Ostwald rule, is evidence for the simultaneous growth of two or more phases of the same composition. Experimental results taken from Barrer (1982), and reproduced in this chapter, provide substantiation, although further examples are needed to lend credibility to this position.

In what follows, we outline briefly, some of the salient features of the kinetic approach.

\subsubsection{A Kinetic Basis for the Ostwald Rule}

Stranski and Totomanow (1933) first laid down the kinetic basis for the Ostwald rule. This was subsequently developed further through a more precise formulation of classical nucleation theory and the effects of heterogeneous nucleation (Gutzow and Toschev, 1968; Dunning, 1969; Gutzow and Avramov, 1974; Steefel and Van Cappellen, 1990), and to account for different mechanisms of crystal growth (Gilmer and Bennema, 1972). Although the derivation of the kinetic theory supporting the Ostwald rule is complex, it has been presented in the literature in various forms on several occasions (Barrer, 1982; Steefel and Van Cappellen, 1990; Chang and Yortsos, 1994; Nordeng and Sibley, 1994; Schmeltzer et al., 1998). In the following paragraphs, we present a simplified summary, freely drawn from the works of Steefel and Van Cappellen (1990), Nordeng and Sibley (1994), and Schmeltzer et al. (1998), but within the context of heterogeneous nucleation of phases from an aqueous phase. This context reflects the natural environment better than the assumption of homogeneous nucleation, which is difficult to confirm by direct observation, and which is extremely unlikely in nature, where abundant substrates exist to serve as heterogeneous nucleation sites.

The theoretical development starts with conceptualization of heterogeneous nucleation of a new phase from a supersaturated solution. It is assumed that a mineral cluster must reach a certain critical radius on a solid substrate, before it can grow spontaneously. This is achieved when the bulk free energy of the phase, and defined by $-n k_{\mathrm{b}} T \ln \Omega$, is equal to or greater than the surface free energy, $\delta G_{\mathrm{ex}}(n)$ of the surface of the nucleus:

$$
\delta G[n]=-n k_{\mathrm{b}} T \ln \Omega+\delta G_{\mathrm{ex}}(n)
$$

where $k_{\mathrm{b}}$ is Boltzmann's constant, and $n$ is the number of unit cells in the cluster.

Let $r^{*}$ be the critical radius of a hemispherical nucleus on a planar substrate, when $\delta G[n]=0$. The critical radius is defined thus:

$$
r^{*}=v \sigma\left(k_{\mathrm{b}} T \ln \Omega\right)
$$

where $v$ is the molar volume, and $\sigma$ is the surface free energy coefficient. The activation energy required to achieve a critical nucleus is: 


$$
\delta G^{*}=\pi 0^{2} \sigma^{3} / 3\left(k_{\mathrm{b}} T \ln \Omega\right)^{2}
$$

The number of heterogeneous nuclei, $N^{*}$, produced is related to $\delta G^{*}$ through:

$$
N^{*}=N \exp \left(-\delta G^{*} / k_{\mathrm{b}} T\right)
$$

where $N$ is the average density of mineral units in the absorption layer surrounding the substrate. It is clear that the number of variables implicit in the above equation can lead nucleation of different phases for different initial conditions. For phases with equivalent $v$ and $\sigma$, the most stable phase will precipitate. However, when differences in either $v$ or $\sigma$ are large, the phase with the simplest stoichiometry, or the smaller surface free energy, is favored. It is also intuitively obvious that the nucleation will favor entities with a low degree of order and simple stoichiometry. The evidence to support a correlation between surface free energy and phase stability is less well established, although the limited amount of data available tends to support this relationship (Parks, 1990; Steefel and Van Cappellen, 1990). The nucleation and growth of a phase depends on its thermodynamic stability at the point of nucleation, and that stability depends, not only on the Gibbs free energy of the bulk solid, but also on the interfacial free energy contribution. Thus, those phases that are thermodynamically more stable when coarsely crystalline (i.e., have a more negative Gibbs free energy of formation), commonly have a larger positive interfacial free energy, which offsets the Gibbs free energy of formation with diminishing particle size. This can result in a crossover point where the more stable phase becomes less stable than its less stable precursor. Figure 3.4-6, taken from Parks (1990), illustrates the surface free energy as a function of size for amorphous silica and quartz.

Once nucleation has taken place, growth must take place, if the nucleated phase is to become macroscopically identifiable. At the same time, those nuclei that increase in size relative to their neighbors, will become less soluble, and their growth will be favored, because $\Omega$ will become larger in relation to smaler crystals. As a result, the process of Ostwald Ripening will occur. Steefel and Van Cappellen (1990) show that the driving force for Ostwald Ripening is the interfacial free energy of the mineral, $\sigma$, as expressed in the following equation after Nielsen (1964):

$$
C, / C=\exp \left[2 \sigma v_{0} / R T\left(1 / r-1 / r^{*}\right)\right]
$$

where $C$ is the concentration of the mineral in solution, and $C_{r}$ is the solubility of a grain with radius, $r$, and $v_{0}$ is the molar volume of the mineral. On the basis of this equation, Steefel and Van Cappellen (1990) derived the following expression for Ostwald Ripening in terms of the population density,

$$
\eta: \partial \eta / \partial t=\partial / \partial r\left[v_{\text {ost }}(r) \eta\right]-\left(3 v_{\text {ost }}(r) \eta\right) / r
$$

where $v_{\text {ost }}$ is the Ostwald Ripening rate. As an illustration of the Ostwald Ripening phenomenon, Steefel and Van Cappellen (1990) considered the ripening of an initial Gaussian distribution of gibbsite crystals. 
The above equation was solved for different times, and the results presented in Figure 3.4-6 of their paper, reproduced below as Figure 3.4-7.

The linear growth rate of the nuclei in a supersaturated medium can be combined with the above equation, and integrated numerically to yield the growth of a particular phase with time, which is a necessary requirement of reaction progress simulations.

Several complicating factors may affect the simulation of a kinetic representation of the Ostwald rule of stages, and attendant Ostwald Ripening. The interfacial free energy is known only for a relatively few minerals, and empirical methods for estimating this parameter have been developed only for relatively insoluble salts, e.g., see Nielsen and Sohnel (1971), Garten and Head (1973) and Sohnel (1982). The estimation of interfacial free energies of participating rock forming minerals will be difficult, and probably require the development of theory relating silicate structures to interfacial free energy. Schmeltzer et al. (1998) point out that Stefan (1886) derived the following relationship between the interfacial free energy and the enthalpy of transformation, $\Delta H$ :

$$
\sigma=\xi \Delta H c_{a}^{2 / 3} / N_{A}^{1 / 3}
$$

where $c_{a}$ is the density of monomeric units in the nucleus, and $N$ is Avogadro's number. $\xi$ is a factor that generally has values ranging between 0.4 and 0.6 . This derivation should be examined further in the light of more recent data on the interfacial free energies of silicate minerals. It should also be noted that the interfacial free energy is not a parameter intrinsic to the mineral phase, but is also a function of the aqueous phase composition, which could in turn affect the identity of the phase to nucleate initially. Barrer (1982) believes that the state of supersaturation may affect the stability of polynuclear complexes, which could facilitate nucleation. Nyvlt (1995) also believes that the fields characterized by the stabilities of different hydrates of a given salt are determined by the aqueous phase favoring formation of clusters corresponding to the respective hydrate. He also shows that aqueous solutions, when quenched below a salt hydrate transition temperature, will nucleate the higher temperature phase, the implication being that the aqueous phase retains a structure conducive to the stabilization of the phase cluster from the higher temperature salt hydrate.

\subsubsection{Recommendations for Further Work to Refine Geochemical Model}

Field evidence shows that alteration of the acid volcaniclastic sequence at $\mathrm{YM}$ and vicinity is subject to a hundred year old Ostwald Rule of Stages. The review of the kinetic basis for the Ostwald rule of stages is preliminary. Not all references have been reviewed, and apparent discrepancies between different authorities have not been reconciled. Therefore, the initial recommendation is to complete the review and prepare a document with consistent symbolism. Some other recommendations are as follows: 
- Determine whether an acceptable means can be found for estimating the surface free energy coefficients of minerals participating in DST THC alteration

- Conduct TEM studies of TSw rocks to estimate the approximate surface areas and crystallinity of minerals participating in alteration

- Create a one-dimensional model and code that can test isothermal scenarios in which tuff alteration is controlled by the Ostwald rule. This model might be an adaptation of that used by Steefel and Van Cappellen (1990).

\subsection{Discussion and Conclusions}

The modeling results over the full 8 year DST indicate that $\mathrm{CO}_{2}$ transport will occur well outside the region of strongly elevated temperatures, thus affecting the rates of dissolution of fracture-lining minerals, such as calcite, much more strongly than cristobalite or quartz. In areas undergoing significant vapor loss through boiling, and in the high-temperature condensation zones, there will be significant losses in $\mathrm{CO}_{2}$ over time. The extent to which the $\mathrm{P}_{\mathrm{CO} 2}$ declines to below the ambient $\mathrm{P}_{\mathrm{CO} 2}$ in the Heated Drift will depend on the exchange of air in the drift and fractures in the drift wall. The effects of these boundary conditions on the model results will be examined in future progress reports. Also, air permeability tests will likely buffer any $\mathrm{CO}_{2}$ losses, and to lesser extent the $\mathrm{P}_{\mathrm{CO} 2}$ increases farther away from the drift. The influence of the tests will also be examined as part of the model refinement.

Measured $\mathrm{CO}_{2}$ in gas samples (Conrad, 1998a, b) confirms the increase in $\mathrm{P}_{\mathrm{CO} 2}$ predicted by the model in the high-temperature regions and in the areas that are still near the ambient temperature. Values below atmospheric have not been found, though, suggesting that exchange with drift air and/or air permeability testing has affected the $\mathrm{P}_{\mathrm{CO} 2}$ at least locally. Carbon and oxygen isotopic studies (Conrad, 1998a, b) are consistent with the conceptual model of $\mathrm{CO}_{2}$ loss through boiling, followed by gas transport, with progressive condensation and dissolution in cooler regions. The incorporation of carbon, oxygen, and hydrogen isotopic systems in future modeling will help constrain not only geochemical processes occurring during the DST but also thermohydrologic and transport processes.

Of the phases considered, cristobalite undergoes the greatest amount of dissolution, with calcite showing the most precipitation. Little amorphous silica is formed; however, the rates of precipitation are low relative to the rate of dryout, such that very high silica concentrations are present in the residual fluid phase. If the final silica in solution were precipitated, the amount of silica precipitation would be roughly equal to the amount of cristobalite and quartz dissolved, which is on the order of 0.1 percent by volume. Over the course of the drift-scale test there would likely be porosity modifications of about a percent of the total fracture porosity, which should not cause a significant change in permeability. Much smaller modifications to the bulk matrix porosity are expected, however localized, modification at fracture walls could be important over longer time periods. 


\section{Acknowledgement}

The authors would like to thank Bill Dam and Ardyth Simmons for their careful review of this chapter.

\section{References}

Apps, J.A. 1997. "Hydrochemical Analysis." In: G.S. Bodvarsson, T.M. Bandurraga, and Y.S. Wu, eds. The Site-Scale Unsaturated Zone Model of Yucca Mountain, Nevada, for the Viability Assessment, Chapter 14. Yucca Mountain Project Level 4 Milestone SP24UFM4, LBNL-40376, UC-814. Berkeley, California: Lawrence Berkeley National Laboratory. DTN: LB970601233129.001 (Q)

Apps, J.A. 1970. The Stability Field of Analcime. Unpublished Ph.D. Thesis, Harvard University, 347p.

Apps, J.A.; Neil, J.M.; and Jun, C.-H. 1989. Thermochemical Properties of Gibbsite, Bayerite, Boehmite, Diaspore and The Aluminate Ion Between 0 and $350^{\circ} \mathrm{C}$. Report LBL-21482, U.S. Nuclear Regulatory Commission Report NUREG/CR-5271. Berkeley, California: Lawrence Berkeley National Laboratory.

Bandurraga, T.M. and Bodvarsson, G.S. 1997. Calibrating Matrix and Fracture Properties Using Inverse Modeling. In: G.S. Bodvarsson, T.M. Bandurraga, and Y.S. Wu, eds. The Site-Scale UnsaturatedZone Model of Yucca Mountain, Nevada, for the Viability Assessment, Chapter 6. Yucca Mountain Project Level 4 Milestone SP24UFM4, Report LBNL-40376, UC-814. Berkeley, California: Lawrence Berkeley National Laboratory. DTN: LB970601233129.001 (Q).

Barrer, R.M. 1982. Hydrothermal Chemistry of Zeolites. Academic Press, New York.

Birkholzer, J.T. and Tsang, Y.W. 1997. Pretest Analysis of the Thermal-Hydrological Conditions of the ESF Drift Scale Test. Yucca Mountain Project Level 4 Milestone SP9322M4. Berkeley, California: Lawrence Berkeley National Laboratory. MOL: 199712010805.0810.

Bish, D.L. and Vaniman, D.T. 1985. Mineralogic Summary of Yucca Mountain, Nevada. Report LA10543-MS. Los Alamos, New Mexico: Los Alamos National Laboratory. DTN: LA000000000110.002 (Non-Q).

Bruton, C.J. 1985. "Predicting Mineral Dissolution and Precipitation During Burial; Synthetic Diagenetic Sequences." In: The Geological Society of America: $98^{\text {th }}$ Annual Meeting, Abstracts with Programs. The Geological Society of America; $98^{\text {th }}$ annual meeting. Orlando, Florida: Geological Society of America. November 28-31, 1985, 17, (7), 533.

Carey, J.W.; Chipera, S.J.; Vaniman, D.T.; Bish, D.L.; Viswanathan, H.S.; and Carter-Krogh, K. 1997. Three-Dimensional Mineralogic Model of Yucca Mountain, Nevada, Rev. 1. Report SP344BM4. Los 
Alamos, New Mexico: Los Alamos National Laboratory. DTN: LAJC831321DN97.009 (Non-Q). DTN: LAJC831321DQ97.008 (Q).

Carlos, C. 1989. Fracture-Coating Mi.nerals in the Topopah Spring Member and Upper Tuff of Calico Hills from Drill Hole J-13. Report LA-11504-MS. Los Alamos, New Mexico: Los Alamos National Laboratory.

Carlos, B.A.; Bish, D.L.; and Chipera, S.J. 1991. "Fracture-Lining Minerals in the Lower Topopah Spring Tuff at Yucca Mountain." Proceedings of the Second International High-Level Radioactive Waste Conference, April, 1991. Las Vegas, Nevada: American Nuclear Society, 1, 486-493. NNA.19910206.0039, LA000000000069.001 (Non-Q).

Carlos, B.A.; Chipera, S.J.; and Bish D.L. 1995. Distribution and Chemistry of Fracture-Lining Zeolites at Yucca Mountain, Nevada. Report LA-12977-MS. Los Alamos, New Mexico: Los Alamos National Laboratory. MOL. 19951027.0169.

Casey, W.H. 1988. "Entropy Production and the Ostwald Step Rule." Journal of Physical Chemistry, 92(1), 226-7.

Chang, J. and Yortsos, Y.C. 1994. "Lamination During Silica Diagenesis-Effects of Clay Content and Ostwald Ripening." American Journal of Science, 294, 137-172.

Chipera, S.J. and Bish, D.L. 1988. Mineralogy of Drill Hole UE-25p\#1 at Yucca Mountain, Nevada. Report LA-11292-MS. Los Alamos, New Mexico: Los Alamos National Laboratory. HQX. 19880609.0034.

Conrad, M. 1998a. "Carbon Isotope Analyses of $\mathrm{CO}_{2}$ Evolved During the Initial Stages of the Drift Scale Test." Chapter 3 in First Quarter TDIF Submission (Hydrological, Radar and Microseismic. Yucca Mountain Project Level 4 Milestone Report SP2770M4. Berkeley, California: Lawrence Berkeley National Laboratory.

Conrad, M. 1998b. "Isotope Analyses of Samples from the Drift Scale Test Hydrology Holes." Chapter 3 in Second Quarter TDIF Submission (Hydrological, Radar and Microseismic. Yucca Mountain Project Level 4 Milestone Report SP2790M4. Berkeley, California: Lawrence Berkeley National Laboratory. DTN: LB980715123142.003 (Q).

Dibble, W.E. Jr. and Tiller, W.A. 1981a. "Non-Equilibrium Water/Rock Interactions. I. Model for Interface-Controlled Reactions." Geochimica et Cosmochimica Acta, 45, 79-92.

Dibble, W.E., Jr. and Tiller, W.A. 1981b. "Kinetic Model of Zeolite Paragenesis in Tuffaceous Sediments." Clays \& Clay Minerals, 29, 323-330. 
Duffy, C.J. 1993. Preliminary Conceptual Model for Mineral Evolution at Yucca Mountain, Nevada. Report LA-12708-MS. Los Alamos, New Mexico: Los Alamos National Laboratory. MOL. 19950630.0267.

Dunning, W.J. 1969. "General and Theoretical Introduction. In Nucleation (A.C. Nettlemoyer, Ed.). Dekker, New York: New York, 1-67.

Erdem, A. and Sand, L.B., 1979. "Metastable Phase Transformations of Zeolite ZSM-5 in the (TPA) 20 Sodium Oxide - Potassium Oxide - Aluminum Oxide - Silicon Dioxide - Water System.” J. Catal., 60(2), p.241-

Feenstra, T. P. and De Bruyn, P.L. 1981. "The Ostwald Rule of Stages in Precipitation from Highly Supersaturated Solutions: a Model and its Application to the Formation of the Nonstoichiometric Amorphous Calcium Phosphate Precursor Phase." J. Colloid Interface Sci., 84(1), 66-72.

Garten, V.A. and Head, R.B. 1973. "Nucleation in Salt Solutions: Faraday Transactions I" J. Chem. Soc, 69, 514-520.

Gilmer, G.H. and Bennema, P. 1972. "Simulation of Crystal Growth with Surface Diffusion. J. Applied Physics, 43(4), 1347-1360.

Gutzow, I. and Toschev, S. 1968. "Non-Steady State Nucleation in the Formation of Isotropic and Anisotropic Phases." Kristall und Technik, 3(4), 485-497.

Gutzow, I. and Avramov, I. 1974. "On the Mechanism of Formation of Amorphous Condensates from the Vapor Phase (I): General Theory.” J. Non-Cryst. Solids, 16, 128-142.

Hardin, E.L. 1998. Near-Field/Altered Zone Models. Yucca Mountain Project Milestone Report SP3100M4. Livermore, California: Lawrence Livermore National Laboratory. DTN: LL980209004242.026 (Q).

Harrar, J.E.; Carley, J.F.; Isherwood, W.F.; and Raber, E. 1990. Report of the Committee to Review the Use of J-13 Well Water in Nevada Nuclear Waste Storage Investigations. UCID-21867. Livermore, California: Lawrence Livermore National Laboratory. NNA.19910131.0274.

Helgeson, H. C.; Delany, J. M.; Nesbitt, H. W.; and Bird, D. K. 1978. "Summary and Critique of the Thermodynamic Properties of Rock Forming Minerals." American Journal of Science, 278-A, 229.

Helgeson, H.C. 1968. "Evaluation of Irreversible Reactions in Geochemical Processes Involving Minerals and Aqueous Solutions-I: Thermodynamic Relations." Geochimica et Cosmochimica Acta, 32, 853875.

Helgeson, H.C.; Garrels, R.M.; and MacKenzie, F.T. 1969. "Evaluation of Irreversible Reactions in Geochemical Processes Involving Minerals and Aqueous Solutions-II: Applications." Geochimica et Cosmochimica Acta, 32, 853-875. 
Holland, T.J.B. and Powell, R. 1985. "An Internally Consistent Thermodynamic Dataset with Uncertainties and Correlations 2: Data and Results." J. Metamorphic Geology, 3, 343-370.

Holser, W.T. 1979. "Mineralogy of Evaporites." Marine Minerals, Mineralogical Society of America Short Course Notes, edited by R.G. Burns, 6, 211-294.

Ijima, A., 1980. "Geology of Natural Zeolites and Zeolitic Rocks." In: L.V.C. Rees, ed., Proc. Fifth Internat. Conf. Zeolites: London, Heyden.

Johnson, J.W; Oelkers, E.H.; and Helgeson, H.C. 1992. "Equilibrium Constants Calculated with, and Data from, SUPCRT92." Computers and Geosciences, 18, 899-947.

Kastner, M. 1979. "Silica Polymorphs. In R.G. Burns, ed. Marine Minerals, Chapter 3. Mineralogical Society of America Short Course Notes, 6, 99-109. Mineralogical Society of America, Washington, DC.

Lebron, I. and Suarez, D.L. 1998. "Kinetics as and Mechanisms as Affected by $\mathrm{P}_{\mathrm{CO} 2}$ and Organic Ligands at $25^{\circ} \mathrm{C}$." Geochimica et Cosmochimica Acta, 62(3), 405-416.

Morse, J.W. and Casey, W.H. 1988. "Ostwald Processes and Mineral Paragenesis in Sediments." American Journal of Science, 288(6), 537-60.

Nielsen, A.E. and Sohnel, O. 1971. "Interfacial Tensions Electrolyte Crystal-Aqueous Solution, from Nucleation Data." J. Cryst. ./Growth, 11, 233-242.

Nielsen, A.E. 1964. Kinetics of Precipitation. Pergamon, New York: New York.

Nordeng, S. H.and Sibley, D.F. 1994. "Dolomite Stoichiometry and Ostwald's Step Rule." Geochim. Cosmochim. Acta, 58(1), 191-6.

Nyvlt, J. 1995. "The Ostwald Rule of Stages." Res. Cryst. Technol. 30(4), 443-9.

Ostwald, W. 1897. "Studien über die Bildung und Umwandlung fester Körper." Zeitschrift für Physikalische Chemie, 22, 289-330.

Paces, T., 1978. "Reversible Control of Aqueous Alurninum and Silica During the Irreversible Evolution of Natural Waters." Geochimica et Cosmochimica Acta,42, 1487-1493

Parks, G.A. 1990. "Surface Energy and Absorption at Mineral-Water Interfaces: An Introduction." Rev. Mineral., 23 (Miner.-Water Interface Geochem.), 133-75.

Pokrovskii, V.A. and Helgeson, H.C. 1995. "Thermodynamic Properties of Aqueous Species and the Solubilities of Minerals at High Pressures and Temperatures: The System $\mathrm{Al}_{2} \mathrm{O} 3-\mathrm{H}_{2} \mathrm{O}-\mathrm{NaCl}$." American Journal of Science, 295, 1255-1342. 
Rimstidt, J.D. and Barnes, H.L. 1980. "The Kinetics of Silica-Water Reactions." Geochimica et Cosmochimica Acta, 44, 1683-1699.

Roberts, S. and Viani, B. 1997. Mineral Abundances from Six Chemistry (SEAMIST) holes in the Drift Scale Heater Test area of the Exploratory Studies Facility. Yucca Mountain Project Level 4 Milestone, SP9510M4. Livermore, California: Lawrence Livermore National Laboratory. DTN: LL980106404244.050 (Q).

Schmelzer, J.; Moeller, J.; and Gutzow, I.Z. 1998. "Ostwald's Rule of Stages: The Effect of Elastic Strains and External Pressure." Phys. Chem. (Munich), 204(1/2), 171-181.

Siffert, B. 1962 "Some Reactions of Silica in Solution: The Formation of Clays. Burl. Serv. Carte. Gest. Alsace Lorraine, 21, 1-86.

Siffert, B. and Wey, R. 1967. "Quantitative Study of the Transformation of Amorphous Silicon into Quartz Between $230^{\circ} \mathrm{C}$ and $350^{\circ} \mathrm{C}$ in the Presence of Alkaline Base." Silicates Industriels, 32(12), 415-422.

Smyth, J. R. 1982. "Zeolite Stability Constraints on Radioactive Waste Isolation in Zeolite-Bearing Volcanic Rocks." Journal of Geology, 90, 195-202.

Sohnel, O., 1982. "Electrolyte Crystal-Aqueous Solution Interfacial Tensions from Crystallization Data." J. Cryst. Growth, 57, 101-108.

Sonnenthal, E.L.; Ahlers, C.F.; and Bodvarsson, G.S. 1997. "Fracture and Fault Properties for the UZ Site-Scale Flow Model." In: G.S. Bodvarsson, T.M. Bandurraga, and Y.S. Wu, eds. The Site-Scale Unsaturated Zone Model of Yucca Mountain, Nevada, for the Viability Assessment, Chapter 7. Yucca Mountain Project Level 4 Milestone SP24UFM4. Report LBNL-40376, UC-814. Berkeley, California: Lawrence Berkeley National Laboratory. DTN: LB970601233129.001 (Q).

Sonnenthal, E.; Spycher, N.; Apps, J.; and Simmons, A. 1998. Thermo-Hydro-Chemical Predictive Analysis for the Drift-Scale Heater Test. Yucca Mountain Project Level 4 Milestone SPY289M4. Berkeley, California: Lawrence Berkeley National Laboratory.

Steefel, C.I. and Van Cappellen, P. 1990. "A New Kinetic Approach to Modeling Water-Rock Interaction: The Role of Nucleation, Precursors, and Ostwald Ripening." Geochimica et Cosmochimica Acta, 54, 2657-2677.

Stefan, J. 1886. Ann. Phys. v. 29, p.665. (Cited in Schmelzer et al., 1998).

Stranski, I.N. and Totomanow, D. 1933. "Keimbildungsgeschwindikeit und Ostwaldische Stefenregel." Zeit. Phys Chem. A, 163, 399-408.

Tarshis, A. L. 1982. Electron Microscopic Examination of Zeolitization and Cooling Devitrification in Silicic Volcanic Rocks. Unpublished Ph.D Thesis, University of California, Santa Cruz, 1982. 
Tsang, Y.W. and Freifeld, B. 1998. "Hydrological baseline measurements," Chapter 2 of ESF Drift Scale Test as-built data and baseline measurements, Yucca Mountain Project Level 4 milestone SPY193M4. Berkeley, California: Lawrence Berkeley National Laboratory. DTN:LB980120123142.004 (Q).

Vaniman, D.T. 1993. “Calcite Deposits in Fractures at Yucca Mountain, Nevada." Proceedings of the Fourth Annual International Conference on High Level Radioactive Waste Management, 2, 19351939. Las Vegas, Nevada: American Nuclear Society. NNA.19931028.001, LA000000000025.001 (Non-Q).

van Santen, R.A. 1998. "Comment on Entropy Production and the Ostwald Step Rule." Journal of Physical Chemistry, 92(1), 248.

van Santen, R. A. 1984. “The Ostwald Step Rule.” Joumal of Physical Chemistry, 88(24), 5768-9.

White, A.F. and Peterson, M.L. 1990. "Role of Reactive-Surface-Area Characterization in Geochemical Kinetic Models." In Melchior, D.C.; Bassett, R. L, eds. Chemical Modeling of Aqueous Systems II. American Chemical Society, $196^{\text {th }}$ national meeting, September 1988. ACS Symposium Series, 416, 461-475.

Williams, L.A.; Parks, G.A.; and Crerar, D.A. 1985. "Silica Diagenesis, I. Solubility Controls." Journal of Sedimentary Petrology, 55(3), 301-311.

Wolery, T.J. 1992. EQ3NR, A Computer Program for Geochemical Aqueous Speciation-Solubility Calculations: Theoretical Manual, User's Guide and Related Documentation (Version 7.0). Report UCRL-MA-110662 PT III. Livermore, California: Lawrence Livermore National Laboratory. MOL. 19980213.0592.

Xu, T.; Gerard. F.; Pruess, K.; and Brimhall, G. 1998. "Introducing Reactive Solute Transport to TOUGH2: Application to Supergene Copper Enrichment." Proceedings of the TOUGH Workshop '98. Berkeley, California: Lawrence Berkeley National Laboratory.

Xu, T.; Gerard, F.; Pruess, K.; and Brimhall, G. 1997. Modeling Non-Isothermal Multiphase Multispecies Reactive Chemical Transport in Geologic Media. Report LBNL-40504, UC-400. Berkeley California: Lawrence Berkeley National Laboratory.

Yang, I.C.; Rattray, G.W.; and Yu, P. 1996a. Interpretation of Chemical and Isotopic Data from Boreholes in the Unsaturated Zone at Yucca Mountain. U.S. Geological Survey Water Resources Investigation Report 96-4058. Denver, Colorado: U.S. Geological Survey. DTN: GS970108312271.001 (Q).

Yang, I.C.; Yu, P.; Rattray, G.W; and Thorstenson, D.C. 1996b. Hydrochemical Investigations and Geochemical Modeling in Characterizing the Unsaturated Zone at Yucca Mountain, Nevada. U.S. Geological Survey Water Resources Investigation Report. Denver, Colorado: U.S. Geological Survey. GS.970108312271.001. 
Yucca Mountain Drift Scale Test Progress Report

Figures 


\section{FRACTURE CHLORIDE: 6 MONTHS}

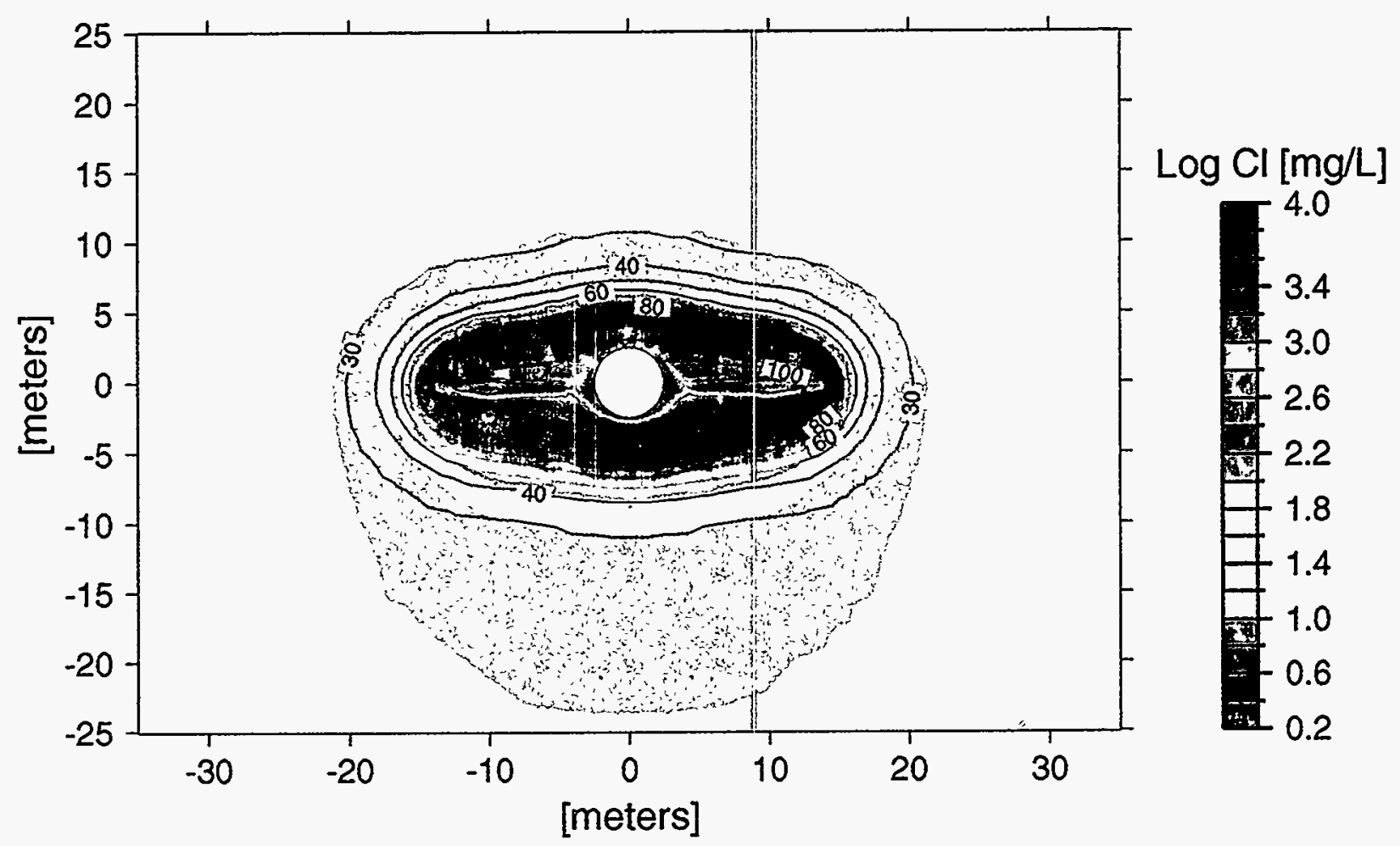

Figure 3.3-1. Chloride concentration in fractures after 6 months of heating. Temperature contours are overlain. 


\section{FRACTURE CHLORIDE: 4 YEARS}

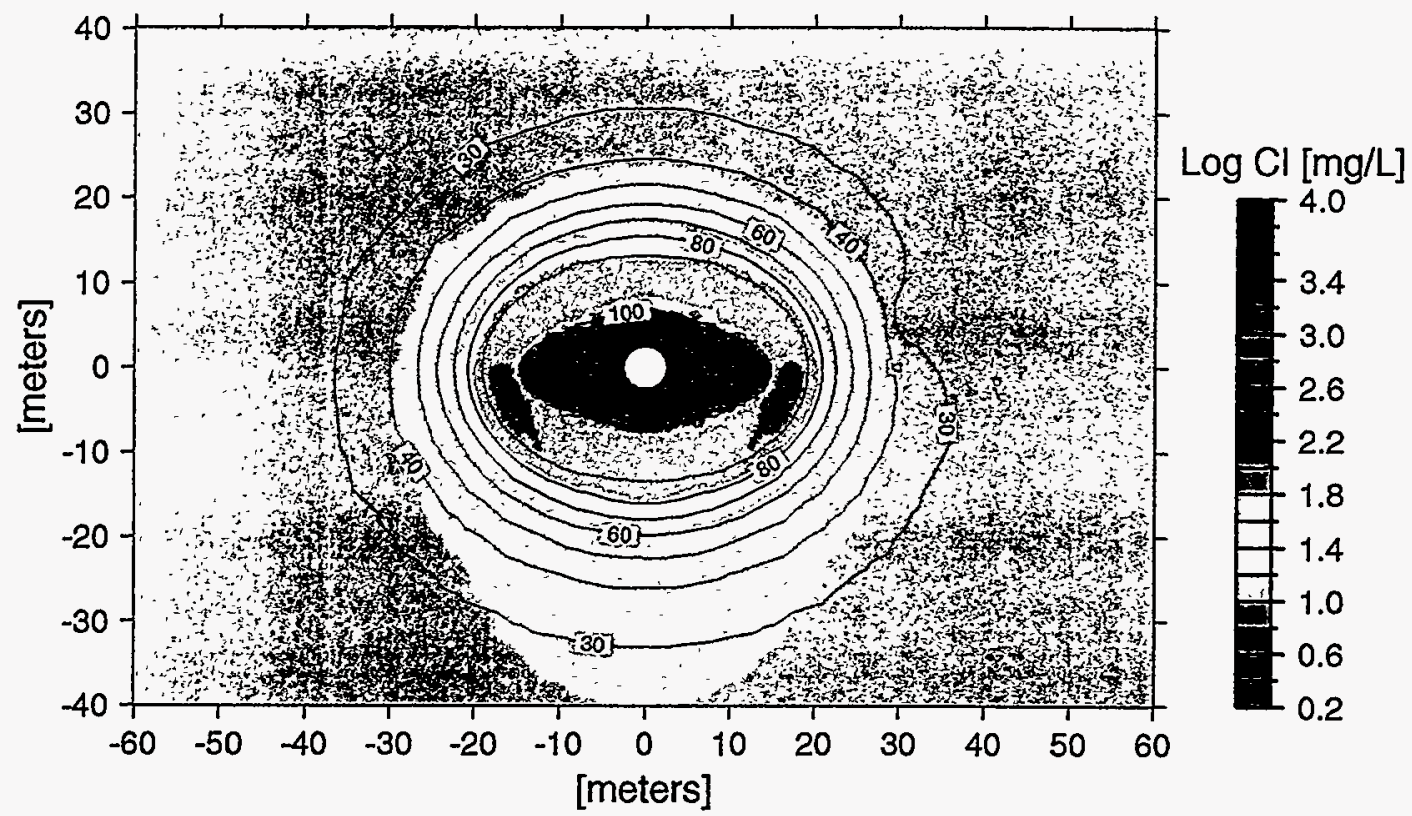

Figure 3.3-2. Chloride concentration in fractures at the end of the 4 year heating cycle. Temperature contours are overlain.

\section{FRACTURE CHLORIDE: 8 YEARS}

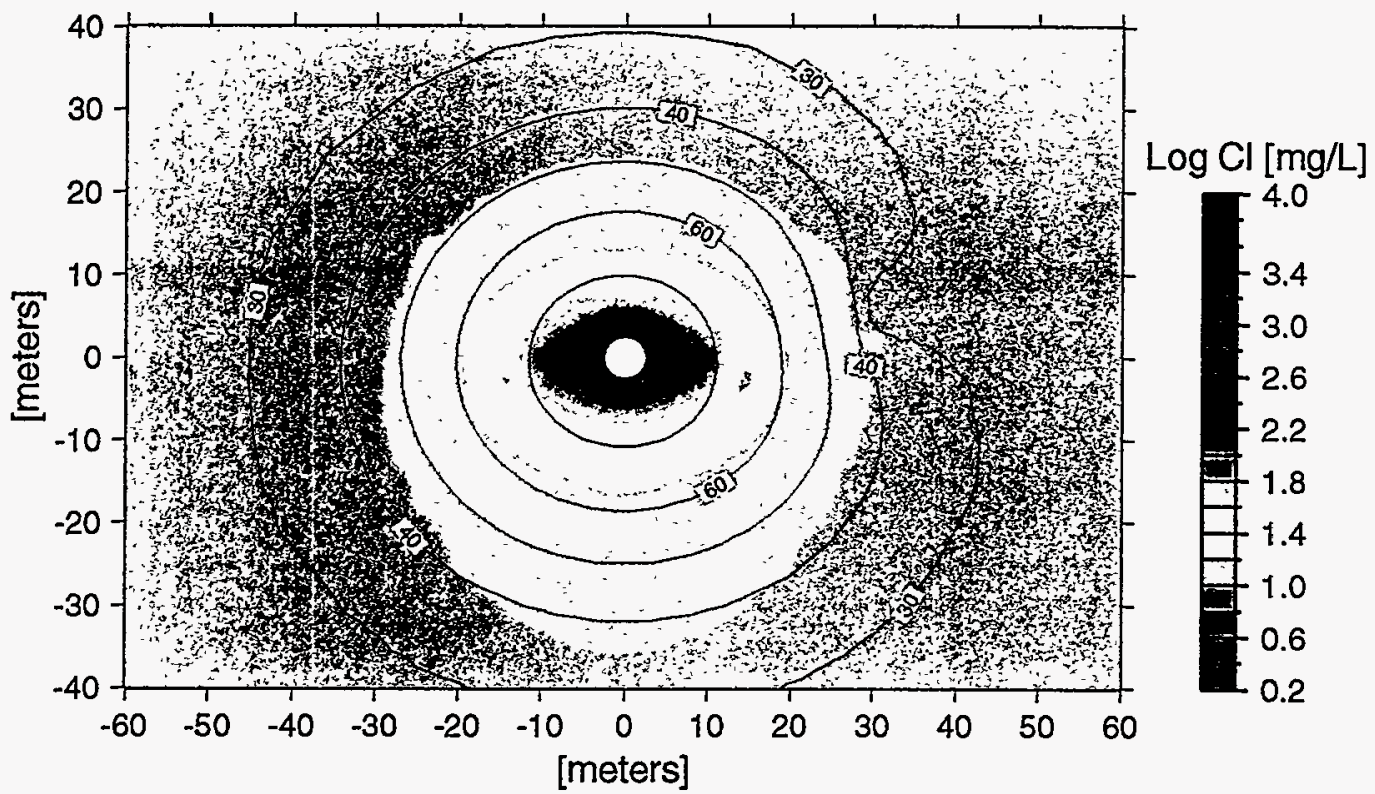

Figure 3.3-3. Chloride concentration in fractures at the end of the 8 year heating and cooling cycles. Temperature contours are overlain. 


\section{FRACTURE LOG PCO $2: 6$ MONTHS}

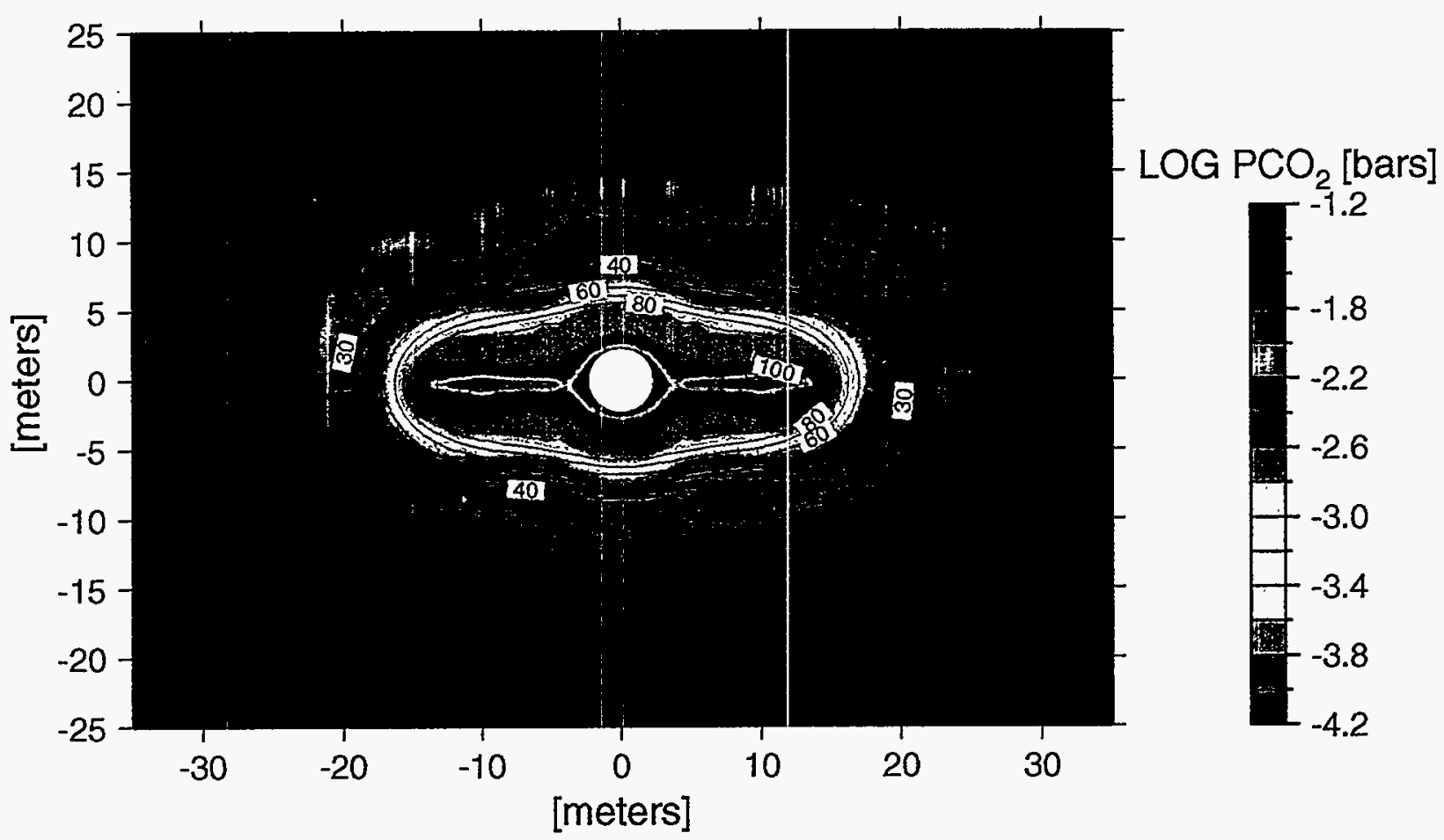

Figure 3.3-4. Partial pressure of $\mathrm{CO} 2$ in fractures after 6 months of heating. Temperature contours are overlain. 


\section{FRACTURE LOG PCO ${ }_{2}: 4$ YEARS}

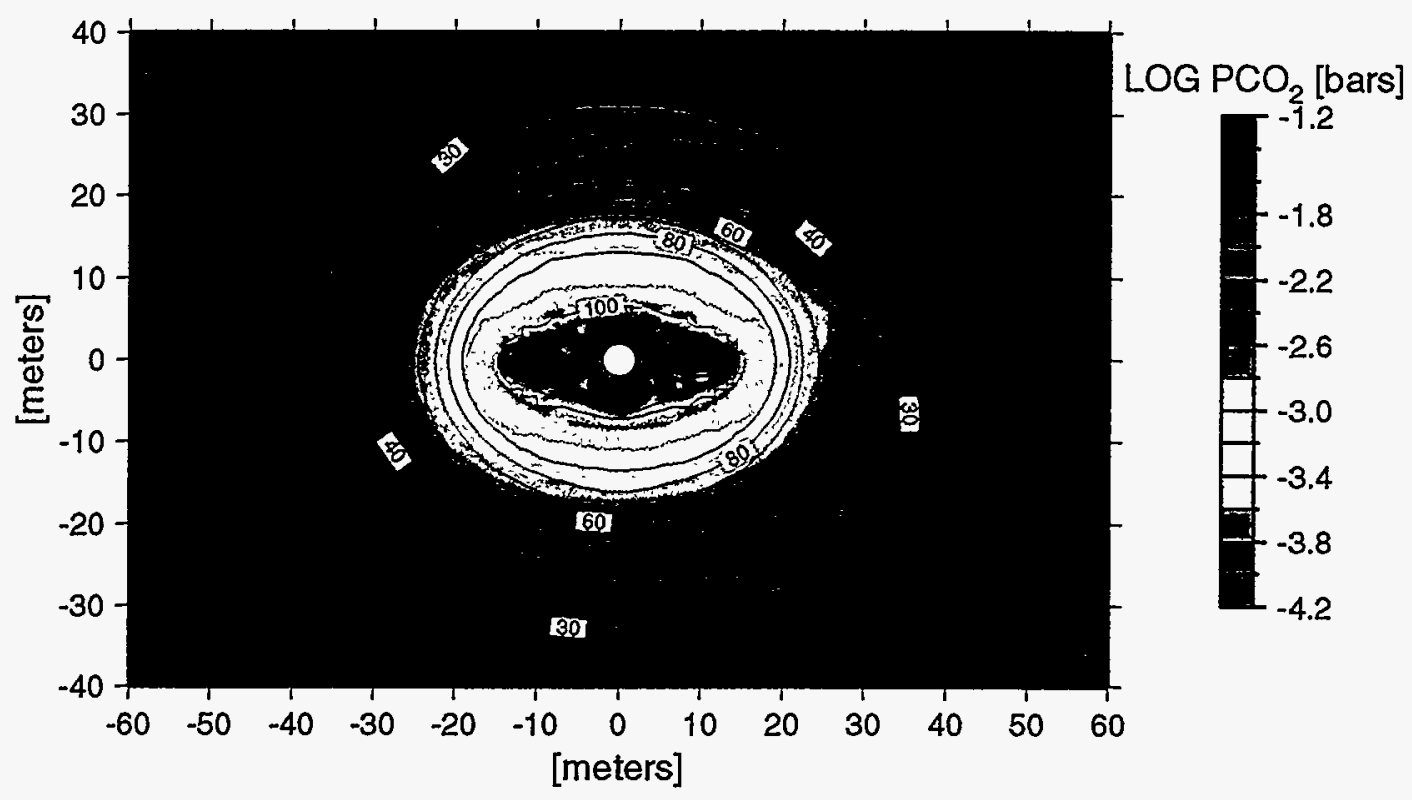

Figure 3.3-5. Partial pressure of $\mathrm{CO} 2$ in fractures at the end of the 4 year heating cycle. Temperature contours are overlain. Irregularities in the temperature profile to the right of the drift are due to the constant temperature observation drift.

\section{FRACTURE LOG PCO ${ }_{2}: 8$ YEARS}

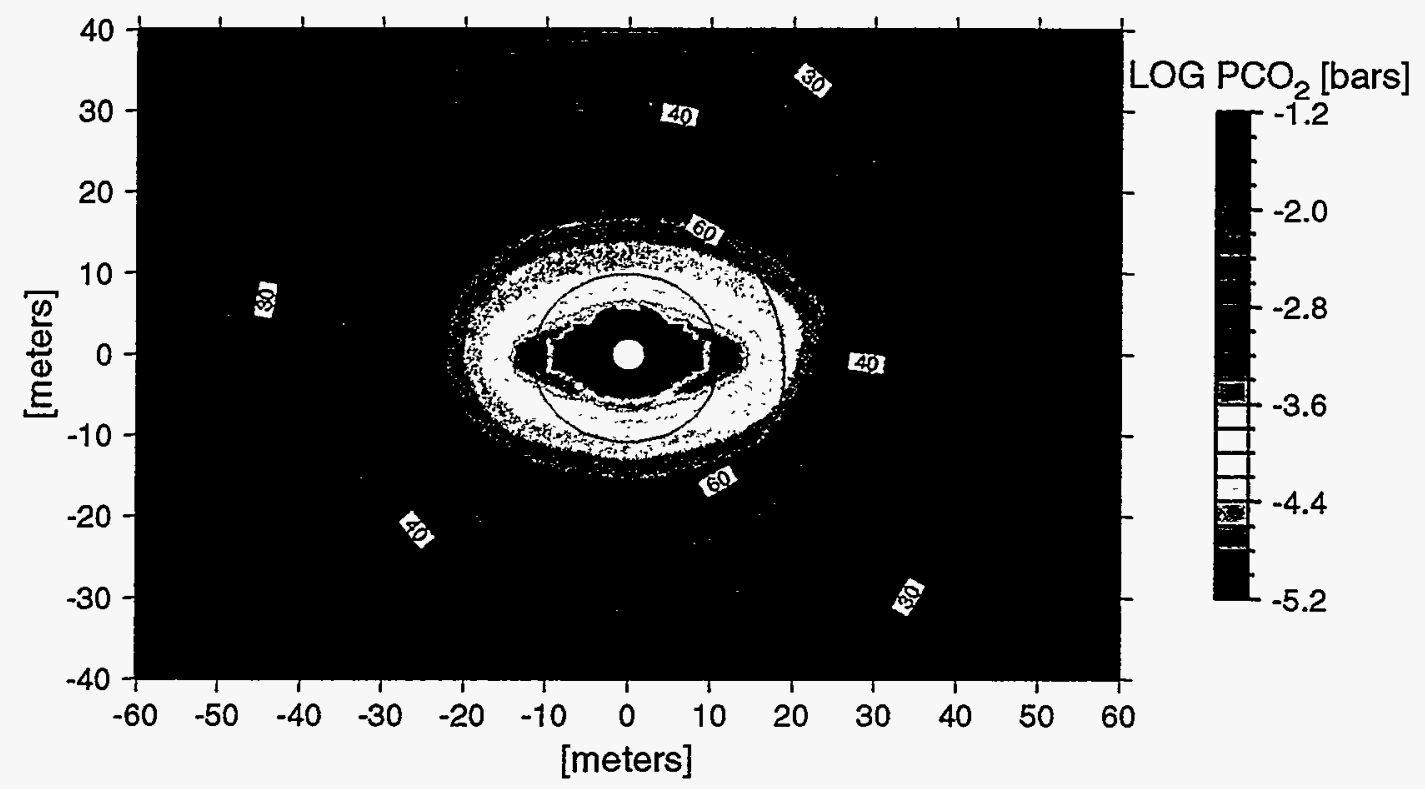

Figure 3.3-6. Partial pressure of $\mathrm{CO} 2$ in fractures at the end of the 8 year heating and cooling cycles. Temperature contours are overlain. 
FRACTURE PH: 6 MONTHS

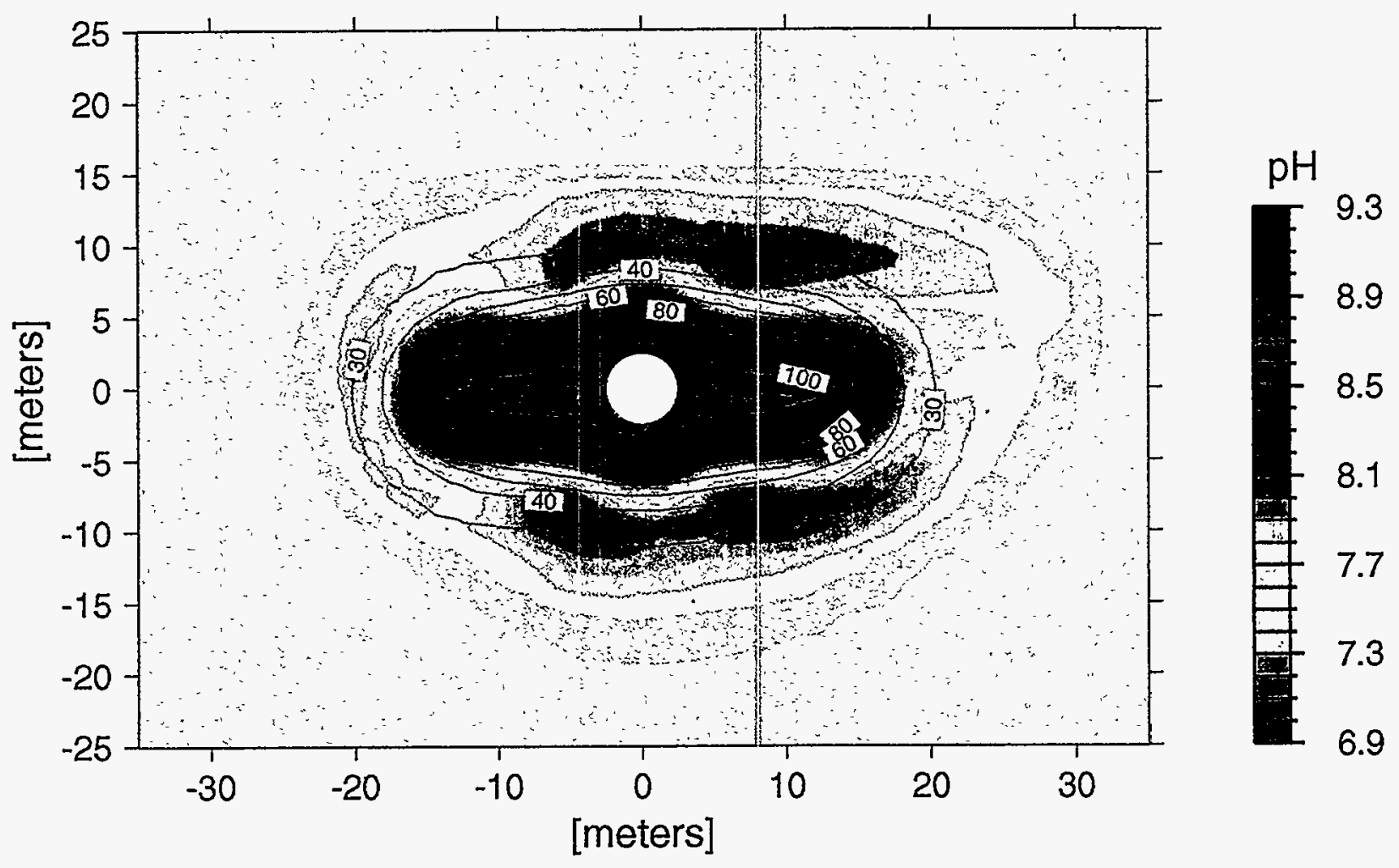

Figure 3.3-7. $\mathrm{pH}$ in fractures after 6 months of heating. Temperature contours are overlain. 


\section{FRACTURE CALCITE: 6 MONTHS}

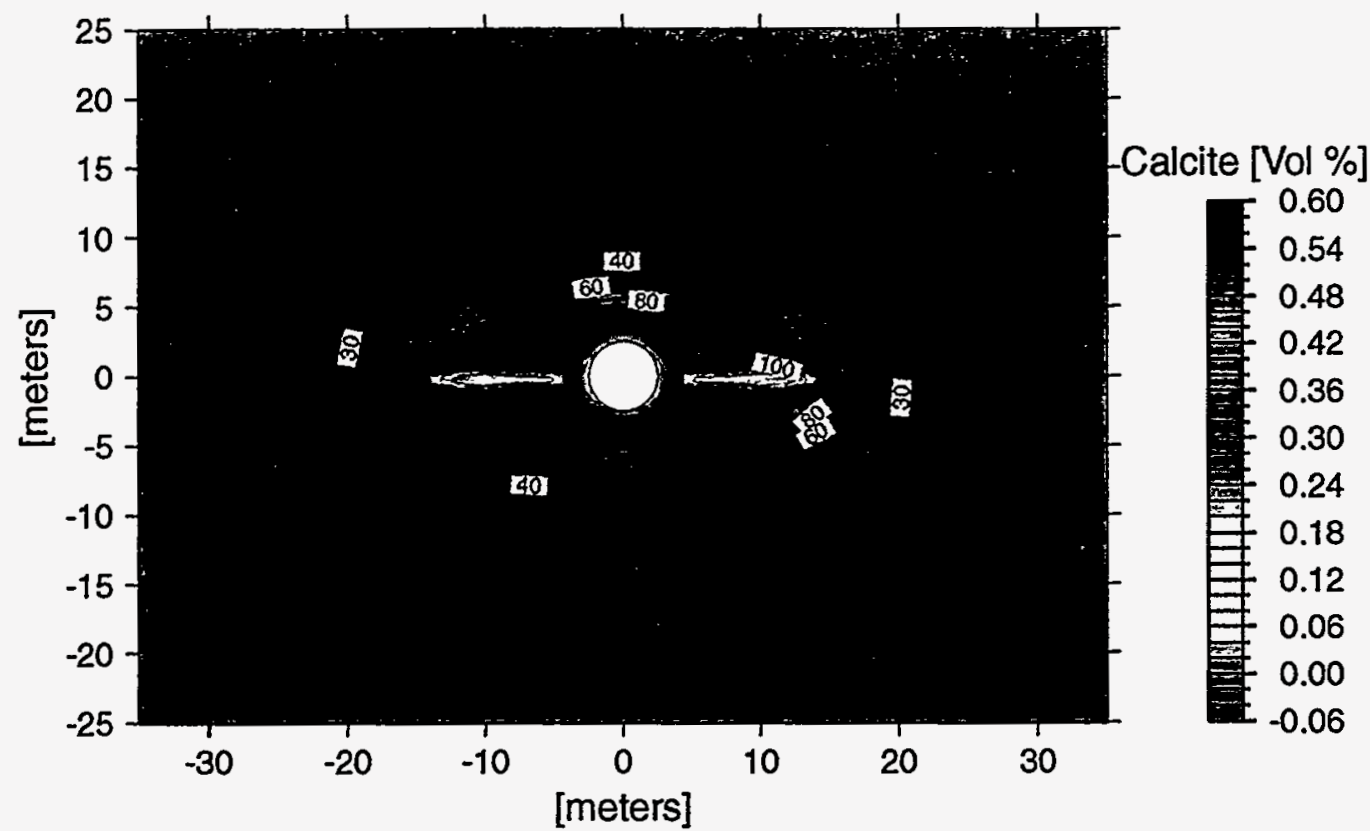

Figure 3.3-8. Calcite volume fraction dissolved/precipitated in fractures after 6 months of heating. Temperature contours are overlain.

FRACTURE CALCITE: 4 YEARS

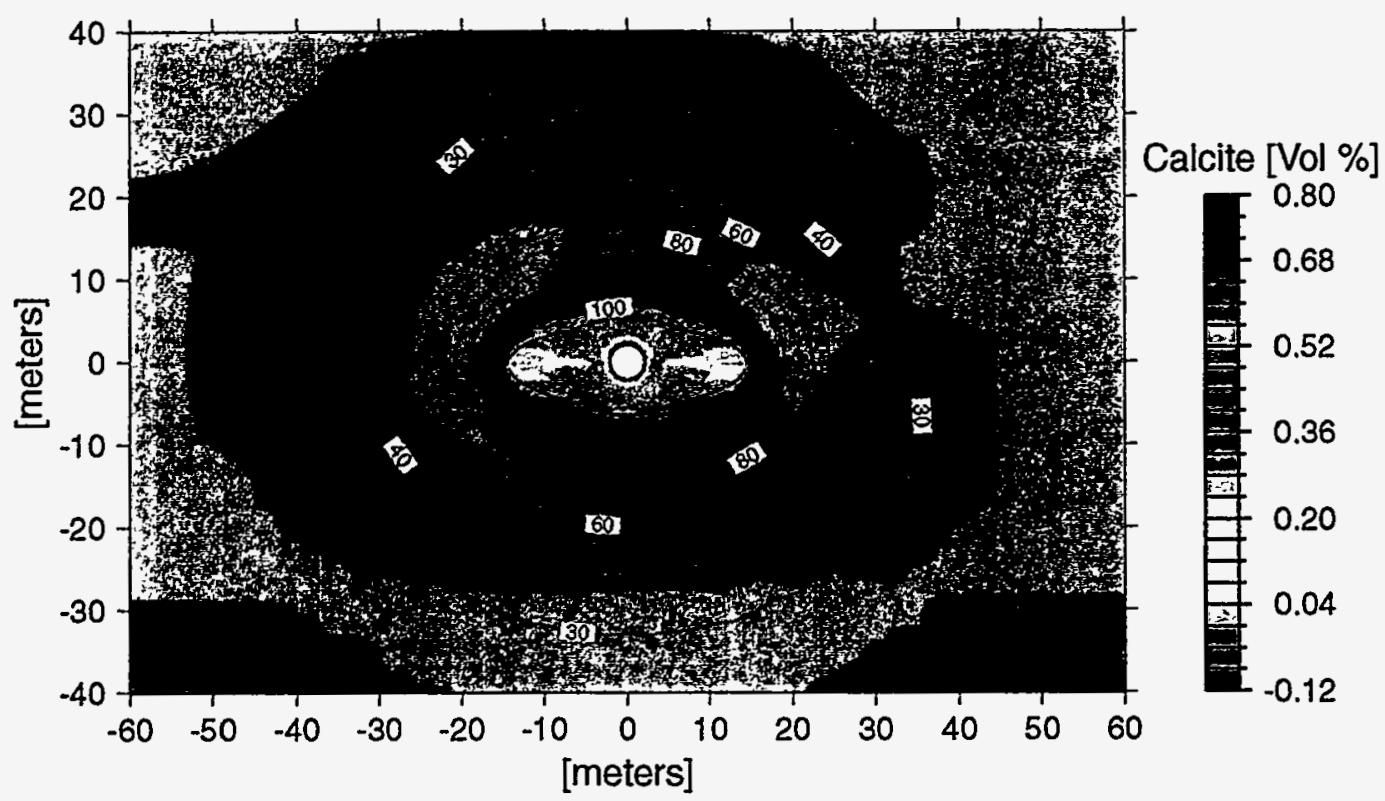

Figure 3.3-9. Calcite volume fraction dissolved/precipitated in fractures at the end of the 4 year heating cycle. Temperature contours are overlain. 


\section{FRACTURE CALCITE: \& YEARS}

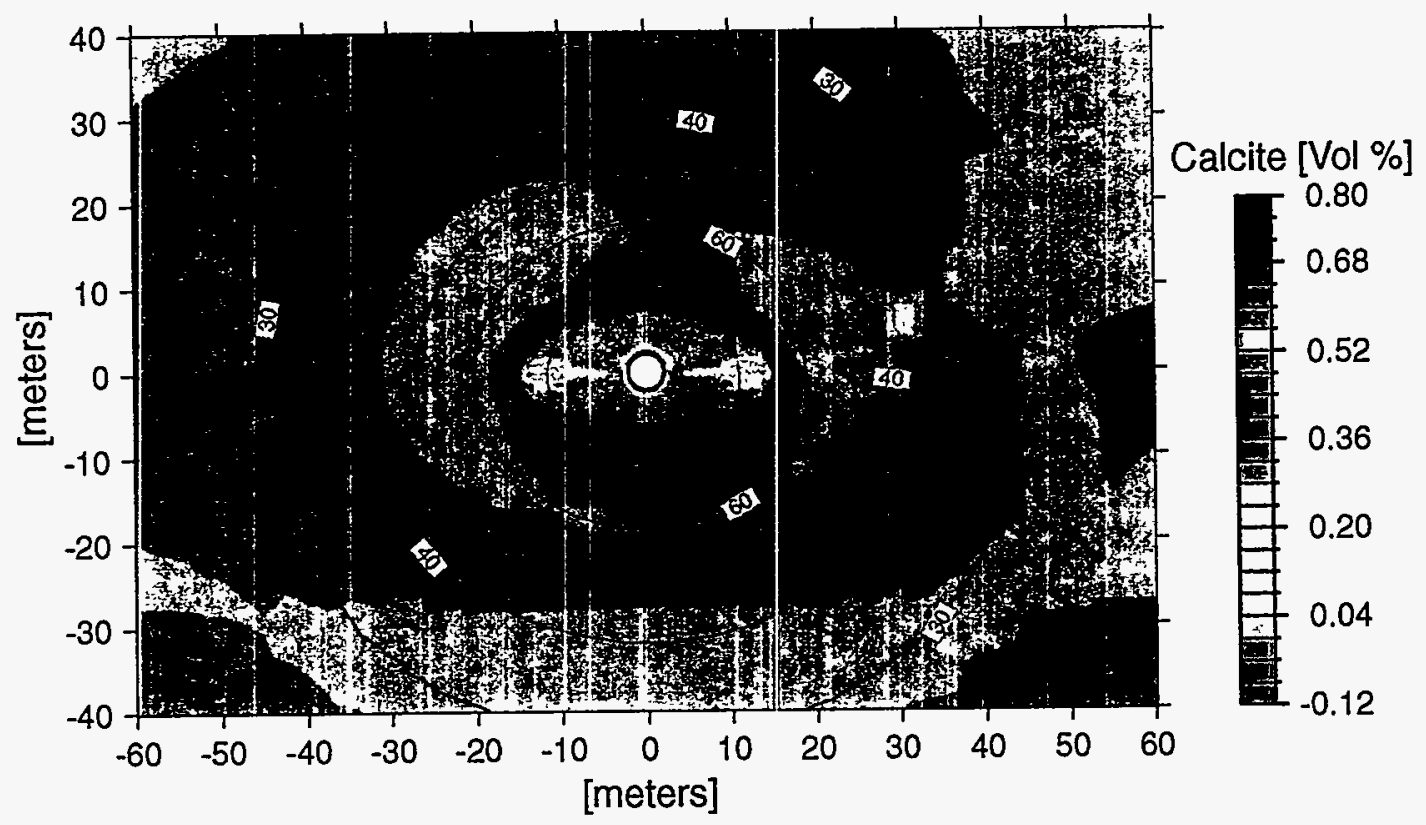

Figure 3.3-10. Calcite volume fraction dissolved/precipitated in fractures at the end of the 8 year heating and cooling cycles. Temperature contour's are overlain. 


\section{FRACTURE CRISTOBALITE: 6 MONTHS}

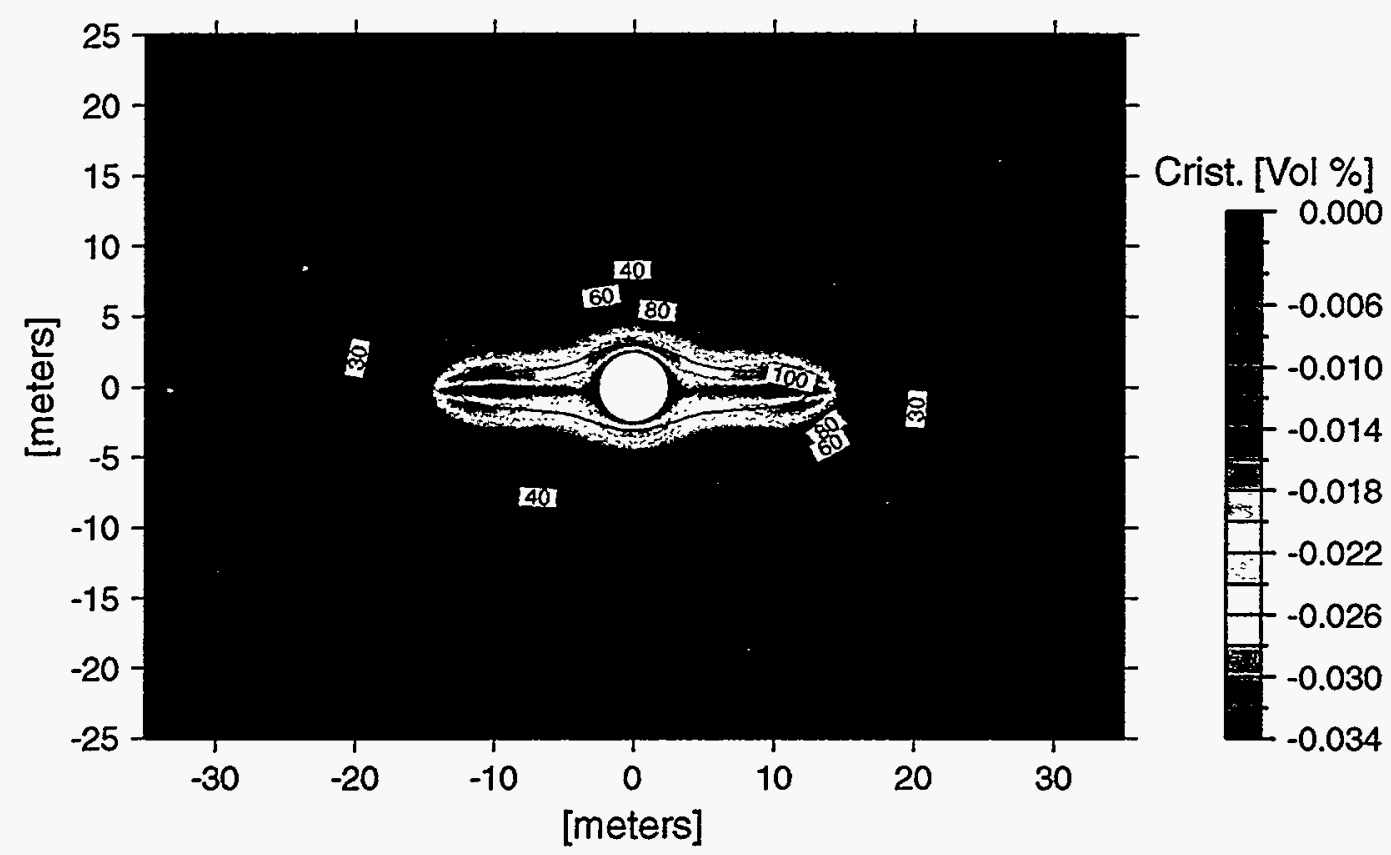

Figure 3.3-11. Cristobalite volume fraction dissolved in fractures after 6 months of heating. Temperature contours are overlain.

FRACTURE CRISTOBALITE: 4 YEARS

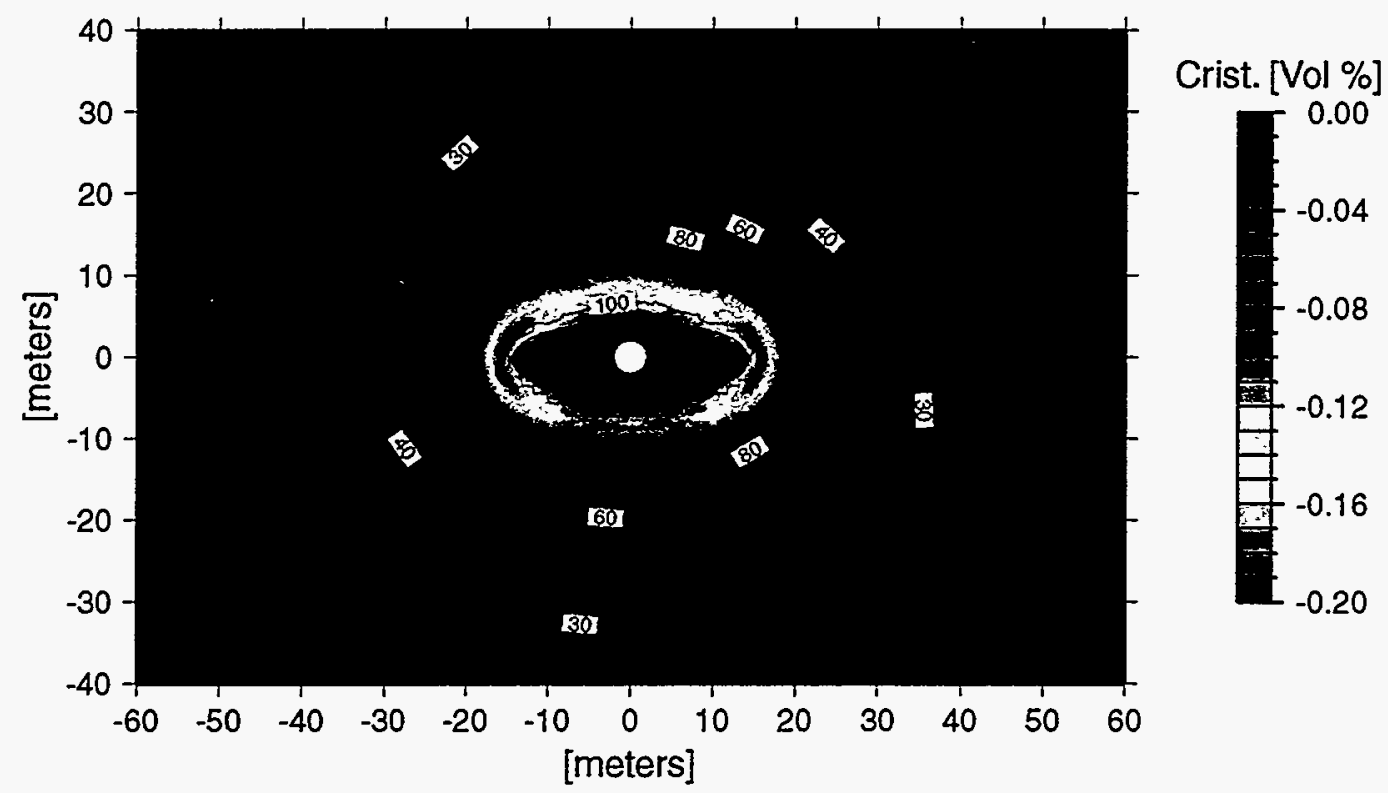

Figure 3.3-12. Cristobalite volume fraction dissolved in fractures at the end of the 4 year heating cycle. Temperature contours are overlain. 
FRACTURE AMORPHOUS SILICA: 8 YEARS

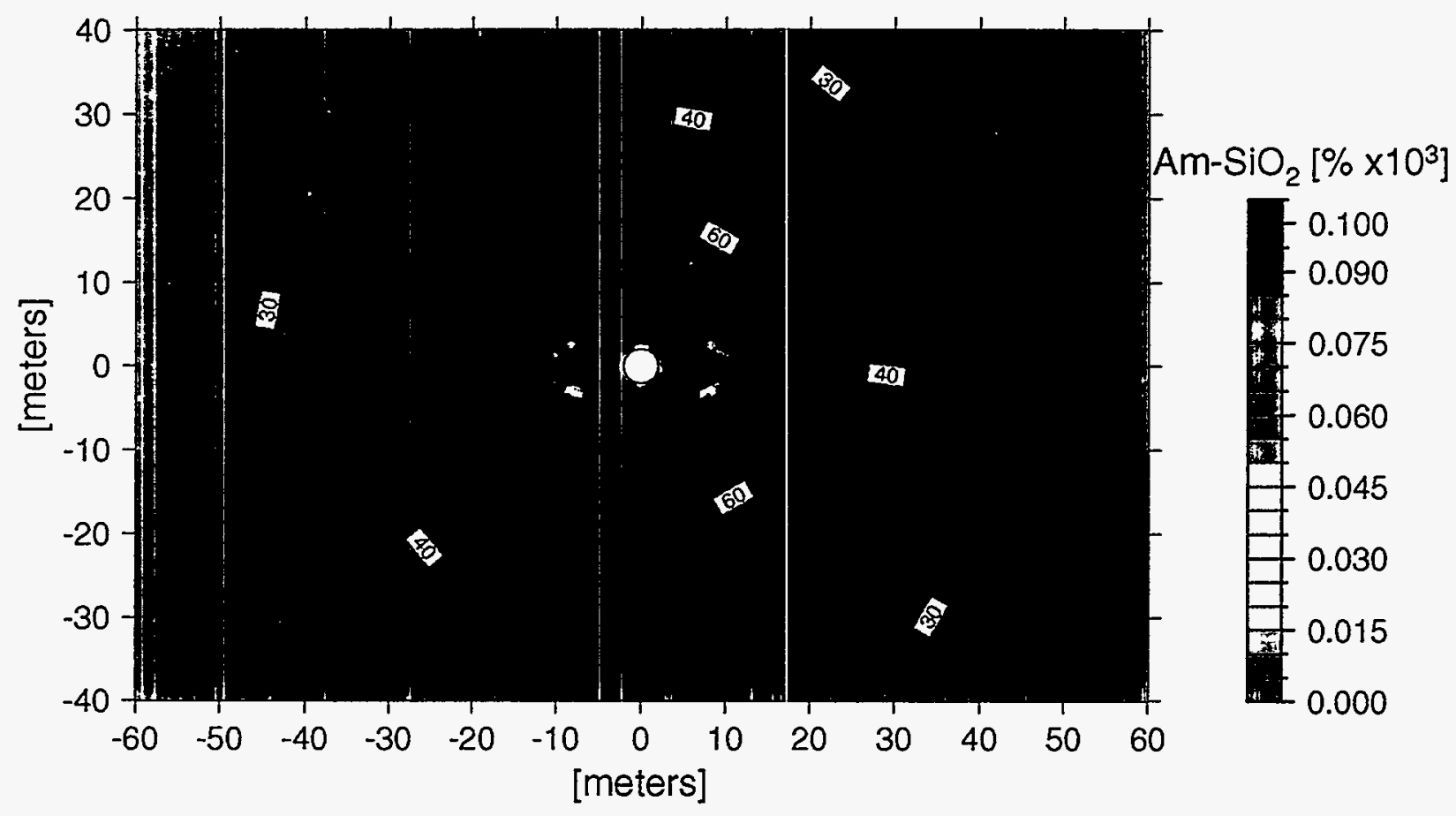

Figure 3.3-13. Amorphous silica volume fraction precipitated in fractures at the end of the 8 year heating and cooling cycles. Temperature contours are overlain. 
A

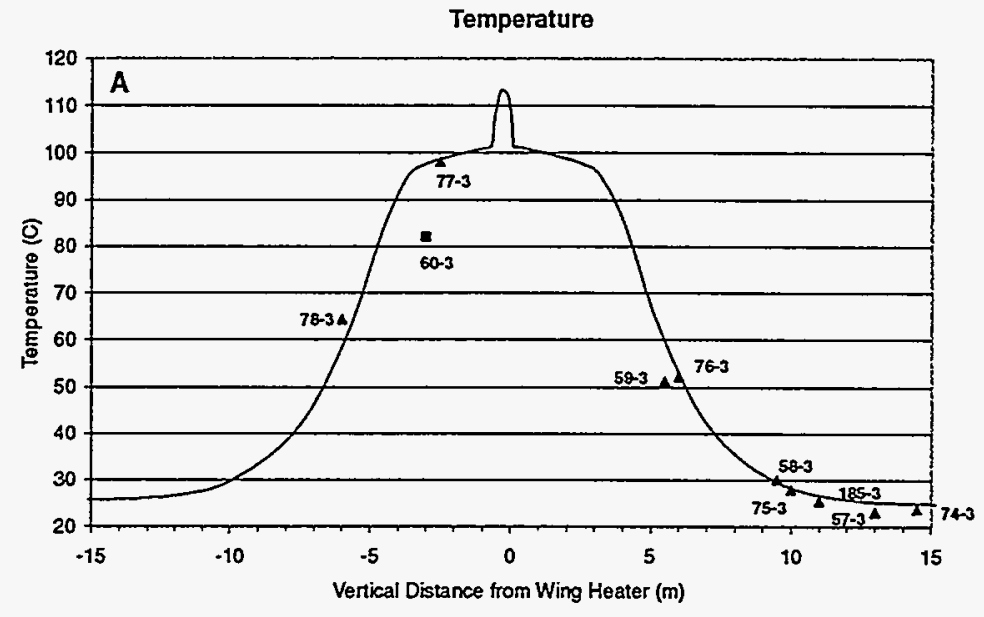

B
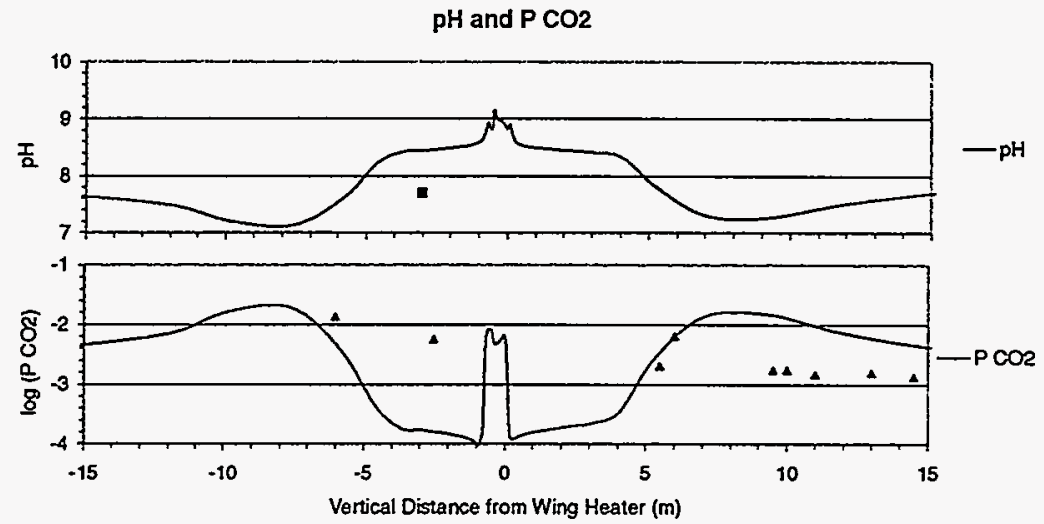

C

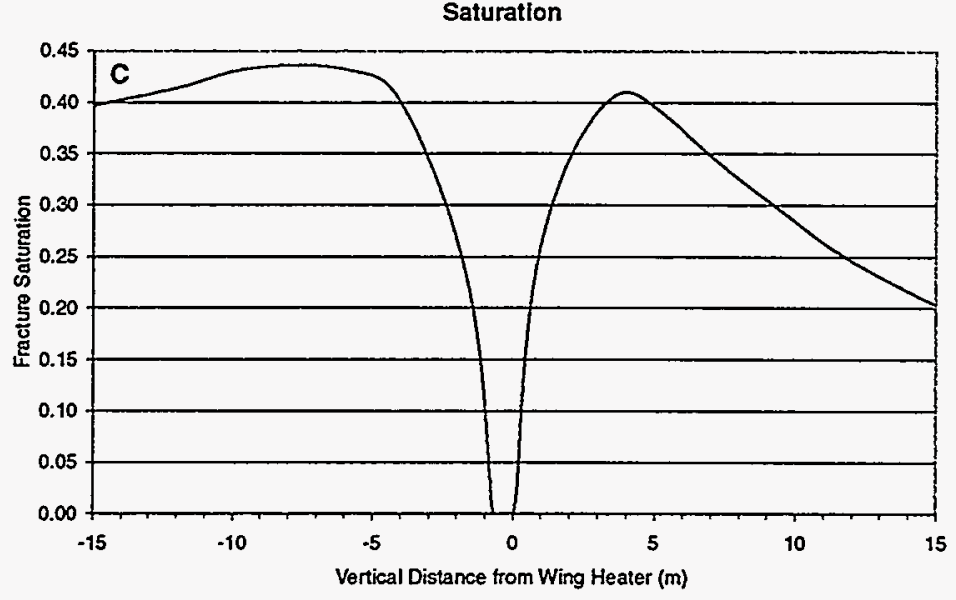

Figure 3.3-14. a) Temperature profile through wing heater after 6 months heating, showing measured temperatures and the sensor locations. b) $\mathrm{pH}$ and $\mathrm{P}_{\mathrm{CO} 2}$ profiles through wing heater after 6 months heating, showing measured values in water, and gas respectively. Locations are as in a) above. c) Liquid saturation in fractures through wing heater after 6 months heating. 

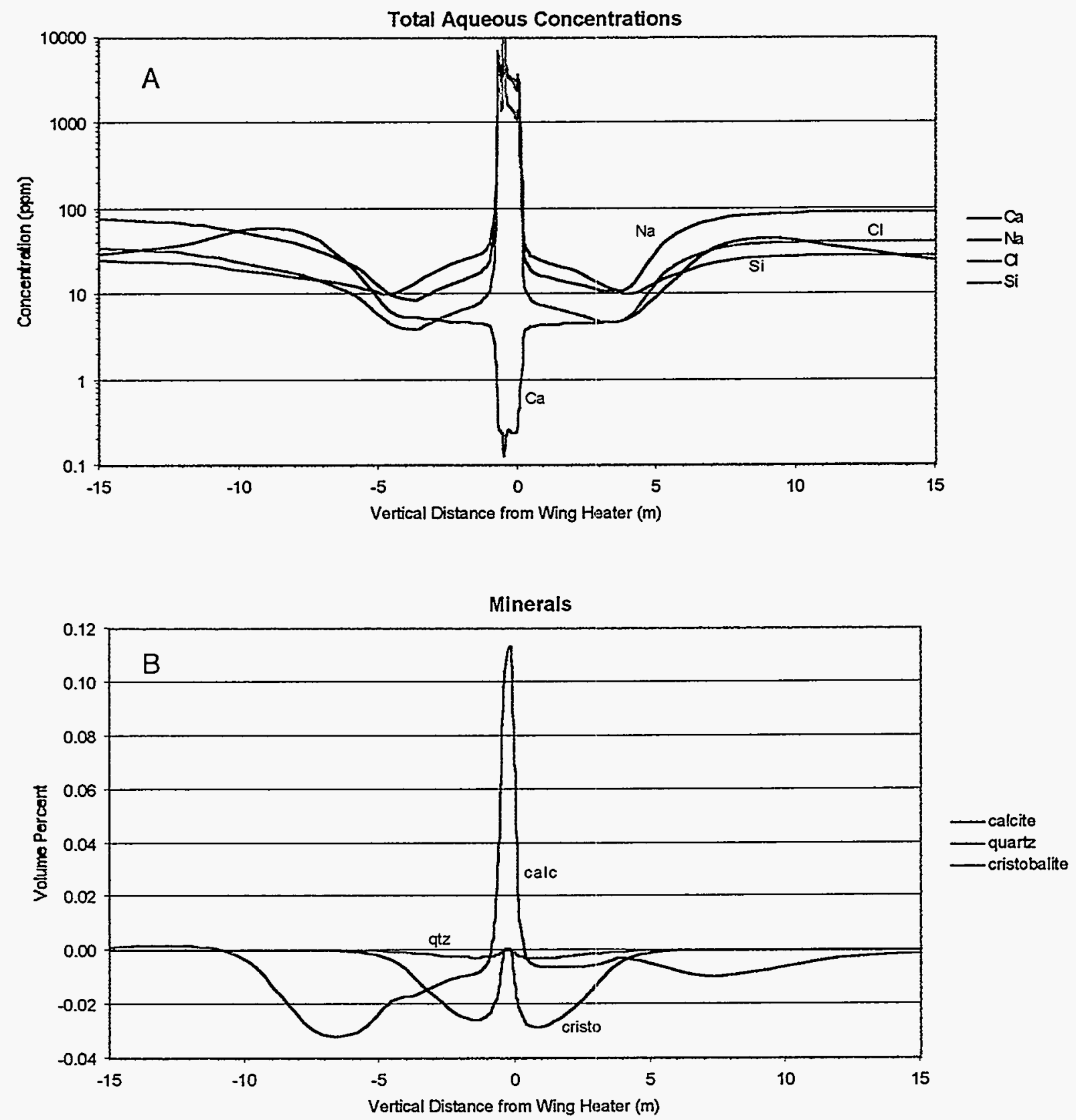

Figure 3.3-15. a) Profile of aqueous species concentrations through wing heater after 6 months heating. b) Mineral volume fractions dissolved/precipitated after 6 months heating. 


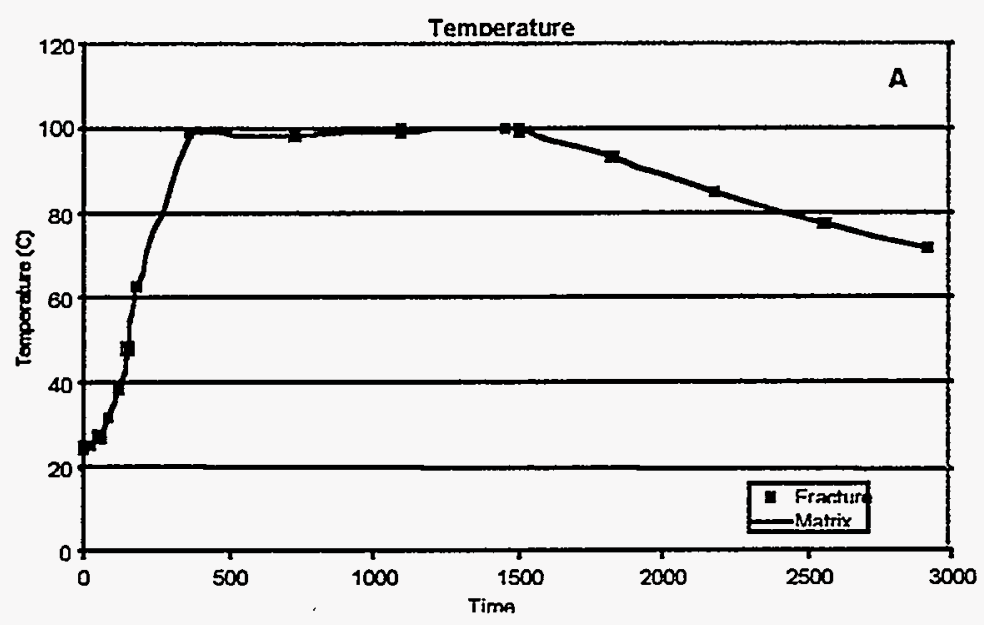

Fracture

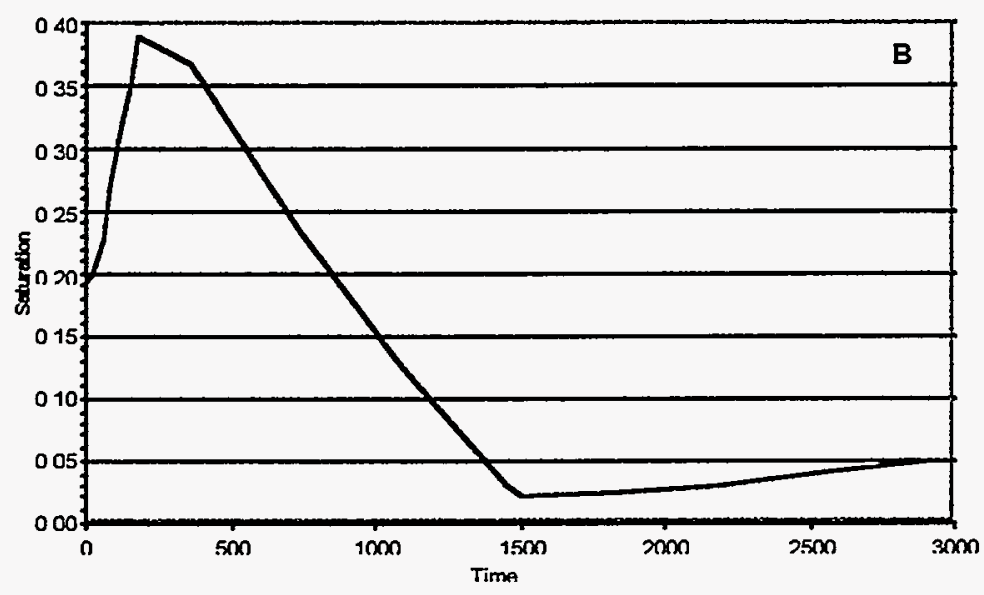

Matrix Saturation

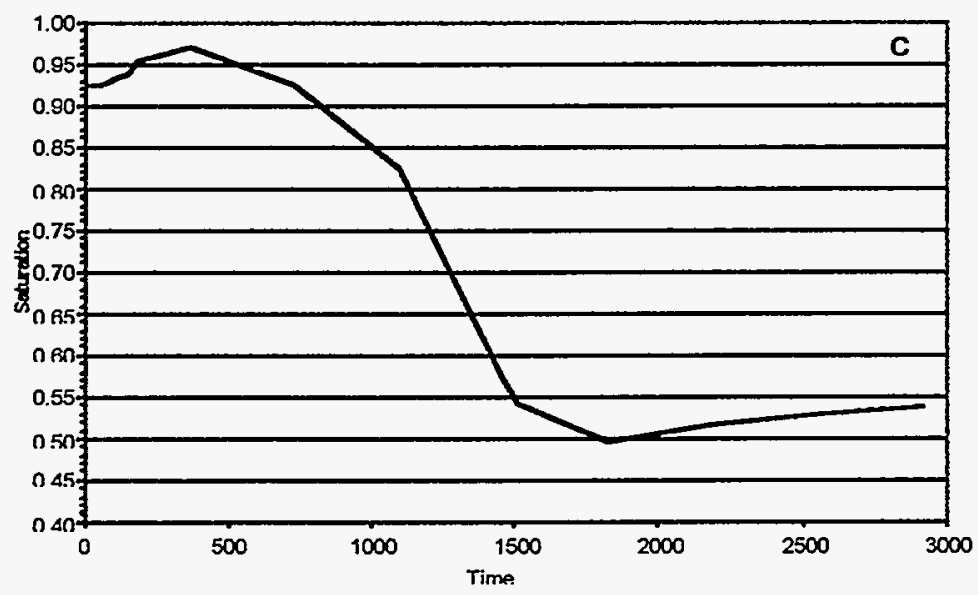

Figure 3.3-16. a) Temperatures over time for the full 8-year heating and cooling cycles at a single element in condensation zone above wing heaters. b) Fracture liquid saturation over time. c) Matrix liquid saturation over time. 
Fracture $\mathrm{pH}$ and $\mathrm{P} \mathrm{CO} 2$
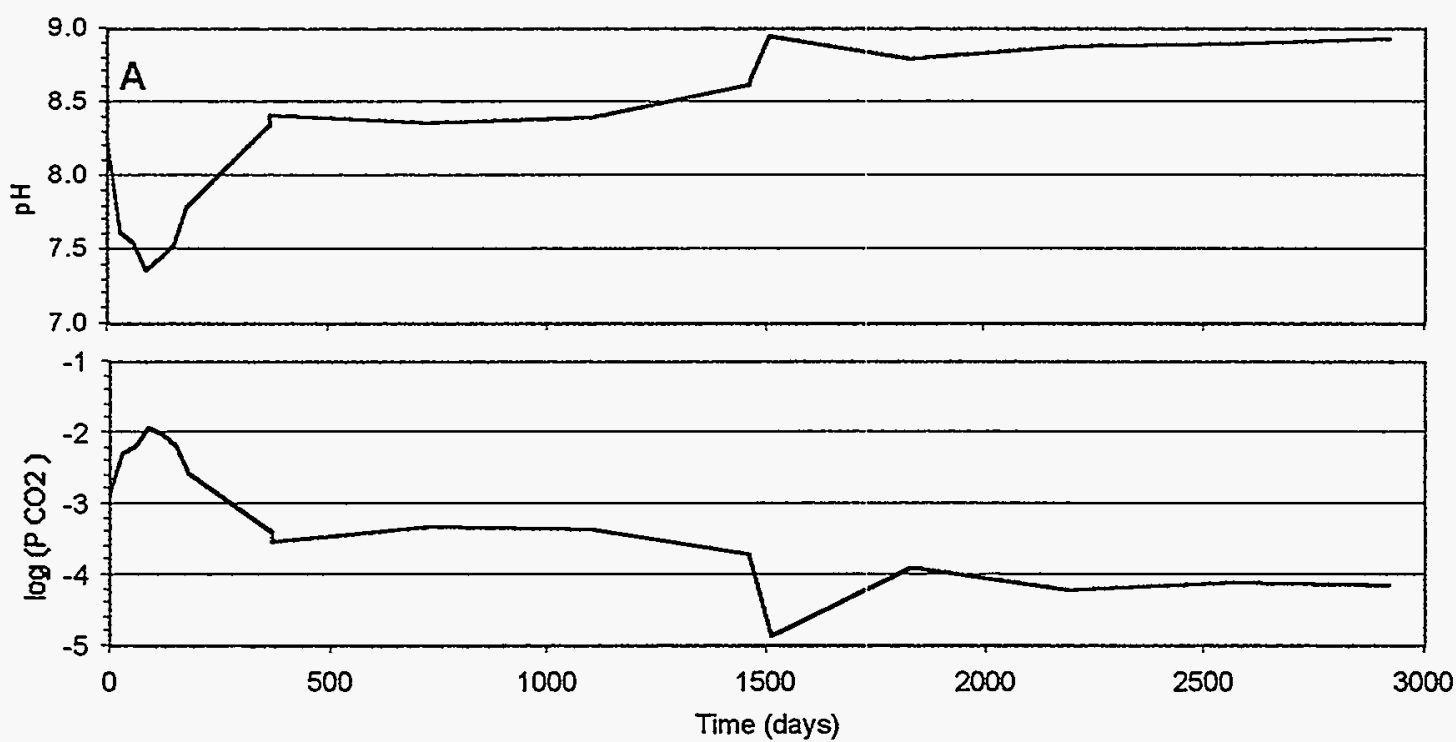

Matrix pH and $\mathrm{P}$ CO2

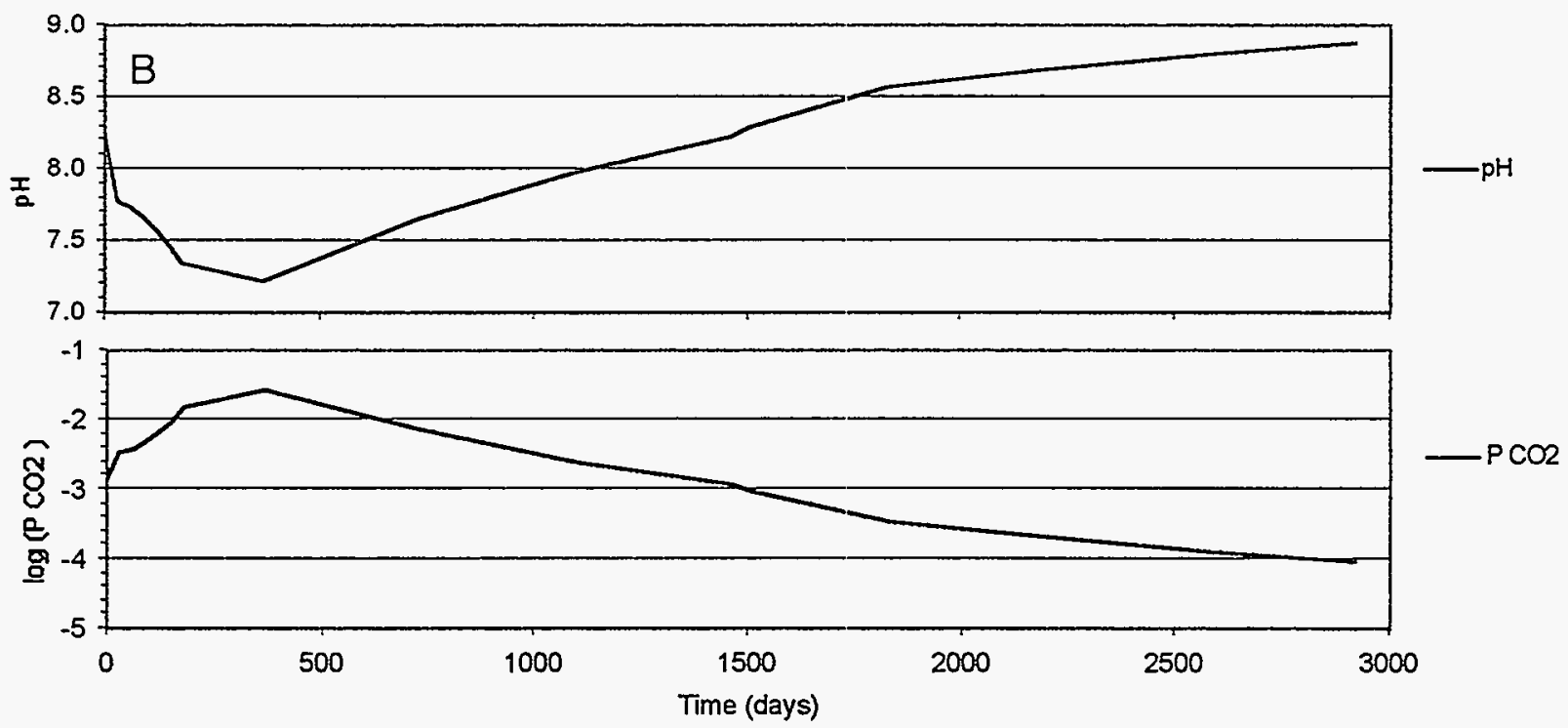

Figure 3.3-17. a) Fracture $\mathrm{pH}$ and $\mathrm{P}_{\mathrm{CO} 2}$ over time for the full 8-year heating and cooling cycles at a single element in condensation zone above wing heaters. b) Matrix $\mathrm{pH}$ and $\mathrm{P}_{\mathrm{CO} 2}$. 
Fracture Aqueous Phase

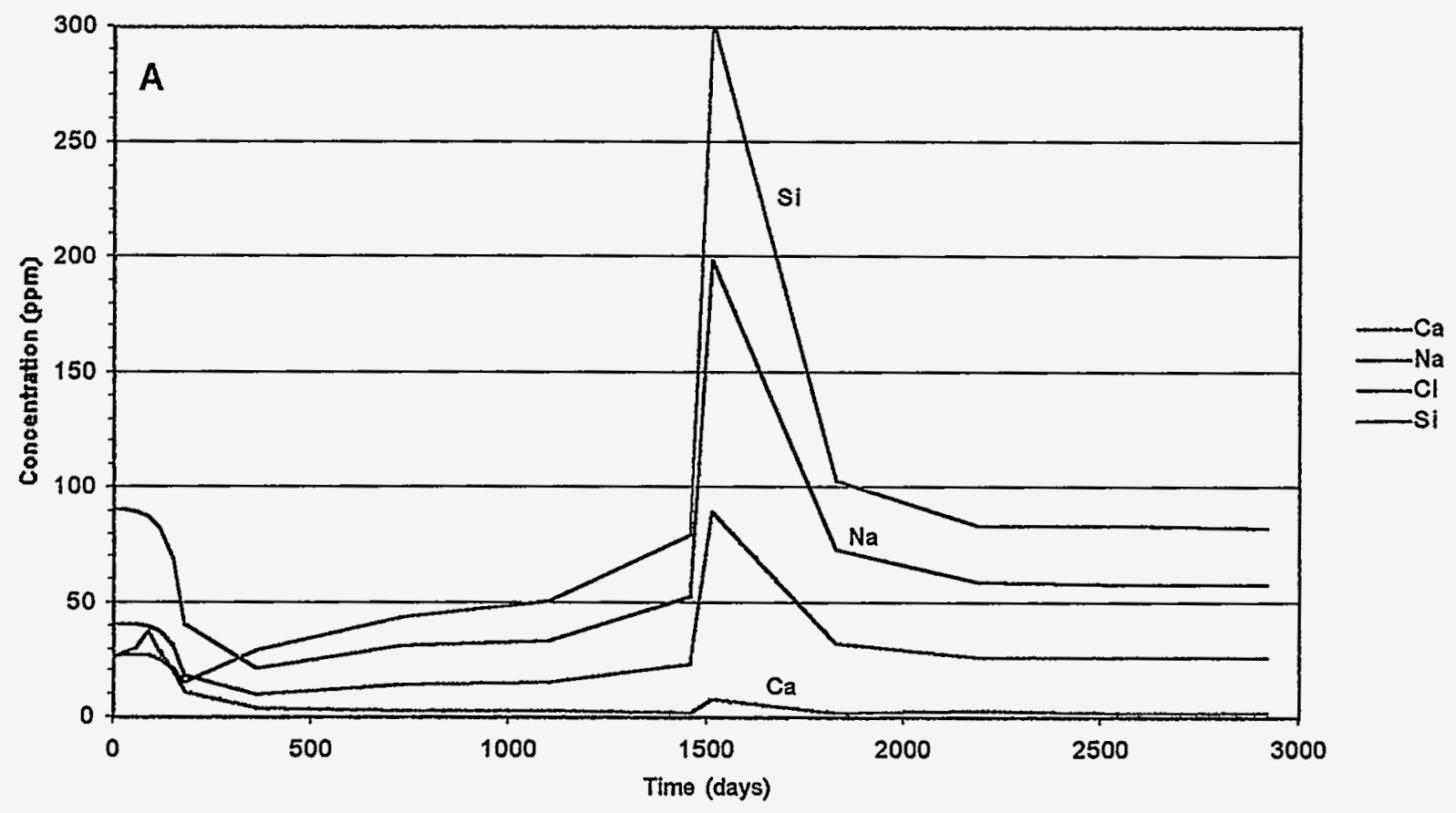

Matrix Aqueous Phase

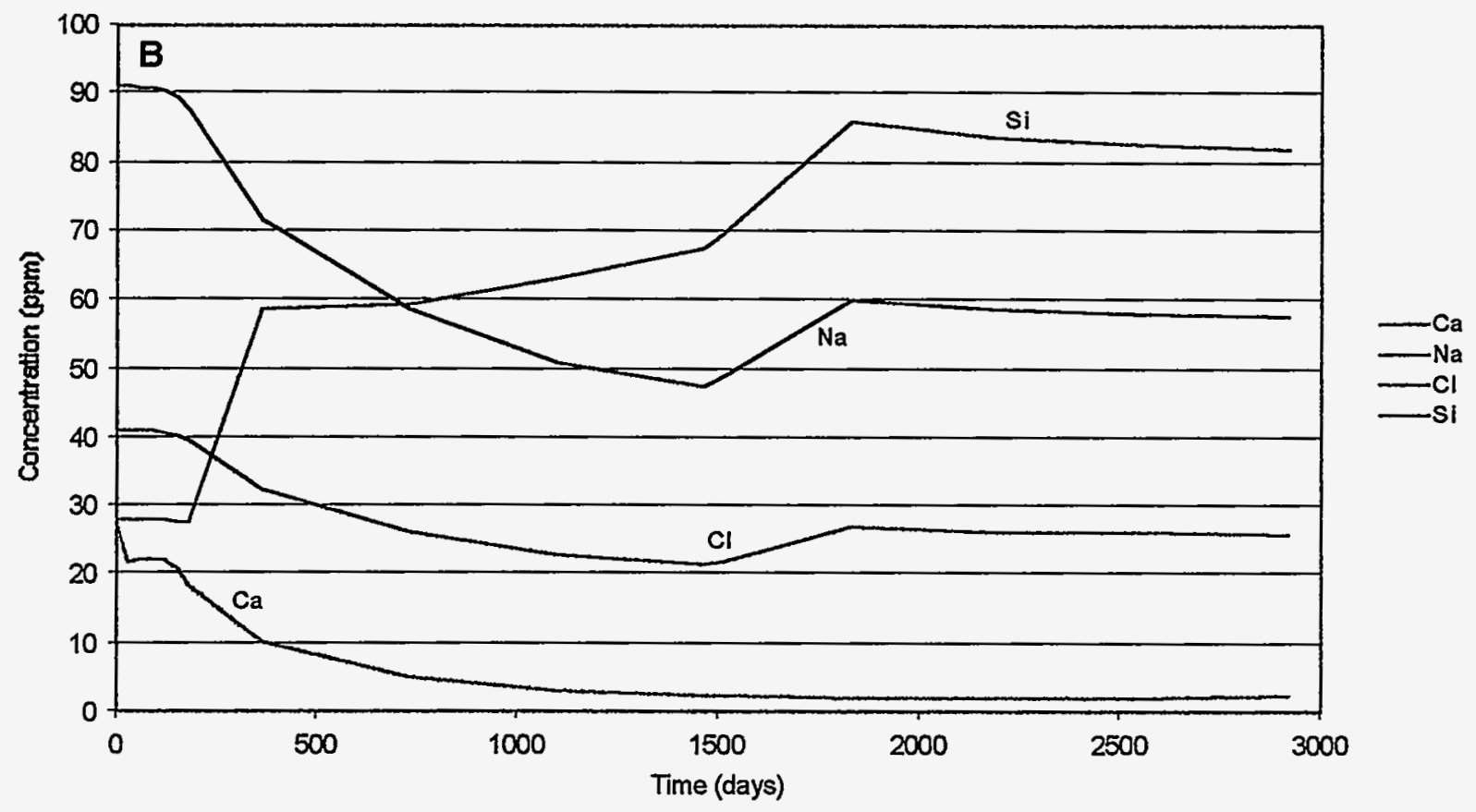

Figure 3.3-18. a) Aqueous species concentrations in fractures over time for the full 8-year heating and cooling cycles at a single element in condensation zone above wing heaters. b) Matrix aqueous species concentrations. 
Fracture Minerals

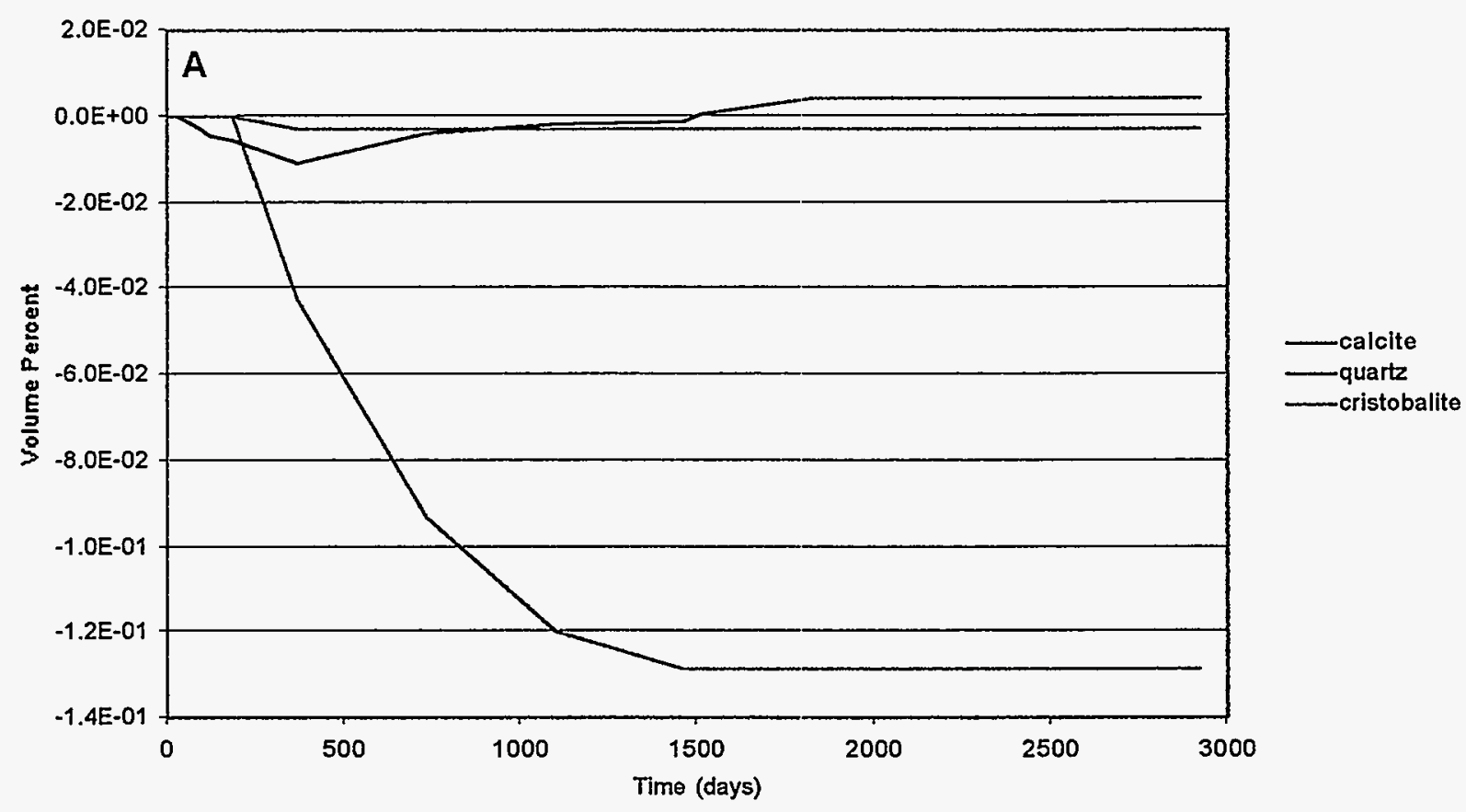

Matrix Minerials

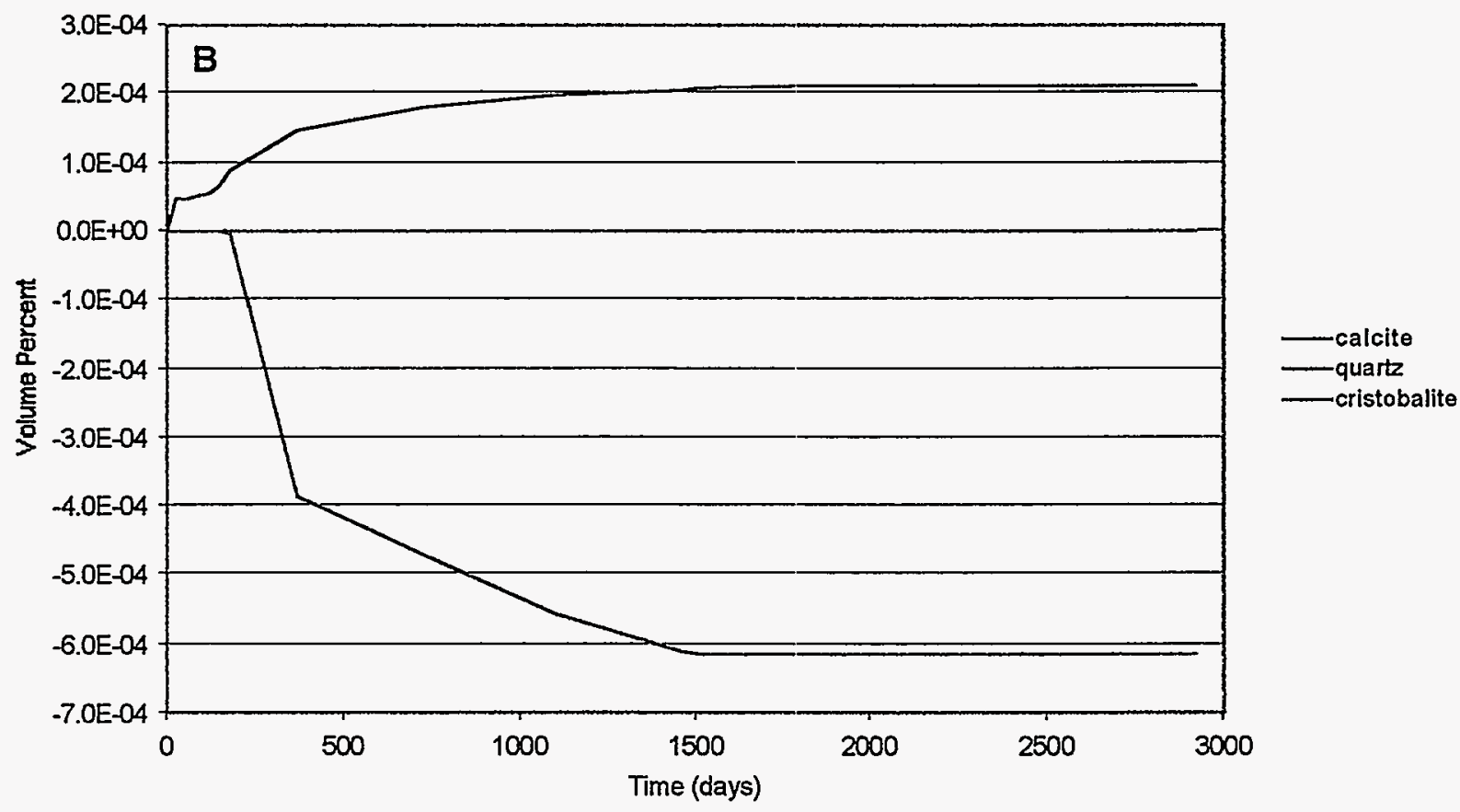

Figure 3.3-19. a) Mineral volume fractions dissolved/precipitated in fractures over time for the full 8year heating and cooling cycles at a single element in condensation zone above wing heaters. b) Mineral volume fractions dissolved/precipitated in matrix. 


\section{Temperature Profile Across Wing Heater}

Six Months

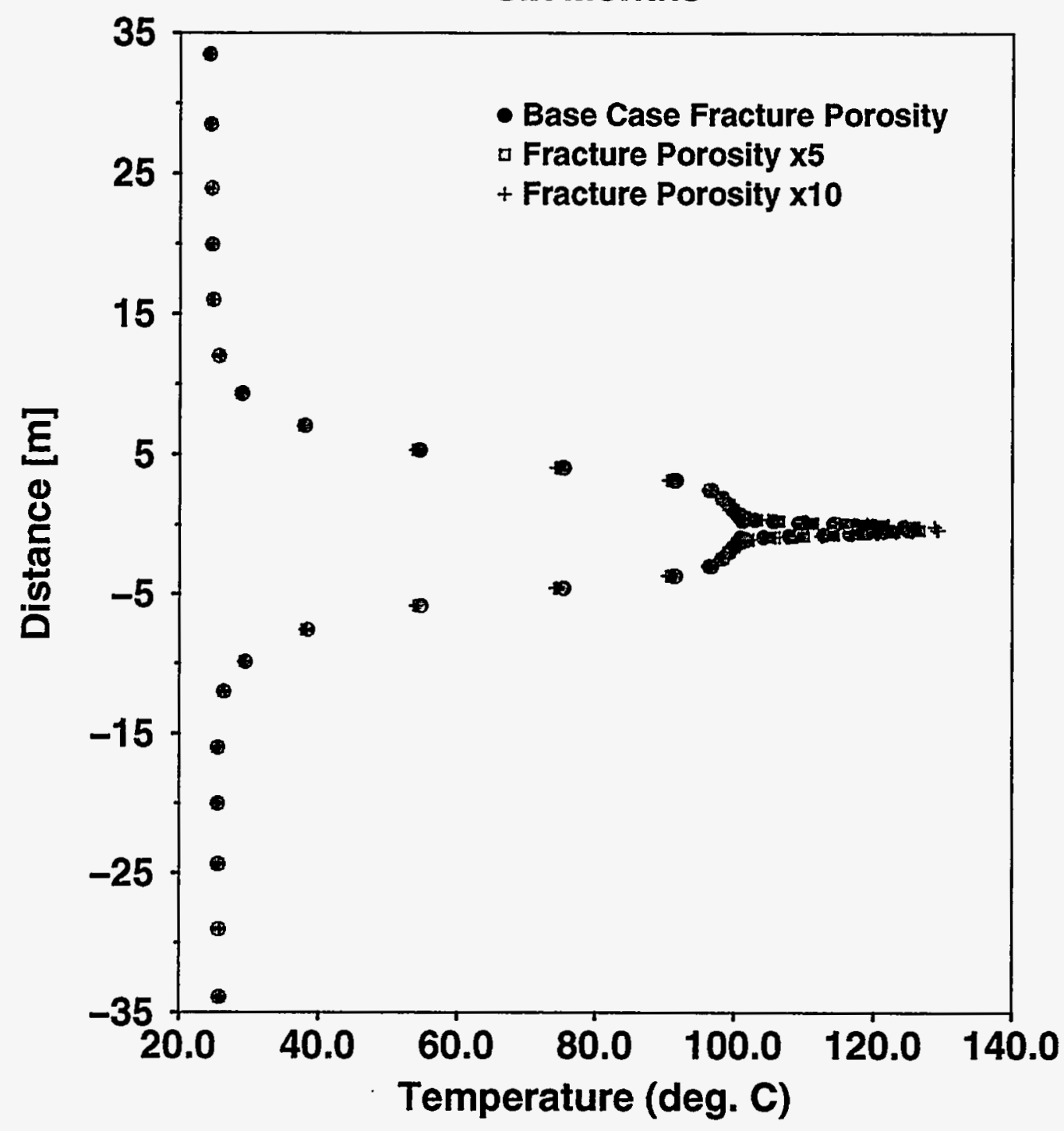

Figure 3.3-20. Vertical temperature profile in fractures through wing heater after 6 months heating for three different fracture porosity simulations. 
Fracture Saturation Across Wing Heater

Six Months

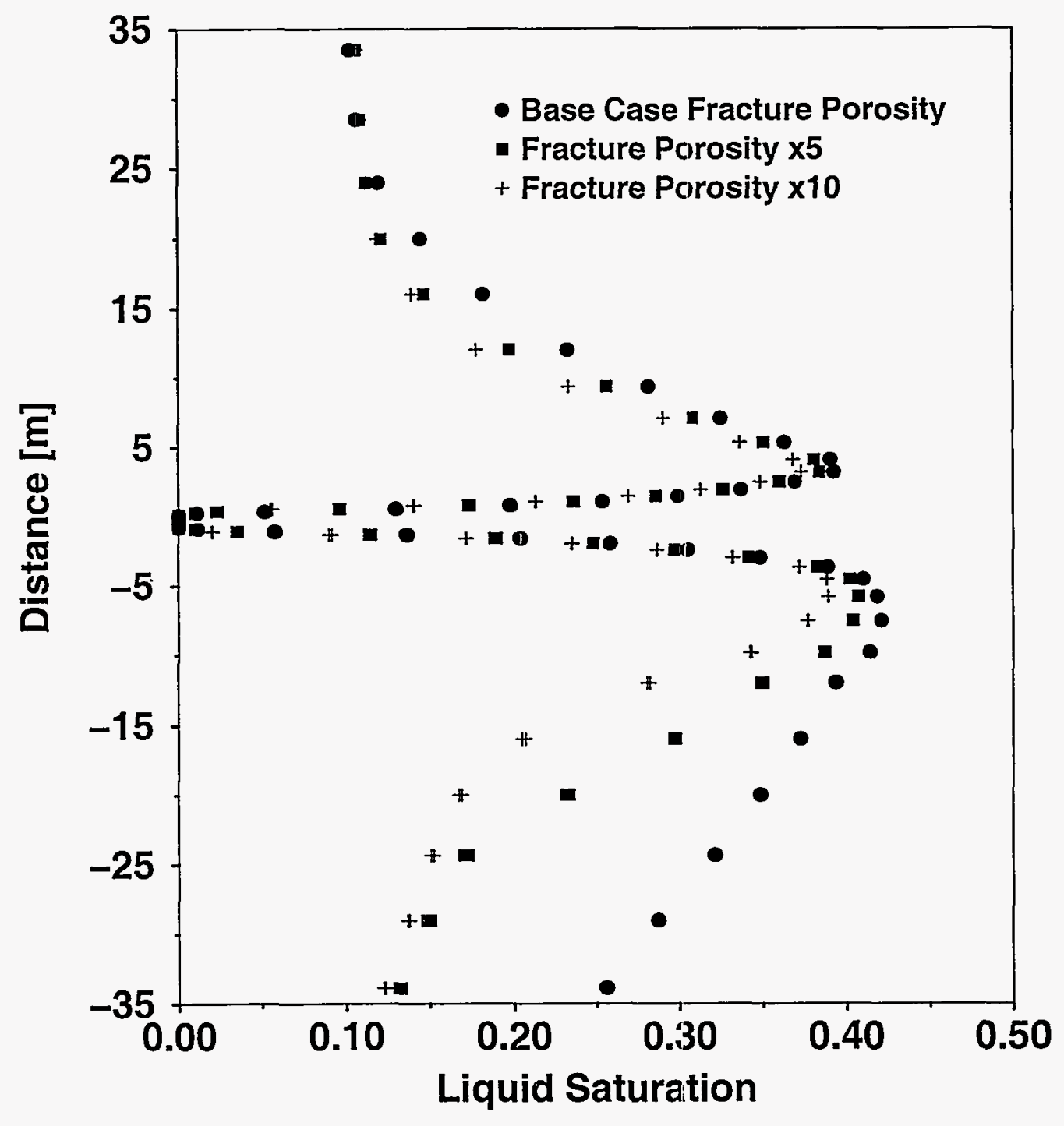

Figure 3.3-21. Vertical liquid saturation profile in fractures through wing heater after 6 months heating for three different fracture porosity simulations. 


\section{Fracture Chloride Across Wing Heater}

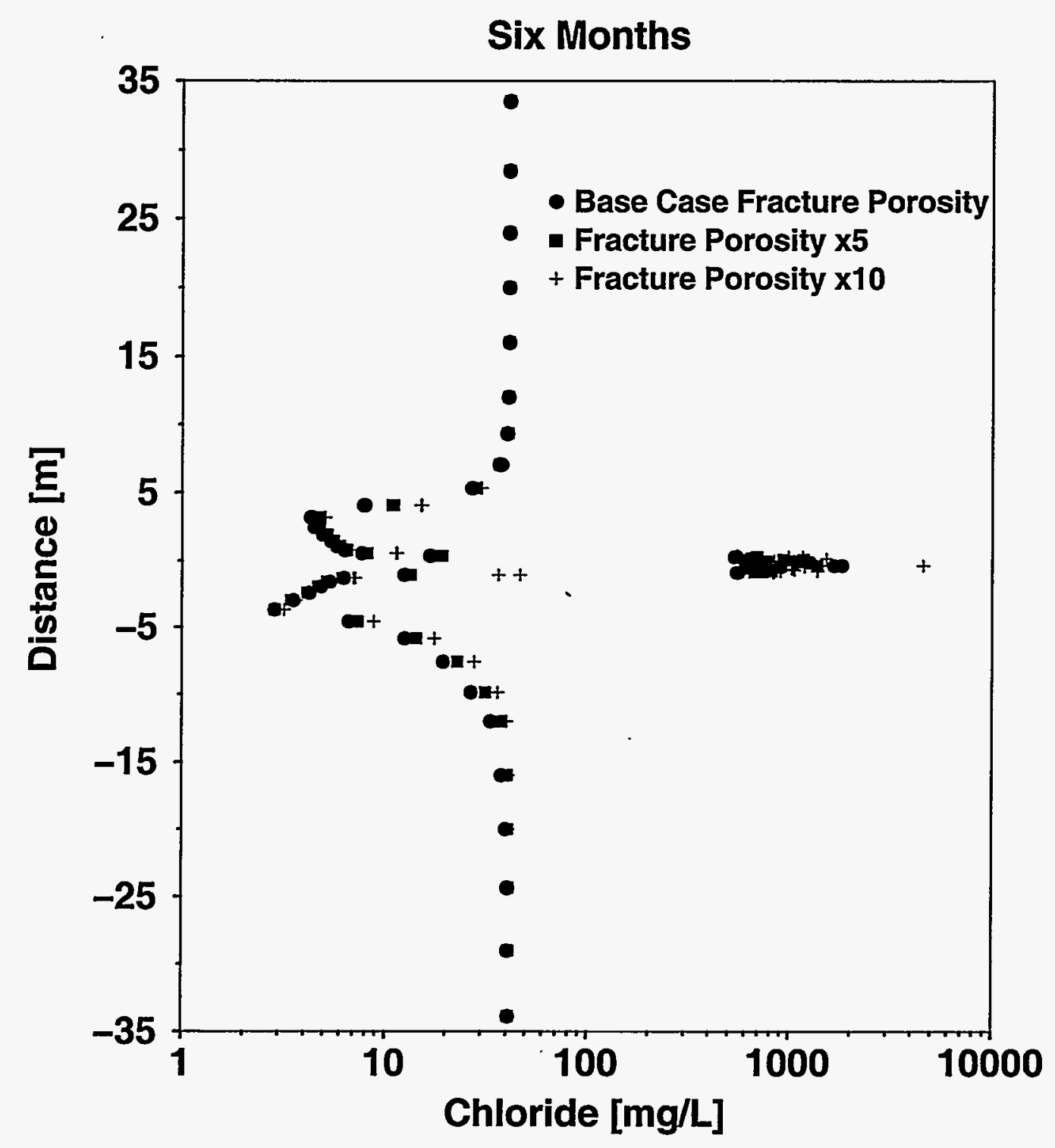

Figure 3.3-22. Vertical chloride concentration profile in fractures through wing heater after 6 months heating for three different fracture porosity simulations. 


\section{Fracture SiO2 (aq) Across Wing Heater}

\section{Six Months}

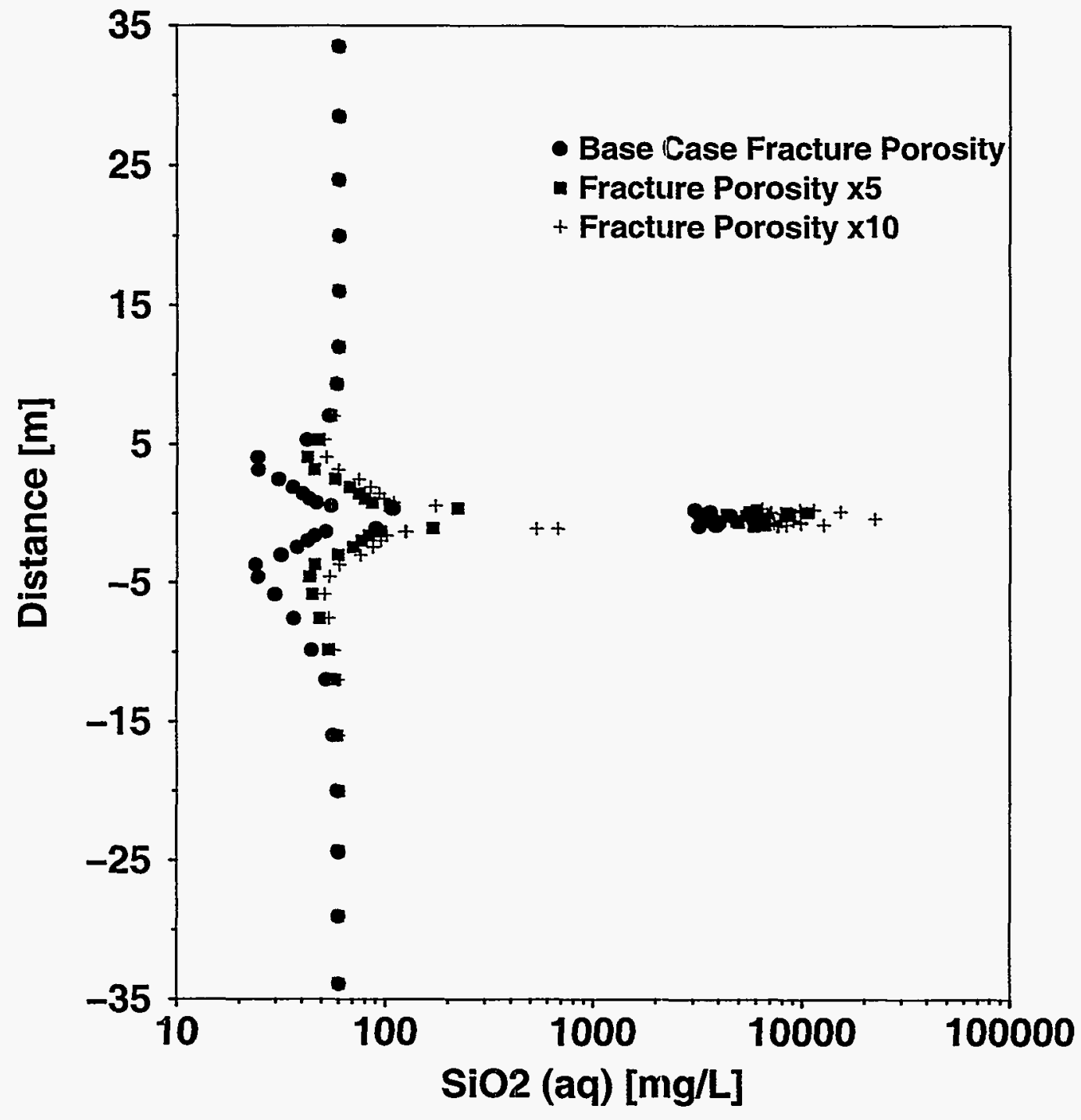

Figure 3.3-23. Vertical aqueous silica concentration profile in fractures through wing heater after 6 months heating for three different fracture porosity simulations. 


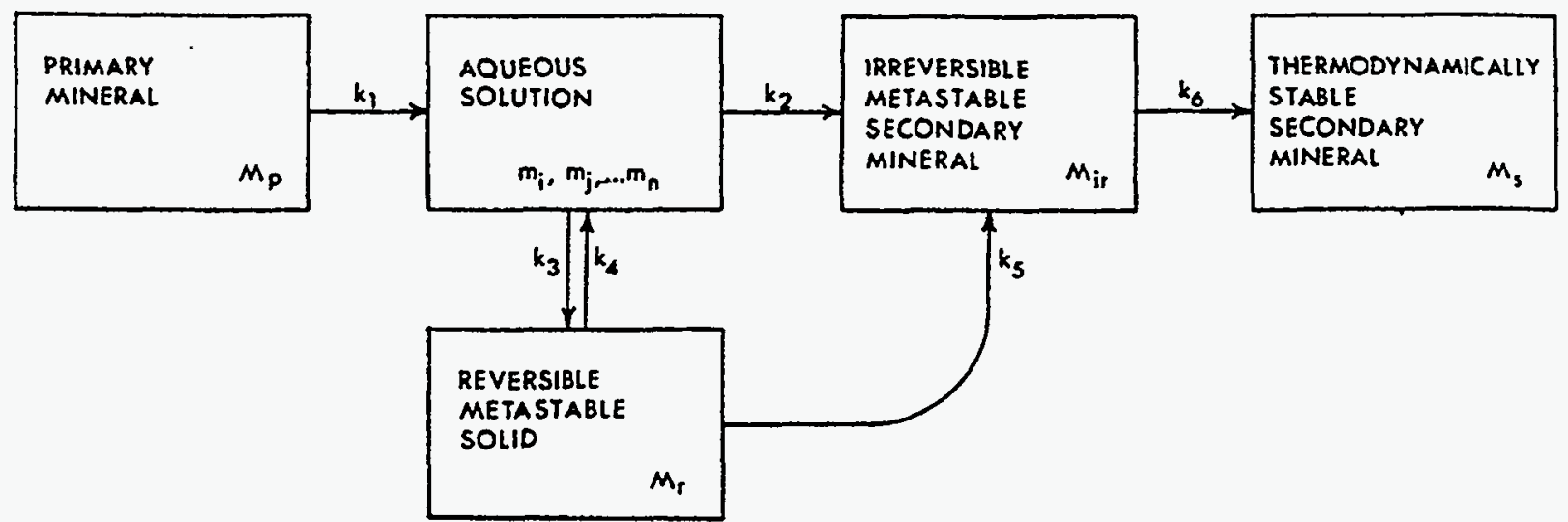

Irreversible transformation of a primary mineral into secondary minerals and the position of a reversible

metastable solid in a natural water system. $\mathrm{M}_{\mathrm{p}}, \mathrm{M}_{\mathrm{s}}, \mathrm{M}_{\mathrm{ir}}, \mathrm{M}_{\mathrm{s}}$ are the extensive masses of the primary mineral and the reversible, irreversible metastable and thermodynamically stable secondary phases respectively. $M_{p}, M_{r}, M_{i r}$, $M_{s}$ are molarites of participating chemical components in aqueous solution.

Figure 3.4-1 From Figure 1 in Paces (1978). 


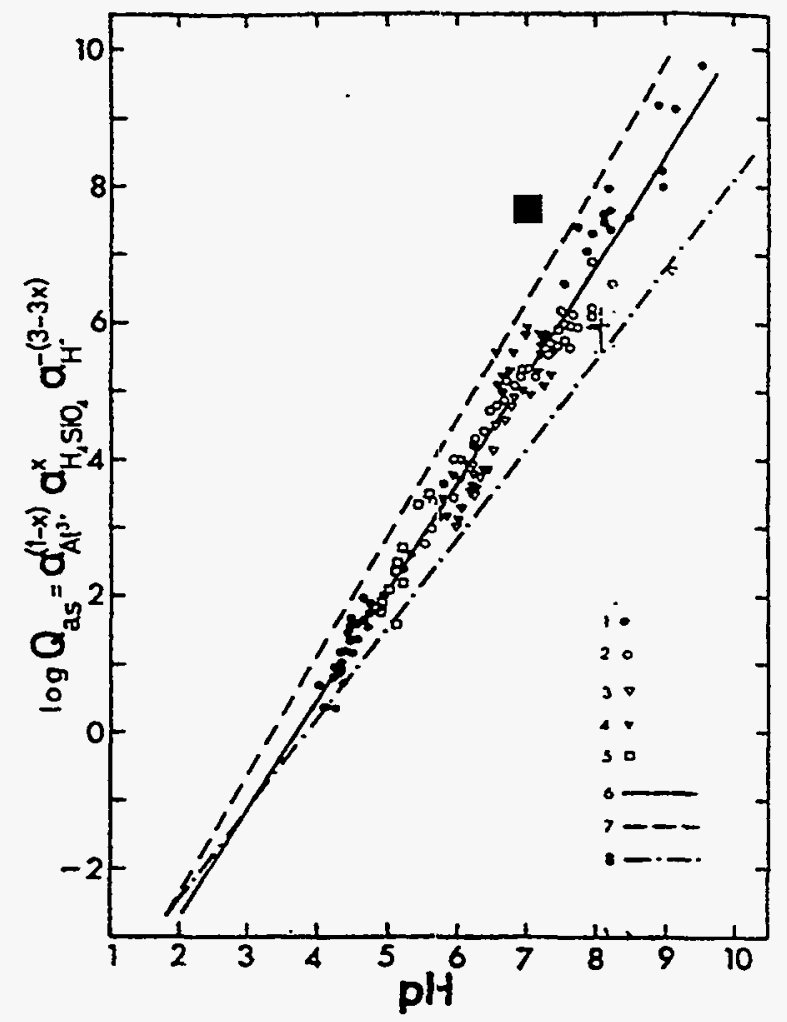

The linear correlation between $\mathrm{pH}$ and logarithm of activity product $\mathrm{Q}_{\mathrm{as}}=\mathrm{a}^{(1-\mathrm{x})}{ }_{\mathrm{Al} 3+} \mathrm{a}_{\mathrm{H} 4 \mathrm{SiO}} / \mathrm{a}^{(3-3 x)}{ }_{\mathrm{H}+}$ in experimental solutions and natural water samples. Symbols 1-5 represent analyses of natural waters and experimental solutions. Box represents J-13 well water (see text). 6 , regression line for all the data points; 7 , linear plot between the solubility products of amorphous alumina and silica at the $\mathrm{pH}$ values of their points of zero charge; 8 , linear plot between the solubility products of raicrocrystalline gibbsite and amorphous silica at the $\mathrm{pH}$ values of their points of zero charge.

Figure 3.4-2 After Figure 2 from Paces (1978). 
o.

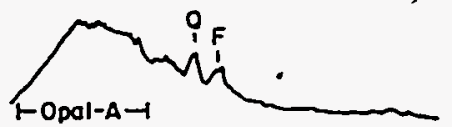

b.

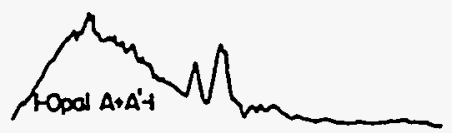

c.

d.

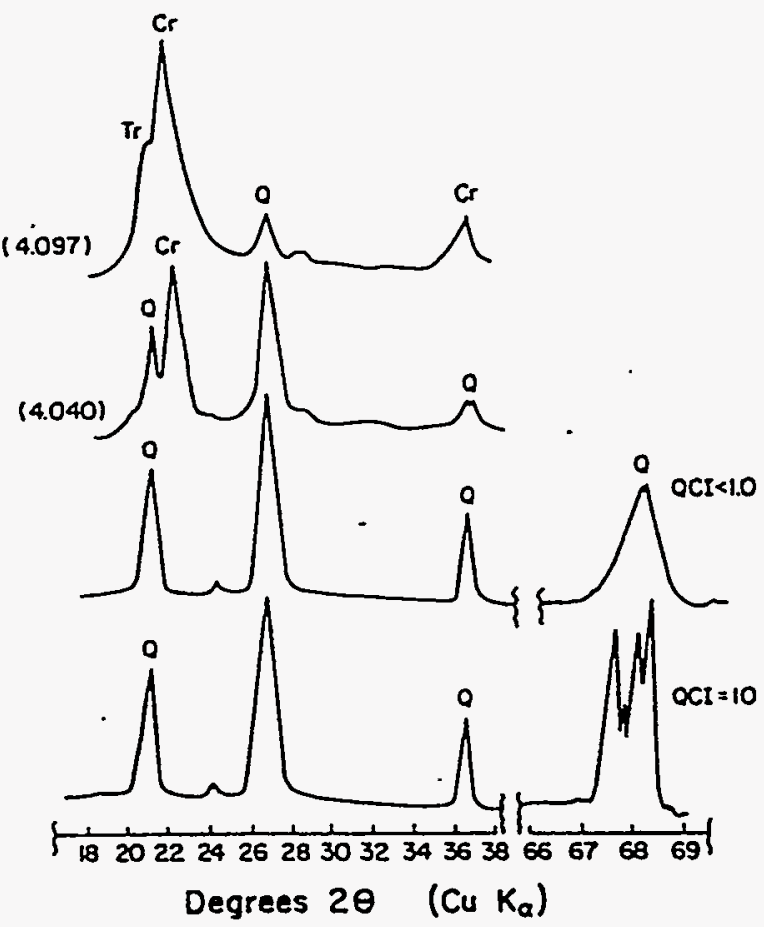

$X R D$ patterns representing the diagenetic sequence. $Q=$ quartz; $F=$ feldspar (detrital); $\mathrm{Cr}=$ cristobalite; $\mathrm{Tr}=$ tridymite. a) Diffuse hump between approximately $19^{\circ}$ and $25^{\circ} 2 \theta$ representing opal-A. b) Opal-A hump showing development of small peaks in the $19-25^{\circ} 2 \theta$ range, reflecting early precipitation of opal- $\mathrm{A}^{\prime}$. c) XRD pattern for opal-CT, with d[101] - spacing $=4.097 \AA$. d) XRD pattern for opal-CT showing increasing crystallinity and decreasing d-spacing with depth. $d[101]-$ spacing $=4.040 \AA$. .e) Transformation of biogenic silica from opal-CT to poorly crystalline quartz. Quartz crystallinity index, measured from the (212) peak of quartz at $67.76^{\circ} 2 \theta,=<1.0 \mathrm{f}$ ). Increased diagenesis causes authingenic quartz to become better ordered, as denoted by a well-formed quartz (212) peak at $67.74^{\circ} 2 \theta$. Quartz crystallinity index of this sample $=10.0$.

Figure 3.4-3 After Figure 2 from Williams et al, (1985). 


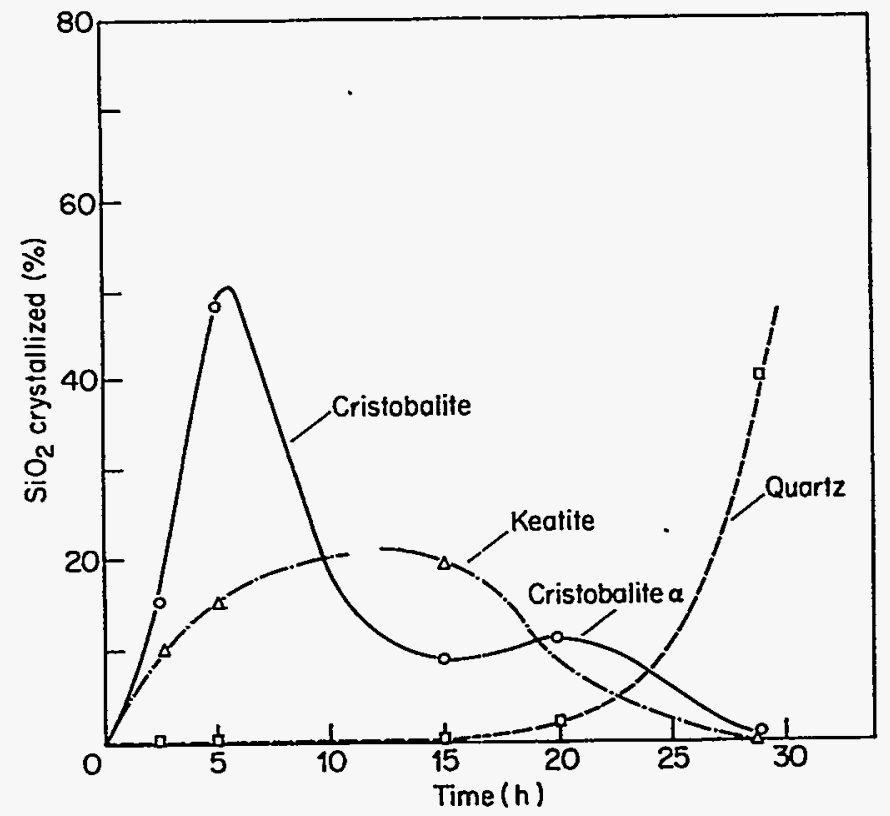

Transformation of amorphous $\mathrm{SiO}_{2}$ to quartz, cristobalite, and keatite as a function of time.

Temperature $300^{\circ} \mathrm{C}$, in presence of $3 \% \mathrm{KOH}$ aq., after Siffert and Wey (1967).

Figure 3.4-4 From Figure 2.14 of Barrer (1982).

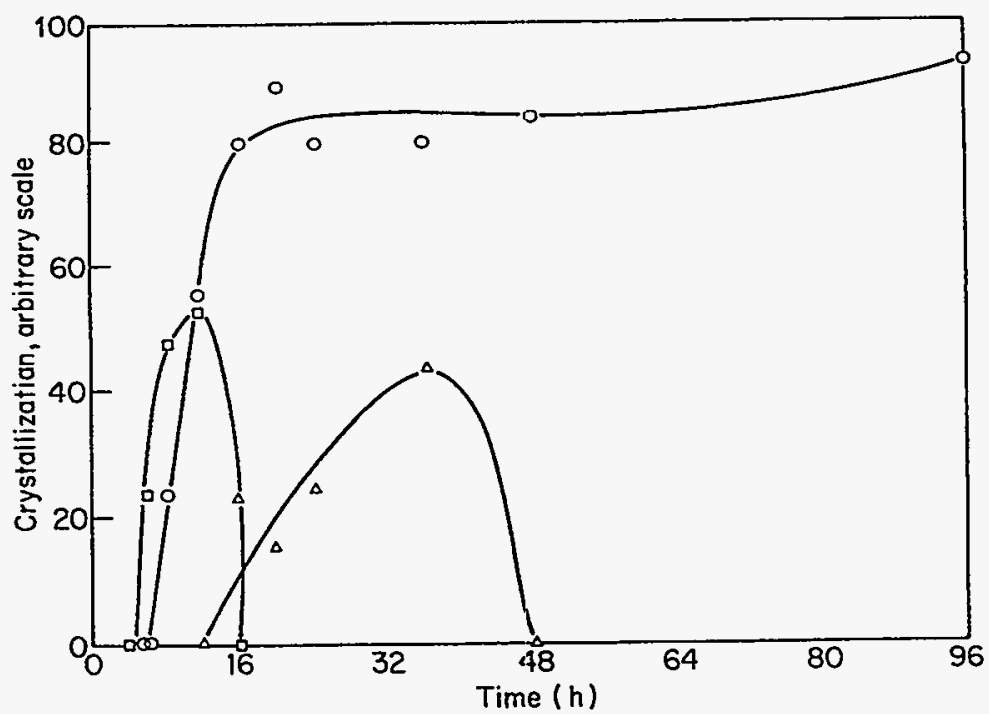

Crystallization curves showing appearance and disappearance of mordenite ( $\square$ ) and an analcime type phase $(\Delta)$ during growth of zeolite ZSM-5 (O) from the parent composition $\left.6(\mathrm{TPA})_{2}\right) \cdot 4 \mathrm{Na}_{2} \mathrm{O} . \mathrm{Al}_{2} \mathrm{O}_{3} .28 \mathrm{SiO}_{2} .750 \mathrm{H}_{2} \mathrm{O}$. After Erdem and Sand (1979).

Figure 3.4-5 From Figure 4.14 of Barrer (1982). 


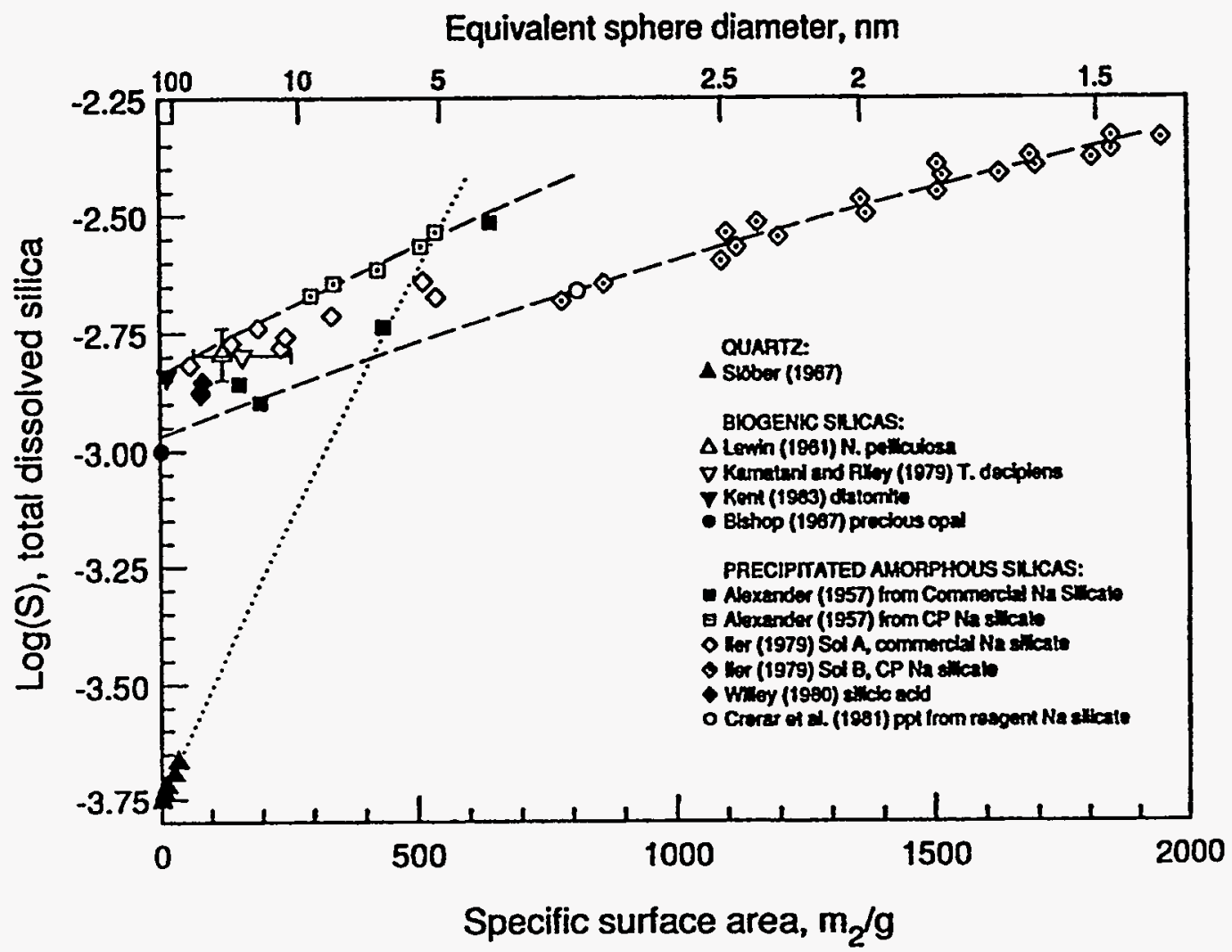

Effect of specific surface area on the solubilities of quartz and amorphous silicas. The lines represent the FreundlichOstwald equation, adapted to allow variation of $\gamma$ with particle size, fitted to selected experimental data and extrapolated far beyond the range of fitted data. For particle sizes smaller than $5 \mathrm{~nm}$, quartz may be more soluble, or less stable, than amorphous silica.

Figure 3.4-6 After Figure 16 from Parks (1990). 


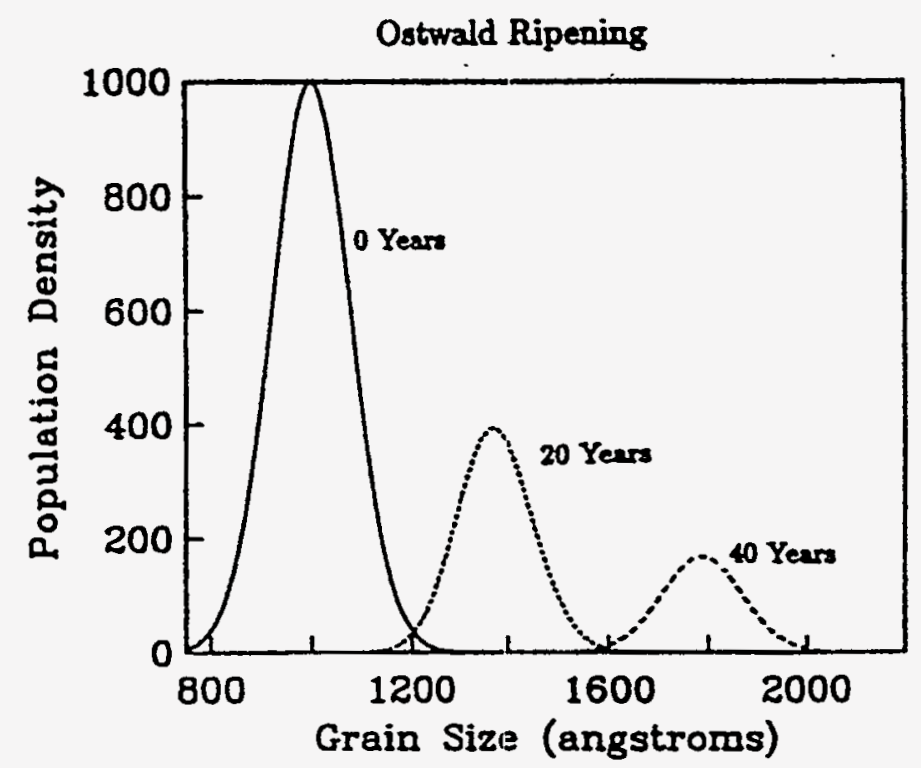

Ostwald Ripening of an initially Gaussian population of gibbsite crystals with an average size of $1000 \AA$ using an interfacial free energy of $350 \mathrm{~mJ} / \mathrm{m}^{2}$. The distribution moves to larger grain sizes, and the total number of crystals in the system decreases with time.

Figure 3.4-7 From Steefel and Van Cappellen (1990). 


\title{
Chapter 4 Interpretive Analysis of the Geophysical Measurements: Ground Penetrating Radar and Acoustic Emission
}

\author{
J. E. Peterson, Jr. and K. H. Williams \\ Earth Science Division, LBNL
}

\subsection{Ground Penetrating Radar (GPR) Introduction}

The objective of the borehole radar data acquisition is to perform repeated surveys in the course of the Drift Scale Test to monitor moisture redistribution and to investigate the effect of heating on potential repository rock. Crosshole radar tomography was initiated in a prototype mode in late FY 1996 to examine if modern radar acquisition and processing methods could be used in the Yucca Mountain environment. During FY 1997, further tests around the Single Heater Test were carried out (Peterson and Williams, 1997), and it was determined that the methods could detect change in rock saturation at the desired scales and resolution. The borehole radar method is one in which ground penetrating radar antennas are lowered into the ground and high frequency electromagnetic signals are transmitted through subsurface material from a transmitting antenna to a receiving antenna. The dielectrical properties of the subsurface material, here the repository rock, influence the properties of the transmitted electromagnetic signal. In particular, the dielectric permitivity of the rock has a strong influence on velocity and attenuation of the propagating signal. For example, the dielectric permitivity of a moist rock has slower signal velocities and increased signal attenuation than the corresponding dry rock, (Greaves, et al. 1996). In addition to moisture, heat also affects the velocity and attenuation of the propagated signal. It is such changes in signal character that are to be measured over the course of the Drift Scale Test.

If sufficient raypaths are recorded, a tomographic image may be constructed through computer processing of the raw data. The information extracted from such data includes the following: (a) the transit time, which depends on the wave velocity, and (b) the amplitude, which depends on the wave attenuation. This information, in the form of a processed tomogram, offers a high-resolution approach to monitoring the changes occurring in the repository rock over the duration of the thermal experiment. The data presented in this report include the pre-heating baseline and first quarter measurements. Subsequent measurements are to be made quarterly in an attempt to monitor the effects of the heater on the repository rock properties over time. 


\subsection{GPR Equipment Description}

All radar data were acquired using the Sensors and Software pulseEKKO 100 ground penetrating radar system, equipped with 50 - and $100-\mathrm{MHz}$ center frequency borehole antennas. The pulseEKKO system consists of six basic components, including a pair of identical antennas, a transmitter electronics unit, a receiver electronics unit, a control console, and a personal computer acting as a recording system and data storage unit.

\subsubsection{Antenna Specifications}

The pulseEKKO antennas are resistively damped dipolar antennas. The antenna radiates with a pattern of a half wavelength dipole. Each antenna pair is designed to have a bandwidth-to-centerfrequency ratio of one. Two sets of antennas were used in the Drift Scale Test; one set with a center frequency of $100 \mathrm{MHz}$, and a $50 \mathrm{MHz}$ antennae pair was used in some cases.

\subsubsection{Transmitter Electronics Specifications}

The pulseEKKO system used in the Drift Scale Test consisted of a $1000 \mathrm{~V}$ transmitter having a peak voltage of $1000 \mathrm{~V}$ with fast rise time of 2.5 nanoseconds. Additionally, a $400 \mathrm{~V}$ transmitter was used when the $1000 \mathrm{~V}$ transmitter failed. The transmitter is powered by $12 \mathrm{~V}$ and emits a pulse on command from the control console. The power radiated from the system is very dependent on the subsurface conditions. The $1000 \mathrm{~V}$ transmitter used here delivers a peak power of 3.2 kilowatts into a $50-\mathrm{Ohm}$ load. Only a small fraction of the available power is actually transformed into a radiated electromagnetic signal because the antennas are damped and are very inefficient radiators.

\subsubsection{Receiver Electronics Specifications}

The receiver electronics digitize the voltage at the receiver antenna connector to 16-bit resolution. The receivers acquire the received waveform with very high fidelity. The receiver electronics clip the incoming voltage at a $50-\mathrm{mV}$ level, and the receiver noise level is nominally around $0.2 \mathrm{mV}$ per stack. Present receiver resolution for a single bit after analog to digital conversion is $0.0015 \mathrm{mV}$.

\subsubsection{Control Console}

The control console provides the overall management of the transmitter and receiver operation. This is a microprocessor-controlled unit that communicates with both the transmitter and receiver electronics and the external PC. The PC passes the system configuration information and the 
acquisition parameters to the control console, which then manages all of the hardware functions of the PulseEKKO radar system.

\subsection{GPR Operating Principles}

The operating principles were as follows:

a) the user defines the time window, sampling interval, and number of pulses to be stacked via the $\mathrm{PC}$ user interface;

b) the user selects the acquisition mode;

c) the PC configures the pulseEKKO console through the PC 's standard RS232 port and the console takes over control of data acquisition;

d) the pulseEKKO console commands the transmitter to fire, which generates a high-voltage pulse shaped by the transmitting antenna into a radiated pulse;

e) the console advises the receiver electronics to digitize the signal from the receiving antenna. The receiver digitizes the ambient electric field present at the receiving antenna according to the band- limiting characteristics of the antenna transfer function. The digital number representing the voltage at the time of acquisition is transferred to the control console;

f) steps (d) and (e) are repeated until the desired waveform length and stack count are achieved;

g) the console transmits the stacked waveform to the PC; and (h) the PC stores the data and displays the radar trace.

\subsection{GPR Survey Methodology}

The borehole radar technique utilized was a crosshole radar profiling method, in which the transmitter and receiver antennas were located in separate boreholes and data were collected with the antennas at various offsets. Data were collected using two acquisition modes. The first was a Zero Offset Profile (ZOP) in which the angular relationship between transmitting and receiving antennas was fixed such that there was no vertical offset between them. The second was a Multiple Offset Profile (MOP) in which the receiving antenna remained at a fixed location while the transmitting antenna was moved incrementally in the second borehole. A series of multiple offset profiles can be combined to yield the data set necessary for tomographic processing. 
The radar data were acquired in ten boreholes orthogonal to the primary direction of the Heater Drift. The boreholes were accessed from the Observation Drift and were the same boreholes used for neutron logging. The ten boreholes include the following:

$\begin{array}{cc}\text { Borehole No.: } & \text { Borehole ID: } \\ 47 & \text { ESF-HD-NEU-1 } \\ 48 & \text { ESF-HD-NEU-2 } \\ 49 & \text { ESF-HD-NEU-3 } \\ 50 & \text { ESF-HD-NEU-4 } \\ 51 & \text { ESF-HD-NEU-5 } \\ 64 & \text { ESF-HD-NEU-6 } \\ 65 & \text { ESF-HD-NEU-7 } \\ 66 & \text { ESF-HD-NEU-8 } \\ 67 & \text { ESF-HD-NEU-9 } \\ 68 & \text { ESF-HD-NEU-10 }\end{array}$

These boreholes form two spatial clusters: Boreholes 47-51 and Boreholes 64-68 form two sets of planes twenty meters apart, perpendicular to the heater drift.

The locations of these boreholes need to be precisely surveyed in order for the radar data to be accurately processed. The convention for the Drift Scale Test as-built coordinates is that the origin $(0,0,0)$ is at the center of the Heated Drift on the hot side of the bulkhead, the $+Y$-axis is along the Heated Drift which parallels the Observation Drift toward the west, the $+\mathrm{X}$-axis runs to the north away from the Observation Drift, and the $+Z$-axis is upward. The as-built survey coordinates (DTN: LANE834244AQ97.001) provide collar, bottom-hole, and several intermediate points between collar and bottom hole for each borehole in the Drift Scale Test-including those used in radar data acquisition. The position of each source and receiver point down the boreholes was determined by interpolating between these borehole coordinates. All of the radar data borehole coordinates are based on the collar and bottom hole coordinates contained in the TDIF (DTN:980120123142.006), (Peterson and Williams, 1998a).

The first-order results derived from the radar data are travel times and the resulting velocities. To determine accurate travel times between the transmitter and receiver antennas, it is necessary to know the precise time at which the transmitter fires (known as time-zero). The procedure used to determine time-zero for the surveys consisted of taking four direct air-wave measurements (the signal from transmitting antenna to receiving antenna in air) with the antennas held in air at a separation of 2.0 meters. The time it takes the wave to travel two meters is 2.0 divided by the speed of light, $3.0 \times 10^{+8}$ which is $6.66 \mathrm{~ns}$. The time-zero is the picked first energy arrival with the antenna two meters apart minus $6.66 \mathrm{~ns}$. After the time-zero data were collected, the antennas were immediately moved into the boreholes and a ZOP data set was collected, concluding with another set of four measurements in air at 2.0-meter separation. To check for time drift, this ZOP data was compared to an equivalent $Z O P$ profile extracted from the MOP data set. If the travel times from this pseudo- 
ZOP profile and the ZOP profiles match, then the time-zero is taken to be a constant. If the travel times between the two profiles divert, then the time-zero must be adjusted where the travel times are not the same. This proved to provide an accurate measure of zero time throughout the surveys. The MOP data sets were collected with the locations determined before the start of the survey. The transmitter and receiver intervals were every 0.25 meters. As in all MOP gathers, the receiving antenna remained at a fixed location $(1 \mathrm{~m}, 1.25 \mathrm{~m}, 1.5 \mathrm{~m}$, etc.) while the transmitting antenna occupied each of its possible locations along the length of the borehole (e.g., $0-35.0 \mathrm{~m}$ at $0.25 \mathrm{~m}$ spacing). In this manner, all MOP gathers were collected and sorted as receiver gathers with filenames corresponding to the well pair being surveyed and the fixed receiver location (e.g., MOP10400 represents an MOP gather collected for well pair \#1 at a receiver location $4.00 \mathrm{~m}$ below the wall surface). In this manner, each of the necessary raypaths was collected and recorded for the subsequent tomographic processing. Following MOP acquisition, a final ZOP dataset is collected as described above. This is done in an attempt to estimate any time-zero drift that may have occurred during the course of the survey. By comparing the two ZOP datasets with the identical data included in the MOP dataset, any time-zero drift may be compensated for and corrected.

As described in the baseline GPR report (Peterson and Williams, 1998a) and the first quarter results (Peterson and Williams, 1998b), radar data were collected between the ten boreholes resulting in a total of eight well pairs. The well pairs include the following (referenced by borehole number): 47$48,48-49,49-50,50-51,64-65,65-66,66-67$, and 67-68. However, the severity of the borehole inclination in the well pairs 47-48 and 64-65 limited the acquisition between these boreholes to ZOP geometry only; full MOP data coverage could not be accomplished. These well pairs represent data coverage that is far enough away from the Heated Drift intersection that the loss is not expected to be severe.

\subsection{GPR Velocity field construction}

Travel times of both the November 1997 and February 1998 surveys have been picked. Between six and eight thousand travel times were picked for each of the six well pairs. However, due to the highpower of the transmitter electronics used $(1000 \mathrm{~V})$, the data from short source to receiver distances were clipped. Also, all data picked from high angle source/receiver pairs (angles greater than 50 degrees) could not be used. The removal of the clipped and high angle travel times resulted in a reduction of the total number of travel times to about one-third of those originally picked. The procedure used to determine zero time for the surveys during the heater test consisted of taking direct air-wave measurements (the signal from transmitter antenna to receiver antenna in air) with the antennas held two meters apart. The time it takes the wave to travel two meters is 2.0 divided by the speed of light, $3.0 \times 10^{8}$, which is 6.66 ns. The zero time, then, is the picked first arrival with the antenna two meters apart minus $6.66 \mathrm{~ns}$. To check for time drift, an equivalent ZOP profile was 
extracted from the MOP data set that could be compared to the ZOP profile acquired from the field. If the travel times from this pseudo-ZOP profile and the ZOP profiles match, then the zero time is taken to be a constant. If the travel times between the two profiles divert, then the zero time must be adjusted where the travel times are not the same. This proved to provide an accurate measure of zero time throughout the surveys.

The six borehole-to-borehole surveys were conducted in two planes defined by five boreholes each; Boreholes 47 through 51 and 64 through 68. The tomographic surveys were conducted between well pairs $48-49,49-50$, and 50-51 in the first plane. Borehole 47 was inclined too steeply upward to be practically used for data collection, so only Zero Offset Profile (ZOP) data were acquired. The other plane included well pairs 65-66, 66-67, and 67-68, with only ZOP data collected from 64-65.

The velocity tomograms were constructed using two $40 \times 40$ meter fields which encompass all five boreholes in each plane. The fields are divided into grids of $160 \times 160$ pixels, producing a pixel dimension of $0.25 \times 0.25$ meters that corresponds to the 0.25 -meter station spacing used in acquisition. The same grid was used for the velocity inversion for the three well pairs in each plane. The multiplicity of the sources and receivers resulted in a dense sampling of the interwell area. The velocity maps are constructed with standard reconstruction software, "CART," which was QA'd under YMP-USGS QA procedures. CART is a user standard algebraic reconstructive tomography method.

\subsubsection{Velocity inversions in the 47-51 plane}

\subsubsection{Borehole pair 48-49}

These boreholes are inclined upward an average of 6 degrees. During the pre-heat survey on Oct. 31,1997 , the 1000-Volt antennae failed, so the 400 Volt antennae was used for receiver depths of 6.50 meters and less down Borehole 48. This switching of antennas resulted in a time-zero shift of 6 ns, which was subtracted from the appropriate travel times. The velocity tomogram of all the borehole pairs are shown in Figure 4.1. The velocity field is rather homogeneous, with slightly lower velocities near the central region.

The First Quarter acquisition of data for this well pair occurred on February 22, 1998. An unknown error in the form of mislocation of the source/receiver or mistiming occurred in acquisition of this data. Therefore, no processing of these travel times was performed.

\subsubsection{Borehole pair 49-50}

The bisecting angle between these boreholes is downward 10 degrees. Due to the distance between boreholes at depth, the $50-\mathrm{MHz}$ antenna was used in data acquisition. No time-zero adjustments were necessary in either the pre-heat or First Quarter surveys. The pre-heat survey was performed on October 30, 1997. The velocity tomogram shows large low velocity features toward the heater drift 
(Figure 4.1). The shape of this feature is probably an artifact of the inversion which tends to cause streaking if the geometry is not adequate to resolve a low velocity zone. This indicates that there exists low velocities, but that the extent of the zones is probably not as observable in the tomogram. The First Quarter acquisition of data for this well pair occurred on February 3, 1998. The velocity tomogram is similar to the baseline velocity structure, except the low velocity feature has noticeably lower velocities (Figure 4.2).

\subsubsection{Borehole pair 50-51}

The bisecting angle between these boreholes is downward 28 degrees. The pre-heat survey was performed on October 30, 1997. The velocity tomogram indicates lower velocities toward the bottom of the boreholes, under the heater drift (Figure 4.1). The First Quarter velocity tomogram, acquired February 4, 1998, looks almost identical to the baseline tomogram (Figure 4.2).

\subsubsection{General interpretation}

Virtually all of the low velocity features can be correlated to borehole cavities or highly fractured zones, as determined by viewing the borehole video logs. Numerous vesicles/cavities of various sizes were observed at the bottom of Borehole 51, producing the observed low velocity zone. Low velocity features near the middle of Boreholes 49 and 50 are also in regions of numerous small cavities.

\subsubsection{Velocity inversions in the 64-68 plane}

\subsubsection{Borehole pair 65-66}

These boreholes are inclined upward an average of 6 degrees. The pre-heat survey was performed on November 6, 1997. The velocity tomogram is shown in Figure 4.3. The velocity field is rather homogeneous with slightly lower velocities just above the heater drift. There is also a sharp low velocity feature at about $\mathrm{x}=-13$ meters which appears to extend down through all three tomograms. The First Quarter acquisition of data for this well pair occurred on February 19-20, 1998. The velocity tomogram is similar to the baseline velocity structure (Figure 4.4).

\subsubsection{Borehole pair 66-67}

These boreholes are inclined downward an average of 10 degrees. The pre-heat survey was performed on November 5, 1997. The velocity tomogram is shown in Figure 4.3. The velocity field is rather homogeneous, except for a sharp low-velocity feature at about $x=-13$ meters, at the same point as a similar feature seen in 65-66. First Quarter acquisition of data for this well pair occurred on February 18,1998 . The $50-\mathrm{MHz}$ antennae was used because of the increase in attenuation of the radar signal. The velocity tomogram is similar to the baseline velocity structure, except for much lower velocities nearest to the heater drift and lower velocities for the feature at $\mathrm{x}=-13$ meters (Figure 4.4). 


\subsubsection{Borehole pair $67-68$}

The bisecting angle between these boreholes is downward 28 degrees. The pre-heat survey was performed on November 5, 1997. The velocity tomogram indicates lower velocities toward the bottom of the boreholes, under the heater drift (Figure 4.3). There is also the low velocity feature at $\mathrm{x}=-13$ meters that was observed in the tomograms for the other borehole pairs. The First Quarter velocity tomogram, acquired February 18, 1998, looks almost identical to the baseline tomogram (Figure 4.4).

\subsubsection{General in te rpretation}

The low-velocity features again can be correlated to cavities and increased fracturing as observed in the video logs. The linear feature at $x=-13.0$ meters corresponds to a zone of vertical fractures and crumbly material, and the low velocity feature at the bottom of well 67 corresponds to an area of numerous cavities and vesicles, similar to those seen in Borehole 51. Even the smallest features such as the red dot at $x=-17$ meter in Borehole 67 corresponds to a large cavity at the top of the borehole, which is why the red dot only appears in the tomogram above Borehole 67 . Air-filled cavities should be zones of high velocity instead of low velocity. However, since the boreholes were subsequently cased after the video logs were taken, it is assumed that the cavities and fractures were filled with the grouting material, which may be of lower velocity than the native material.

\subsubsection{Velocity differences between first quarter and pre-heat acquisition}

The travel times for each source-receiver pair from. the two surveys are subtracted and inverted for slowness. (The original travel times are also inverted for slowness, but velocity, the inverse of slowness, is shown in the tomograms. However, the inverse of the difference slowness does not produce the difference velocity.) The slowness values are converted to velocity and the difference tomograms are shown in Figures 4.5 and 4.6. The average absolute velocity value is $1.0 \times 10^{8} \mathrm{~m} / \mathrm{s}$, so a difference value of $0.02 \times 10^{8} \mathrm{~m} / \mathrm{s}$ is about a $2 \%$ change in velocity.

\subsubsection{Velocity differences in the 47-51 plane}

The difference tomograms for Plane 47-51 are shown in Figure 4.5. There is no difference tomogram for borehole pair $49-48$ because of the data problems in the second survey. Figure 4.5 shows a large change in velocity at the heater drift end of borehole pair 50-49. This is most likely due to an increase in temperature from the wing heaters parallel to the plane of the tomogram and about 0.8 meters away (note in Figure 4.5 the horizontal borehole extending from the heater drift near $(0,0)$ to about $x=-14$ meters). The wing heater is almost parallel with the boreholes. The velocity change that such a geometry produces is not resolvable in the vertical dimension and will be smeared across the tomogram, as seen in Figure 4.3. There has been a decrease in velocity in this area, but the bounds of that decrease cannot be accurately resolved. There are mostly small changes 
in velocity observed in the 51-50 tomogram except for a significant velocity increase below the heater drift.

\subsubsection{Velocity differences in the 64-68 plane}

The difference tomograms for Plane 64-68 are shown in Figure 4.6. A large change in velocity is observed at the heater drift end of borehole pair 66-67, similar to, but not as strong as the feature seen in Figure 4.5. As in the case of the 47-51 plane, this velocity decrease is most likely due to an increase in temperature produced by the wing heaters. This velocity decrease extends across Borehole 67 into the 67-68 tomogram. Velocity increases are observed above and below the heater drift.

\subsection{Saturation estimates from GPR data}

For low electrical conductivity environments and at the frequencies used for GPR imaging, the relationship between electromagnetic wave velocity and dielectric constant is $v=c / \sqrt{\mathrm{K}}$ (Davis and Annan, 1989), where $v$ is velocity, $c$ is the velocity of light and $K$ is dielectric constant. Temperature and saturation are two parameters that affect the dielectric constant and thus the velocity change in this experiment. The dielectric constant of dry rocks is 3 to 6 and of water is 80 ; the dielectric constant of a material increases and thus the velocity decreases with increasing saturation. However, temperature dependence of the dielectric constant is not negligible and must be compensated for in the estimation of saturation from dielectric constant estimates.

Saturation estimates can be obtained from ground-penetrating radar by obtaining relationships between frequency, temperature, saturation, and dielectric constant under laboratory conditions. These relationships can then be used, together with field measurements of dielectric constants from radar and field measurements of temperature, to predict the interwellbore saturation. Laboratory measurements of dielectric constant as a function of saturation and temperature were obtained from Topopah Springs Tuff cores. An example of these laboratory measurements obtained using a $1-\mathrm{MHz}$ signal is shown in Figure 4.7, where it is observed that dielectric constant increases with both temperature and saturation. Regression or neural net analysis can be used to obtain a relationship between the logarithm of saturation and the explanatory variables of temperature, frequency, and dielectric constant. Frequency must be included as a variable, since the laboratory measurements use only a range of frequencies up to $1 \mathrm{MHz}$ while the field radar acquisition frequency is $100 \mathrm{MHz}$. At this point, we are studying different methods of fitting the laboratory values to obtain saturation estimates.

An alternative method of relating the dielectric constant to saturation and temperature is to use regression or neural net analysis, using dielectric constants obtained at the wellbore from crosshole radar borehole measurements of saturation obtained from neutron logs, and borehole temperature 
measurements. This method will also produce a dielectric constant-saturation-temperature relationship that can be used in a predictive manner to estimate interwellbore saturation. Drawbacks of this method are that the inverted radar velocities are less reliable near the wellbore, and the neutron logs must be of good quality.

For the saturation estimates to be accurate, the temperature at each pixel must be determined. To date, no temperature data exist for these boreholes since temperature sensors were not installed. Temperature logging of these boreholes is in the plan. The temperature may be interpolated from the actual field measurements or from a temperature model. For the preliminary studies here we will use a temperature model. The temperature at each tomogram pixel was calculated using the thermohydrological numerical model of Birkholzer and Tsang (1998). A two-dimensional slice was taken from the temperature model at points close to the tomogram planes. The temperature at each pixel was determined by taking an average of the two nearest temperature points of the model. The temperature profile for the two planes are shown in Figures 4.8 and 4.9. We are in the process of separating out the effects of temperature from change in saturation from the data.

\subsection{GPR Summary}

Baseline radar velocity tomograms and the first quarter radar velocity tomograms show significant differences. The largest velocity changes occur near the wing heaters, since they are only 0.8 meters from the planes of the tomograms. This seems to correlate well with the temperature field interpolated from the temperature model. Alternative approaches are being used to calculate the change in saturation, using information provided from the laboratory and neutron logging-data.

\subsection{Acoustic Emission}

The heater drift was monitored for acoustic emissions continuously until April 1, 1998 (Peterson et al., 1998). These microseismic data were intended to monitor mocrofracturing activities arising from thermal-mechanical coupling. During this early phase of heating, only 12 microseismic events were detected, 7 of which could be located. The other events probably all occurred at the same location and the general area could be estimated. The microseismic events were located using the following method: The $P$ and $S$ arrival times were picked for each event. An 80x80x80-meter block representing the drift scale test was then gridded into $1 \times 1 \times 1$ meter voxels. Then, using a constant velocity field, travel time residuals were calculated for each of these voxels at $0.5 \mathrm{msec}$ time increments. The RMS residual for each voxel was then calculated, and the voxel producing the 
smallest residual was taken as the location. The locations and time of the events that could be located are given below.

$\begin{array}{lllllll}\text { DATE } & \text { TIME } & \text { residual } & \text { X } & Y & Z & \text { origin time } \\ \text { 2-04-1998 } & 4: 13: 58.14 & 0.057491 & 1.000000 & 31.000000 & 3.000000 & 4.500000 \\ \text { 2-06-1998 } & 11: 14: 41.73 & 0.177277 & 0.000000 & 33.000000 & 0.000000 & 4.500000 \\ \text { 3-31-1998 } & 10: 04: 03.95 & 0.033347 & -17.000000 & 14.000000 & 1.000000 & 1.500000 \\ 3-31-1998 & 10: 04: 12.80 & 0.233276 & -30.000000 & 28.000000 & 5.000000 & 6.250000 \\ 3-31-1998 & 10: 04: 25.49 & 0.021544 & -37.000000 & 32.000000 & 4.000000 & 8.000000 \\ 4-07-1998 & 23: 02: 56.87 & 0.017260 & 0.000000 & 28.000000 & 1.000000 & 5.500000 \\ 4-08-1998 & 6: 47: 03.33 & 0.095750 & 1.000000 & 31.000000 & 2.000000 & 4.250000\end{array}$

A swarm of 4 events occurred around midnight, April 7, 1998. These events were detected at only two stations, 7 and 11 , which have coordinates of $(9.25,11.95,9.24)$ and $(-9.08,11.68,9.00)$ respectively. It is assumed that the location of these events is somewhere above these two stations, since they were the only two stations that detected them, and the energy was quite strong. If they occurred anywhere below, other stations would surely detect them. The actual times of these events are given below.

$\begin{array}{ll}\text { DATE } & \text { TIME } \\ \text { 4-07-1998 } & 23: 26: 39.11 \\ 4-08-1998 & 1: 59: 53.70 \\ 4-08-1998 & 2: 00: 21.54 \\ 4-08-1998 & 2: 00: 24.45\end{array}$

Four of the seven located events are near the drift wall at approximately $\mathrm{Y}=30$ meters. The $\mathrm{X}$ and $\mathrm{Z}$ values would put them within the drift, which is obviously incorrect, but the error in location is at least a few meters. These events are probably due to a release in stress at the drift wall at around $Y=30$ meters. The other three events occur within several meters of each other and may be due to some shifting.

\subsection{QA Status of Data}

All geophysical measurements discussed above were carried out by qualified personnel using calibrated equipment under the YMP-LBNL QA Program. 


\section{Acknowledgement}

The authors would like to thank Ernest Majer and Yvonne Tsang for their careful review of this chapter.

\section{References}

Birkholzer, J.T. and Tsang, Y.T. 1998. "Comparison of Temperature Data with ThermalHydrological Model Predictions.” Chapter 6 in ESF Drift Scale Test as Built Data and Baseline Measurements (Hydrologic, Radar and Microseismic). Yucca Mountain Project Milestone Report SP277OM4. Berkeley, California: Lawrence Berkeley National Laboratory.

Davis, J. and Annan, A. 1989. "Ground Penetrating Radar for High Resolution Mapping of Soil and Rock Stratigraphy.” Geophysical Prospecting, 37, 531-551.

Greaves, R.J.; Lesmes, D.P.; Lee, J.M.; and Toksoz, M.N. 1996. "Velocity Variations and Water Content Estimates from Multi-Offset Ground Penetrating Radar.” Geophysics 61 (3), 683-695.

Peterson, J.E and Williams, K.H. 1997. To Assess the Effectiveness of the Ground Penetrating Radar Method in Measuring Moisture Content in the Single Heater Test. Yucca Mountain Project Milestone Report SP9241M4. Berkeley, California: Lawrence Berkeley National Laboratory.

Peterson, J.E and Williams, K.H. 1998a. ESF Drift Scale Test as Built Data and Baseline Measurements (Hydrologic, Radar, and Microseismic). Chapter 4 of Yucca Mountain Project Milestone Report SPY193M4. Berkeley, California: Lawrence Berkeley National Laboratory. DTN:LB980120123142.006 (Q).

Peterson, J.E and Williams, K.H. 1998b. "Radar Imaging at the Drift Scale Heater Test." Chapter 4 in First Quarter TDIF Submission for the Drift Scale (Hydrological, Radar, Microseismic). Yucca Mountain Project Milestone Report SP2770M4. Berkeley, California: Lawrence Berkeley National Laboratory. DTN:LB980420123142.003 (Q).

Peterson, J.E.; Williams, K.H.; and Majer, E.L. 1998. “Acoustic Emission Monitoring/Seismic Wave Monitoring: First Quarter Data." Chapter 5 in First Quarter TDIF Submission for the Drift Scale (hydrological, radar, microseismic). Yucca Mountain Project Milestone Report SP2770M4. Berkeley, California: Lawrence Berkeley National Laboratory. DTN:LB980420123142.004 (Q). 
Yucca Mountain Drift Scale Test Progress Report

\section{Figures}




\section{YUCCA MTN DRIFT SCALE HEATER TEST (GPR RESULTS)}

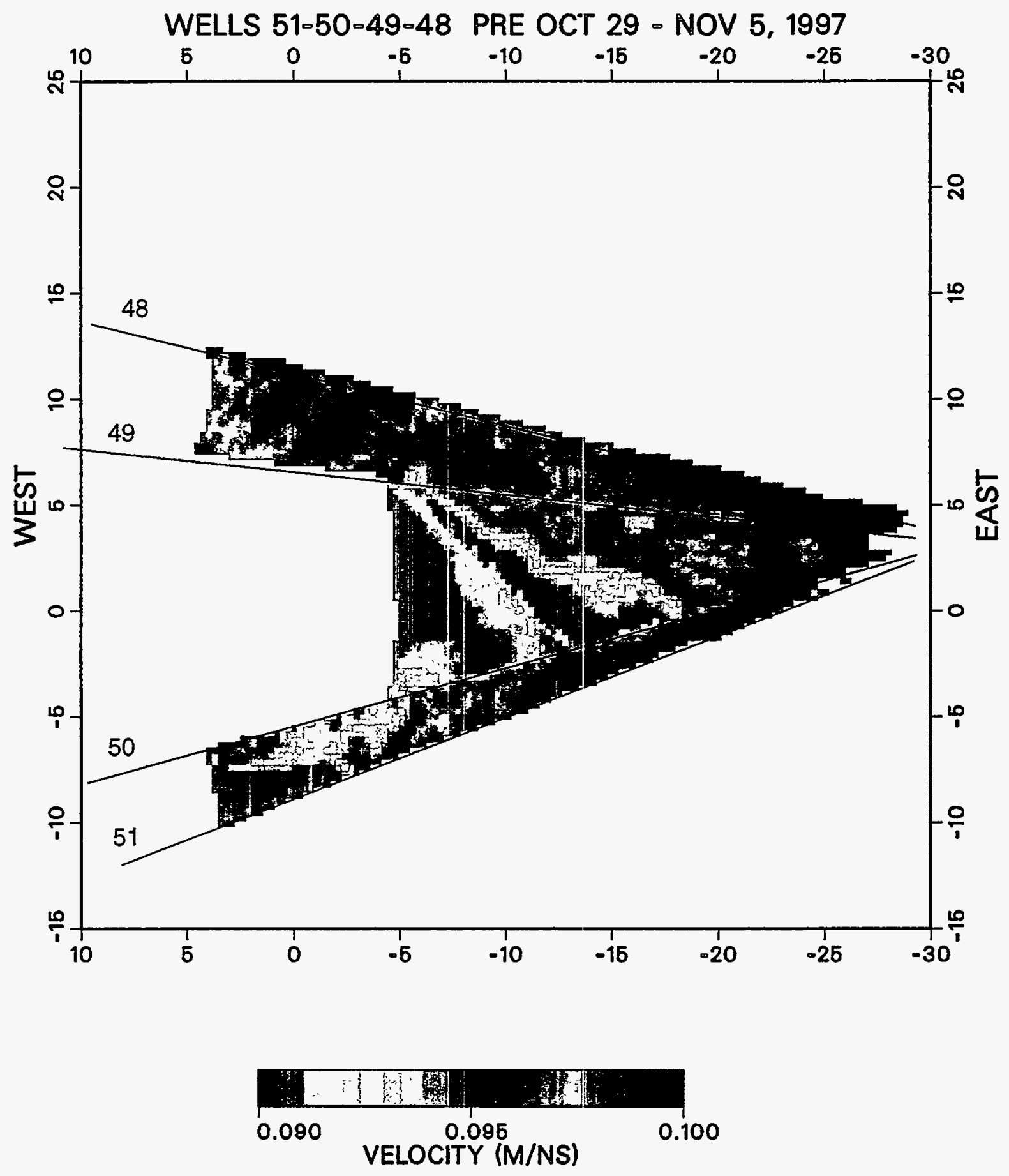

Figure 4.1. Velocity tomogram in the 51-47 plane for the Pre-heat baseline data. 


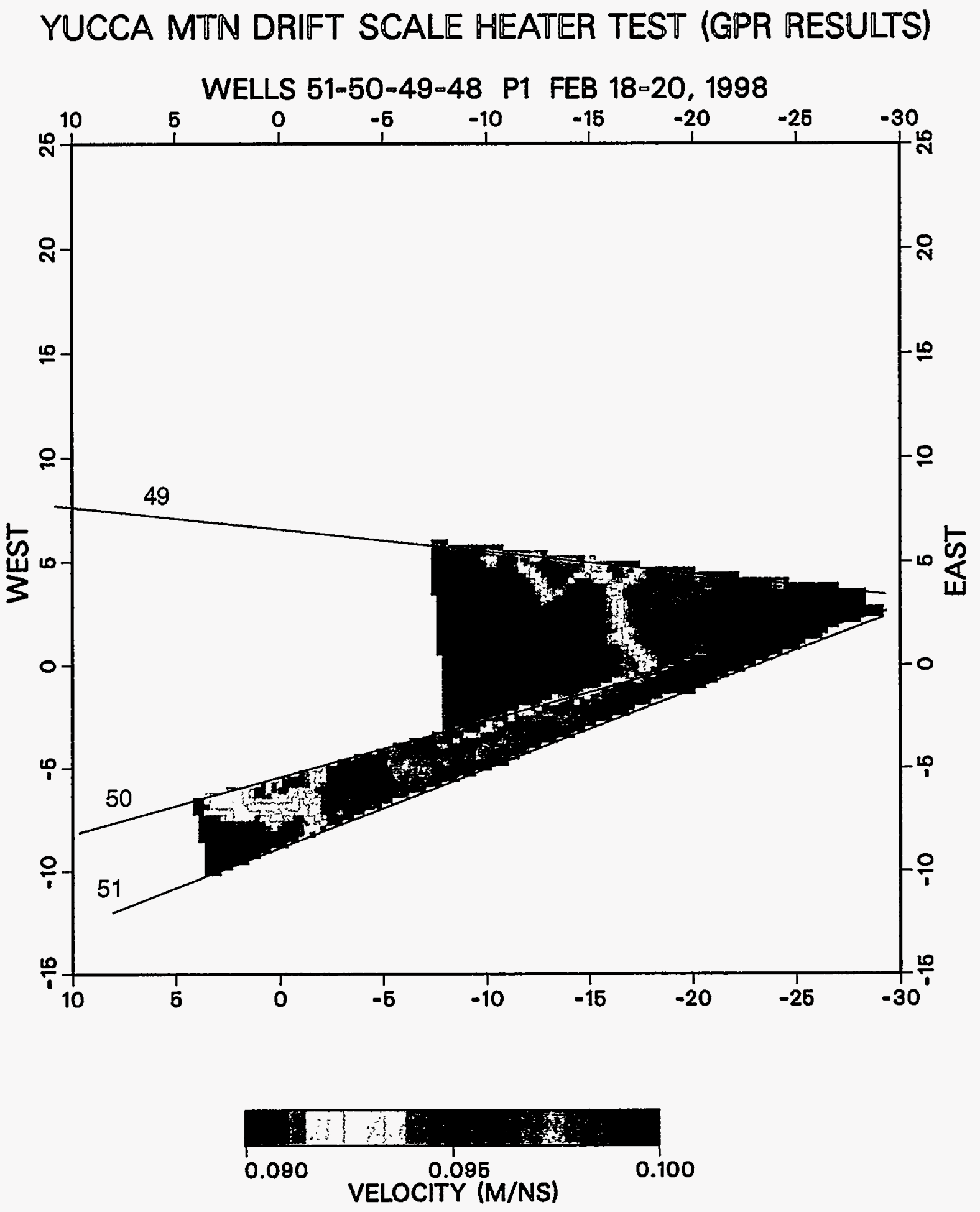

Figure 4.2. Velocity tomogram in the $51-47$ plane for the first quarter data. 


\section{YUCCA MTN DRIFT SCALE HEATER TEST (GPR RESULTS)}

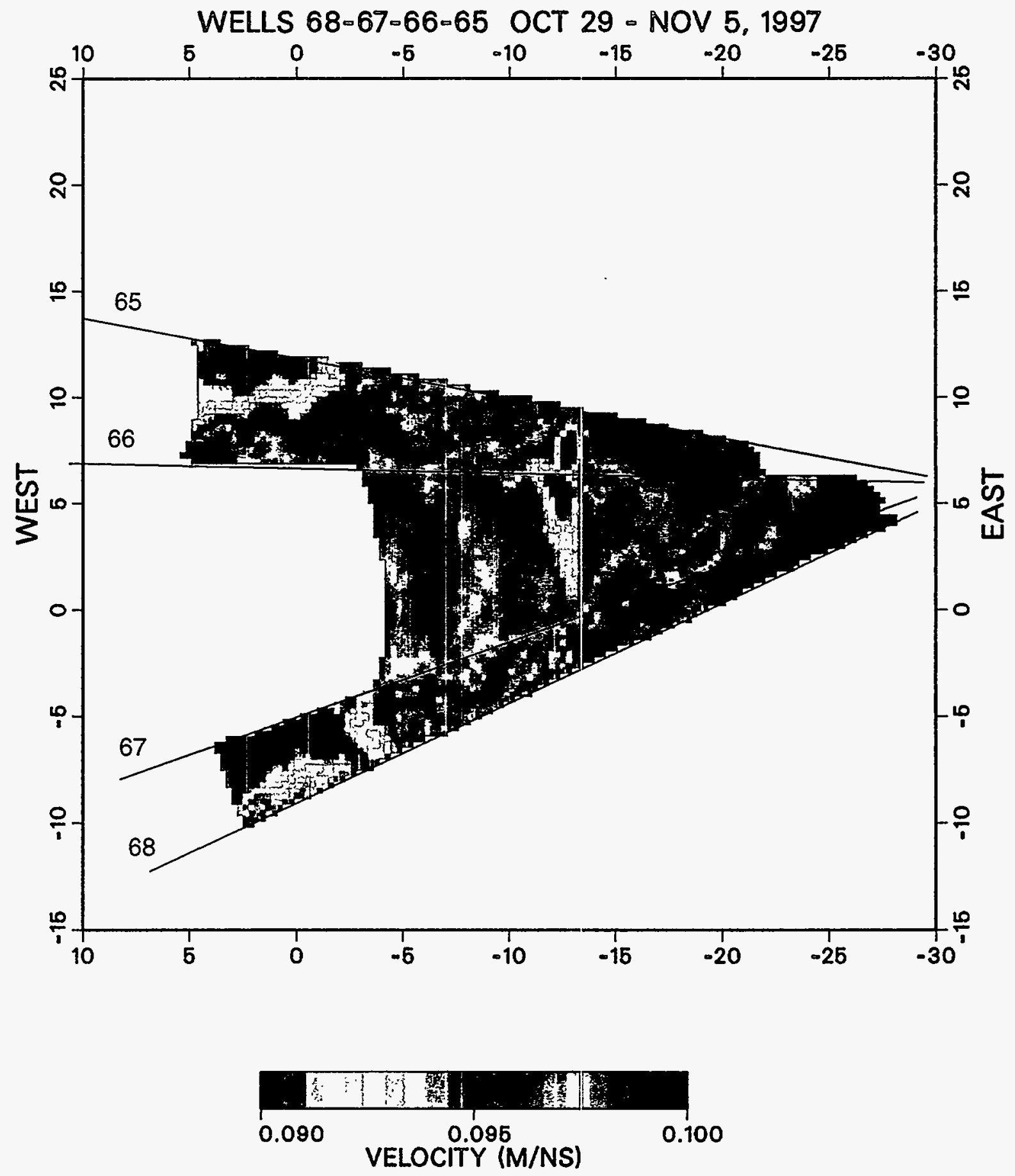

Figure 4.3. Velocity tomogram in the 68-64 plane for the Pre-heat baseline data. 


\section{YUCCA MTN DRIFT SCALE HEATER TEST (GPR RESULTS)}

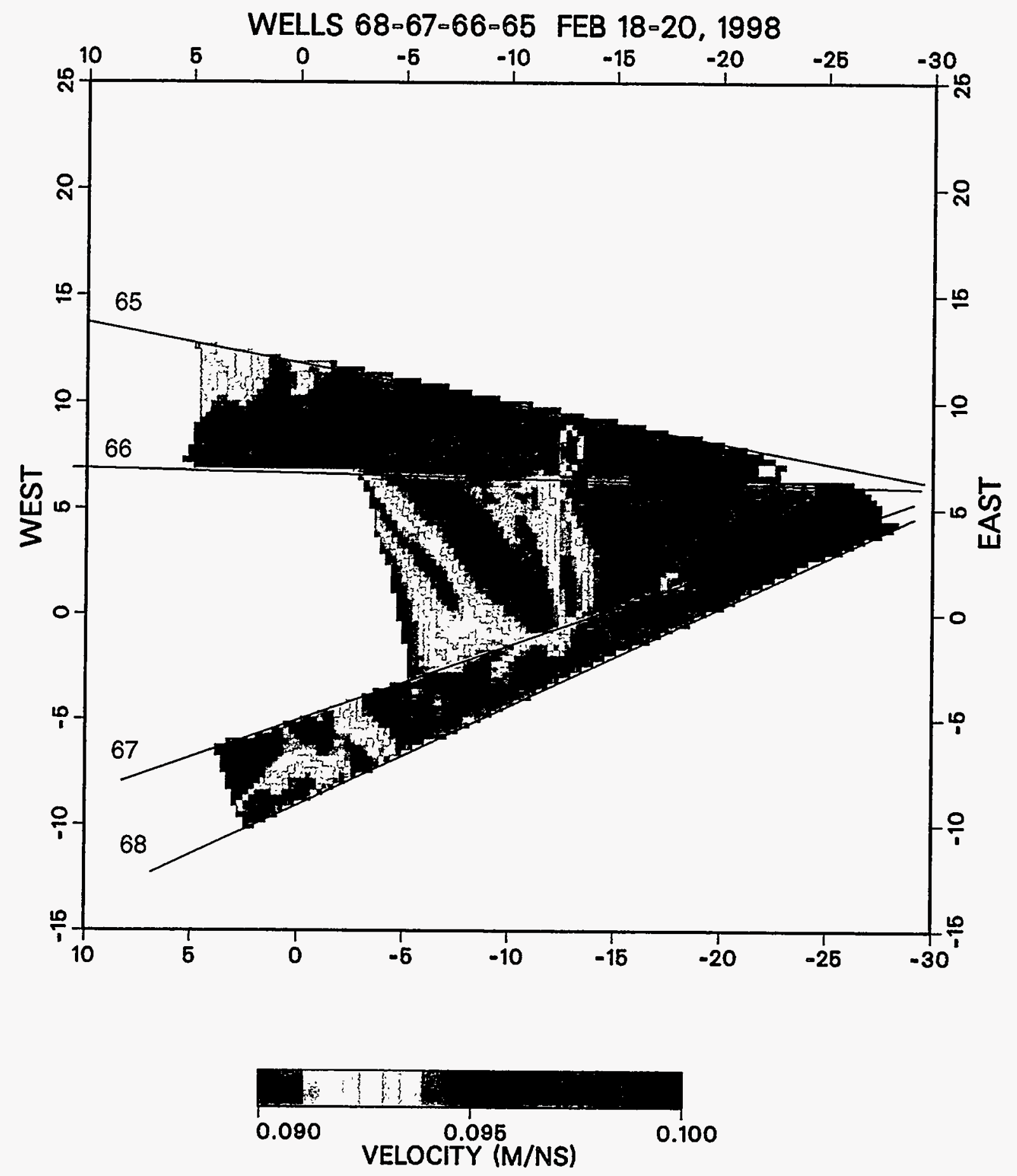

Figure 4.4. Velocity inversion results for the boreholes in the 68-64 plane for the first quarter data. 


\section{YUCCA MTN DRIFT SCALE HEATER TEST (GPR RESULTS)}

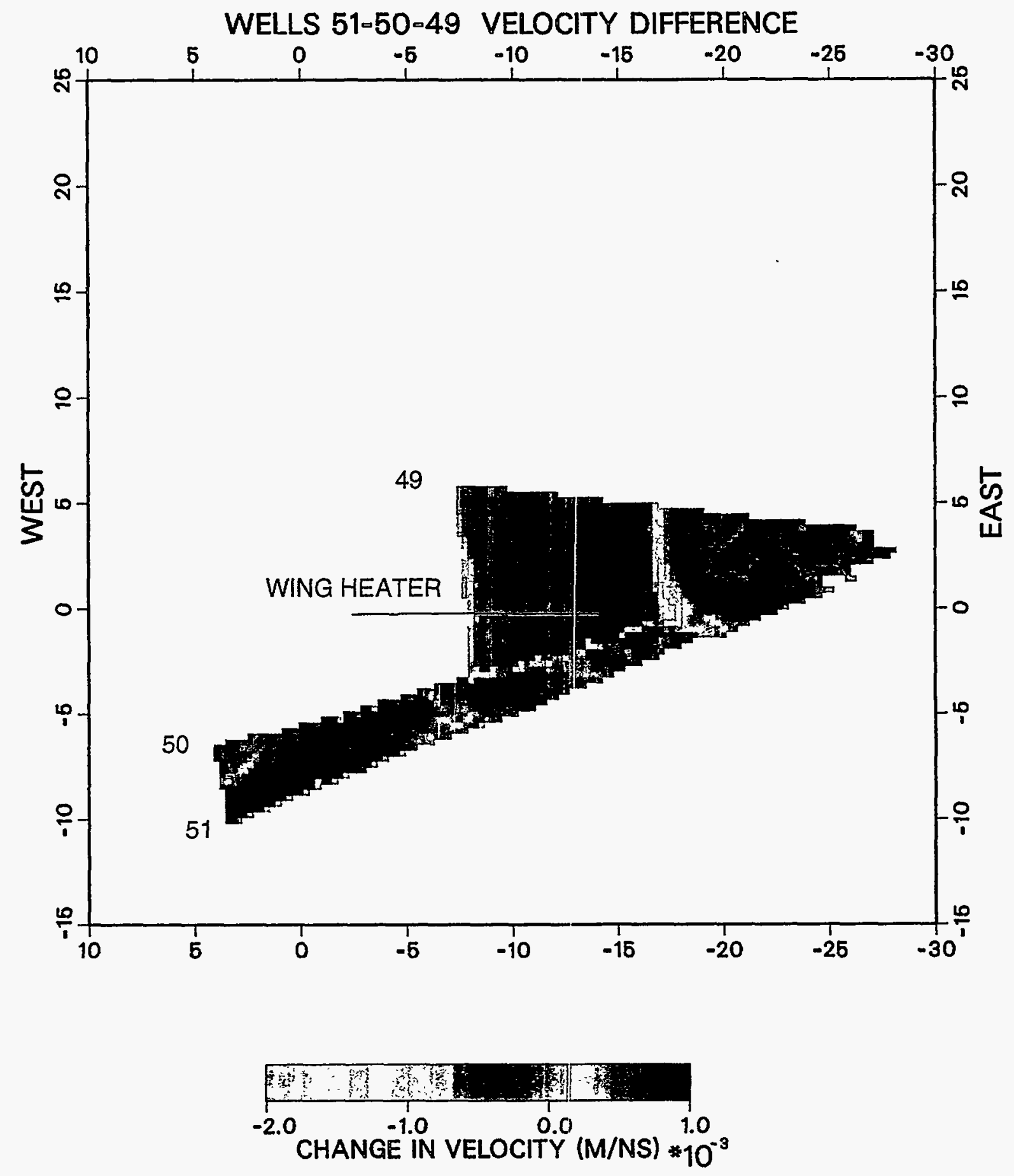

Figure 4.5. Change in velocity from pre-heat (Figure 4.1) and after first quarter (Figure 4.2). 


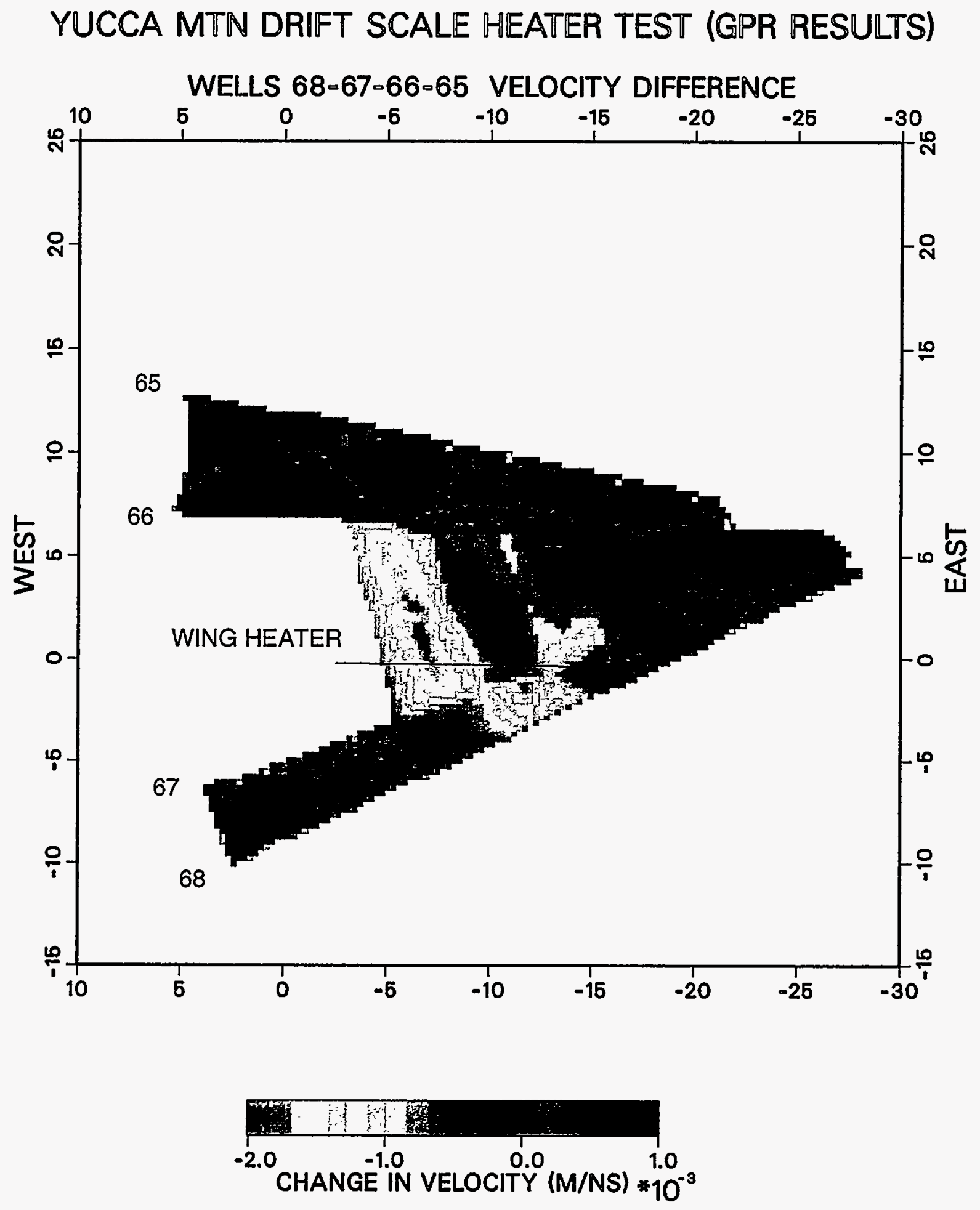

Figure 4.6. Change in velocity from pre-heat (Figure 4.3) and after first quarter (Figure 4.4). 


\section{LABORATORY RESULTS FOR $1 \mathrm{MHz}$}

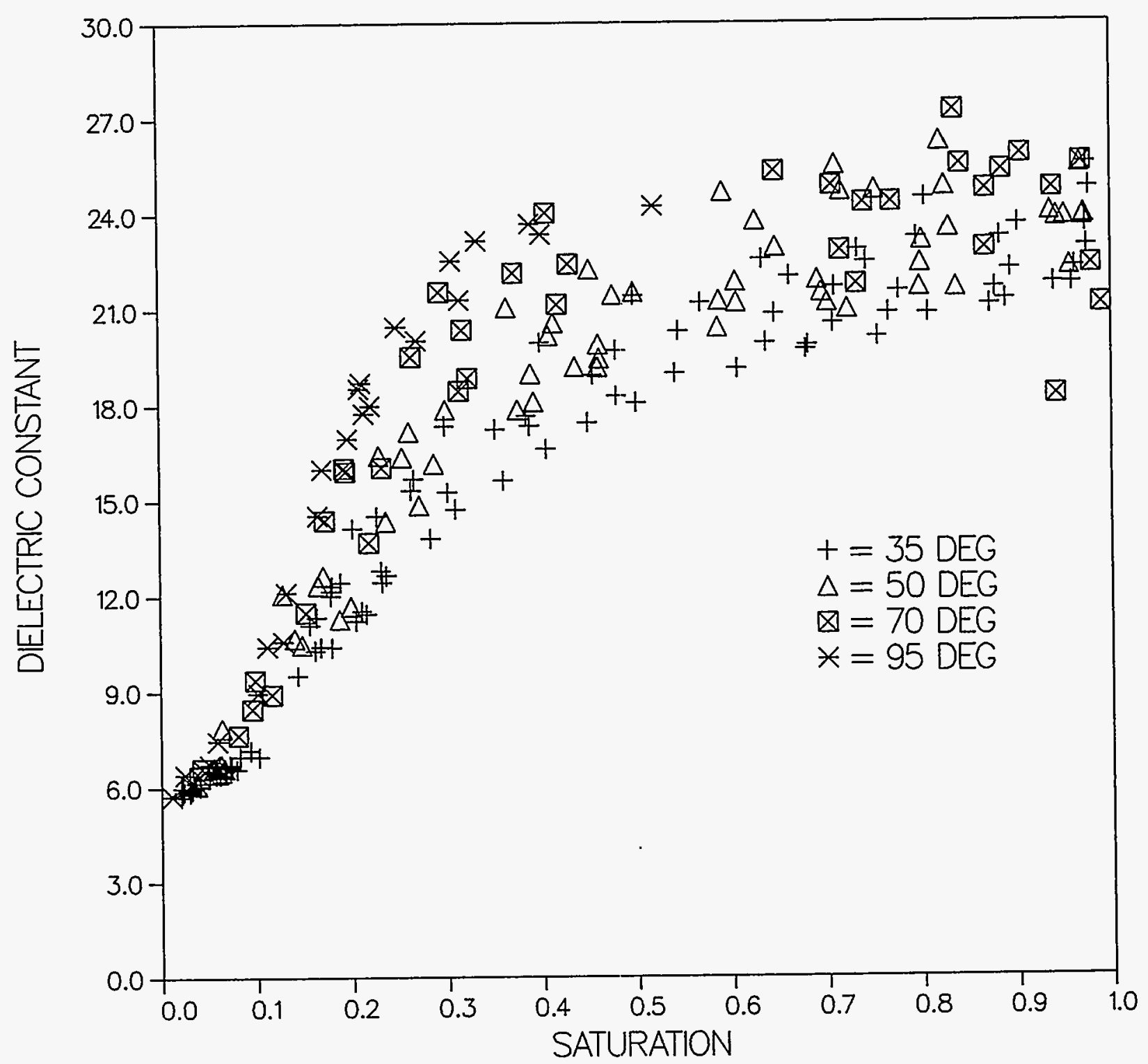

Figure 4.7a. Laboratory results determining dielectric constants at $1 \mathrm{Mhz}$ and a range of saturation and temperature. 


\section{DIELECTRIC AT 50 DEG}

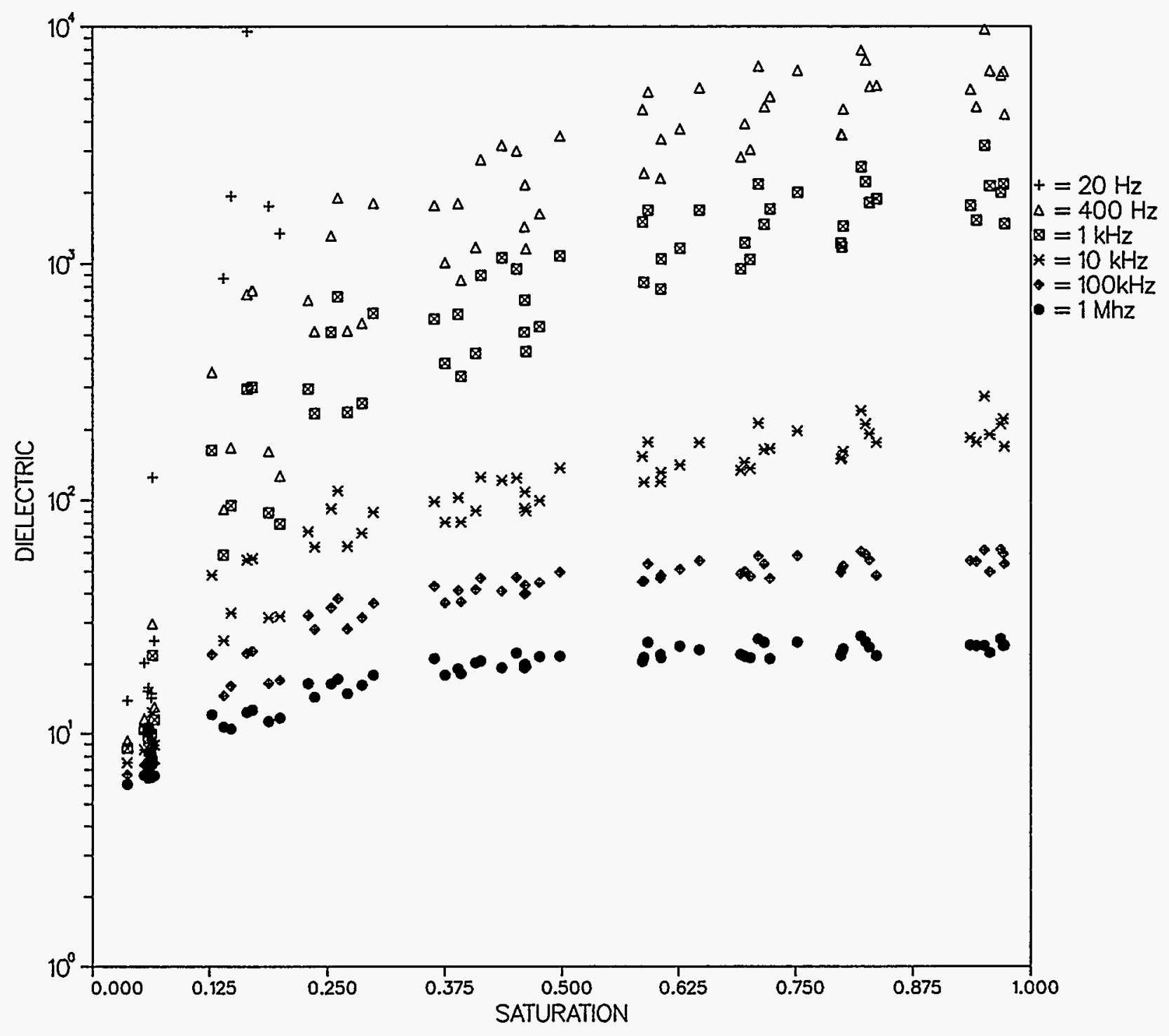

Figure 4.7b. Laboratory results determining dielectric constants at a range of frequencies, saturation, and temperature. 


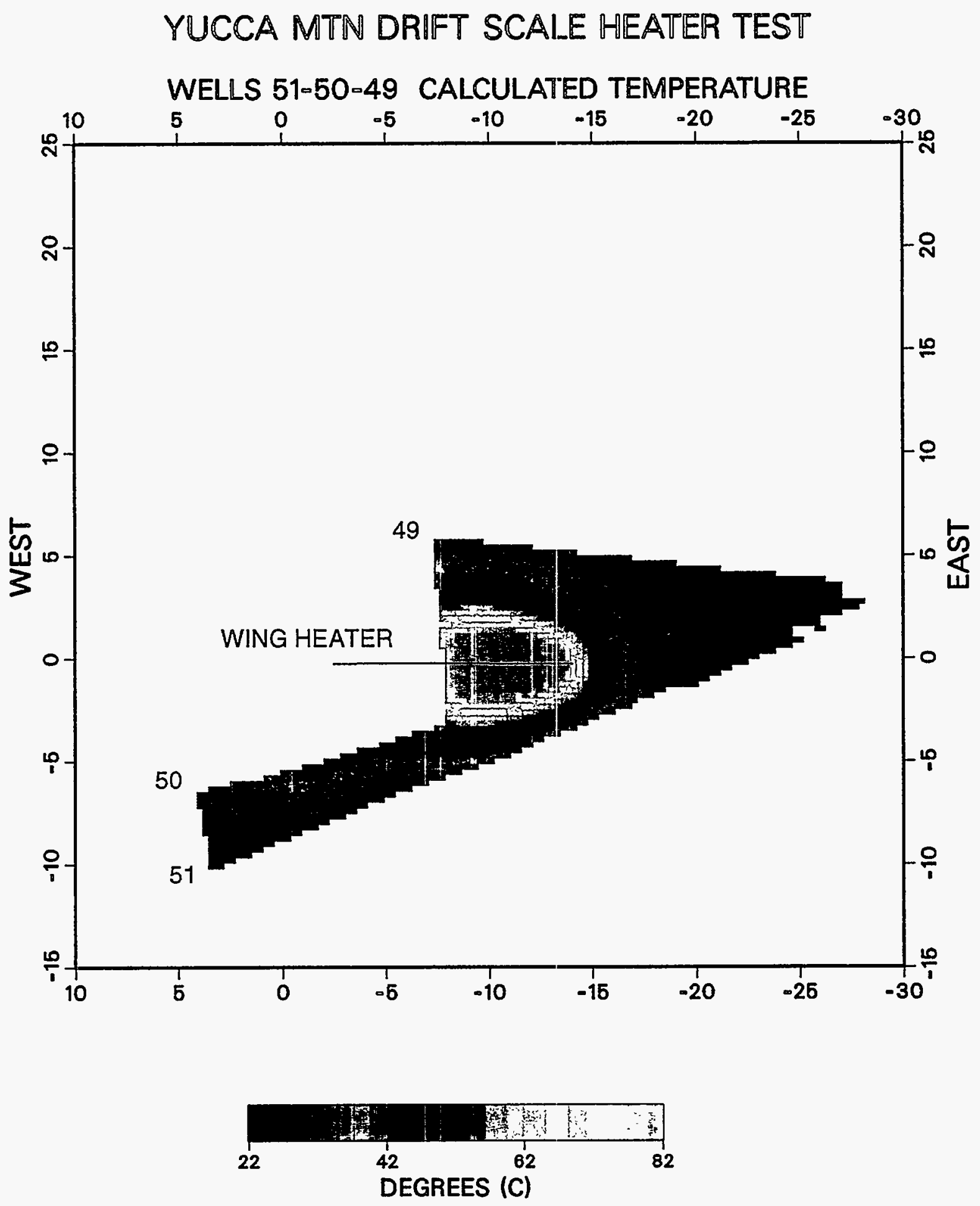

Figure 4.8. Temperature profile for the 51-47 plane as interpolated from the temperature model of Birkholzer and Tsang (1998). 


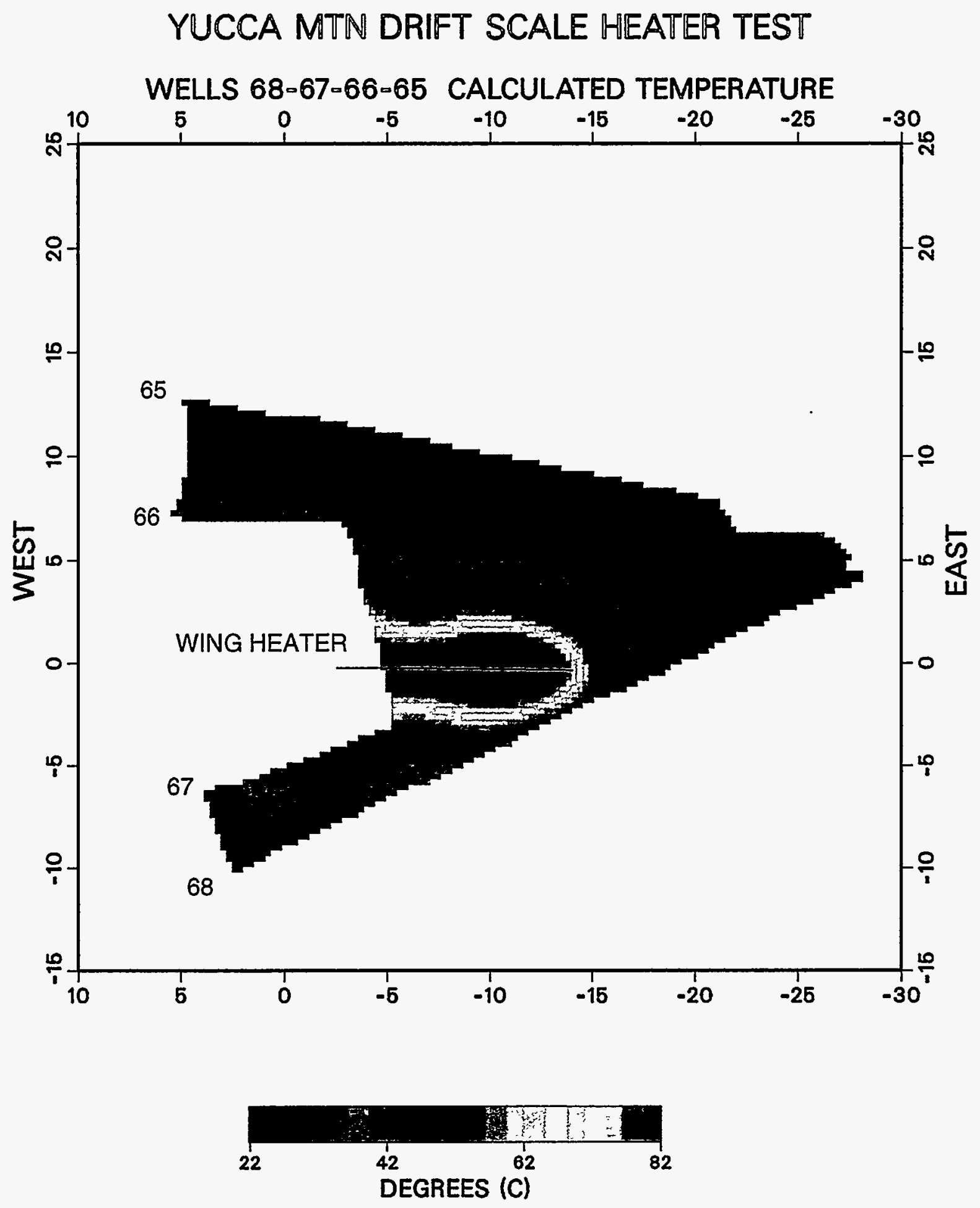

Figure 4.9. Temperature profile for the 64-68 plane as interpolated from the temperature model of Birkholzer and Tsang (1998). 